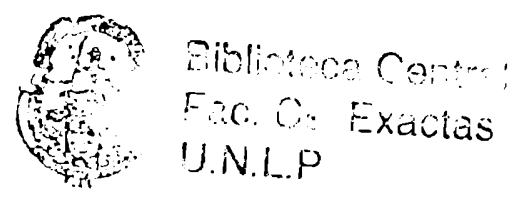

\title{
ASPECTOS HEMATIMÉTRICOS, MORFOLÓGICOS Y BIOQUÍMICOS DE ERITROCITOS ESTABILIZADOS Y ADICIONADOS CON ANTIOXIDANTES
}

Bioq. María Alejandra Fernández Alberti

Directora

Dra. Nilda Ester Fink

Trabajo de Tesis para optar al grado de Doctor de la Facultad De Ciencias Exactas

\section{Lugar de trabajo}

Cátedra de Análisis Clínicos I, Especialidad Hematología, Área Bioquímica Clínica, Departamento de Ciencias Biológicas, Facultad de Ciencias Exactas, Universidad Nacional de La Plata

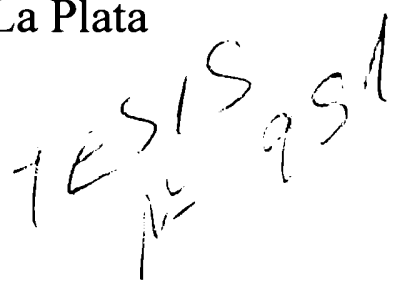

La Plata, 2001. 


\section{A Fernando}

\section{A mis padres}

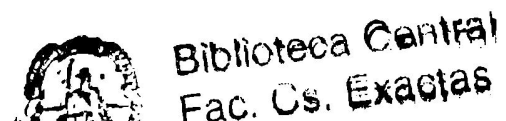

Mri Fac. Cs. Exactas (S.S.T.P
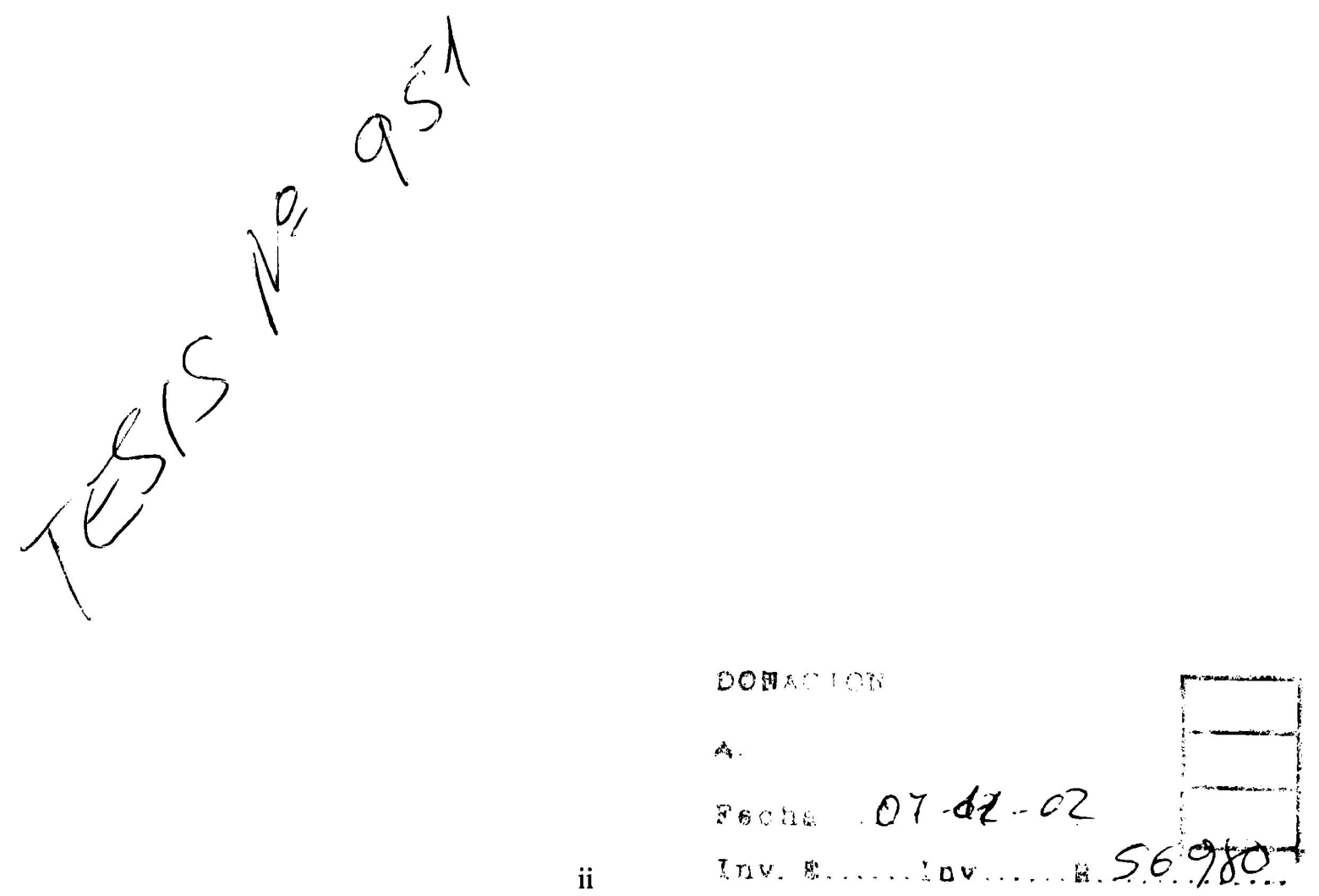


\section{Agradecimientos}

- A la Dra. Nilda E. Fink por la formación teórica y experimental brindada y por contribuir con su apoyo y sus críticas a mi crecimiento en el tema de Tesis.

- A mis compañeros de la Especialidad Hematología de la Facultad de Ciencias Exactas, por su amistad, su apoyo y su aliento permanente.

- Al Consejo Nacional de Investigaciones Científicas y Tecnológicas (CONICET) por haberme otorgado becas que permitieron la realización de este Trabajo de Tesis.

- A la Fundación Bioquímica Argentina, en especial al Dr. Daniel Mazziotta, por haber permitido el uso de equipamiento que facilitó la obtención de gran parte de los datos de este Trabajo de Tesis.

- A la Lic. María del Carmen Apezteguía por haberme brindado una gran ayuda en el tratamiento estadístico de los datos de esta Tesis.

- Al Lic. Santiago Cabutti por su gran colaboración en la preparación de las láminas fotográficas.

- A los miembros del CIDCA, en especial a su Directora la Dra. Cristina Añón, al Sr. Aldo Campana y al Sr. Raúl Martino del CINDECA, por su contribución en la realización de algunos pasos experimentales de esta Tesis.

- Al Dr. Horacio Falomir del Departamento de Física de la Facultad de Ciencias Exactas de esta Facultad por su ayuda en la implementación del modelo matemático empleado.

- Al Dr. Daniel Bragantini del Hospital de Clínicas de la UBA, por permitir el uso de equipamiento necesario para parte de este Trabajo de Tesis. 
- Al Dr. Alfredo Salibián por su apoyo y colaboración durante el desarrollo de esta Tesis.

- A la Srta. Ana María Martínez por su eficiencia en la preparación de este manuscrito.

- Al Lic. Oscar Constanza de la Cátedra de Microbiología de la Facultad de Ciencias Exactas por su colaboración en la parte experimental.

- A todas las personas que de alguna manera colaboraron en alguna etapa de la realización de esta Tesis. 


\section{Resumen}

El estudio de las alteraciones bioquímicas y hematimétricas que sufre la sangre entera (SE) durante su almacenamiento es un objetivo importante en Hematología. Conocer los cambios que experimentan células como los glóbulos rojos (GR) permite determinar los períodos máximos de estabilidad de la misma. Una de las maneras de prolongar el tiempo de conservación de la SE es mediante la estabilización de las membranas de las células. En 1991, fue propuesta por Reardon et al., una muestra de sangre entera estabilizada con una mezcla de glutaraldehído y formaldehído (SEE).

En este Trabajo de Tesis se estudiaron parámetros hematimétricos, morfológicos y bioquímicos en 12 lotes de SEE almacenada a $4^{\circ} \mathrm{C}$ midiendo diferentes variables, cada 10 días, por un período de 4 meses, con la finalidad de profundizar en el conocimiento de las alteraciones de dichos parámetros y definir los límites de estabilidad de los mismos.

Estudios hematológicos:

- Medición de diez parámetros hematimétricos (utilizando un contador Hematológico, realizando 10 repeticiones): Glóbulos blancos (GB), glóbulos rojos (GR), plaquetas (Plt), hemoglobina $(\mathrm{Hb})$, hematocrito (Hto), VCM, HCM, CHCM, RDW y PVM;

- Parámetros morfológicos: cambios celulares observados en extendidos coloreados con el método de May Grunwald-Giemsa.

Estudios bioquímicos: 
- Fragilidad osmótica (FO) (método de Dacie-Lewis, 1994), lipoperoxidación (cuantificación de los niveles de malondialdehído en plasma, método de Wong et al.,1987), proteínas de la membrana (electroforesis en PAGE-SDS, método de Steck y Yu, 1973), niveles de acetilcolinesterasa (AChE) (método cinético de Weber, 1966), niveles de pseudocolinesterasa (PChE) (método de Szasz, 1968) y niveles de 2,3-DPG (test UV de Boehringer Manheim).

- Niveles plasmáticos de vitamina E por HPLC (método de Leenher et al, 1978).

Se estudió además el efecto del agregado de 2 antioxidantes: vitamina E (succinato ácido de $\alpha$-tocoferol) en cinco concentraciones 0,$11 ; 0,17 ; 0,23 ; 0,45$ y 0,56 $\mu \mathrm{M}$ y vitamina $\mathrm{C}$ (ácido ascórbico) en dos concentraciones 0,68 y $1,36 \mathrm{mM}$, así como también el efecto del agregado de ambas vitaminas, sobre los parámetros mencionados. En todos los lotes, como control, se midieron los mismos parámetros en muestras de sangre entera sin estabilizar (SE).

En nuestros resultados encontramos:

- Parámetros hematimétricos y morfológicos: la SEE mantiene los parámetros hematimétricos durante el tiempo estudiado dentro del intervalo marcado por $\bar{x}_{\text {dial }} \pm 2 \mathrm{DE}$, salvo para los GB, el VCM, el Hto y las Plt, que dependiendo del lote, se alejan del intervalo entre los días 40 y 60 . El VCM, por ejemplo, presentó en algunos lotes un aumento de hasta un $16 \%$ durante los 120 días de almacenamiento, aunque este aumento es menor al observado en la SE durante el mismo tiempo (25\%). En cuanto a los GB, en algunos lotes la variación en su recuento para la SEE no fue significativa aún a los 120 días de almacenamiento, mientras que las muestras de SE presentan una disminución a los 10 días de hasta un 65\%. El agregado de los antioxidantes mejoró el tiempo máximo de almacenamiento, -período en el cual los valores se mantienen en el 
intervalo determinado por $\bar{x}_{\text {díal }} \pm 2 \mathrm{DE}-$, de algunos parámetros hematimétricos, como por ejemplo el recuento de plaquetas y el PVM. En cuanto a la morfología, los GR de la SEE presentan una menor anisocitosis que los de SE a los 120 días y ésta es aún menor en las muestras adicionadas con los antioxidantes, reflejado por los valores de RDW.

- Parámetros que miden los cambios de la membrana: Al comparar la FO de la SEE a los 10 días de almacenamiento con la de la SE, se encontró que en la primera la concentración de ClNa que produce el $50 \%$ de hemólisis es significativamente mayor $(p<0,05)$. Esto puede deberse a que la membrana de los GR estabilizados es menos deformable y por lo tanto las células son menos resistentes al estrés osmótico. La adición de vitamina $\mathrm{E}$ no pudo evitar las alteraciones de la membrana provocadas por la adición de los aldehídos, razón por la cual su agregado no produjo diferencias significativa en este parámetro ( $\mathrm{p}>0,05)$.

En las electroforesis de las proteínas de membrana del GR, aparecen en la SEE los polímeros de alto peso molecular debidos a los cross-linkings entre las proteínas, los cuales no se observan en la SE. Los porcentajes de cada proteína se mantienen durante al menos 80 días sin variaciones significativas $(p>0,05)$ y los diferentes tratamientos no mostraron diferencias entre los mismos.

Los niveles de AChE de la SEE son menores a los de la SE y entre los días 10 y 40 no presentan variaciones significativas $(p>0,05)$, la estabilización de la membrana si bien en un principio lleva a una disminución en la actividad de la enzima, con el tiempo ayuda a mantenerla dentro de los valores del intervalo dado por la $\bar{x} \pm 2 \mathrm{DE}$. Durante ese período, se puede considerar este material como estable en cuanto a sus niveles de AChE y de utilidad como material control.

- Parámetros que miden los cambios metabólicos: 
Los niveles de MDA en la SEE aumentan entre 1,5 y 4 veces luego de 120 días mientras que en la SE aumentan entre 6 y 8 veces. Al comparar las diferentes muestras de un mismo lote, se obtienen diferencias significativas entre la SE y los demás tratamientos $(p<0,01)$, pero no se observaron diferencias entre la SEE y la SEE adicionada con las vitaminas $(\mathrm{p}>0,10)$.

Los niveles de 2,3-DPG en la SE descienden hasta valores cercanos a cero luego de 30 días, mientras que en la SEE esto ocurre recién a los 80 días y en las muestras adicionadas con los antioxidantes se encontró que en algunos casos aún a los 100 días estos niveles se mantenían en un $40 \%$ del valor inicial. La disminución de este metabolito, íntimamente relacionado con el metabolismo energético, es menor en la SEE que en la SE y la adición de antioxidantes permitió mejorar aún más la conservación del mismo.

Podemos mencionar entonces que el agregado de los antioxidantes en las concentraciones mencionadas permitió sólo conseguir leves mejorías en la conservación de algunos parámetros ( como por ejemplo Plt, PVM, 2,3-DPG) pero en ninguno de los casos estas mejoras fueron altamente significativas. La adición a la muestra de una mezcla de ambas vitaminas no presentó mejoras estadísticamente significativas en ninguno de los parámetros mencionados, aunque sí mejoras leves que se traducen en CV\% menores para algunos parámetros.

Mantener una muestra de sangre entera estable por períodos de tiempo prolongados (más de 4 meses) es uno de los objetivos más difíciles de conseguir en el laboratorio clínico. Podemos afirmar que este material, el que es recomendado por el ICSH para su utilización en Control de Calidad en Hematología, permite, según nuestros resultados, obtener una muestra que puede ser utilizada en el laboratorio 
clínico para control de varios parámetros hematimétricos y/o bioquímicos, pero con diferentes límites de tiempos. 


\section{Contenido}

Agradecimientos

Página

iii

Resumen $\quad$ v

Indice de abreviaturas $\quad$ xiii

Introducción

1. Descripción morfológica y funcional del glóbulo rojo (GR) 3

1.1. Membrana 3

1.1.1. Composición lipídica de la membrana 5

$\begin{array}{ll}\text { 1.1.2. Composición proteica de la membrana } & 7\end{array}$

$\begin{array}{ll}\text { 1.1.3. Enzimas de la membrana } & 14\end{array}$

2. Alteraciones de la sangre entera durante el envejecimiento in vitro a $4^{\circ} \mathrm{C} \quad 16$

$\begin{array}{ll}\text { 2.1. Cambios en los parámetros hematimétricos } & 17\end{array}$

2.2. Cambios en las propiedades de los GR 18

$\begin{array}{ll}\text { 2.2.1. Cambios en la forma, volumen y densidad de los GR } & 18\end{array}$

2.2.2. Cambios en la deformabilidad y la estabilidad de la membrana de GR

2.2.3. Cambios en la permeabilidad de la membrana del GR 23

2.2.4. Cambios en la fragilidad osmótica de los GR 24

2.3. Cambios en las proteínas 26

2.3.1. Alteración de la actividad de enzimas 25

2.3.2. Cambios en las interacciones entre las proteínas 29

2.4. Cambios en los lípidos de la membrana $\quad 31$

$\begin{array}{ll}\text { 2.4.1. Lipoperoxidación } & 32\end{array}$

2.5. Cambios en el metabolismo energético 39

3. soluciones empleadas para el almacenamiento de SE y/o GR 41

4. Estabilización de la membrana de GR 46

5. Efecto del agregado de antioxidantes 48

$\begin{array}{ll}\text { 5.1. Acción de la vitamina E } & 50\end{array}$

Objetivos y diseño experimental $\quad 55$

1. Objetivo principal $\quad 56$

2. Objetivo secundario $\quad 56$

3. Diseño experimental: diagrama $\quad 57$

4. Detalle del diseño experimental 58

Material y métodos y Resultados 61

1. Medición de parámetros hematimétricos $\quad 62$

1.1. Material y métodos $\quad 52$

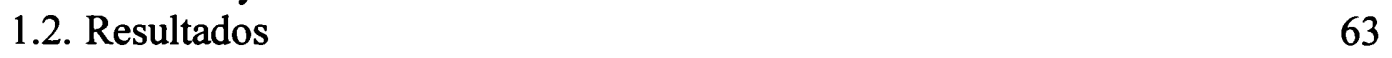

1.2.1. Control de los autoanalizadores 63

1.2.2. Medición de la reproducibilidad 65

$\begin{array}{ll}\text { 1.2.3. Control antimicrobiano } & 67\end{array}$

$\begin{array}{ll}\text { 1.2.4. Experiencias exploratorias } & 67\end{array}$ 
1.2.5. Seguimiento de los parámetros hematimétricos a largo plazo

Página

1.2.6. Efecto del momento de adición del antioxidante

2. Estudio de la morfología celular

2.1. Material y métodos

94

2.2. Resultados

94

3. Medición de la fragilidad osmótica $\quad 100$

$\begin{array}{ll}\text { 3.1. Material y métodos } & 100\end{array}$

$\begin{array}{ll}\text { 3.2. Resultados } & 103\end{array}$

4. Electroforesis de las proteínas de membrana 113

4.1. Material y métodos $\quad 113$

$\begin{array}{ll}\text { 4.2. Resultados } & 114\end{array}$

5. Medición de 2,3-difosfoglicerato 122

5.1. Material y métodos $\quad 122$

5.2. Resultados 124

6. Medición de la actividad de colinesterasas 126

6.1. Material y métodos 126

6.1.1. Medición de colinesterasa eritrocitaria (AChE) 126

$\begin{array}{ll}\text { 6.1.2. Medición de colinesterasa plasmática } & 127\end{array}$

$\begin{array}{ll}\text { 6.2. Resultados } & 128\end{array}$

6.2.1. Medición de colinesterasa eritrocitaria $\quad 128$

$\begin{array}{ll}\text { 6.2.2. Medición de colinesterasa plasmática } & 134\end{array}$

\begin{tabular}{lr} 
7. Lipoperoxidación & 140 \\
\hline & 140
\end{tabular}

$\begin{array}{ll}\text { 7.1. Material y métodos } & 140\end{array}$

$\begin{array}{ll}\text { 7.2. Resultados } & 141\end{array}$

8. Medición de la vitamina E plasmática 146

8.1. Material y métodos 146

$\begin{array}{ll}\text { 8.2. Resultados } & 147\end{array}$

$\begin{array}{ll}\text { Discusión } & 150\end{array}$

1. Estabilidad a largo plazo de la muestra de SEE

1.1. Estudios hematológicos $\quad 153$

1.1.1. Variación de los parámetros hematimétricos $\quad 153$

1.1.2. Cambios en la morfología celular 161

1.2. Estudios bioquímicos 162

1.2.1. Cambios en la fragilidad osmótica 162

1.2.2. Cambios en las proteínas de la membrana plasmática eritrocitaria 165

1.2.3. Cambios en los niveles de 2,3-DPG 167

1.2.4. Cambios en la actividad de las colinesterasas 168

1.2.5. Lipoperoxidación 171

2. Efecto de la adición de antioxidantes sobre la estabilidad a largo plazo de la SEE

$\begin{array}{ll}\text { 2.1. Estudios hematológicos } & 174 \\ \text { 2.2. Estudios bioquímicos } & 177\end{array}$

$\begin{array}{ll}\text { 2.2.1. Cambios en la fragilidad osmótica } & 177\end{array}$ 


\section{Página}

2.2.2. Cambios en las proteínas de la membrana plasmática eritrocitaria

2.2.3. Cambios en los niveles de 2,3-DPG 179

$\begin{array}{ll}\text { 2.2.4. Cambios en la actividad de las colinesterasas } & 180\end{array}$

$\begin{array}{ll}\text { 2.2.5. Lipoperoxidación } & 181\end{array}$

$\begin{array}{lr}\text { Conclusiones } & 184\end{array}$

$\begin{array}{ll}\text { Bibliografia } & 187\end{array}$ 


\section{Indice de abreviaturas}

\begin{tabular}{|c|c|}
\hline 2,3-DPG & 2,3-difosfoglicerato \\
\hline Abs & Absorbancia \\
\hline $\mathrm{ACD}$ & Ácido cítrico- Citrato- Dextrosa \\
\hline $\mathrm{AChE}$ & Acetilcolinesterasa \\
\hline ADSOL & Solución aditiva \\
\hline AMP & Monofosfato de Adenosina \\
\hline ATP & Trifosfato de Adenosina \\
\hline CHCM & Concentración de hemoglobina corpuscular media \\
\hline CPD & Citrato-Fosfato-Dextrosa \\
\hline CPD-A & Citrato-Fosfato-Dextrosa-Adenina \\
\hline Col. & Colesterol no esterificado \\
\hline $\mathrm{CV}$ & Coeficiente de variación \\
\hline $\mathrm{DE}$ & Desvío estándar \\
\hline EAS & Soluciones aditivas experimentales \\
\hline EDTA & Ácido etilendiaminotetraacético \\
\hline FO & Fragilidad osmótica \\
\hline G-6-PD & Glucosa 6-fosfato deshidrogenasa \\
\hline GAP-DH & Gliceraldehido-3-fosfato deshidrogenasa \\
\hline GB & Glóbulo blanco \\
\hline $\mathrm{GDH}$ & Glicero-3-fosfato deshidrogenasa \\
\hline GOT & Transaminasa glutámico oxalacética \\
\hline GPA & Glicoforina A \\
\hline GPB & Glicoforina B \\
\hline GPC & Glicoforina $\mathrm{C}$ \\
\hline GPD & Glicoforina D \\
\hline GPE & Glicoforina $\mathrm{E}$ \\
\hline GR & Glóbulo rojo \\
\hline $\mathrm{Hb}$ & Hemoglobina \\
\hline HBsAg & Antígeno de superficie del virus de la hepatitis B \\
\hline $\mathrm{HCM}$ & Hemoglobina corpuscular media \\
\hline $\mathrm{HCV}$ & Virus de la hepatitis C \\
\hline HIV & Virus de la inmunodeficiencia humana \\
\hline Hto & Hematocrito \\
\hline $\mathrm{ICSH}$ & Comité Internacional de Estandarización en Hematología \\
\hline IMP & Inosin-monofosfato \\
\hline LCAT & Lecitín-colesterol-acilttransferasa \\
\hline MDA & Malondialdehido \\
\hline Met-Hb & Metahemoglobina \\
\hline NAD + & Nicotinamida adenosina dinucleótido oxidado \\
\hline NADH & Nicotinamida adenosina dinucleótido reducido \\
\hline NEM & N-etilmaleimida \\
\hline $\mathrm{PA}$ & Ácido fosfatídico \\
\hline PAGE-SDS & Poliacrilamida- Dodecil-sulfato de sodio \\
\hline PAS & Ácido periódico-Shiff \\
\hline PC & Fosfatidilcolina \\
\hline $\mathrm{PChE}$ & Pseudocolinesterasa \\
\hline $\mathrm{PE}$ & Fosfatidiletanolamina \\
\hline
\end{tabular}




$\begin{array}{ll}\text { PG } & \text { Fosfoglicerato } \\ \text { PGK } & \text { Fosfoglicerato kinasa } \\ \text { PGM } & \text { Fosfoglicerato mutasa } \\ \text { PI } & \text { Fosfatidilinositol } \\ \text { Pi } & \text { Fósforo inorgánico } \\ \text { PLP } & \text { Fosfolípidos } \\ \text { Plt } & \text { Plaquetas } \\ \text { PM } & \text { Peso Molecular } \\ \text { PS } & \text { Fosfatidilserina } \\ \text { PVM } & \text { Volumen plaquetario medio } \\ \text { PRPP } & \text { Fosforibosilpirofosfato } \\ \text { RDW } & \text { Amplitud de la distribución del diámetro de los de GR } \\ \text { SAG } & \\ \text { SAGM } & \text { Cloruro de sodio, adenina, glucosa, manitol } \\ \text { SE } & \text { Sangre entera } \\ \text { SEE } & \text { Sangre entera estabilizada } \\ \text { SM } & \text { Esfingomielina } \\ \text { Sp } & \text { Espectrina } \\ \text { TBARS } & \text { Sustancias reactivas al ácido tiobarbitúrico } \\ \text { TEP } & \text { Tetraetoxipropano } \\ \text { TIM } & \text { Triosafosfato isomerasa } \\ \text { VCM } & \text { Volumen corpuscular medio }\end{array}$




\section{INTRODUCCIÓN}


La sangre entera (SE) es una suspensión acuosa de sales, minerales, nutrientes, sustancias de deshecho y células: glóbulos rojos (GR), glóbulos blancos (GB) y plaquetas (Plt). Mejorar la calidad y el tiempo de almacenamiento de la SE a $4^{\circ} \mathrm{C}$ es un objetivo buscado en diferentes campos de la Hematología. El tiempo máximo de almacenamiento de la SE a $4^{\circ} \mathrm{C}$ depende de varios factores como los cambios de $\mathrm{pH}$, el agotamiento de nutrientes, la disminución de energía en forma de trifosfato de adenosina (ATP), las oxidaciones sufridas por los lípidos y las proteínas tanto del plasma como de las membranas celulares (Greenwalt et al., 1993).

La mayor parte de las alteraciones que ocurren en la SE durante el almacenamiento están directamente relacionadas con las sufridas por los GR. El estudio del envejecimiento del eritrocito ha sido un tema de interés desde hace mucho tiempo, ya que se trata de una célula fácil de obtener y que puede tomarse como modelo para comprender los deterioros de otros tipos celulares (Bartosz, 1996). Es una célula desprovista de núcleo y otras organelas y por lo tanto no puede sintetizar proteínas de novo. Este hecho la hace incapaz de sustituir proteínas $\mathrm{u}$ otros componentes celulares que son dañados durante su envejecimiento tanto in vivo como in vitro. Se ha usado como modelo para comprender de qué manera una célula senescente o dañada puede ser removida de la circulación. Por otro lado, se ha convertido en un material utilizado en el laboratorio clínico para el estudio de diversas actividades enzimáticas y otros parámetros bioquímicos (Bartosz, 1996).

Los eritrocitos sufren durante su preservación in vitro, numerosas alteraciones morfológicas, fisiológicas y bioquímicas que son de interés en áreas como hemoterapia (Barretto, 1983; Fagiolo, 1986), control de calidad en hematimetría (Morgan, 1978), inmunología (Cohen, 1986) y bioquímica (Beutler, 1984). Se han propuesto numerosas 
soluciones preservadoras para el mantenimiento de las actividades metabólicas de los hematíes por largos períodos, desde que se introdujera por primera vez el ácido cítricocitrato-dextrosa (ACD) como anticoagulante y preservador de la sangre in vitro para transfusiones (Arduini et al., 1997). El conocimiento de los cambios que sufre el GR durante el envejecimiento in vitro es importante en las transfusiones, ya que las lesiones ocurridas durante el almacenamiento prolongado están directamente asociadas con la reducción en el porcentaje de recuperación postransfusional (Arduini et al., 1997).

Entre los cambios ocasionados en los GR en SE por el almacenamiento prolongado, estudiados con el fin de conocer su supervivencia luego de las transfusiones, podemos mencionar: la disminución de los niveles de 2,3-difosfoglicerato (2,3-DPG) que lleva a un aumento de la afinidad de la hemoglobina (Hb) por el oxígeno, el aumento de la fragilidad osmótica debida a la acumulación de lactato que conduce a una disminución de la viabilidad, y los cambios en la forma desde discos bicóncavos a formas crenadas, lo cual altera su circulación (Greenwalt et al., 1993).

El presente trabajo se centralizó en los cambios producidos en los GR por el almacenamiento prolongado de sangre entera estabilizada (SEE) a $4^{\circ} \mathrm{C}$. Por esta razón se describirán en la presente introducción las principales características de esta célula y las alteraciones que la misma sufre durante el almacenamiento de $\mathrm{SE}$ a $4^{\circ} \mathrm{C}$. Acerca de los GB y las Plt, sólo se hará referencia a los cambios en los recuentos celulares, y en cuanto a las variaciones plasmáticas se describirán únicamente las relacionadas en forma directa con alteraciones en la membrana del eritrocito.

\section{Descripción morfológica y funcional del glóbulo rojo}

\subsection{Membrana}

La membrana del GR mantiene la integridad del mismo cumpliendo con 
diferentes funciones (Gallagher et al., 1998):

a) Mantener la capacidad de deformación del eritrocito.

b) Responder a la eritropoyetina durante la eritropoyesis por unión a ligandos específicos.

c) Importar el Fe necesario para la síntesis de $\mathrm{Hb}$.

d) Retener componentes vitales como por ejemplo los fosfatos orgánicos.

e) Actuar como una barrera que ayude a mantener la concentración interna de varios iones y metabolitos, las cuales difieren marcadamente de la concentración encontrada en el medio exterior (plasma).

f) Remover los productos de deshecho del metabolismo celular.

g) Secuestrar los reductores necesarios para impedir los daños provocados por el oxígeno.

h) Ayudar a regular el metabolismo eritrocitario por unión e inactivación selectiva y reversible a las enzimas glicolíticas.

Para cumplir con algunas de estas funciones, la membrana debe ser insoluble en solución acuosa por lo que no es sorprendente pensar que aproximadamente la mitad de su masa está constituida por lípidos acomodados en una bicapa. Para poder servir de barrera, contiene bombas y canales para el movimiento de sodio, potasio, calcio y glutatión oxidado y facilita el transporte de glucosa y otros metabolitos pequeños. Es también responsable de mantener la forma bicóncava de la célula, propiedad en la que juegan un papel importante las proteínas, además de los lípidos.

El eritrocito debe ser una célula fácilmente deformable y, para que esto sea posible, se deben mantener: a) la geometría celular, con una gran relación área/volumen, que permita a la célula sufrir deformaciones a volumen constante; b) la viscosidad del contenido celular, determinada principalmente por las propiedades y la concentración de 
la $\mathrm{Hb}$ y c) las propiedades viscoelásticas intrínsecas de la membrana (Mohandas y Chasis, 1993).

Todas las propiedades de la membrana están reflejadas en las características de sus componentes.

\subsubsection{Composición lipídica de la membrana}

Los lípidos de la célula madura que se encuentran en la membrana plasmática son responsables de sus propiedades fisicas. Los principales son los fosfolípidos (PLP) y el colesterol no esterificado (col.), que constituyen el $95 \%$ de los lípidos de la membrana y están presentes en proporciones prácticamente iguales (relación molar col./PLP $=0,8$. Existen además, pequeñas cantidades de glicolípidos, glicéridos y algunos ácidos grasos libres. Los PLP predominantes son: fosfatidilcolina (PC) $30 \%$, fosfatidiletanolamina (PE) 28\%, esfingomielina (SM) 25\% y fosfatidilserina (PS) $14 \%$. También pequeñas cantidades de ácido fosfatídico (PA), fosfatidilinositol (PI) y lisofosfatidilcolina (Palek, 1995). Se disponen en forma de bicapa, con las cabezas polares hacia el citosol y el plasma y las largas cadenas de ácidos grasos hacia el interior hidrofóbico de la membrana. Este interior hidrofóbico facilita la flexibilidad y la deformabilidad fisiológicas necesarias para la membrana del GR. Varias de las proteínas de membrana se encuentran inmersas en esta porción, algunas sólo en la mitad externa y otras -principalmente con funciones transportadoras- atravesándola por completo.

Los PLP se encuentran asimétricamente distribuidos entre las porciones externa e interna de la membrana, el $80 \%$ de la PE y la PS se encuentran en la cara interna, mientras que el $\mathbf{8 0 \%}$ de la PC y la SM se encuentran en la mitad externa, hacia el plasma. Esta asimetría es mantenida por tres factores: a) un movimiento pasivo de PLP 
a través de la membrana en el cual tienen un papel importante las proteínas integrales, b) la intervención de una aminofosfolípido-translocasa o flipasa, dependiente de ATP, la cual transloca PE y PS desde la porción externa a la interna de la membrana y c) un efecto estabilizante de las proteínas del citoesqueleto al interactuar con los PLP, principalmente la PS negativamente cargada (Kuypers et al., 1993; Dumaswala, 1996a). Una consecuencia importante de la asimetría involucra justamente esta unión entre la membrana y el citoesqueleto, que sirve como sostén de la misma e influye en su estabilidad y deformabilidad. Se han establecido interacciones entre el citoesqueleto y las proteínas inmersas entre los PLP, como la banda 3 y las glicoproteínas. También hay interacciones entre espectrina (Sp) y PE, entre Sp y PS y entre banda 4.1 y PS. In vitro, la Sp interactúa fuertemente con los PLP aniónicos (PS, PA y PI) (Bonnet y Begard, 1984). Además, se ha demostrado que la asimetría de los PLP se pierde cuando los grupos - SH de la $\mathrm{Sp}$ son oxidados por agentes como la N-etilmaleimida (NEM) que provocan la formación de oligómeros de Sp (Haest et al., 1978; Bergmann et al., 1984; Kuypers et al., 1993).

Los PLP contienen dos cadenas de ácidos grasos unidas a una molécula de glicerol. La ausencia de un ácido graso influye en las características físicas del PLP. Así, los lisofosfátidos (lisoPLP), que son PLP que contienen un solo ácido graso, son menos lipofilicos y se concentran en las interfases, incrementando las cualidades detergentes y la velocidad de intercambio entre la membrana celular y el plasma. Estos lisoPLP en bajas concentraciones $(0,0002 \mathrm{M})$ pueden causar la lisis de los GR y en concentraciones menores pueden causar cambios profundos y a veces irreversibles en la forma del GR como es la formación de equinocitos (Shohet, 1990).

Por lo expuesto anteriormente, la composición lipídica de la membrana determina parcialmente su viscosidad y su fluidez. Algún cambio en esta composición 
afecta estas características, por ejemplo un incremento de colesterol, con el consecuente aumento de la relación col./PLP, provoca la disminución de la fluidez (Kakimoto et al., 1995) y la disminución de la deformabilidad, como ocurre en los pacientes urémicos donde ésta es una de las causas de anemia (Langsdorf y Zydney, 1993). Por otra parte, un aumento en la cantidad de ácidos grasos saturados en los PLP aumenta la rigidez (Palek, 1995).

El GR maduro no posee la capacidad de realizar síntesis de novo de ácidos grasos. Sin embargo, durante toda su vida la célula renueva constantemente sus lípidos intercambiándolos con el plasma en una forma pasiva y en otra activa. Esta última requiere de ATP, lisoPLP, magnesio y coenzima A. Así, luego de la formación de la acil-coenzima A se produce la incorporación de un ácido graso al lisoPLP. In vitro, cuando los niveles de ATP descienden hasta 0,1 o $0,2 \mathrm{mM}$, la acilación de los lisoPLP cesa y comienzan a aumentar los niveles de éstos en la célula, conduciendo, como se comentara anteriormente, a la formación de equinocitos (Devaux, 1992).

\subsubsection{Composición proteica de la membrana}

Las proteínas de la membrana del eritrocito pueden ser extraídas luego de una hemólisis hipotónica y separadas por electroforesis en geles de poliacrilamida y dodecilsulfato de sodio (PAGE-SDS). En la Tabla 1 se muestra la composición proteica de la membrana y la localización de las proteínas en un gel de PAGE-SDS. Se dividen en dos grupos:

\section{Grupo 1: Proteinas integrales}

Están inmersas en la bicapa lipídica y unidas a los lípidos por enlaces apolares. Confieren fluidez a la membrana y pueden ser extraídas sólo con detergentes. Participan 
en el mantenimiento de la forma del eritrocito mediante su unión al citoesqueleto y son las siguientes:

a) Glicoforinas: constituyen el $2 \%$ del total de las proteínas de membrana. Son glicoproteínas que casi siempre contienen en su estructura ácido siálico, que se exterioriza hacia la superficie externa del eritrocito dando lugar al glicocálix y están asociadas con diferentes antígenos de la membrana eritrocitaria. Las glicoforinas A, B y E están asociadas con los antígenos de los grupos sanguíneos MNS y las glicoforinas C y D lo están con los antígenos de los grupos sanguíneos Gerbich (Ge). Estas proteínas corren en forma anómala en los geles de SDS, ya que las largas cadenas de carbohidratos que poseen interfieren por un lado en la unión con el SDS y por otro lado, en la reacción de coloración con el Coomasie Blue de manera que no pueden observarse con esta técnica y necesitan de coloraciones especiales como el ácido periódico-Schiff (PAS).

Glicoforina A (GPA): es la mayor sialoglicoproteína del glóbulo rojo, hay aproximadamente un millón de copias por célula. Es la primera en detectarse en los proeritroblastos y es marcadora de la serie eritroide. Se encuentra en la membrana asociada a la proteína banda 3 . Los aminoácidos situados en las posiciones 1 y 5 de su extremo terminal determinan la antigenicidad de los grupos $\mathrm{M}$ y $\mathrm{N}$ (Gallagher et al., 1998).

Glicoforina B (GPB): es estructuralmente semejante a la anterior, pero se encuentra en menor cantidad, aproximadamente 15000 copias por célula. Además de la secuencia peptídica que aporta la reactividad de antígeno $\mathrm{N}$, transporta los antígenos $\mathrm{S}$, s y U. La GPB además forma un complejo macromolecular con las glicoproteínas $\mathrm{Rh}$, que forman los antígenos $\mathrm{Rh}$, la glicoproteína $\mathrm{Rh} 55, \mathrm{CD} 47$ y proteínas que forman los antígenos Duffy y LW (Gallagher et al., 1998). 
Glicoforina E (GPE): Su función es desconocida y su gen se encuentra orientado en tándem junto con los de la GPA y GPB (Gallagher et al., 1998).

Glicoforinas C (GPC) y D (GPD): la GPC no es específica de la serie eritroide. Normalmente, la GPC glicosilada aparece en la unidad formadora de colonias eritroides. La GPD es una forma acortada de la GPC, posee 21 aminoácidos menos en el extremo $\mathrm{NH}_{2}$-terminal. Hay 143000 copias de GPC y 82000 de GPD por célula. La GPC determina la antigenicidad del grupo sanguíneo Gerbich.

Las glicoforinas proveen la mayor parte de la carga negativa que necesitan los eritrocitos para evitar pegarse entre ellos y con las paredes de los vasos sanguíneos. La GPC se une a la proteína 4.1 y a la p55 y entonces, ayuda a mantener el citoesqueleto anclado a la membrana (Gallagher et al., 1998).

b) Proteína Banda 3 o canal aniónico: es la principal proteína integral de la membrana del GR, constituyendo el $25 \%$ a $30 \%$ del total de las proteínas. Es una proteína de aproximadamente $95 \mathrm{kD}$ de peso molecular y cada célula contiene 1,2 millones de copias. Su fragmento oligosacárido es el responsable de la antigenicidad li y ABH. Migra en los geles PAGE-SDS como una banda difusa debido a la heterogeneidad de su glicosilación. Posee varias funciones:

i) Es una proteína de intercambio aniónico. Los 1,2 millones de canales en cada GR intercambian entre $10^{10}$ y $10^{11}$ aniones cloruro y bicarbonato por segundo. Esto permite que el bicarbonato producido por la anhidrasa carbónica en el interior del GR sea traspasado al plasma y se incremente el transporte de $\mathrm{CO}_{2}$ de los tejidos a los pulmones. Por su parte, $\mathrm{el}^{+}$producido en la reacción de la anhidrasa carbónica se une a la $\mathrm{Hb}$ y facilita la liberación de $\mathrm{O}_{2}$ en los tejidos (efecto Bohr). La especificidad por los aniones de este canal no está limitada a estos dos aniones: sulfato, fosfato, piruvato y superóxido también son transportados a través de él, pero con menor velocidad. 
ii) Existe evidencia de que puede ser una flipasa, de que influye en la deformabilidad de la membrana del GR y de que interviene en el metabolismo, la senescencia y posiblemente en la forma del GR (Gallagher et al., 1998). El extremo $\mathrm{NH}_{2}$-terminal de esta proteína se une a enzimas de la vía glicolítica como la gliceraldehído-3-fosfato deshidrogenasa, la fosfogliceratoquinasa y la aldolasa. La unión a la membrana inhibe la actividad de las enzimas y está regulada por los sustratos, los cofactores, la presencia de inhibidores y por fosforilación de residuos de tirosina. La proteína banda 3, al unir estas enzimas, es entonces un regulador de la glicólisis en los GR. Así, algunos oxidantes que estimulan la fosforilación de sus residuos de tirosina, elevan la velocidad de la glicólisis. Este extremo $\mathrm{NH}_{2}$-terminal también une $\mathrm{Hb}$; la deoxihemoglobina se liga mejor que la oxihemoglobina, pero esta unión a la deoxihemoglobina es inhibida por el 2,3-DPG. En condiciones fisiológicas, aproximadamente la mitad de las moléculas de banda 3 están unidas a la $\mathrm{Hb}$. Los hemicromos, una forma de la $\mathrm{Hb}$ parcialmente desnaturalizada, se unen más fuertemente y forman agregados con esta proteína; estos agregados influyen en el envejecimiento del GR (Gallagher et al., 1998).

iii) Interviene en la unión del citoesqueleto a la membrana uniéndose a la ankirina, la proteína 4.1 y la proteína 4.2 .

c) Otras: En el GR existen otras proteínas integrales entre las que se encuentran las proteínas $\mathrm{Rh}$, los antígenos Kell, los antígenos Duffy, transportadores de glucosa, urea y aminoácidos, ATPasas, incluyendo la $\mathrm{Na}^{+}, \mathrm{K}^{+}-$ATPasa, la $\mathrm{Ca}^{+2}-$ ATPasa, y la $\mathrm{Mg}^{+2}$-ATPasa, varias kinasas y fosfatasas, la acetilcolinesterasa (AChE) y receptores para diferentes moléculas como transferrina, insulina, hormona tiroidea, hormona paratiroidea, agonistas $\beta$-adrenérgicos, entre otras. 
Grupo 2: Proteínas periféricas o citoesqueleto submembranal

Suelen llamarse extrínsecas porque pueden ser removidas de la membrana por el tratamiento con soluciones alcalinas o de baja fuerza iónica, sin romper la bicapa. Este citoesqueleto es el principal responsable de mantener la forma y la deformabilidad del GR (Gallagher et al., 1998). Varias de estas proteínas son miembros de la superfamilia de proteínas que ligan la actina, las cuales poseen homología en un dominio común de unión a la actina. A esta superfamilia pertenecen por ejemplo la Sp y la aducina (Hartwig, 1995). Por microscopía electrónica este esqueleto aparece como una malla de proteínas íntimamente relacionadas que se encuentra subyacente a la bicapa lipídica. Constituyen aproximadamente el $60 \%$ de las proteínas totales e incluyen: espectrina, actina, tropomiosina, tropomodulina, aducina, ankirina, proteína 4.1, dematina, proteína 4.2 y proteínas de la región 7 del gel de PAGE-SDS (Tabla 1).

La estructura básica fundamental de este citoesqueleto está constituida por la espectrina, la actina, la proteína 4.1 y la ankirina, ya que el esqueleto retiene su forma si alguna de las otras proteínas es removida, pero se desintegra si la espectrina o la actina son extraídas (Shohet y Beutler, 1990).

La espectrina, que constituye el $75 \%$ de la masa del esqueleto, está compuesta por dos subunidades $\alpha$ y $\beta$ (bandas 1 y 2), las cuales son estructuralmente diferentes y están codificadas por genes ubicados en distintos cromosomas (1 para $\alpha$ y 14 para $\beta$ ). Comprenden entre el $25 \%$ y $30 \%$ de las proteínas totales de la membrana y están presentes unas 200000 copias por célula. Las cadenas $\alpha$ y $\beta$ se encuentran en solución formando heterodímeros (estructura helicoidal antiparalela). Los dímeros se asocian preferentemente para formar tetrámeros y oligómeros, por interacciones cabeza-cabeza y cola-cola (asociaciones laterales). Cuando las proteínas son extraídas a $0^{\circ} \mathrm{C}$, las moléculas de $\mathrm{Sp}$ pueden separarse en su forma nativa: tetrámeros y oligómeros. Una 
interrupción en las asociaciones espectrina-espectrina ( $\mathrm{Sp}-\mathrm{Sp}$ ) lleva a alteraciones en la forma del GR y, en ocasiones, a anemias hemolíticas (Palek,1995).

La unión cola-cola del dímero está mediada por la actina y la proteína 4.1. La unión cabeza-cabeza, ocurre por contacto directo entre las hebras complementarias del heterodímero. Cada 6 unidades de Sp se unen a un oligómero de actina formando una red irregular de estructura aproximadamente hexagonal y cada unión Sp-actina se estabiliza mediante la formación de un complejo ternario con la proteína 4.1. Se trata de una proteína altamente flexible capaz de asumir una gran variedad de configuraciones, siendo esta propiedad crítica para que la membrana eritrocitaria pueda cumplir su función. Las funciones de la $\mathrm{Sp}$ eritrocitaria son las de mantener la forma, regular la movilidad lateral de las proteínas integrales y, como ya se mencionó, proveer un soporte estructural para los lípidos de la bicapa. Estas funciones son mediadas por interacciones de la Sp con otras proteínas (Gallagher et al., 1998).

El anclaje del citoesqueleto a la membrana ocurre a través de una asociación específica entre la $\beta$-espectrina, la banda 3 y la ankirina y, por la interacción entre la Sp y la glicoforina $\mathrm{C}$, mediada por la proteína 4.1. El efecto de estas interacciones perfectamente orquestadas es producir un citoesqueleto fuerte y flexible que está intimamente relacionado con la bicapa lipídica y que es capaz de soportar una integridad física que debe destacarse.

La ankirina o proteína 2.1 posee tres dominios que establecen contacto con la banda 3 , la Sp (cadena $\beta$ ) y banda 3-Sp, hecho que la convierte en una proteína clave en el anclaje del citoesqueleto a la membrana (Haest, 1982).

La proteína 4.1 tiene estructura globular y se separa en los geles de poliacrilamida-SDS en sus dos isoformas: $4.1 \mathrm{a}$ y $4.1 \mathrm{~b}$. La isoforma $4.1 \mathrm{~b}$ predomina en los reticulocitos y se convierte en 4.1a por desaminación de un residuo de Asn 502. 
Otras proteínas del esqueleto de la membrana son, como ya se mencionó, la actina y sus proteínas asociadas: desmatina, aducina, tropomiosina, tropomodulina y banda 7 , que contribuyen a mantener su conformación y estabilidad molecular y, la proteína 4.2, que se une a la banda 3, contribuyendo a su oligomerización.

Los contactos horizontales entre estas proteínas mantienen la integridad estructural de la célula, explicando la alta fuerza de tensión del GR. Las conexiones verticales proteína-proteína y proteína-lípido de la bicapa, son críticas en la estabilización de la bicapa lipídica, ya que además de ayudar a mantener la distribución de los PLP, evitan la pérdida de fragmentos de la misma bajo la forma de microvesículas (Haest, 1982; Shohet y Beutler, 1990).

Tabla 1. Proteínas de la membrana del glóbulo rojo

\begin{tabular}{|c|c|c|c|c|}
\hline Banda & Proteína & $\begin{array}{c}\text { Peso Molecular (kD) } \\
\text { (gel/calculado) }\end{array}$ & $\begin{array}{c}\text { Copias/célula } \\
(\mathrm{x} \mathrm{10})\end{array}$ & $\%$ del total \\
\hline 1 & $\alpha$-espectrina & $240 / 281$ & 240 & 16 \\
\hline 2 & $\beta$-espectrina & $220 / 246$ & 240 & 14 \\
\hline 2.1 & Ankirina & $210 / 206$ & 120 & 4.5 \\
\hline 2.9 & $\alpha$-aducina & $103 / 81$ & 30 & $<1$ \\
& $\beta$-aducina & $97 / 80$ & 30 & $<1$ \\
\hline 3 & canal aniónico & $90-100 / 102$ & 1200 & 27 \\
\hline 4.1 & Proteína 4.1 & $80 / 78$ & 200 & 5 \\
\hline 4.2 & Palidina & $72 / 77$ & 200 & 5 \\
\hline 4.9 & Desmatina & $50 /--$ & 40 & 1 \\
& p55 & $55 / 53$ & 80 & -- \\
\hline 5 & $\beta-$ Actina & $42 / 43$ & $400-500$ & 5.5 \\
& Tropomodulina & $41 / 43$ & 30 & -- \\
\hline 6 & G-3P-D & $35 / 36$ & 30 & -- \\
\hline 7 & Estomatina & $31 / 32$ & -- & 4 \\
& Tropomiosina & $27 / 29$ & 70 & 3.4 \\
\hline 8 & Proteína 8 & $23 /--$ & 200 & $1-2$ \\
\hline PAS-1* & Glicoforina A & $31 / 14$ & $500-1000$ & 1.6 \\
\hline PAS-2* & Glicoforina C & $36 / 14$ & $50-100$ & 0.1 \\
\hline PAS-3* & Glicoforina B & $20 / 8$ & $100-300$ & 0.2 \\
& Glicoforina D & $23 / 11$ & 20 & 0.02 \\
& Glicoforina E & $--/ 6$ & -- & -- \\
\hline
\end{tabular}

* No se observan con la coloración de Coomasie Blue, son observables sólo por medio de una coloración especial: PAS (véase texto) 


\subsubsection{Enzimas de la membrana}

Existen varias enzimas asociadas a la membrana del GR, entre ellas se encuentran la $\mathrm{Na}^{+}-\mathrm{K}^{+}$-ATPasa, la $\mathrm{Mg}^{+2}$-ATPasa, la AChE, cuyas actividades están influenciadas por cambios en la composición lipídica y en la fluidez de la membrana (Kakimoto et al., 1995). En relación a estas enzimas de membrana, en esta tesis nos referiremos sólo a la $\mathrm{AChE}$.

La AChE eritrocitaria (EC 3.1.1.7) es conocida también como colinesterasa verdadera, colinesterasa específica o colinesterasa tipo I. Las colinesterasas son enzimas que catalizan la hidrólisis de los ésteres de colina. Esta enzima cataliza la hidrólisis de acetilcolina y de acetil-beta-metilcolina, pero no de otros tipos de ésteres de colina. Presenta inhibición por el sustrato, está involucrada en la transmisión de la sinapsis colinérgica en el sistema nervioso y se la encuentra también en células hemopoyéticas como GR, plaquetas, linfocitos y posiblemente en granulocitos (Lawson y Barr, 1987).

Es parte integral de la membrana del GR (sólo puede ser solubilizada en presencia de detergentes no iónicos) y la digestión con enzimas proteolíticas ha demostrado que se encuentra en la cara externa de la misma. Es clasificada como una proteína anfipática, ya que tiene un dominio hidrofóbico que le permite anclarse a la membrana y otro hidrofílico, orientado al citosol, que conserva la actividad enzimática (Heller y Hanahan, 1972). Además cumple con otras propiedades características de las proteínas anfipáticas: a) para poder ser extraída intacta de la membrana requiere de detergentes con los cuales interactúa formando micelas, forma agregados, pero no precipita cuando se quita el detergente, y posee la capacidad de ser reconstituida en liposomas; b) la porción hidrofílica, una vez separada por acción de proteasas, no conserva la propiedad de agregarse ni de unirse a detergentes o a liposomas (Rosenberry y Scoggin, 1984). 
Se encuentra como dímero ( $\mathrm{PM}=160000)$, conteniendo un puente disulfuro que une las subunidades. Existen entre 700 y 800 dímeros por GR. In vitro se puede obtener la forma monomérica por tratamiento con 2-mercaptoetanol o ácido iodoacético. Esta forma monomérica es activa y se ha demostrado que la formación del dímero no es esencial para que la proteína sea anfipática (Ott et al., 1984).

Cuando la enzima es solubilizada en Tritón X-100, en soluciones de alta fuerza iónica, se pueden evidenciar por electroforesis en geles de poliacrilamida más de seis formas con pesos moleculares desde 66000 hasta 562000, que presentan diferentes puntos isoeléctricos, pero poseen igual actividad hidrolítica. Una vez extraído el detergente, se observa que la enzima se presenta bajo la forma de monómeros o dímeros. La formación de los dímeros se debe a interacciones hidrofóbicas entre las subunidades y las mismas pueden ser revertidas adicionando nuevamente el detergente. Esto demuestra que en el detergente se forman micelas que estabilizan las subunidades por medio de interacciones hidrofóbicas (Rosenberry y Scoggin, 1984).

Se pueden diferenciar dos tipos de AChE: una asimétrica, que se encuentra principalmente en los tejidos neuromusculares y otra globular. Esta última puede, a su vez, dividirse en dos tipos: en el primero, la enzima es una proteína integral de membrana que puede interactuar con los detergentes no iónicos luego de su extracción $\mathrm{y}$, en el segundo, se encuentran las proteínas solubles que no se unen a los detergentes. La AChE eritrocitaria, por todo lo expuesto anteriormente, es una proteína globular del primer tipo (Bon et al., 1979).

En cuanto a la función de esta enzima, no se ha alcanzado aún ninguna conclusión (Meuling, 1992). Se sabe que la $\mathrm{AChE}$ tiene un rol importante en la síntesis de PLP en otros tejidos, pero no se ha podido demostrar que esto ocurra en el GR. Por otro lado, existen evidencias de que la inhibición de la enzima en GR maduros, no 
afecta la vida media del GR y entonces, no es causante de anemia (Goldin et al., 1964; Metz et al., 1961; De Sandre et al., 1963; Lund-Karlsen et al., 1981).

\section{Alteraciones de la sangre entera durante el envejecimiento in vitro a $4^{\circ} \mathrm{C}$}

Los principales inconvenientes asociados con la preservación de la sangre in vitro están relacionados, por un lado, con la integridad del metabolismo energético de los eritrocitos, el cual es mantenido durante cierto tiempo por la glicólisis anaeróbica y, por otra parte, con los GB y las plaquetas, los cuales tienden a formar microagregados.

Las alteraciones sufridas por los hematíes in vitro suelen ser algo diferentes a las que ocurren in vivo, donde los GR pueden intercambiar metabolitos con el plasma, están sujetos al estrés mecánico e interactúan con las células del endotelio vascular y las del sistema retículo endotelial (Bartosz, 1996).

Como se mencionara anteriormente, durante el almacenamiento los GR pierden ATP, 2,3-DPG y $\mathrm{K}^{+}$intracelular y además liberan microvesículas enriquecidas en las proteínas banda 3, proteína 4.1 y AChE (Dumaswala, 1996a).

El envejecimiento del GR in vitro está asociado a diferentes cambios: a) disminución de la deformabilidad celular; b) cambios en la densidad celular; c) disminución de los niveles de ATP, PLP y col.; d) pérdida de la actividad de las enzimas, incluyendo la $\mathrm{AChE}$ y e) liberación de carbohidratos desde la membrana celular (Ando et al., 1995).

También existen evidencias que demuestran que los daños oxidativos tienen influencia en el envejecimiento del GR. La acumulación de productos generados por la lipoperoxidación como los hidroperóxidos y los aldehídos, pueden causar daños estructurales en las proteínas y las enzimas. Se ha demostrado que una gran variedad de 
estos aldehídos pueden provocar la polimerización de las proteínas, la formación de PLP fluorescentes y la formación de grupos carbonilo en las proteínas, causando así, cambios en las propiedades fisicoquímicas de la célula (Ando et al., 1995).

\subsection{Cambios en los parámetros hematimétricos}

El almacenamiento de $\mathrm{SE}$ a $4^{\circ} \mathrm{C}$ produce alteraciones en los parámetros hematimétricos, que se hacen significativas a medida que aumenta el tiempo de almacenamiento y dependen del anticoagulante empleado. Se ha determinado por ejemplo que el anticoagulante ácido etilendiaminotetraacético (EDTA) mantiene los elementos celulares de la sangre por más tiempo que el oxalato o la heparina, mientras que los niveles de $\mathrm{Hb}$ se mantienen por varios días, los recuentos de GB permanecen invariables por 48 horas a $4^{\circ} \mathrm{C}$ (Lampasso, 1968).

Se ha estudiado el efecto de la temperatura en la que se almacena la SE sobre los parámetros hematimétricos. Cuando la sangre es almacenada a temperatura ambiente en $\mathrm{K}_{2}$-EDTA, luego de 72 horas ocurre un aumento significativo en el volumen corpuscular medio (VCM) que se ve además reflejado en el aumento del hematocrito (Hto) y la disminución de la concentración de $\mathrm{Hb}$ corpuscular media (CHCM). En cambio, si la sangre permanece a $4^{\circ} \mathrm{C}$, en el mismo lapso de tiempo las variaciones no son significativas para ningún parámetro (Bellamy y Hinchliffe, 1990).

Cohle et al (1981) demostraron también que la SE extraída en EDTA-K , $_{3}$ almacenada a $4^{\circ} \mathrm{C}$ durante tres días, cuando es agitada diariamente al menos 15 minutos, no presenta variaciones significativas en el recuento de GR, GB y Plt, los niveles de $\mathrm{Hb}$, Hto, VCM, Hb corpuscular media (HCM) y CHCM; mientras que si la sangre es conservada a temperatura ambiente, luego de 24 horas se produce un aumento significativo en VCM y Hto y una disminución en CHCM. 


\subsection{Cambios en las propiedades de los GR}

\subsubsection{Cambios en la forma, volumen y densidad de los GR}

El GR normal tiene una forma de disco regular de 7-8 $\mu \mathrm{m}$ de diámetro, con una depresión en su centro, llamada discocito. In vitro, los cambios en el volumen y la densidad celulares, que llevan a cambios en la forma del GR se deben principalmente a:

a) Alteraciones en el transporte de cationes a través de la membrana: el hematíe posee una concentración intracelular de cationes muy baja con respecto al plasma y la Hb se comporta como un anión. Por lo tanto, para poder mantener esa diferencia de concentraciones iónicas, se debe disponer de una determinada cantidad de energía. Cuando las fuentes de energía descienden, ocurre que la excesiva entrada de cationes en el hematíe, principalmente $\mathrm{Na}^{+}$, arrastra una cantidad de agua que se traduce en un aumento del volumen celular (Beutler y Kuhl, 1988; Bartosz, 1996).

b) Pérdida de microvesículas: son fragmentos de membrana que encierran porciones de citoplasma y se ha comprobado que se forman durante el almacenamiento in vitro. En circulación no se han encontrado, posiblemente debido a que ni bien se forman son eliminadas por las células del sistema retículo endotelial (Bartosz, 1996). Existen dos posibles mecanismos para explicar esta fragmentación. El primero propone una interrupción en las interacciones proteína-proteína que lleva a la formación de microvesículas esféricas con la misma composición que las membranas intactas de las cuales provienen (Chasis y Mohandas, 1986). El segundo postula que fallas en las interacciones lípido-proteína del citoesqueleto conducen a la formación de microvesículas que contienen PLP, col, proteínas integrales, pocas proteínas del citoesqueleto y no poseen Sp (Wagner et al., 1986). Esta pérdida de material de membrana puede deberse en parte a la disminución de ATP durante el almacenamiento 
prolongado. In vivo, este efecto puede ser causado por la continua exposición de los GR a las fuerzas de estiramiento en la microcirculación (Chasis y Mohandas, 1986).

Luego de 8 semanas de almacenamiento en ACD, los GR son predominantemente esferoequinocitos de los cuales entre $20 \%$ y $30 \%$ no pueden revertir su forma a discocitos, aún con la adición de ATP. Estos cambios ocurren en un medio donde los niveles de ATP descienden lentamente hasta $10 \%$ y $20 \%$ de lo normal (no a $0 \%$ ) y sin evidencias de grandes acumulaciones de calcio ni grandes cambios de $\mathrm{pH}$ (Wolfe, 1985). Cuando los niveles de ATP disminuyen entre un $10 \%$ y un $15 \%$, los GR comienzan a desarrollar espículas y aparecen los equinocitos. La forma de los GR puede revertirse luego de hasta 20 horas de almacenamiento, aún después de la pérdida completa de ATP, mediante la adición de glucosa y nucleótidos de purina al medio, los cuales retornan los niveles de ATP a la normalidad. Sin embargo, luego de más de 28 horas del agotamiento del ATP, la formación de esferoequinocitos, con la consecuente disminución de la relación área/volumen, es irreversible. En ese momento, los GR pierden PLP y col. en forma de vesículas y la formación de los esferoequinocitos lleva a un aumento en la viscosidad y en la fragilidad osmótica (Meryman et al., 1986).

Como la disminución de los niveles de ATP promueve directa o indirectamente la pérdida de lípidos en forma de vesículas, estudiar la composición de las membranas de las mismas podría indicar el mecanismo por el cual se forman. Contienen cantidades balanceadas de col. y PLP y están enriquecidas en diacilglicerol y ácido fosfatídico sugiriendo que su formación estaría asociada con la acción de la fosfodiesterasa dependiente de calcio sobre la cara interna de la membrana (Wolfe, 1985). Estas vesículas también contienen diferentes cantidades en las proteínas de la membrana, poseen disminuidas las cantidades de $\mathrm{Sp}$, proteína 4.1, proteína banda 3 y glicoforinas, sugiriendo, como ya se mencionó, las alteraciones en las relaciones verticales y 
horizontales durante el almacenamiento (Dumaswala, 1996a).

La edad de los eritrocitos influye en su tendencia a formar microvesículas. Se ha demostrado que durante el almacenamiento en citrato-fosfato-dextrosa-adenina (CPD$A_{1}$ ) como anticoagulante, los GR jóvenes forman mayor cantidad de vesículas que los GR adultos del mismo donante, los cuales ya habrían sufrido vesiculización in vivo (Greenwalt y Dumaswala, 1988).

La forma de los GR puede ser estabilizada por cross-linking entre las proteínas de la membrana, ya sea debido a la formación de puentes disulfuro inducidos por oxidantes, como por el cross-linking catalizado por la transglutaminasa citosólica dependiente de calcio. Estas modificaciones de las proteínas son como fijadores endógenos que estabilizan la forma de las células in vitro (Gallagher, 1998).

En cuanto a la variación del VCM y la densidad, es conocido que in vivo, a medida que los GR maduran disminuye su VCM y por lo tanto aumenta su densidad. (Bartosz, 1996). In vitro en cambio, esto depende del anticoagulante utilizado, principalmente de las concentraciones de manitol en el mismo y del tiempo de almacenamiento. Por ejemplo, el almacenamiento de la SE durante 30 días a $4^{\circ} \mathrm{C}$ en ACD o en CPD- $A_{1}$ produce un incremento en la densidad de los GR (Rocchigiani, 1989). Por el contrario, en el anticoagulante citrato-fosfato-dextrosa (CPD) se produce un aumento del VCM y entonces hay una disminución en la densidad de los GR (Bartosz, 1996).

\subsubsection{Cambios en la deformabilidad y la estabilidad de la membrana de GR}

La deformabilidad, que es la propiedad del GR de cambiar reversiblemente de forma bajo la influencia de condiciones físicas externas o internas, se determina a partir de la máxima elongación que puede sufrir la membrana del GR ante una determinada 
fuerza externa. La estabilidad se define como la máxima deformación que una membrana puede sufrir por acción de una fuerza y recuperar su forma original, luego que la fuerza aplicada es removida. Una membrana estable permite que los GR circulen sin fragmentarse, mientras que una membrana capaz de deformarse le permite atravesar los pequeños capilares recuperando luego la forma original (Chasis y Mohandas, 1986).

La deformabilidad y la estabilidad de la membrana dependen, como ya se mencionó, de las interacciones lípido-lípido y lípido-proteína. Durante la deformación de la membrana, su estiramiento está restringido por la incompresibilidad de la bicapa lipídica y, por el contrario, facilitado por la traslocación de colesterol del interior al exterior de la bicapa. La bicapa lipídica no puede expandir su área más de un 3\% a 4\% (Palek, 1995).

La deformación reversible de la membrana eritrocitaria ocurre con cambios en la geometría, pero sin cambiar el área expuesta. Durante la misma ocurre un rearreglo en el cual algunas moléculas de Sp sufren un estiramiento, mientras que otras asumen una forma más plegada. Con el aumento de la fuerza exterior, las moléculas de Sp se estiran hasta alcanzar su máxima extensión, siendo éste el punto de máxima deformabilidad. Cuando las células son expuestas a fuerzas mayores, o cuando el sometimiento a estas fuerzas es continuo, la membrana falla y estas fallas ocurren principalmente en las interacciones $\mathrm{Sp}-\mathrm{Sp}$ y en las $\mathrm{Sp}$-actina-proteína 4.1 y resultan en una fragmentación del GR (Chasis y Mohandas, 1986).

Tratamientos de membranas de GR con diferentes metabolitos han permitido demostrar que las proteínas del citoesqueleto juegan un papel crucial en determinar estas propiedades. Entre estos tratamientos se pueden mencionar (Chasis y Mohandas, 1986):

a) La incubación con 2,3-DPG, que provoca la disociación de las uniones Sp-actina 
y Sp-proteína 4.1, conduce a una disminución de la deformabilidad y un aumento de la estabilidad de la membrana. Estos efectos son además reversibles, indicando que las alteraciones del 2,3-DPG sobre las proteínas no son definitivas.

b) El agregado de NEM, que altera las asociaciones Sp-Sp por formación de puentes disulfuro entre los dímeros y los tetrámeros de la $\mathrm{Sp}$, conduce a cambios en la membrana que dependen de la dosis y el tiempo de exposición a la droga. Incrementos en el contenido de dímeros de Sp en la membrana se correlacionan directamente con disminuciones en la estabilidad. A bajas concentraciones de NEM, la estabilidad de la membrana aumenta en los primeros minutos y luego decrece, hasta que disminuye en un $80 \%$ luego de 60 minutos.

c) Tratando las membranas con diamida o con malondialdehido (MDA), agentes oxidantes de grupos sulfhidrilos, se demostró que el cross-linking oxidativo entre las proteínas de la membrana produce un aumento en la estabilidad y una disminución en la deformabilidad.

Para que la membrana se deforme normalmente, el citoesqueleto debe ser capaz de soportar el plegamiento y desplegamiento de las moléculas de Sp. Por lo tanto, los incrementos en las asociaciones intermoleculares e intramoleculares de las proteínas del citoesqueleto entre sí y con las proteínas integrales pueden tener un profundo efecto sobre la deformabilidad de la membrana. La disminución en la deformabilidad de la membrana debidas a los cross-linkings oxidativos entre las moléculas de Sp se debería a que éstos limitan, por un lado la posibilidad de esta proteína de plegarse y desplegarse ante una determinada fuerza y, por otro lado, ocasionan un incremento en las uniones con las proteínas integrales (Chasis y Mohandas, 1986). 


\subsubsection{Cambios en la permeabilidad de la membrana del GR}

Normalmente, la membrana de los GR es prácticamente impermeable a los cationes mono y divalentes, manteniendo una alta concentración intracelular de $\mathrm{K}^{+}$, baja de $\mathrm{Na}^{+}$y muy baja de $\mathrm{Ca}^{+2}$. En contraste, es altamente permeable al agua y a los aniones. La glucosa atraviesa la membrana a través de su transportador, mientras que las grandes moléculas cargadas, como el ATP, no pueden atravesar la membrana del GR.

Las formas de transporte para aniones y cationes en esta membrana se pueden dividir en cinco categorías:

a) Intercambiadores como el intercambiador de $\mathrm{Na}^{+} / \mathrm{H}^{+}$y el intercambiador de aniones.

b) Cotransportadores en los cuales el movimiento de uno o más solutos a través de la membrana están acoplados en la misma dirección, como el cotransportador de $\mathrm{K}^{+} / \mathrm{Cl}^{-}$.

c) El canal de $\mathrm{Ca}^{+2} / \mathrm{K}^{+}$, el cual lleva a una pérdida selectiva de $\mathrm{K}^{+}$, en respuesta a un aumento intracelular de $\mathrm{Ca}^{+2}$.

d) El transporte pasivo de cationes, que mueve $\mathrm{K}^{+} \mathrm{y} \mathrm{Na}^{+}$en la dirección de sus gradientes de concentración.

e) Las bombas como la $\mathrm{Na}^{+} / \mathrm{K}^{+}$ATPasa y la bomba de $\mathrm{Ca}^{+2}$.

Todos estos mecanismos de transporte juegan un papel muy importante en el mantenimiento del volumen del GR.

Durante el envejecimiento del eritrocito algunos mecanismos de transporte de cationes pierden actividad, mientras que otros son activados. El cotransportador de $\mathrm{K}^{+} / \mathrm{Cl}^{-}$por ejemplo, que se sabe es activado por la acción de agentes oxidantes, está presente sólo en los reticulocitos (aunque su presencia puede notarse en GR maduros que poseen $\mathrm{Hb}$ mutadas). Por su lado, la disminución de la actividad de la bomba 
$\mathrm{Na}^{+} / \mathrm{K}^{+}$ATPasa es un marcador de envejecimiento. En los GR maduros también hay un aumento en la pérdida de $\mathrm{K}^{+}$y una disminución en la actividad de la bomba de $\mathrm{Ca}^{+2}$, aunque en los GR senescentes no hay cambios en la concentración intracelular de $\mathrm{Ca}^{+2}$. La velocidad de intercambio de aniones mediada por la proteína banda 3 también disminuye con la edad del GR. Durante la maduración, por otra parte, ocurre una despolarización de la membrana que afecta el transporte de electrolitos a través de la misma (Bartosz, 1986).

\subsubsection{Cambios en la fragilidad osmótica de los GR}

Cuando las células se someten a soluciones hipotónicas, como ocurre durante el test de fragilidad osmótica, adoptan una forma esférica y luego se lisan descargando el contenido de $\mathrm{Hb}$ al sobrenadante. La fragilidad osmótica puede usarse para determinar los cambios que puede soportar la membrana del GR ante un shock osmótico (Krinsky et al., 1974).

En general, la membrana eritrocitaria se vuelve más frágil con el envejecimiento. In vitro, se produce un aumento progresivo de la fragilidad osmótica de la célula, que estaría relacionado, entre otras causas, con la acumulación intracelular de lactato que sale del GR lentamente a través de un proceso mediado por transportadores, ejerciendo por lo tanto un efecto osmótico (Lachant et al., 1984).

El aumento de volumen de los GR, que puede ocurrir durante el almacenamiento, se refleja en un aumento de la fragilidad osmótica. Varios factores influyen en el volumen de los GR durante el almacenamiento. Uno de ellos es la unión del 2,3-DPG a la $\mathrm{Hb}$, ya que a medida que la cantidad de este anión polivalente disminuye, es reemplazado por aniones monovalentes que ejercen un mayor efecto osmótico (Beutler y Kuhl, 1988). 
Cuando los GR son almacenados, aun en soluciones que contienen aditivos como adenina, fosfatos y glucosa, sufren una hemólisis que no puede ser evitada, pero esta lisis osmótica producida durante el almacenamiento ha sido minimizada con el empleo de soluciones isotónicas que contienen $\mathrm{ClNa}$ y manitol. Está demostrado que este último reduce la lisis en un 50\% (Moore, 1987; Beutler y Kuhl, 1988).

Este aumento de la fragilidad de las células es por otra parte, secundario a la disminución de los niveles de ATP y a la consecuente pérdida de asimetría en los PLP de la membrana, que conduce al progresivo aumento en el cambio de forma de discocito a esferocito (de Jong et al., 1996). Los esferocitos, al tener una menor relación área/volumen pueden soportar el ingreso de una menor cantidad de agua (Gallagher et al., 1990).

\subsection{Cambios en las proteínas}

Como los GR no pueden sintetizar proteínas, una vez que son liberados de la médula ósea, la manera en la cual sus enzimas disminuyen su actividad en el tiempo, ya sea en circulación o in vitro, ha sido muy estudiada. Los estudios in vitro se han realizado separando los diferentes GR por centrifugación. De esta manera se ha encontrado que enzimas como la glucosa-6-fosfatodeshidrogenasa (G-6-PD) y la transaminasa glutámico oxalacética (GOT), entre otras, manifiestan una mayor actividad en los eritrocitos jóvenes que en los eritrocitos envejecidos (Beutler, 1985).

\subsubsection{Alteración de la actividad de enzimas}

Desde 1955 se consideran dos alternativas para explicar el decaimiento de la actividad de las enzimas durante el envejecimiento del eritrocito: la primera propone un decaimiento en forma lineal, de orden cero, y la segunda lo considera exponencial, de 
primer orden. Si se asume una pérdida lineal de la actividad enzimática, se debería pensar que la actividad de esa enzima en los reticulocitos no debería ser más de dos veces mayor a la actividad promedio del eritrocito maduro y que luego, durante la segunda mitad de la vida del GR, su decaimiento la llevaría a actividades negativas. En 1985, Beutler propuso un modelo de decaimiento basado en dos etapas, la primera muy rápida y la segunda lenta. Este mecanismo consiste en una destrucción rápida de las enzimas una vez liberado el GR de médula ósea; luego la actividad parece permanecer bastante estable durante toda la siguiente etapa en la vida del eritrocito. Por lo tanto, la mayor diferencia en la actividad enzimática aparecería en el pasaje de reticulocito a GR maduro (Beutler, 1985).

Las enzimas que sólo poseen vestigios de actividad o están ausentes en los GR maduros (enzimas mitocondriales o del metabolismo de los nucleótidos) son eliminadas en el pasaje de reticulocito a GR maduro, mientras que las enzimas que son requeridas a través de la vida del GR decaen durante la misma con diferentes velocidades (Beutler, 1985).

\section{Acetilcolinesterasa (AChE)}

La $\mathrm{AChE}$ es una enzima cuya actividad disminuye progresivamente con el envejecimiento del GR. Los GR envejecidos, separados por centrifugación de los GR jóvenes, presentan menor actividad de AChE. Por fraccionamiento en un gradiente de ficol/triosil y posterior inmunoelectroforesis para cuantificar la enzima, se demostró que su actividad disminuye prácticamente a cero en los reticulocitos, aumenta con la maduración a eritrocito y luego decrece a medida que la célula envejece. Esta disminución obedece a dos factores: la disminución de la cantidad de proteína por pérdidas en la formación de vesículas y a cambios en la interacción lípido-proteína 
(Galbraiths y Watts, 1981).

Como ya se mencionó, es una enzima ligada a la membrana, por lo tanto su actividad varía junto con los cambios de la misma durante el envejecimiento del eritrocito. Dentro de estos cambios, se encuentran la disminución de la fluidez lipídica y aumentos en el potencial de interfase. Los GR después de 6 días de almacenamiento a $4^{\circ} \mathrm{C}$ presentan una disminución en la carga negativa de la superficie, posiblemente debida a la remoción del ácido siálico (Lawson y Barr, 1987). Este último cambio lleva a un aumento del $\mathrm{Km}$ de la $\mathrm{AChE}$, ya que un potencial de membrana menos negativo, disminuye la atracción hacia el sustrato catiónico de la enzima (Grzelinzka et al., 1983). Además hay una variación en la composición lipídica de la membrana de modo que los GR maduros poseen una menor relación col./PLP que es seguida de una disminución en la actividad de las enzimas asociadas a membrana (Kamber et al., 1984; Kakimoto et al., 1995).

Existen evidencias que demuestran que los cambios o alteraciones conformacionales en los lípidos de membrana alteran la actividad de la enzima, ya que el entorno hidrofóbico de la enzima es muy importante para mantener su actividad catalítica (Frenkel et al., 1980). La porción hidrofóbica de los fosfolípidos de la membrana le proporciona además cierta protección ante la digestión de proteasas (Römer-Lüthi et al., 1980).

Se ha observado que pacientes con cirrosis hepática, que presentan alteraciones en la enzima lecitín-colesterol-aciltransferasa (LCAT) -y por lo tanto la relación col./PLP aumentada- presentan una disminución en la fluidez de la membrana que influye fisiológicamente en importantes enzimas como la $\mathrm{Na}^{+}-\mathrm{K}^{+}$ATPasa, la $\mathrm{Mg}^{+2}$ ATPasa y la AChE, encontrándose en esta última una correlación positiva entre la fluidez y su actividad ( Kakimoto et al., 1995). 


\section{Pseucolinesterasa}

La butirilcolinesterasa (EC 3.1.1.8), conocida como pseudocolinesterasa (PChE), colinesterasa inespecífica, colinesterasa tipo II o colinesterasa sérica, cataliza la hidrólisis de diversos ésteres de colina, fenílicos, nitrofenílicos y otros. No presenta inhibición por sustrato y es sintetizada en el hígado. La función específica de esta colinesterasa en el plasma es aún desconocida, su actividad está influenciada por condiciones fisiológicas (enfermedades hepáticas, infecciones agudas, alteraciones de tiroides, entre otras) y por patologías (Brock, 1990). Dentro de la toxicología ambiental y la medicina ocupacional la medición de su actividad se ha usado para indicar por ejemplo la exposición a ịnsecticidas organofosforados y carbamatos (Brock, 1990; Meuling et al., 1992; Stefanidou, 1998). Se ha estudiado la variabilidad interindividuo, teniendo en cuenta factores como edad, sexo, peso corporal y altura, encontrándose que la actividad de la PChE es mayor en hombres que en mujeres y que existe una correlación positiva entre la actividad de la enzima con relación al peso y la edad (Brock, 1990). Además se determinó la variación intraindividuo (midiendo la actividad en muestras del mismo individuo tomadas en diferentes meses) encontrando una diferencia entre la máxima y la mínima actividad de cada paciente que oscila entre un $3 \%$ y un $42 \%$ (Brock, 1990).

Se ha demostrado que la actividad de la PChE no varía en forma significativa por un período de 130 días, en muestras de sangre entera o hemolizados almacenados a una temperatura de $-20^{\circ} \mathrm{C}$, hallándose un coeficiente de variación porcentual (CV\%) total de 19,9 (Meuling et al., 1992). 


\subsubsection{Cambios en las interacciones entre las proteínas}

Ya se ha comentado que errores en la estructura o función del citoesqueleto membranal pueden ser los responsables de algunos de los fenómenos de membrana asociados con el almacenamiento. Por ejemplo, la interacción entre la Sp y la actina que está involucrada en fenómenos dependientes de ATP como son el equilibrio entre discocito y equinocito y los cambios en la viscoelasticidad (Liu y Palek, 1979). En la clínica, se han descripto deficiencias de Sp, problemas en las interacciones Sp-proteína 4.1 (ya sean defectos en la interacción Sp-proteína 4.1 o deficiencias de proteína 4.1), algunas anomalías en la conversión de dímeros en tetrámeros, deficiencias en las interacciones ankirina-proteína banda 3, que conducen a pérdidas espontáneas del área de membrana, que como ya se explicó es uno de los mayores problemas durante el almacenamiento.

La disminución del ATP celular, durante el almacenamiento in vitro, provoca alteraciones potencialmente importantes en las interacciones proteína-proteína. En una primera etapa ocurre la formación de uniones disulfuro reversibles (se rompen si se restauran los niveles de ATP) y luego, cuando el descenso es casi total, se produce la formación irreversible de polímeros. Uno de los primeros cambios observados es el aumento en la interacción Sp-proteína 4.1 formándose oligómeros. Esto lleva a alteraciones en los demás componentes de la membrana, volviéndolos vulnerables a la formación de uniones disulfuro y de polímeros de alto peso molecular. Las electroforesis en PAGE-SDS de las proteínas de membrana de células deplecionadas en ATP demuestran que éstas contienen heteropolímeros resultantes de la formación de uniones disulfuro entre las proteínas vecinas, que no se encuentran en los GR frescos (Liu y Palek, 1979).

Se ha observado además que cuando la SE es almacenada en $\mathrm{CPD}$, la Sp pierde 
luego de tres semanas su capacidad de unirse a la proteína 4.1, un defecto que lleva a la formación de esferocitos (Wolfe et al., 1983).

Teniendo en cuenta el cross-linking oxidativo de las proteínas de la membrana durante la disminución de los niveles de ATP, se examinó el efecto de las condiciones aeróbicas y anaeróbicas sobre los cambios en la forma de discocito a equinocito observando que, si la depleción del ATP ocurre en aerobiosis, el cambio de forma se puede revertir sólo en un $68 \%$ y a baja velocidad (4 horas). Si en cambio, ocurre en anaerobiosis o en presencia de algún agente reductor, la reversión es del $89 \%$ a $98 \%$. Estos datos apoyan la hipótesis ya mencionada de que la oxidación ejerce un efecto importante en perturbar el correcto funcionamiento de la membrana del eritrocito (Liu y Palek, 1979).

El mecanismo por el cual los rearreglos en el citoesqueleto de la membrana pueden conducir a cambios en la forma, se podría relacionar con una contracción en la porción interna de la bicapa, secundaria a la disminución de los niveles de ATP, que induciría la crenación (Snyder et al., 1985). Se sabe, que las interacciones proteínaproteína influyen en las interacciones proteína-PLP, llevando consecuentemente a alteraciones en la asimetría de los PLP, lo cual conduce a cambios en la forma y en la fragilidad de los GR (de Jong et al., 1996).

También debemos mencionar las alteraciones ocasionadas por la interacción de las moléculas de $\mathrm{Hb}$ con la $\mathrm{Sp}$. La formación de estos complejos requiere algún mecanismo oxidativo, son más abundantes en los GR senescentes y se ha demostrado que ayudan a la formación de vesículas (Snyder et al., 1985). En GR estresados, sometidos a depleciones de ATP en anemias hemolíticas o durante el almacenamiento, existe una acumulación de proteínas citoplasmáticas, especialmente $\mathrm{Hb}$. Liu y Palek (1979) han demostrado que la $\mathrm{Hb}$ en concentraciones fisiológicas puede inducir un 
aumento en las interacciones Sp-Sp en solución. Un aumento de la concentración de tetrámeros in vitro, podría ser responsable de algunas de las alteraciones del almacenamiento, como por ejemplo los ya mencionados cambios de forma. La formación de polímeros entre moléculas de Sp puede deberse también a otros cambios producidos durante el almacenamiento como la generación de MDA (producto de la peroxidación de los lípidos de la membrana), la formación de puentes disulfuro debida a la disminución en los mecanismos antioxidantes, la formación de radicales libres en las proteínas, probablemente por reacción homolítica (ruptura de una molécula orgánica de manera que cada átomo de carbono de cada fragmento producido retiene un electrón) (Hochstein y Jain, 1981).

\subsection{Cambios en los lípidos de la membrana}

Como se mencionó anteriormente, existe evidencia de que las interacciones lípido-proteína son necesarias para mantener la asimetría de la bicapa. La pérdida de esta asimetría puede conducir a cambios en las propiedades de la membrana (de Jong et al., 1996).

Puede ocurrir que las moléculas que no posean ningún efecto sobre las proteínas de la membrana puedan alterar la asimetría de la bicapa lipídica, interaccionando de manera desigual con PLP de la cara externa o de la interna. Por ejemplo, los compuestos negativamente cargados son repelidos por la porción interna de la bicapa, conduciendo a una expansión de la porción externa de la misma, con la consecuente crenación y equinocitosis. Por el contrario, la expansión preferencial de la porción interna provocada por compuestos positivamente cargados, conduce a la estomatocitosis (Palek, 1995). 


\subsubsection{Lipoperoxidación}

Durante el almacenamiento a $4^{\circ} \mathrm{C}$, los GR sufren daños oxidativos que se manifiestan en sus membranas; esto se evidencia por ejemplo en la formación de agregados de la proteína banda 3, que conducen a un aumento en la expresión de sitios de unión al anticuerpo IgG antibanda 3 (Ando et al., 1993). Se ha demostrado además la formación de hidroperóxidos lipídicos durante el envejecimiento tanto in vitro como en circulación, ya que se ha encontrado una mayor cantidad de hidroperóxidos de PC y PE en los GR envejecidos que en los GR jóvenes. Los productos aldehídicos generados a partir de estos hidroperóxidos pueden causar daños en proteínas estructurales y en enzimas llevando a alteraciones en las propiedades físicoquímicas de las células (Ando et al., 1995).

El estrés oxidativo es una expresión utilizada para describir la acción de varias especies activas del oxígeno sobre diferentes tejidos humanos. Está involucrado en varios procesos patológicos como el envejecimiento, las enfermedades respiratorias y cardiovasculares, el cáncer, las enfermedades neurológicas como la enfermedad de Parkinson y la demencia senil (Favier et al., 1995).

El oxígeno es indispensable para la vida, pero en concentraciones superiores a la normal puede resultar muy peligroso para los sistemas vivientes. Su principal toxicidad es atribuida a los radicales libres que de él derivan, los cuales se pueden formar durante el metabolismo celular o poseer un origen exógeno (Pierre, 1995). En los últimos años se ha estudiado el efecto de estos radicales libres sobre los lípidos, las proteínas y los genes. Los efectos ocasionados varían notablemente con el tipo de organismo estudiado, la edad, el estado fisiológico y la dieta, ya que en esta última se pueden consumir cantidades variables de vitaminas $\mathrm{A}, \mathrm{E}$ y $\mathrm{C}$, metales de transición, antioxidantes adicionados a alimentos y ácidos grasos poliinsaturados, diferentes sustancias que 
tienen influencia en los efectos de los radicales libres (Halliwell y Gutteridge, 1984).

La acción de los radicales libres sobre las membranas celulares se manifiesta principalmente en la lipoperoxidación, la cual se puede definir como el deterioro oxidativo de los ácidos grasos poliinsaturados. Los principales responsables a los que se les adjudica el inicio de las reacciones de peroxidación son las especies reactivas del oxígeno (Hochstein y Jain, 1981).

El inicio de la lipoperoxidación en una membrana se debe al ataque de sustancias lo suficientemente reactivas como para sustraer un átomo de hidrógeno de la cadena hidrocarbonada de un ácido graso poliinsaturado, provocando que en este último quede un átomo de carbono con un electrón desapareado (reacción 1). Este radical en el ácido graso poliinsaturado tiende a estabilizarse por un rearreglo intramolecular formando un dieno conjugado, que rápidamente reacciona con el $\mathrm{O}_{2}$ para dar un radical peróxido (reacción 2) que es capaz de extraer un átomo de hidrógeno de otro lípido para formar un hidroperóxido lipídico (Lípido- $\mathrm{O}_{2} \mathrm{H}$ ) y así continuar con una reacción de lipoperoxidación en cadena (reacción 3).

- Reacción 1: Lípido-H $+{ }^{\cdot} \mathrm{OH} \rightarrow$ Lípido $^{\cdot}+\mathrm{H}_{2} \mathrm{O}$

- Reacción 2: Lípido (después del rearreglo) $+\mathrm{O}_{2} \rightarrow{\text { Lípido- }{ }_{2}}^{*}$

- Reacción 3: Lípido- $\mathrm{O}_{2}{ }^{-}+$Lípido- $\mathrm{H} \rightarrow$ Lipido- $\mathrm{O}_{2} \mathrm{H}+$ Lípido

Los hidroperóxidos lipídicos son medianamente estables a temperaturas fisiológicas y uno de los principales roles de los metales de transición es el de catalizar su descomposición. Juegan un papel importante en esta reacción las moléculas que complejan estos metales como $\mathrm{Hb}$, metaHb, peroxidasa, citocromo $\mathrm{P}-450$ y otros citocromos. Todas estas moléculas contribuyen a la propagación de la lipoperoxidación in vivo (Halliwell y Gutteridge, 1984). Los compuestos con el hierro en su estado reducido reaccionan con los Lípido- $\mathrm{O}_{2} \mathrm{H}$ para dar radicales alcóxido (Lípido-O) 
(reacción 4), mientras que los compuestos con $\mathrm{Fe}^{+3}$ cuando reaccionan forman un radical peróxido $\left(\right.$ Lípido- $\left.{ }_{2}{ }^{\circ}\right)($ reacción 5$)$.

- Reacción 4: Lípido- $\mathrm{O}_{2} \mathrm{H}+\mathrm{Fe}^{+2}$-complejo $\rightarrow \mathrm{Fe}^{+3}$-complejo $+\mathrm{OH}^{-}+$Lípido-O

- Reacción 5: Lípido- $\mathrm{O}_{2} \mathrm{H}+\mathrm{Fe}^{+3}$-complejo $\rightarrow \mathrm{Fe}^{+2}$-complejo $+\mathrm{H}^{+}+$Lípido- $\mathrm{O}_{2}$.

Tanto el radical alcóxido como el peróxido son capaces de estimular la reacción en cadena de la lipoperoxidación (reacción 3).

El oxígeno molecular es diatómico, su estado fundamental es un triplete $\left({ }^{3} \mathrm{O}_{2}\right)$, es paramagnético y no puede reaccionar con las moléculas diamagnéticas sin romper la restricción del spin. Debido a su naturaleza no polar, se trata de una molécula más soluble en medios orgánicos que en agua (Pierre, 1995).

Entre las especies reactivas derivadas del oxígeno encontramos:

a) El oxígeno singlete, ${ }^{1} \mathrm{O}_{2}$ : es el más importante en los sistemas vivos, no posee electrones desapareados y no es un radical; se forma a través de reacciones que involucran la excitación luminosa o en reacciones de excitación química. Por ejemplo:

$$
\begin{array}{lll}
\mathrm{Fe}(\mathrm{III})+\mathrm{R}-\mathrm{O}-\mathrm{O}-\mathrm{H} & \rightarrow & \mathrm{Fe}=\mathrm{O}+\mathrm{R}-\mathrm{OH} \\
\mathrm{Fe}=\mathrm{O}+\mathrm{R}-\mathrm{O}-\mathrm{O}-\mathrm{H} & \rightarrow & \mathrm{Fe}-(\mathrm{III})+\mathrm{R}-\mathrm{OH}+{ }^{1} \mathrm{O}_{2}
\end{array}
$$

El ${ }^{1} \mathrm{O}_{2}$ difunde a través de las membranas, sus targets biológicos son membranas, ácidos nucleicos y proteínas. Existen varios compuestos que actúan como desactivadores de esta especie, entre ellos encontramos los $\beta$-carotenos, algunas aminas y fenoles (Pierre, 1995).

b) El anión superóxido, $\mathrm{O}_{2}{ }^{-}$: se forma cuando el $\mathrm{O}_{2}$ en su estado fundamental $\left({ }^{3} \mathrm{O}_{2}\right)$ acepta sólo un electrón, se produce en todas las células aeróbicas, principalmente en células fagocíticas, cuando se ponen en contacto con microorganismos patógenos como mecanismo de defensa. Disuelto en solventes orgánicos es una especie altamente reactiva, mientras que en solución acuosa es pobremente reactivo. Su dismutación a $\mathrm{O}_{2}$ 
y $\mathrm{H}_{2} \mathrm{O}_{2}$ ocurre en etapas:

$$
\begin{gathered}
\mathrm{O}_{2}^{-}+\mathrm{H}^{+} \rightarrow \mathrm{HO}_{2}^{-} \\
\mathrm{HO}_{2}^{-}+\mathrm{O}_{2}^{-}+\mathrm{H}^{+} \rightarrow \mathrm{H}_{2} \mathrm{O}_{2}+\mathrm{O}_{2}
\end{gathered}
$$

$$
2 \mathrm{O}_{2}^{-}+2 \mathrm{H}^{+} \rightarrow \quad \mathrm{H}_{2} \mathrm{O}_{2}+\mathrm{O}_{2}
$$

El daño causado en los tejidos por este anión puede ser atribuido a él mismo o al radical hidroperóxido $\left(\mathrm{HO}_{2}{ }^{\circ}\right)$, que es aún más reactivo. La formación de este radical es favorecida por la disminución del $\mathrm{pH}$ (Halliwell, 1984). El radical $\mathrm{HO}_{2} \cdot$ es un buen aceptor de electrones, resultando en la formación del anión hidroperóxido $\left(\mathrm{HO}_{2}{ }^{-}\right)$el cual, puede extraer $\mathrm{H}^{+}$de los $\mathrm{C}-\mathrm{H}$ alílicos, causando la lipoperoxidación. En el eritrocito se pueden liberar radicales $\mathrm{O}_{2}{ }^{-}$cuando se forma metaHb a partir de la oxiHb. Este anión atraviesa las membranas celulares sólo lentamente, pero en la membrana del GR posee un canal específico por el cual puede atravesar (Halliwell, 1984).

c) El peróxido de hidrógeno: se puede generar por dismutación del superóxido o por la acción de oxidasas como la glicolato oxidasa, la superóxido dismutasa o las peroxidasas. En los diferentes tejidos, el $\mathrm{H}_{2} \mathrm{O}_{2}$ generado es removido por enzimas específicas como la catalasa y la glutatión peroxidasa (Halliwell, 1984).

d) El radical oxidrilo: su formación a partir del agua requiere de alta energía, la cual puede ser suplantada por radiación ionizante o ultrasonido. Se puede formar en las reacciones de reducción de metaloproteínas, cuando el agente reductor es $\mathrm{el}_{2}^{-}$y ocurre la reacción de Haber-Weiss catalizada por el hierro:

$$
\mathrm{H}_{2} \mathrm{O}_{2}+\mathrm{O}_{2}^{-} \rightarrow \mathrm{O}_{2}+\mathrm{OH}^{-}+{ }^{-} \mathrm{OH}
$$

Por otro lado, la principal toxicidad del peróxido de hidrógeno radica en la generación de radicales $\mathrm{OH}^{*}$, ya sea por acción de la luz UV o por la reacción en presencia de $\mathrm{Fe}^{+2}$ o reacción de Fenton: 


$$
\mathrm{H}_{2} \mathrm{O}_{2}+\mathrm{Fe}^{+2} \rightarrow \mathrm{HO}^{-}+\mathrm{HO}^{-}+\mathrm{Fe}^{+3}
$$

A su vez trazas de $\mathrm{Fe}^{+3}$ pueden reaccionar con el $\mathrm{H}_{2} \mathrm{O}_{2}$ :

$$
\mathrm{Fe}^{+3}+\mathrm{H}_{2} \mathrm{O}_{2} \rightarrow \mathrm{Fe}^{+2}+\mathrm{O}_{2}^{-}+\mathrm{H}^{+}
$$

O también pueden ocurrir otras reacciones:

$$
\begin{aligned}
& \mathrm{OH}^{\cdot}+\mathrm{H}_{2} \mathrm{O}_{2} \rightarrow \mathrm{H}_{2} \mathrm{O}+\mathrm{H}^{+}+\mathrm{O}_{2}^{-} \\
& \mathrm{OH}^{\cdot}+\mathrm{Fe}^{+3} \rightarrow \mathrm{Fe}^{+2}+\mathrm{O}_{2}
\end{aligned}
$$

Así se observa cómo una simple mezcla de $\mathrm{H}_{2} \mathrm{O}_{2}$ y sales de hierro puede provocar una serie completa de reacciones involucrando radicales libres.

El principal riesgo de la formación del radical oxidrilo radica en que éste es altamente reactivo, tiene una vida media muy corta y puede reaccionar rápidamente con toda clase de moléculas halladas en el lugar de su formación, no atraviesa las membranas celulares, reacciona con el componente de la misma que encuentra primero (Halliwell, 1984). Además, reacciona con azúcares, aminoácidos, PLP, bases de DNA y ácidos orgánicos. Estas reacciones pueden ocurrir por tres mecanismos diferentes: a) extracción de un átomo de hidrógeno, como por ejemplo a un ácido graso; b) adición a un anillo aromático, como por ejemplo a las bases del DNA; c) transferencia de electrones, provocando nuevos radicales. El primero de estos mecanismos, como ya se mencionó, es el que puede conducir a la lipoperoxidación (Halliwell, 1984).

El GR es una célula que constantemente sufre daños por la acción de estos radicales libres, ya que está expuesta a elevadas tensiones de oxígeno, es rica en lípidos poliinsaturados y en hierro y se encuentra en un medio en el cual está constantemente expuesta a la generación de radicales libres tanto extra como intracelulares. Desde el interior, la conversión de oxihemoglobina en metahemoglobina genera $\mathrm{O}_{2}^{-} \mathrm{y}$, desde el exterior, está expuesta a la liberación de $\mathrm{O}_{2}^{-} \mathrm{y} \mathrm{H}_{2} \mathrm{O}_{2}$ a partir de los granulocitos (Chiu et al., 1989). 
En el plasma, la medida de la lipoperoxidación se realiza a través de la cuantificación de las sustancias que reaccionan con el ácido tiobarbitúrico (TBARS) entre los que se encuentra el MDA (Ruiz et al., 1999). El MDA es un producto de la degradación de los hidroperóxidos (Figura 1) (Stocks et al., 1972; Janero, 1990).

Se ha demostrado que la adición de MDA a los GR provoca, debido a su capacidad para formar bases de Schiff con los grupos amino de las proteínas, una disminución específica en los porcentajes de las bandas 1 y 2 de la Sp y un aumento de bandas de alto peso molecular, mientras que las otras proteínas de la membrana del GR permanecen inalteradas: Estos cambios son además proporcionales a la cantidad de MDA adicionada a los GR (Hochstein y Jain, 1981). Por otra parte, se ha verificado que los GR envejecidos, separados en gradientes de centrifugación, presentan los mismos tipos de polímeros de proteínas de alto peso molecular que aquellos GR a los que se les había adicionado MDA, demostrando que éste podría ser el causante de la formación de dichos polímeros durante el envejecimiento (Hochstein y Jain, 1981).

La determinación del MDA aplicada a los GR es una medida sensible y reproducible de la tendencia hemolítica. Se ha encontrado que en algunas enfermedades hemolíticas hay una elevada tendencia en los lípidos de la membrana de los GR a la autoxidación, en particular en anemias hemolíticas autoinmunes, talasemia mayor y deficiencia de G-6-PD (Stocks et al., 1971). 
Figura 1. Formación de MDA a partir de un ácido graso poliinsaturado

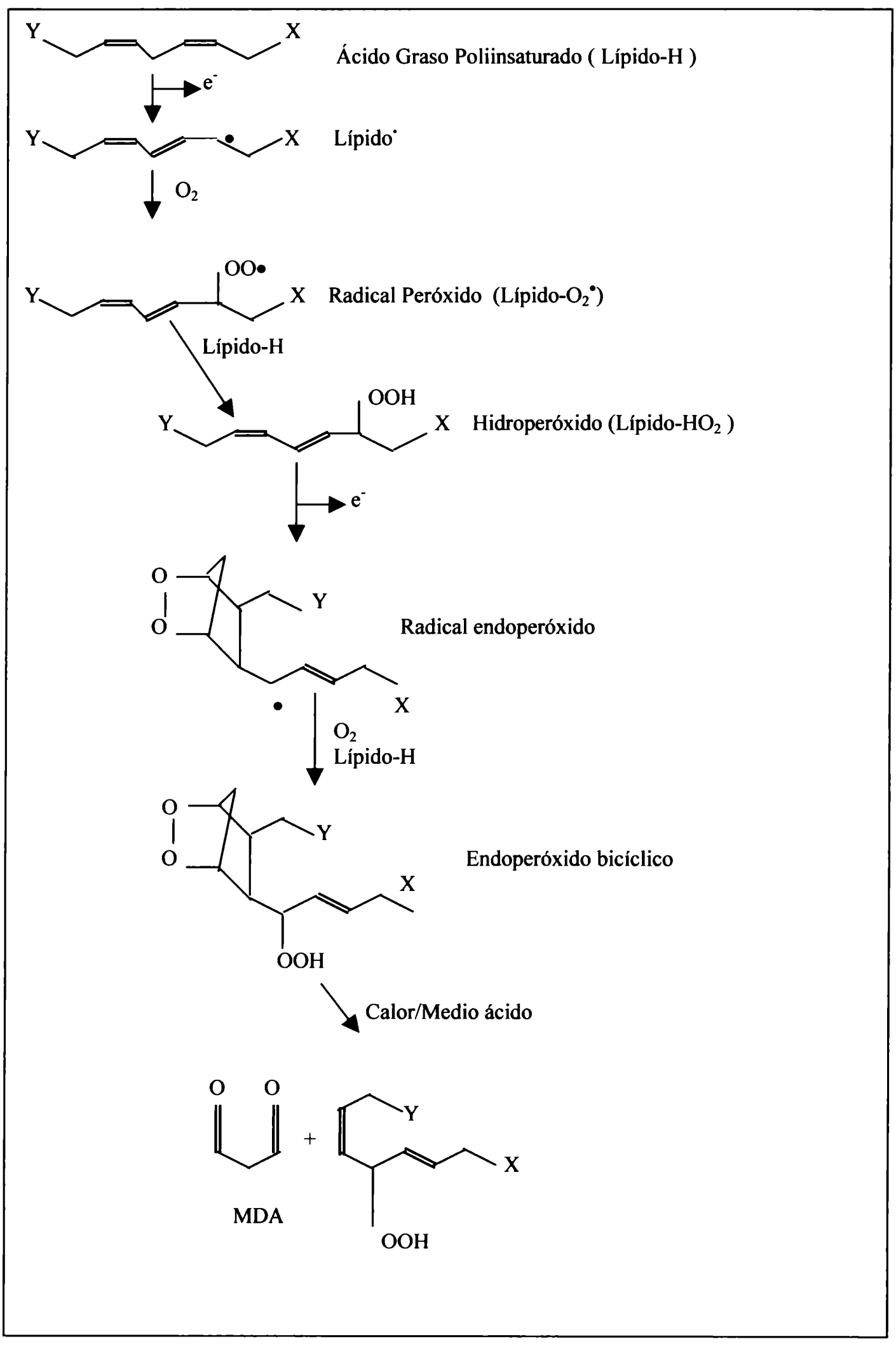




\subsection{Cambios en el metabolismo energético}

Entre los cambios que se producen en el almacenamiento, se encuentra la ya mencionada disminución en los niveles de ATP y 2,3-DPG. El único mecanismo por el cual los GR pueden generar ATP es la vía glicolítica. El ATP es esencial para mantener fosforiladas las proteínas de la membrana y permitir el funcionamiento de las bombas $\left(\mathrm{Na}^{+} / \mathrm{K}^{+}\right.$ATPasa y de $\left.\mathrm{Ca}^{+2}\right)$ que mantienen los iones fuera de la célula, en contra del gradiente. Existe una correlación lineal entre la supervivencia de los GR y los niveles de ATP. El ATP se consume durante el almacenamiento no sólo para mantener la integridad de la membrana, sino también por la deaminación irreversible del adenosinmonofosfato (AMP) a inosinmonofosfato (IMP) y luego a hipoxantina (Moore, 1987).

La velocidad de decaimiento en los niveles de ATP depende del medio en el cual se conserva la SE. Por ejemplo, en ACD el contenido de ATP de los eritrocitos disminuye luego de 15 semanas de almacenamiento a $4^{\circ} \mathrm{C}$; a niveles indetectables y junto con esta disminución se pierde la deformabilidad de los GR (Nishi et al.,1983).

Los principales efectos asociados a este hecho durante la incubación en un medio con buffer sin glucosa se pueden dividir, según la disminución de los niveles de ATP (Wolfe, 1985), según el esquema de la Figura 2.

Entre estas lesiones ocurridas por el agotamiento del ATP, las más importantes son las relacionadas con la pérdida de área de superficie y el incremento de la viscosidad del GR. 
Figura 2. Esquema de efectos asociados a este hecho durante la incubación en un medio con buffer sin glucosa se pueden dividir, según la disminución de los niveles de ATP
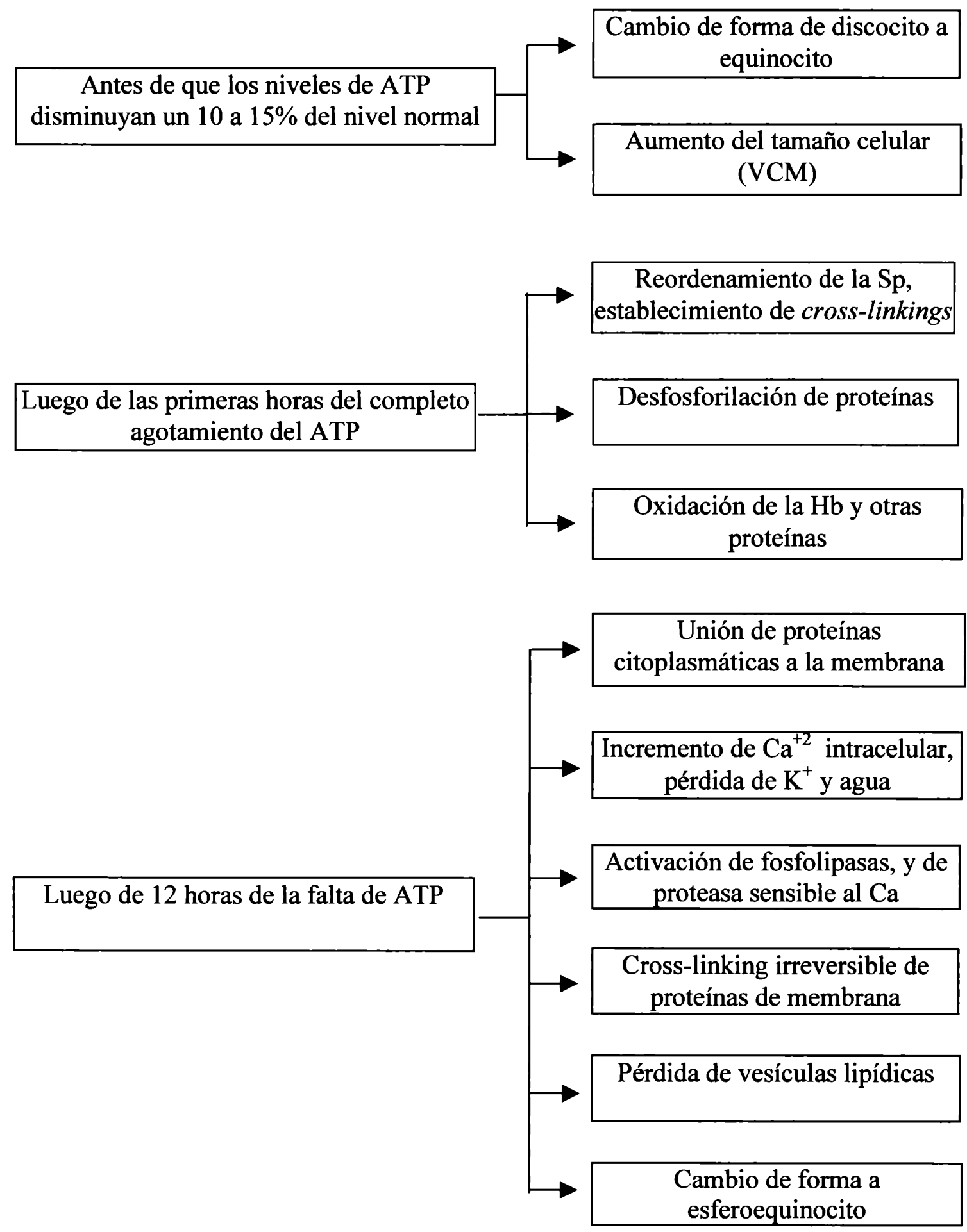
El descenso en los niveles de 2,3-DPG también depende del medio de almacenamiento. En los GR almacenados en el anticoagulante ACD, los niveles de 2,3DPG descienden un $60 \%$ después de una semana y un $90 \%$ después de dos semanas. Cuando el anticoagulante usado es CPD, la disminución de los niveles de 2,3-DPG es más lenta: luego de dos semanas disminuye un $20 \%$. En cambio, los GR almacenados en una solución de manitol, adenina, sales y glucosa (ADSOL) no presentan variaciones significativas en los niveles de 2,3-DPG, luego de 35 días de almacenamiento a $4^{\circ} \mathrm{C}$ (Heaton et al., 1981). Por último, podemos mencionar que en un medio de cloruro de sodio, adenina, glucosa, manitol y glioxilato (SAGM), el tiempo necesario para que se alcance un valor límite indetectable es de 60 días (Saint-Blancard et al., 1988)

Se ha demostrado que la deformabilidad y la estabilidad son dos propiedades de la membrana que pueden ser modificadas por tratamientos con 2,3-DPG, produciéndose una disminución en la deformabilidad y un aumento de la estabilidad (Chasis y Mohandas, 1986). Además, Sheetz et al., 1978 observaron que concentraciones milimolares de 2,3-DPG podían provocar la disociación de las proteínas del citoesqueleto y restringir el movimiento lateral de las proteínas integrales dentro de la bicapa, aunque este efecto no es muy específico y puede asignarse también a otros polifosfatos (Chasis y Monadas, 1986).

\section{Soluciones empleadas para el almacenamiento de SE y/o GR}

En el presente trabajo se han discutido los cambios sufridos por los GR en diferentes soluciones preservadoras. Por esta razón, esta sección está dedicada a mencionar brevemente algunas de estas soluciones y cómo se fueron modificando con la única finalidad de mejorar la calidad de los GR y de la SE preservada. 
Desde la Segunda Guerra Mundial se ha intentado prolongar el tiempo de almacenamiento de los GR. Así se han probado numerosas formas de almacenamiento con la finalidad de aumentar la viabilidad de los mismos luego de las transfusiones (Beutler, 2000). La mayoría de las soluciones preservadoras contienen nutrientes y sales para darle la isotonicidad deseada (Sohmer et al., 1981). Como se sabe, la viabilidad de los GR postransfusiones depende de sus niveles de ATP, ya que GR con bajos niveles de ATP no pueden fosforilar la glucosa y, por lo tanto, están condenados a quedar fuera de circulación, pero por otra parte, altos niveles de ATP, como único parámetro considerado, no aseguran la supervivencia de los GR luego del almacenamiento (Beutler, 2000).

En un comienzo, la SE era almacenada en soluciones alcalinas de citrato de sodio, conteniendo glucosa. Esta solución fue rápidamente acidificada para producir el $\mathrm{ACD}$, ya que se había demostrado que en medio alcalino la activación de la hexoquinasa y la inactivación de la gliceraldehído fosfato deshidrogenasa llevan a una rápida depleción del ATP (Beutler, 2000). Los primeros almacenamientos en ACD fueron en botellas de vidrio; luego el vidrio fue reemplazado por el plástico. Se ha demostrado que el dietilhexilftalato usado en la fabricación del cloruro de polivinilo de las bolsas posee efectos estabilizadores en la membrana del GR (Moore, 1987).

El medio ACD fue luego reemplazado por CPD con la finalidad de mejorar la preservación de los niveles de 2,3-DPG. Se sabe que ninguno de los medios son muy efectivos en mantener los niveles de 2,3-DPG, aunque éste retorna a los niveles normales sólo 8 horas después de la transfusión. Se conoce que la clave para mantener sus niveles en el almacenamiento se encuentra en la estabilización del pH (Beutler, 2000). Durante el almacenamiento en soluciones como el ACD, la disminución del pH hasta niveles de 4,5 a 5,5, conduce a una inmediata disminución en la capacidad de 
deformación del GR, frena la producción de ATP y acelera la formación de estomatocitos. (Wolfe, 1985).

Se han ido mejorando los medios mediante la adición de adenina como sustrato para inducir la síntesis de nucleótidos de adenina y se han ido cambiando las osmolaridades. Así surgieron los medios CPD-A 1 , CPD- $\mathrm{A}_{2}$, ADSOL y SAG, entre otros. La composición de estos medios puede verse en la Tabla 2.

En estos medios era aún un problema el alto porcentaje de hemólisis luego de 30 días de almacenamiento, por esta razón, se adicionó, en ocasiones, manitol, que es capaz de prevenir la hemólisis por un efecto osmótico. Por ejemplo, el medio SAG fue modificado a SAGM (Beutler y Kuhl, 1988).

El medio CPD-A $\mathrm{A}_{1}$ permite mantener la viabilidad de los GR durante 35 días, este tiempo estaría limitado por los niveles de glucosa y de ATP, por eso el medio CPD-A contiene el doble de adenina y 1,4 veces más de glucosa, permitiendo prolongar el tiempo de almacenamiento a 42 días (Sohmer et al., 1981).

En 1986, Meryman et al., propusieron que el incremento de la tensión de superficie de la membrana de los GR almacenados podría limitar la pérdida de membrana en forma de vesículas, evitando la formación de las espículas que se forman durante el almacenamiento. La conservación de los GR en soluciones hipotónicas inducen una "hinchazón" de los mismos y permiten según estos autores almacenarlos por 14 semanas manteniendo una viabilidad del $75 \%$ luego de las transfusiones. En 1996, fue propuesta por Greenwalt et al. la solución EAS 25, un medio hipotónico que contiene glicerol $150 \mathrm{mM}$, como medio para preservar por más tiempo a los GR; este medio mantiene los niveles de ATP por un período de 6 semanas más elevados que el ADSOL (Greenwalt et al., 1996). 


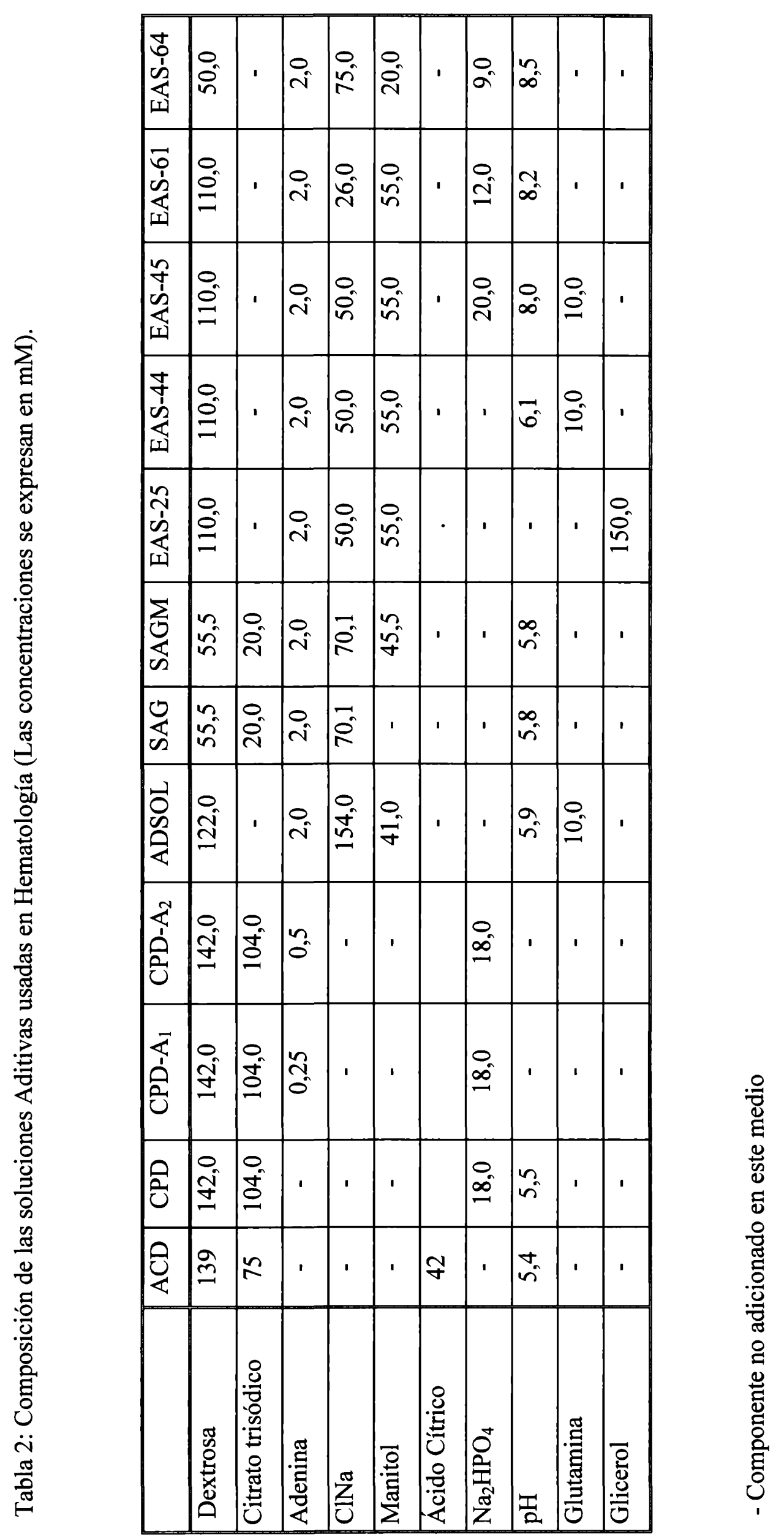


Sin embargo, estos resultados presentan dos limitaciones: por un lado, ninguno de los estudios examina el efecto de las soluciones hipotónicas sobre el volumen estándar de los GR, sobre el Hto obtenido por centrifugación y sobre la concentración de sales compatibles con las transfusiones. Por otra parte, no son estudiados ni los niveles de ATP ni la morfología de los GR luego del almacenamiento; sólo se considera la viabilidad de los mismos después de la transfusión. Por estas razones, los estudios de Babcock et al., 2000 demostraron, mediante la comparación de GR almacenados por 8 semanas en un medio hipotónico con GR almacenados en un medio isotónico, que la mejor conservación obtenida en estos medios no es debida a la hipotonicidad, sino a otros agregados en estos mismos medios como el manitol y las sales de amonio.

Por otra parte, se ha demostrado que soluciones que contienen glutamina (EAS 44) y glutamina más fosfatos (EAS 45) mantienen los niveles de ATP en los eritrocitos y el balance iónico transmembranal, mejor que los medios convencionales. El almacenamiento en medios de soluciones aditivas experimentales (EAS) disminuye los niveles de vesiculización comparado con el medio ADSOL (Dumaswala, 1996b).

Actualmente, el almacenamiento de los GR concentrados está limitado a 42 días. Durante este tiempo ocurren los cambios ya descriptos en la morfología, la membrana y la integridad metabólica (Arduini et al., 1997). Aproximadamente el 25\% de los PLP de la membrana se pierden bajo la forma de microvesículas luego de 42 días en un medio SAG adicionado con fosfato monosódico. La pérdida de membrana es probablemente responsable del aumento de los niveles de $\mathrm{Hb}$ extracelular ya que las microvesículas contienen aproximadamente el $70 \%$ de la $\mathrm{Hb}$ extracelular (Arduini et al., 1997).

El incremento de las concentraciones de fosfatos y el $\mathrm{pH}$ de las soluciones (EAS) llevaría a aumentar la concentración de ATP luego del almacenamiento durante 7 semanas. A su vez, aumentar el volumen de solución EAS con relación al volumen de 
GR, también conduciría a alcanzar concentraciones de ATP superiores, mejorar la morfología de los GR y disminuir la hemólisis (Hess et al., 2000a). La solución EAS 64 permite almacenar los GR por 10 semanas con una viabilidad, luego de 24 horas de la transfusión, del $80 \%$ y con una hemólisis del 0,5\% (Hess et al., 2000b). Estas ventajas se deben a los elevados valores de $\mathrm{pH}$ y a las concentraciones de adenina y fosfatos que llevan a una inmediata síntesis de ATP. Los niveles de ATP aumentan después de 1 hora de la mezcla de la solución con los GR y permanece en estos niveles a lo largo del almacenamiento.

También se ha demostrado que remover los GB de las soluciones disminuye el porcentaje de hemólisis, ya que como se sabe los GB liberan enzimas que pueden atacar la membrana de los GR (Hess et al., 2000b). Por otra parte, las lesiones durante el almacenamiento no sólo están relacionadas con la disminución del metabolismo. Así, los plásticos presentes en las bolsas de sangre proporcionan, como ya se mencionó, protección a los GR durante el almacenamiento, pero poseen efectos dañinos sobre los GB (Arduini et al., 1997).

\section{Estabilización de la membrana del GR}

Se han utilizado diferentes reactivos capaces de modificar las propiedades de la membrana del GR con la finalidad de mantenerla estable por períodos de tiempo prolongados. Estos reactivos incluyen por ejemplo el 1,5-difluoro-2,4-dinitrobenceno, imidoésteres y glutaraldehído. El establecimiento de cross-linkings entre las proteínas y los lípidos de la membrana por la acción de estos reactivos, si bien permite la retención de ciertas propiedades de la membrana, produce también la pérdida de otras. Se ha

encontrado por ejemplo, que el agregado de glutaraldehído, formaldehído o acetaldehído para fijar los GR conduce a una pérdida de $\mathrm{K}^{+}$. Además, si bien la reacción 
con el glutaraldehído es inmediata, la reacción con los otros dos necesita entre 5 y 24 horas respectivamente (Krinsky et al., 1974).

El glutaraldehído, cuando se utiliza como fijador, promueve la formación de oligómeros en las proteínas de la membrana por establecimiento de cross-linkings, por interacciones entre moléculas proteicas. Se ha comprobado la existencia de un polímero de alto peso molecular formado principalmente por $\mathrm{Sp}$ y banda 3, el cual se produce por la disminución de ATP en condiciones aeróbicas sólo en presencia de glutaraldehído. Se ha propuesto además que este mismo polímero se formaría por la oxidación espontánea de grupos -SH (Liu y Palek, 1979; Wolfe, 1985).

El glutaraldehído es una sustancia que forma enlaces covalentes estables con los grupos $\varepsilon$-lisina de las proteinas. Se ha estudiado el efecto que produce el cross-linking, ocasionado por el glutaraldehído, sobre la actividad de las enzimas de membrana como la $\mathrm{AChE}$. Esta enzima es un dímero en presencia de Tritón $\mathrm{X}-100$ y luego de la remoción del detergente forma agregados de diferentes pesos moleculares. Si estos agregados son incubados con glutaraldheído y luego analizados en presencia de detergente, se observa que éste no puede disociar las especies oligoméricas debido a que están estabilizadas por uniones covalentes. Por otro lado, cuando se estudia el efecto del cross-linking en presencia del detergente, se observa que no hay variación en la actividad antes y después del mismo. La incubación con glutaraldehído podría llevar a la formación de oligómeros de la enzima (Römer-Lüthi et al., 1980). Se ha demostrado, además, que concentraciones de glutaraldheido de $0,5 \%$ producen una inhibición en la enzima, la cual depende del tiempo de exposición al aldehído, alcanzando un $27 \%$ de inhibición luego de 4,5 horas de fijación (Skaer, 1973).

Por otra parte, se sabe que el tratamiento con glutaraldehído incrementa la carga eléctrica de la membrana en más de un $10 \%$. Ésta puede ser una razón de la alteración 
en la actividad de la AChE y de la disminución de la aglutinabilidad (Nishi et al., 1983).

La estabilización de los GR con glutaraldehído debe realizarse con cuidado; el tiempo y las concentraciones de aldehído son críticas para asegurar una estabilización de las células sin fijarlas. La estabilización, a diferencia de la fijación, permite la lisis de los GR en unos segundos sin dejar turbidez, posibilitando que sean usados para medir la concentración de $\mathrm{Hb}$, ya sea con contadores hematológicos o por el método manual de la cianmetahemoglobina y que también permitan el recuento de GB y Plt sin causar interferencia (Morgan et al., 1978).

Se ha demostrado que el glutaraldehído reduce la deformabilidad de los GR y este efecto es dependiente de la concentración del mismo (Corry y Meiselman, 1978; Nishi et al., 1983); por otra parte, la deformabilidad no es restaurada luego de lavar los GR con solución fisiológica, indicando un efecto irreversible (Nishi et al., 1983). Este efecto puede ser también relacionado con el aumento de VCM y el Hto que se observa en los GR estabilizados con glutaraldehído ya que debido a la poca deformabilidad ocurre una disminución en la capacidad de empaquetamiento de los mismos. Por otra parte, cuando el VCM es determinado por métodos electrónicos también se observa este aumento explicado por la orientación de las células cuando atraviesan los orificios de medida (Corry y Meiselman, 1978)

\section{Efecto del agregado de antioxidantes}

Los lípidos de la membrana del GR son muy susceptibles a la oxidación bajo condiciones de estrés oxidativo. Esta oxidación puede ser causante de un envejecimiento prematuro del GR y el mismo puede ser reducido in vitro mediante el agregado de agentes antioxidantes (Stocks et al., 1972). Por otra parte, ya se mencionó que el GR está altamente expuesto a la acción de radicales libres que pueden generarse 
tanto intra como extracelularmente; por esta razón la célula está dotada de mecanismos de defensa que intentan reparar o prevenir la acumulación de moléculas dañadas por la oxidación. Entre éstos se incluyen enzimas como la catalasa, glutatión peroxidasa, superóxido dismutasa, enzimas que tratan de mantener niveles adecuados de glutatión reducido, enzimas proteolíticas para remover las proteínas oxidadas y además moléculas pequeñas como las vitaminas $\mathrm{A}, \mathrm{E}$ y $\mathrm{C}$, el ácido úrico, el glutatión, la albúmina y la bilirrubina (Chiu et al., 1989; Pincemail, 1995).

Un antioxidante se puede definir, como un compuesto o sustancia que inhibe la oxidación. Halliwell y Gutteridge (1984) lo definieron como una sustancia que, cuando está presente a bajas concentraciones comparadas con la concentración del sustrato oxidable, se consume decayendo significativamente, o sin consumirse inhibe la oxidación de dicho sustrato (Pincemail, 1995). También puede ser definido como un compuesto que protege los sistemas biológicos contra los efectos de procesos o reacciones que pueden causar oxidaciones excesivas (Krinsky, 1992). Se pueden dividir en dos grupos:

a) Con actividad enzimática: entre los que se encuentran las enzimas que remueven los radicales libres formados (catalasa, glutatión peroxidasa, superóxido dismutasa), las moléculas que bloquean la actividad enzimática (por ejemplo el alopurinol, inhibidor de la xantino oxidasa) y moléculas que complejan metales que son potentes catalizadores de las reacciones de los radicales libres.

b) Sin actividad enzimática: son moléculas que reaccionan mol a mol con el radical libre y son por lo tanto consumidas durante la reacción, entre estos se encuentran las vitaminas A y C, el glutatión, el manitol e incluso la vitamina E. Esta última es una vitamina que actúa como antioxidante bloqueando la oxidación de los lípidos, se consume en la reacción, pero puede ser regenerada por un ciclo catalítico que involucra 
al ácido ascórbico (Pincemail, 1995).

En este trabajo se estudió el efecto de dos antioxidantes pertenecientes a este último grupo adicionados a muestras de sangre: la vitamina $\mathrm{E}$ y la vitamina $\mathrm{C}$.

\subsection{Acción de la vitamina $\mathrm{E}$}

Es un tocoferol formado por 4 isómeros diferentes, alfa, beta, gama y deltatocoferol. El $\alpha$-tocoferol es el isómero hallado en el plasma y se ha demostrado desde 1968 por Horwitt et al., que es el más efectivo en la prevención de la lipoperoxidación. Su estructura molecular es la siguiente:

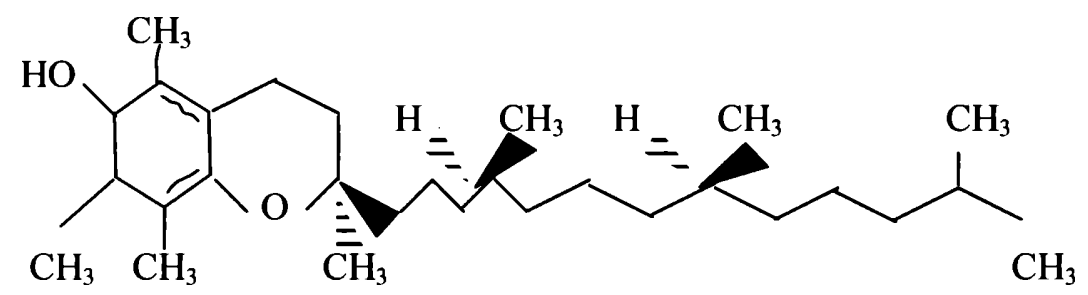

Actúa como antioxidante protegiendo a los lípidos insaturados de la peroxidación. Estos lípidos peroxidados incrementan la susceptibilidad de los eritrocitos a la hemólisis inducida por el peróxido de hidrógeno (Bland, 1980).

Desde 1945, la vitamina E comenzó a usarse en la dieta de pollos para prevenir la diátesis exudativa, un edema acompañado de una extensa hemorragia capilar. La lipoperoxidación incrementa la permeabilidad capilar y causa la diátesis exudativa; la vitamina $\mathrm{E}$ actúa como un antioxidante liposoluble, probablemente uniéndose a la membrana (Combs y Scott, 1974).

En 1962 se comprobó también su acción en humanos: actúa in vivo, a nivel de la membrana celular previniéndola de las peroxidaciones, es un scavenger de 
radicales libres, por lo tanto protege a los GR de la hemólisis peroxidativa, que depende del porcentaje de ácidos grasos poliinsaturados presentes en la membrana fundamentalmente dependiente de la dieta (Combs et al., 1975).

En dietas con bajos niveles de vitamina E, no hay síntomas de lipoperoxidación a menos que la misma sea suplementada con un alto contenido en ácidos grasos poliinsaturados. Se ha encontrado además que la vitamina $\mathrm{E}$ actúa en levaduras previniendo la lisis (Scott et al., 1956).

Se ha propuesto además que en ausencia de vitamina $\mathrm{E}$ ocurren cambios en la permeabilidad y estabilidad de la membrana. La acción de la vitamina E ( $\alpha$-tocoferol) como antioxidante está sostenida por un lado porque se ha demostrado que otras sustancias antioxidantes previenen ciertos síntomas producidos por deficiencia de esta vitamina y además porque se demostró in vitro, que la vitamina $\mathrm{E}$ inhibe la autoxidación de los ácidos grasos poliinsaturados (Lucy, 1972).

Según estos mismos autores la acción in vivo de la vitamina $\mathrm{E}$ está relacionada con el mantenimiento del selenio en estado reducido, lo cual fue demostrado en ratas. Se ha demostrado además que la vitamina $\mathrm{E}$ in vitro es un inhibidor de la hemólisis producida por agentes oxidantes, ya que se encontró que inhibe la hemólisis producida por adición de retinol en eritrocitos de conejo (Lucy, 1972).

El $\alpha$-tocoferol es el antioxidante más importante de la membrana del GR; se ha demostrado que adicionado tanto in vivo como in vitro protege las células de la hemólisis inducida por irradiación gamma externa o por los radicales libres endógenos (May et al., 1998). La reacción de protección del $\alpha$-tocoferol en la membrana se esquematiza en la Figura 3: la vitamina E reacciona con los radicales peróxido (LOO•), produciendo un hidroperóxido lipídico $(\mathrm{LOOH})$ relativamente estable y el radical tocoferoxilo, interrumpiendo de esta manera la propagación de la lipoperoxidación. De 
hecho, la vitamina $\mathrm{E}$ es el principal antioxidante liposoluble que protege los lípidos del daño oxidativo (Sies et al.,1992).

Usando liposomas de fosfatidilcolina como modelos de membrana se encontró que cuando la lipoperoxidación es estimulada por un iniciador hidrosoluble como el 2,2'-azobis(2-amidinopropano), el $\alpha$-tocoferol, protege rápidamente los liposomas de la peroxidación (Sies et al.,1992).

Figura 3: Acción de la vitamina E como antioxidante.

LH

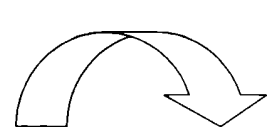

LOO• LOOH
L• Propagación<smiles>[R]C1(C)CCC2C(C)=C(C)C(C)=C(C)C2O1</smiles>

Radical tocoferilo

LOO•<smiles>[R]C1(C)CCC2=C(C)C(=O)C(C)=C(C)C2(O)O1</smiles><smiles>[R]C(C)(O)CCC1=C(C)C(=O)C(C)=C(C)C1=O</smiles>

Tocoferil Quinona

LH: Lípido; L•: radical lipídico centrado en el carbono; LOO•: radical peroxilipídico

A su vez, se ha demostrado que la vitamina $\mathrm{C}$ puede reaccionar con los radicales de la vitamina $\mathrm{E}$ regenerándola. Los radicales de vitamina $\mathrm{C}$ formados son reducidos nuevamente a vitamina $\mathrm{C}$ por enzimas NADPH dependientes (Chiu et al., 1989). 
También se demostró que la vitamina E de la membrana del GR se puede regenerar por medio de la vitamina $\mathrm{C}$ presente tanto en el plasma como en el interior del eritrocito (May et al., 1998).

\subsection{Acción de la vitamina C}

Es una vitamina hidrosoluble. Su forma oxidada, el dehidroascorbato, debido a la presencia del grupo enodiol, es un potente agente reductor. La siguiente es la estructura del L-ascorbato:

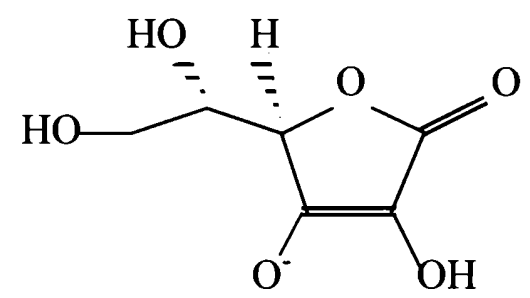

El ascorbato es el antioxidante hidrosoluble fisiológico más efectivo, que posee el plasma contra los daños ocasionados por el estrés oxidativo. Se ha demostrado que es el único antioxidante endógeno que puede proteger completamente los lípidos del daño peroxidativo inducido por radicales peroxilos hidrosolubles. Actúa atrapando estos radicales en la fase acuosa, antes de que los mismos difundan hacia los lípidos donde puedan iniciar la lipoperoxidación. De esta manera, es el único antioxidante que puede prevenir la lipoperoxidación ocasionada por radicales acuosos. Los demás, como $\alpha-$ tocoferol, urato o proteínas con grupos tioles, actúan disminuyendo la velocidad de su propagación (Frei et al., 1989). También actúa protegiendo de oxidantes como el superóxido, el peróxido de hidrógeno, el hipoclorito, el radical oxidrilo y el oxígeno singlete (Sies et al.,1992).

Se sabe que el ascorbato puede actuar como antioxidante o como prooxidante 
dependiendo de su concentración y de la presencia de metales de transición. En plasma, sin embargo, mantiene su actividad antioxidante aún en elevadas concentraciones. No se observa la actividad prooxidante hasta alcanzar concentraciones superiores a $5 \mathrm{mM}$. Este hecho se debe a que los metales de transición, necesarios para catalizar las reacciones de los radicales libres y la autooxidación de la vitamina $\mathrm{C}$, no se encuentran disponibles en el plasma, sino que se hallan fuertemente unidos a proteínas (Shinar, 1983; Frei et al., 1989).

Se ha demostrado además que las células deplecionadas en ascorbato lisan más rápidamente en presencia del radical libre 4-hidroxi-2,2,6,6-piperidiniloxilo (Tempol) que las células controles con ascorbato. (May et al., 1998). Estos mismos autores demostraron que el ascorbato protege a la vitamina E de la membrana de la oxidación, ya que:

a) El ascorbato puede reaccionar directamente con el oxidante disminuyendo la cantidad disponible para oxidar el $\alpha$-tocoferol. Esta reacción puede ocurrir por la entrada del oxidante al interior de la célula o por salida del ascorbato al medio extracelular, aunque el pasaje del ascorbato a través de la membrana es muy lento.

b) El oxidante provocaría la oxidación del $\alpha$-tocoferol que se encuentra en la membrana y éste es luego reducido por el ascorbato intracelular. 


\title{
OBJETIVOS Y
}

\author{
DISEÑO
}

\section{EXPERIMENTAL}




\section{OBJETIVO PRINCIPAL}

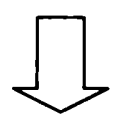

Estudio de la estabilidad a largo plazo de SEE mantenida a $4^{\circ} \mathrm{C}$ :

Seguimiento de las alteraciones de parámetros hematimétricos en SE y de cambios morfológicos de los GR.

Seguimiento de cambios bioquímicos que sufren los GR.

\section{OBJETIVO SECUNDARIO}

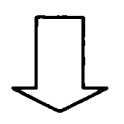

Mejorar la estabilidad a largo plazo de la SEE mediante el agregado de vitamina $\mathrm{E}$ y/o vitamina $\mathrm{C}$. 


\section{DISEÑO EXPERIMENTAL}

Sangre humana de Banco de Sangre, con no más de 24 hs desde su extracción, con serología negativa para HIV, HBsAg y HCV

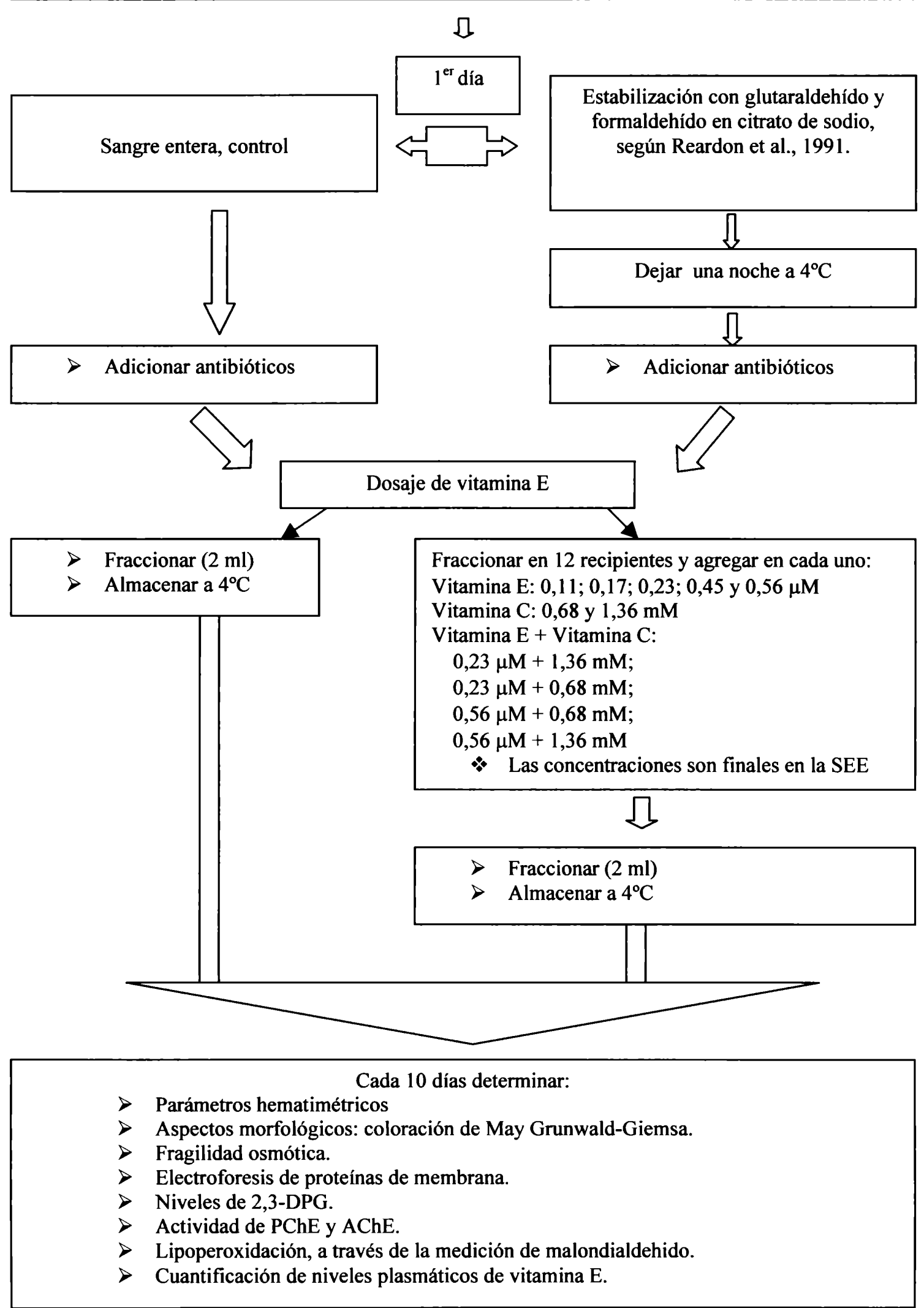




\section{Detalle del diseño experimental}

Se utilizó sangre humana extraida en CPD como anticoagulante, proveniente de banco de sangre, con no más de 24 horas desde su extracción, con serología negativa para HIV, HBsAg y HCV. Cada lote fue preparado con una bolsa de sangre. En caso de requerirse más de una, éstas debían ser isogrupo $\mathrm{ABO}$ y se mezclaban y homogeneizaban antes de estabilizarlas.

En el primer día, la sangre entera fue estabilizada siguiendo el método de Reardon et al.(1991) modificado, con una solución de citrato trisódico adicionada con glutaraldehído (50\%) y formaldehído (37-40\%), adicionada con antibióticos y antimicóticos. Los antibióticos utilizados fueron los recomendados por la Organización Mundial de la Salud (OMS) (Lewis, 1992): penicilina y gentamicina, ambos en una concentración final de $25 \mathrm{mg} / 500 \mathrm{ml}$. El antimicótico utilizado fue anfotericina $\mathrm{B}$ en una concentración final de $2 \mathrm{mg} / \mathrm{L}$. La solución estabilizadora fue agregada gota a gota con agitación constante.

Al día siguiente, la sangre fue adicionada con vitamina $\mathrm{E}$ (succinato ácido de $\alpha$ tocoferol) (Sigma, Saint Louis MO, Estados Unidos) en diferentes concentraciones: $0,11,0,17,0,23,0,45$ y $0,56 \mu \mathrm{M}$, con vitamina C (ácido ascórbico) (Malinkrodt) 0,68 y $1,36 \mathrm{mM}$, o con mezclas de ambas vitaminas: vit $\mathrm{E}=0,23 \mu \mathrm{M}+$ vit $\mathrm{C}=1,36 \mathrm{mM}$; vit $\mathrm{E}=0,23 \mu \mathrm{M}+$ vit $\mathrm{C}=0,68 \mathrm{mM}$; vit $\mathrm{E}=0,56 \mu \mathrm{M}+$ vit $\mathrm{C}=0,68 \mathrm{mM}$; vit $\mathrm{E}=0,56 \mu \mathrm{M}+$ vit $\mathrm{C}=1,36 \mathrm{mM}$. La concentración de las vitaminas fue elegida teniendo en cuenta los niveles adicionados en los medios de cultivo. Se eligió el succinato ácido de $\alpha$-tocoferol porque se disuelve en medio acuoso con mayor facilidad que el $\alpha$-tocoferol. La sal sódica del succinato ácido de $\alpha$-tocoferol es soluble en solventes polares, por ejemplo su solubilidad en cloroformo es de $50 \mathrm{mg} / \mathrm{ml}$; en agua forma soluciones acuosas $0,2 \%$ 
que tienen un $\mathrm{pH}=3,5$ (Merck, 1989). Las soluciones madres preparadas por nosotros no superaban la concentración de $0,01 \%$.

Se mantuvo en heladera por una noche y se prepararon alícuotas de $2 \mathrm{ml}$ cada una, en recipientes de plástico estériles. Estas fracciones se conservaron a $4^{\circ} \mathrm{C}$ durante todo el tiempo de duración de las experiencias.

Los diferentes parámetros se estudiaron cada diez días por un período de 120 días.

Se utilizaron como controles alícuotas de sangre entera anticoagulada sin estabilizar y alícuotas de sangre entera estabilizada sin el agregado de ningún antioxidante.

Se cuantificaron los niveles plasmáticos de vitamina E por HPLC en muestras de SE y SEE para observar si la misma era consumida durante el almacenamiento.

Se prepararon en total 12 lotes. Los dos primeros (Lote SE080296 y SE010396 ) fueron realizados como estudios preliminares para poder especificar las condiciones experimentales de los lotes siguientes: número de recuentos a realizarse por vez, tiempo máximo de almacenamiento y otros.

En todos los lotes, los antioxidantes fueron agregados después de la estabilización, sólo en los lotes SE020297 y SE120598 se estudió el efecto del agregado antes de la estabilización.

En estas experiencias, para evaluar la estabilidad y verificar los cambios producidos durante el almacenamiento se midieron los siguientes parámetros:

D Parámetros hematimétricos: GB, GR, Hb, Hto, VCM, HCM, CHCM, amplitud de la distribución del diámetro de los GR (RDW), Plt y volumen plaquetario medio (PVM).

Aspectos morfológicos: coloración de May Grunwald-Giemsa. 
Fragilidad osmótica.

Electroforesis de proteínas de membrana.

Niveles de 2,3-DPG.

Actividad de PChE y AChE.

Lipoperoxidación a través de la medición de malondialdehido.

Cuantificación de niveles plasmáticos de vitamina E por HPLC. 


\section{MATERIAL Y MÉTODOS}

\section{RESULTADOS}




\section{Medición de parámetros hematimétricos}

\subsection{Material y métodos}

La sangre humana fue obtenida y procesada según lo explicado en el diseño experimental.

Se evaluaron diez parámetros hematimétricos: recuento de GB, GR, Plt, determinación de Hb, Hto, VCM, HCM, CHCM, RDW y PVM. Los contadores utilizados fueron un NOVA Celltrack 12 y un Coulter JT, que fueron controlados con controles comerciales de NOVA y de Coulter (4C Plus Coulter Cell Control) respectivamente, en tres niveles (normal, bajo y alto), como control interno. Para el control externo, se participó en el programa del International External Quality Assesment Scheme (IEQAS) de la OMS, en el que se controlaron los niveles de GB, Hb y Plt cada tres meses.

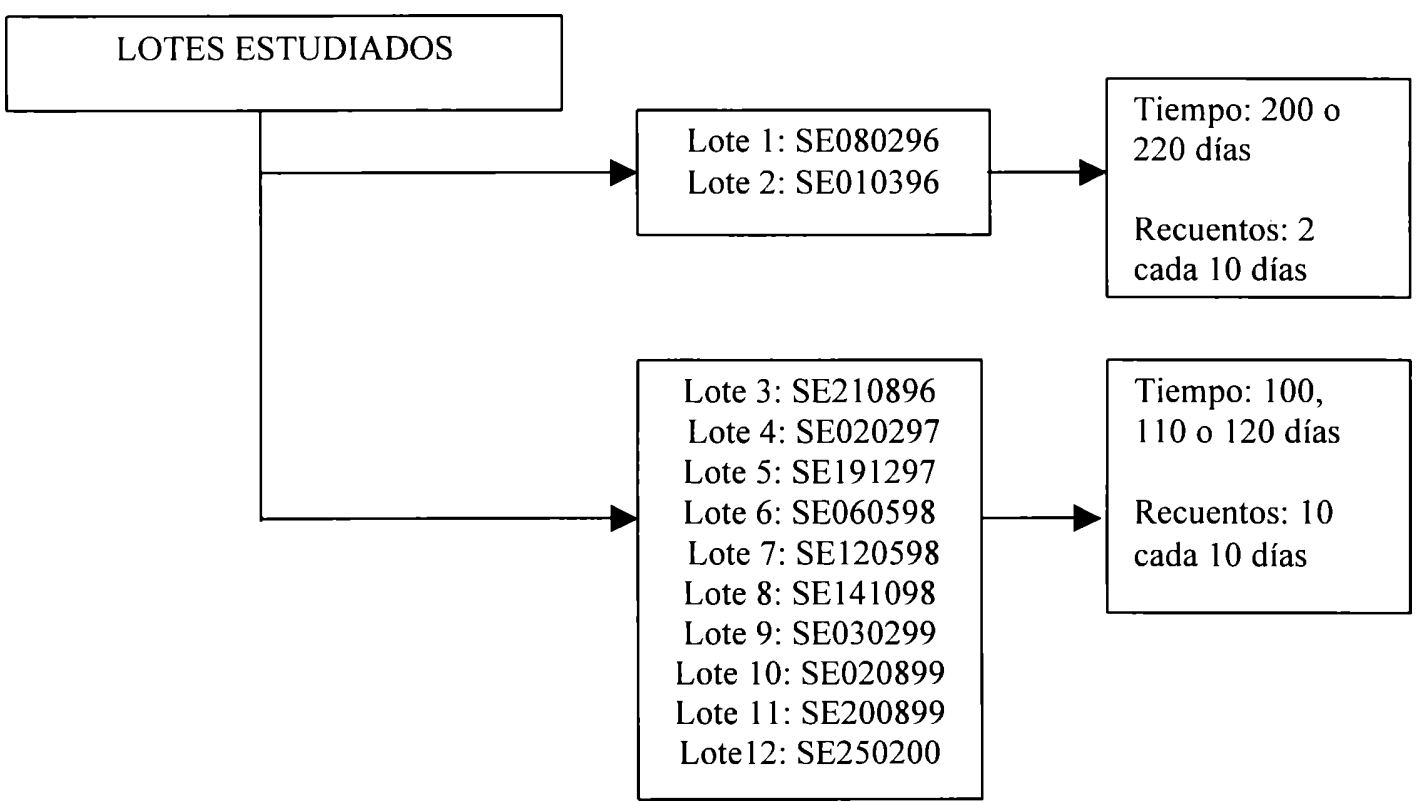

Las muestras correspondientes a los lotes 1 a 7 fueron analizadas en el contador NOVA-Celltrack 12. En las experiencias correspondientes a los lotes 8 a 12, las muestras fueron analizadas en el contador Coulter-JT. 
En cada una de las experiencias se realizaron cálculos estadísticos intracorrida, medias, desvíos estándar (DE) y CV\% de cada analito, para las diez repeticiones realizadas cada diez días, observando si los valores medios obtenidos se escapaban del intervalo dado por $\bar{x}_{\text {(dia l) }} \pm 2 \mathrm{DE}$, con el fin de determinar los tiempos de almacenamiento máximos (tiempos de tolerancia máximos). Se consideró que este tiempo máximo quedaba determinado por el día a partir del cual los valores quedaban fuera del intervalo, es decir por $\bar{x}_{(\text {día 1) }} \pm 2 \mathrm{DE}$, en dos determinaciones consecutivas. Además, se calcularon los valores promedio, el DE y el CV\% teniendo en cuenta todos los datos desde el inicio de la experiencia y se realizó un análisis unifactorial de varianza para observar si existían diferencias significativas entre los tratamientos.

El análisis estadístico de los datos se realizó mediante el Software SPSS 10.0 para Windows.

\subsection{Resultados}

\subsubsection{Control de los autoanalizadores}

Los contadores automatizados fueron controlados a lo largo de todas las experiencias, como se mencionó anteriormente, con un sistema de control de calidad interno (4C Plus Coulter Cell Control) y otro externo (IEQAS, OMS). En la Figura 4 se muestran los gráficos de Levy-Jennigs para los diferentes parámetros en el autoanalizador Coulter JT a lo largo de un mes, para el control 4C Plus Coulter Cell Control en el nivel normal, a modo de ejemplo. Las medias y los DE utilizados en las gráficas corresponden a los aportados por el proveedor para cada una de las variables medidas. 
Figura 4. Diagrama de Levy-Jenings para los diferentes parámetros hematimétricos: control interno del contador hematológico Coulter JT (Control normal Coulter Plus 4C, período: 30 días)
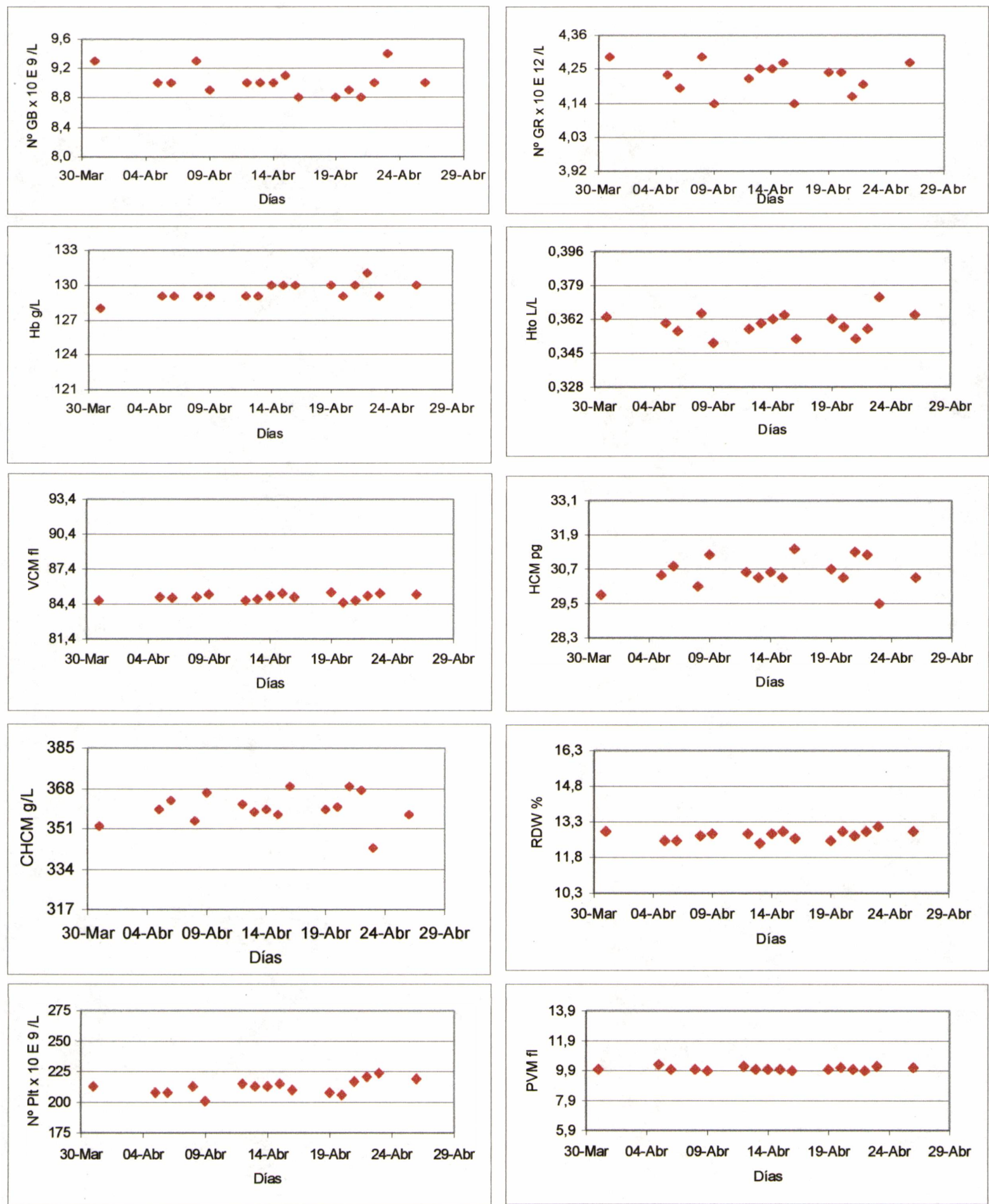

Los valores del eje $y$ corresponden a la media y los SD aportados por el proveedor para cada parámetro. 
En cuanto a la participación en el IEQAS, se analizaron cuatro encuestas anuales, en las cuales los resultados fueron evaluados y expresados como índices de desviación (ID). Los ID indican la diferencia entre el resultado del participante y la media consenso, expresada en DE y se calcula según:

$$
\mathrm{ID}=\frac{\text { Resultado individual }- \text { Media consenso para la prueba }}{\text { DE consenso }}
$$

Nuestro laboratorio tuvo valores aceptados con ID $<2$.

\subsubsection{Medición de la reproducibilidad}

En la Tabla 3 se muestran los CV\% intraensayo para cada uno de los parámetros hematimétricos, medidos en ambos contadores, realizando repeticiones en una sola corrida de una muestra de SE fresca anticoagulada en ACD. 


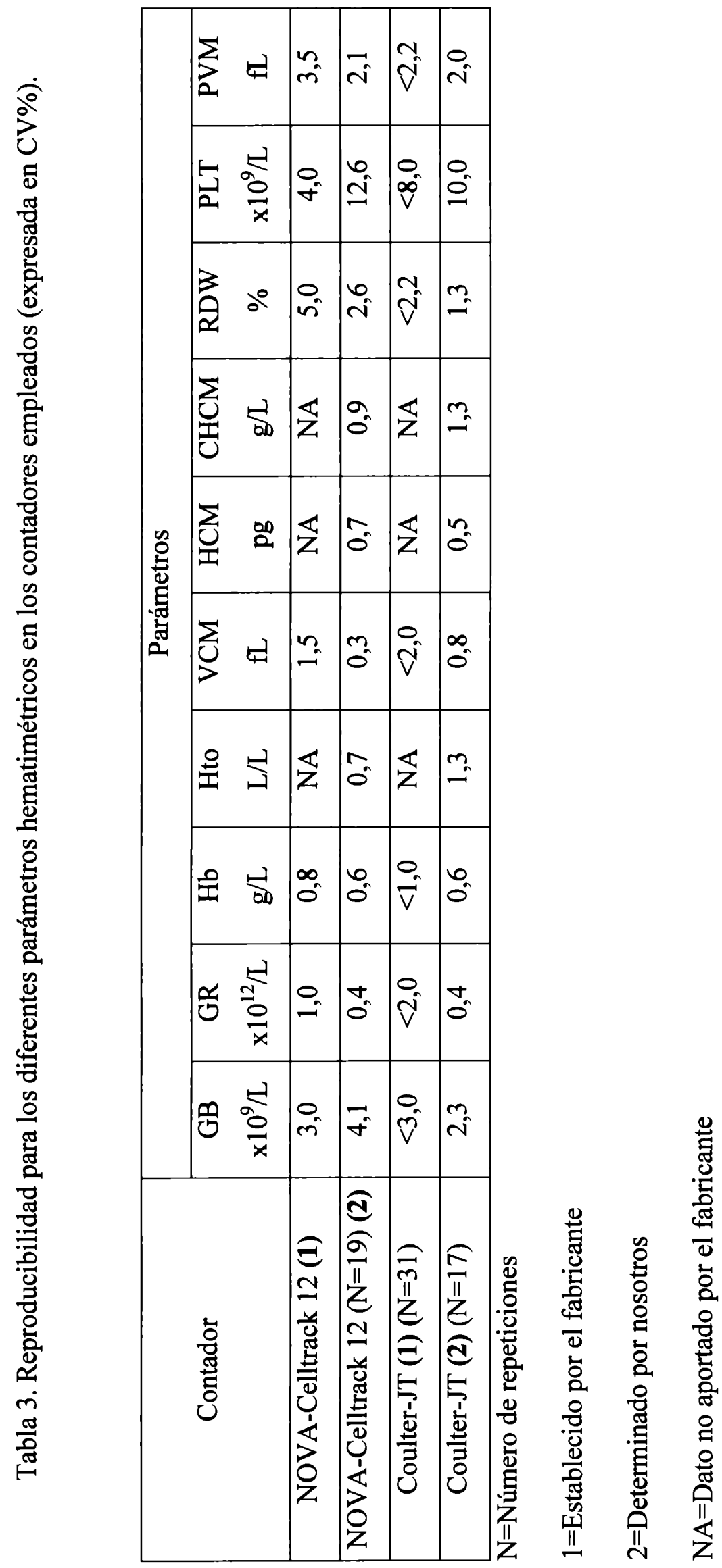




\subsubsection{Control antimicrobiano}

Se realizó un control de crecimiento de microorganismos a los 120 días de almacenamiento en muestras de cada tratamiento tomadas al azar. Se sembraron placas de cultivo de:

a) agar tripteina soya (Britania): tripteina $15,0 \mathrm{~g}$; peptona de soya $5,0 \mathrm{~g}$; $\mathrm{ClNa}$ 5,0 g; agar 15,0 g en $1000 \mathrm{ml}$ de agua destilada csp.

b) Caldo infusión cerebro corazón (Britania): infusión de cerebro $200 \mathrm{~g}$; infusión de corazón $250 \mathrm{~g}$; peptona $10 \mathrm{~g}$; $\mathrm{ClNa} 0,5 \mathrm{~g}$; glucosa $2 \mathrm{~g}$; $\mathrm{PO}_{4} \mathrm{HNa}_{2} 2,5 \mathrm{~g}$ en $1000 \mathrm{ml}$ de agua destilada c.s.p.

No se observó crecimiento microbiano en ningún tratamiento de SEE a los 120 días de almacenamiento.

\subsubsection{Experiencias exploratorias}

En la experiencia SE080296, se probó el efecto de la adición de los antioxidantes, vitamina $E=0,11 \mu \mathrm{M}$ y vitamina $\mathrm{C}=0,68 \mathrm{mM}$ a una muestra de $\mathrm{SE}$ sin estabilizar y a una muestra de SEE. Los resultados de las $\bar{x} \pm \mathrm{DE}$ y los CV\%, teniendo en cuenta todos los datos desde el primer día, se muestran en la Tabla 4. En la experiencia SE010396 se adicionó vitamina E en diferentes concentraciones: 0,11, 0,17, $0,23,0,45$ y $0,56 \mu \mathrm{M}$ y en la Tabla 5 se muestran los resultados de las $\bar{x} \pm \mathrm{DE}$ y los CV\% obtenidos durante todos los recuentos en el período total de 200 días.

Al observarse que luego de 120 días algunos parámetros sufrían variaciones que se alejaban demasiado del valor inicial (por ejemplo el VCM que sufrió aumentos de 7,1 a 9,6\%), dependiendo de la concentración de vitamina $\mathrm{E}$ agregada y que por otra parte la muestra presentó una hemólisis muy importante, se decidió fijar este tiempo como límite para el almacenamiento. Además, para aumentar la confiabilidad en el 
tratamiento estadístico de los datos, permitiendo que las medias cada diez días no perdieran significancia frente a la media total, se comenzaron a realizar diez repeticiones de cada muestra, cada diez días.

La medición de los parámetros hematimétricos permitió seguir la variación del número total de GB y Plt, así como el PVM, en el tiempo. Si bien el objetivo de este trabajo está centrado en los eritrocitos, la Figura 5 muestra las diferencias en los valores de GB y Plt entre las muestras de SE y las de SEE del lote SE080296, mostrando que la sola adición de alguno de los antioxidantes no permitía mejorar la conservación de las Plt ni de los leucocitos, pero sí lo hace la estabilización de la sangre. Sin embargo, para estos mismos parámetros, los CV\% totales para la SE adicionada con las vitaminas, en el tiempo de 80 días son menores a la SE sin el agregado de las mismas en el mismo lapso de tiempo (Tabla 4).

Al analizar estadísticamente, mediante un ANOVA unifactorial, los datos del lote SE010396 (Tabla 5), se encontró que para los GB existían diferencias significativas entre los diferentes tratamientos $(p<0,05)$ teniendo en cuenta los días como covariable. Esta diferencia se mantenía aún quitando del análisis la muestra de SEE sin vitamina E, indicando que existían diferencias entre las muestras adicionadas con las diferentes concentraciones de la vitamina. Para los GR en cambio, se vio que existían diferencias significativas entre la muestra de SEE y las adicionadas con vitamina $E(p<0,05)$, pero no entre las muestras adicionadas con las diferentes concentraciones de la vitamina ( $\mathrm{p}>0,05)$. Una observación similar se tuvo al analizar las Plt, cuyos valores de significancia fueron $\mathrm{p}<0,01$ al comparar todos los tratamientos y $\mathrm{p}>0,05$ cuando la SEE no es considerada en el análisis. El VCM presentó una diferencia significativa entre tratamientos $(p<0,02)$. Para los demás parámetros no se encontraron en este lote diferencias significativas entre los tratamientos $(p>0,05)$. 


\begin{tabular}{|c|c|c|c|c|c|c|c|}
\hline$\sum_{a}$ & 盐总 & 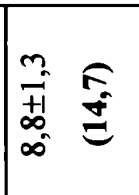 & 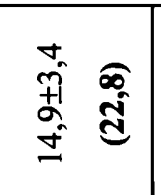 & 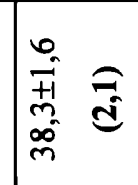 & $\begin{array}{l}\infty \\
0 \\
0 \\
0 \\
0 \\
\infty\end{array}$ & 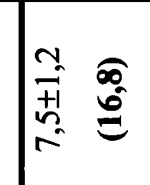 & 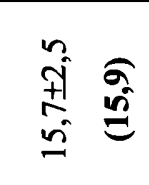 \\
\hline ज़ & 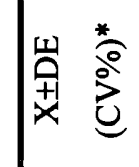 & 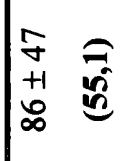 & 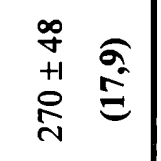 & 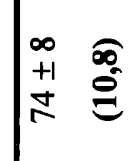 & 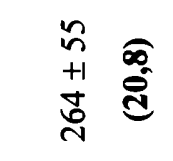 & 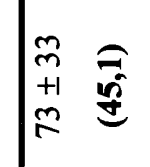 & 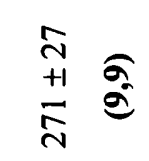 \\
\hline 㞔。 & 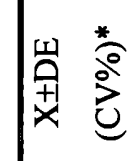 & 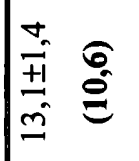 & 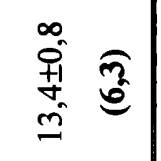 & 集等 & 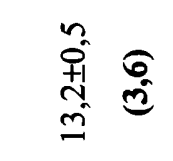 & 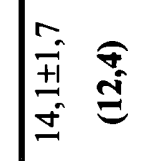 & 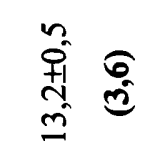 \\
\hline 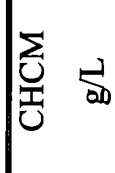 & 㙉落 & 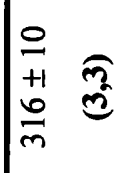 & 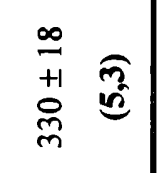 & 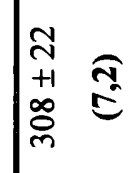 & 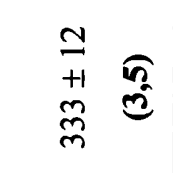 & 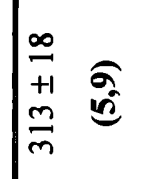 & 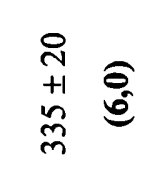 \\
\hline$\sum_{0}^{2}$ & 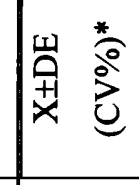 & 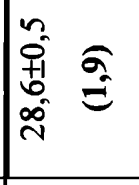 & 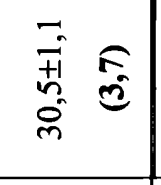 & 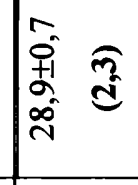 & 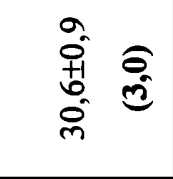 & 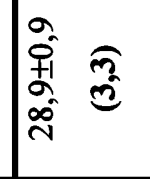 & 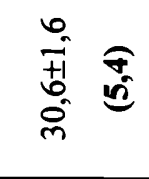 \\
\hline$\sum_{0}$ & 岀 & 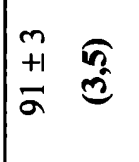 & $\begin{array}{ll}m & \widehat{n} \\
2 & 0 \\
2 & 0\end{array}$ & 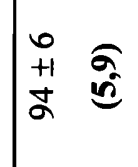 & $\begin{array}{ll}n & \widehat{D} \\
0 \\
\alpha\end{array}$ & 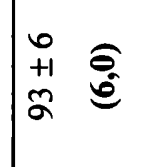 & 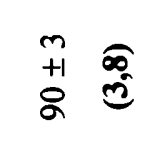 \\
\hline د & 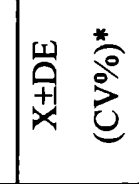 & 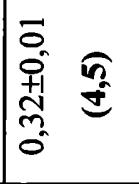 & 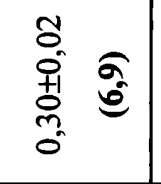 & 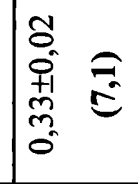 & 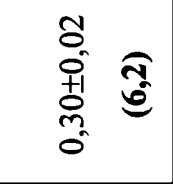 & 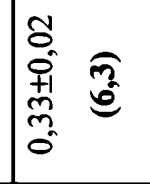 & 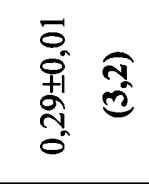 \\
\hline 웅 & 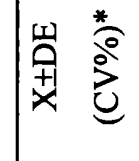 & 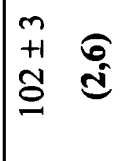 & 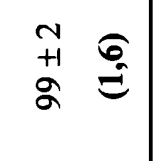 & 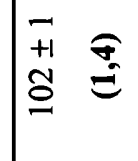 & $\begin{array}{l}+ \\
+ \\
2 \\
\alpha\end{array}$ & 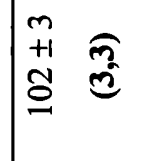 & 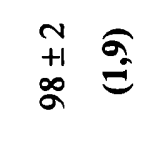 \\
\hline$\approx \frac{\overrightarrow{5}}{\frac{0}{6}}$ & 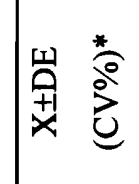 & 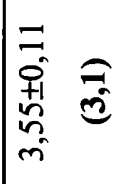 & 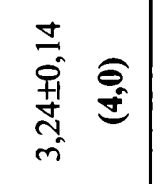 & 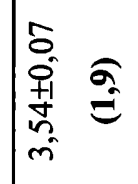 & 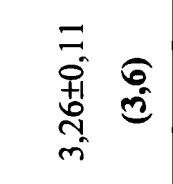 & 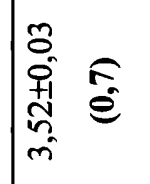 & 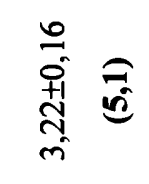 \\
\hline 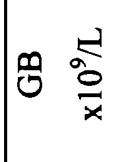 & 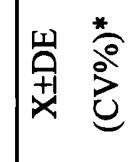 & 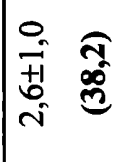 & 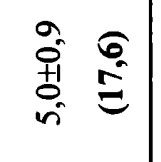 & 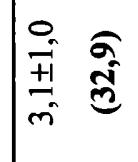 & 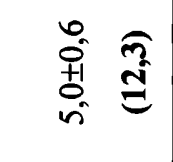 & 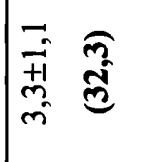 & $\begin{array}{l}\text { के } \\
\text { में } \\
\text { ते }\end{array}$ \\
\hline & \multirow{2}{*}{ 递 } & س & 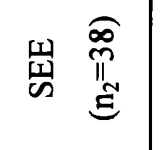 & 岁 & 崫焉 & 崖 & 兽蒂 \\
\hline & & 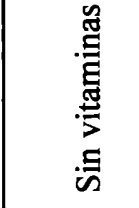 & & & & & \\
\hline
\end{tabular}




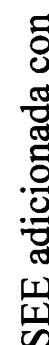

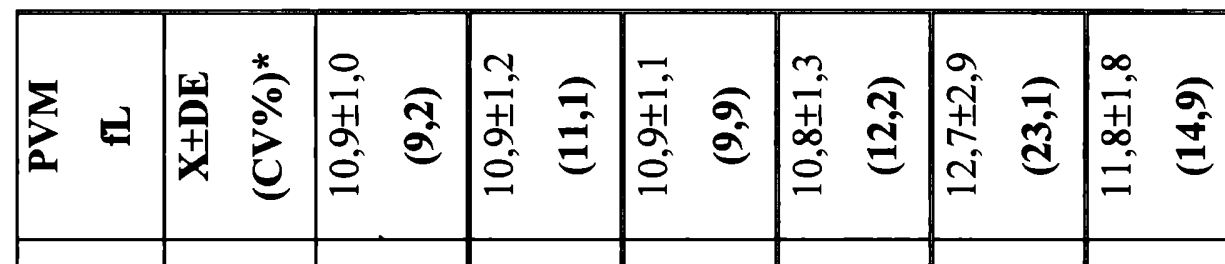

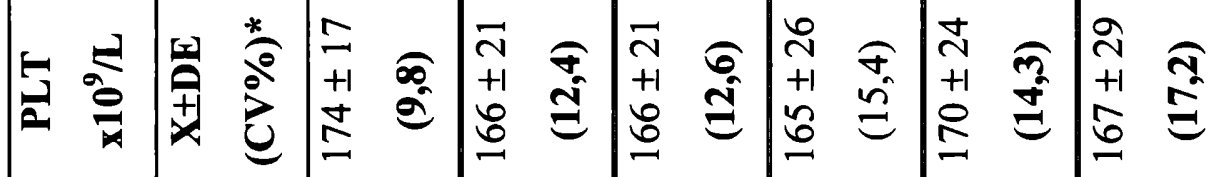

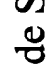

急 (a)

¿

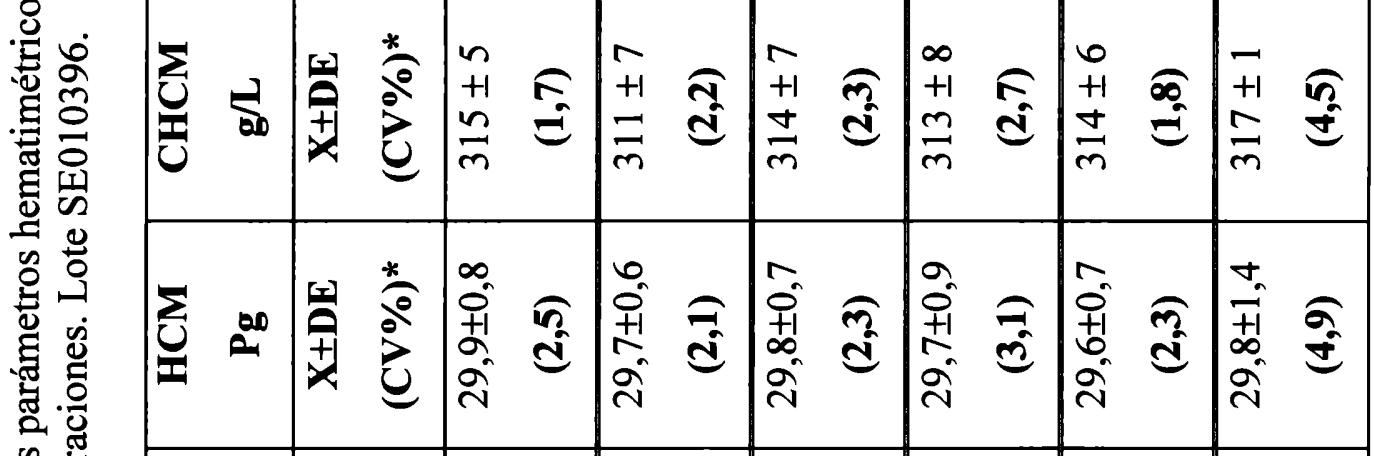
क)

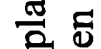

임디

크. 콜

疋

\begin{tabular}{|c|c|c|c|c|c|c|c|c|c|c|c|c|c|c|c|}
\hline$\stackrel{8}{ \pm}$ & $\stackrel{\Xi}{\Omega}$ & $\frac{\sqrt[x]{2}}{\partial}$ & 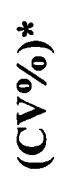 & $\begin{array}{l}\overline{0} \\
0 \\
0 \\
+1 \\
\infty \\
\text { m. } \\
0\end{array}$ & हூ & $\begin{array}{l}\overline{0} \\
0 \\
+1 \\
\infty \\
\text { ñ } \\
0\end{array}$ & ஸि & 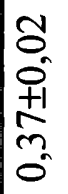 & $\begin{array}{l}\text { fo } \\
\text { है }\end{array}$ & $\begin{array}{l}0 \\
0 \\
0 \\
+1 \\
\text { m. } \\
\text { n. }\end{array}$ & $\underset{\text { có }}{\overparen{6}}$ & $\begin{array}{l}\overline{0} \\
0 \\
0 \\
+1 \\
\infty \\
m \\
0\end{array}$ & लू & $\begin{array}{l}\text { O } \\
\delta \\
0 \\
+1 \\
\infty \\
\infty \\
0\end{array}$ & 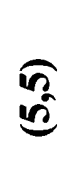 \\
\hline$\hat{I}$ & $\vec{D}_{0}$ & 嘼 & 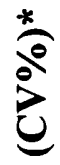 & $\begin{array}{l}m \\
+1 \\
a \\
=\end{array}$ & ca & $\begin{array}{l}m \\
+1 \\
9 \\
\Xi\end{array}$ & ¿্d & $\begin{array}{l}0 \\
+1 \\
\infty \\
=\end{array}$ & $\underset{2}{\overparen{d}}$ & $\begin{array}{l}n \\
+1 \\
\Xi \\
\Xi\end{array}$ & $\underset{ \pm}{\stackrel{2}{f}}$ & $\begin{array}{l}m \\
+1 \\
a \\
\equiv\end{array}$ & న & $\begin{array}{l}0 \\
+1 \\
\end{array}$ & $\begin{array}{l}\text { fo } \\
\text { ve }\end{array}$ \\
\hline
\end{tabular}

\begin{tabular}{|c|c|c|c|c|c|c|c|c|c|c|c|c|c|}
\hline$\frac{2}{2}$ & 冷 & 巳e & $\mid$\begin{tabular}{l}
$m$ \\
\hdashline 0 \\
+1 \\
0 \\
0 \\
$m$ \\
$m$
\end{tabular} & స్ & $\begin{array}{l}8 \\
0 \\
0 \\
+1 \\
2 \\
\text { m. }\end{array}$ & ત્ & 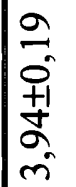 & f & $\begin{array}{l}0 \\
+1 \\
\text { On }\end{array}$ & $\begin{array}{l}\text { fo } \\
\text { f }\end{array}$ & \begin{tabular}{l} 
\pm \\
0 \\
0 \\
+1 \\
0 \\
0 \\
\multirow{1}{*}{}
\end{tabular} & $\underset{\text { fo }}{\text { for }}$ & 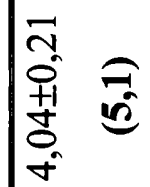 \\
\hline
\end{tabular}

\begin{tabular}{|c|c|c|c|c|c|c|c|c|c|c|c|c|}
\hline ڤึ & 畺 & 苂 & $\begin{array}{l}n \\
0 \\
+1 \\
n \\
n \\
n\end{array}$ & है & $\begin{array}{ll}n & 0 \\
0 & 0 \\
+1 & 0 \\
n & 0 \\
r & 0\end{array}$ & 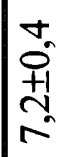 & 皇 & $\begin{array}{l}0 \\
0 \\
0 \\
+1 \\
2 \\
-1\end{array}$ & $\stackrel{f}{5}$ & $\mid \begin{array}{l}\infty \\
0 \\
0 \\
+1 \\
\infty \\
-1\end{array}$ & $\underline{\underline{\theta}}$ & $\mid \begin{array}{c}\infty \\
0 \\
+1 \\
\\
n\end{array}$ \\
\hline 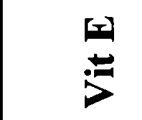 & $\sum_{I}$ & & 0 & & $\Xi_{0}$ & $\frac{5}{6}$ & & $\tilde{N}_{0}$ & & $\frac{n}{8}$ & & గొ \\
\hline
\end{tabular}


Figura 5. Estabilidad a largo plazo de los recuentos de GB (a) y Plt (b) en muestras de SE, SEE y SEE adicionada con vitaminas E y C. Lote SE080296.

Cada punto corresponde a una media de dos repeticiones
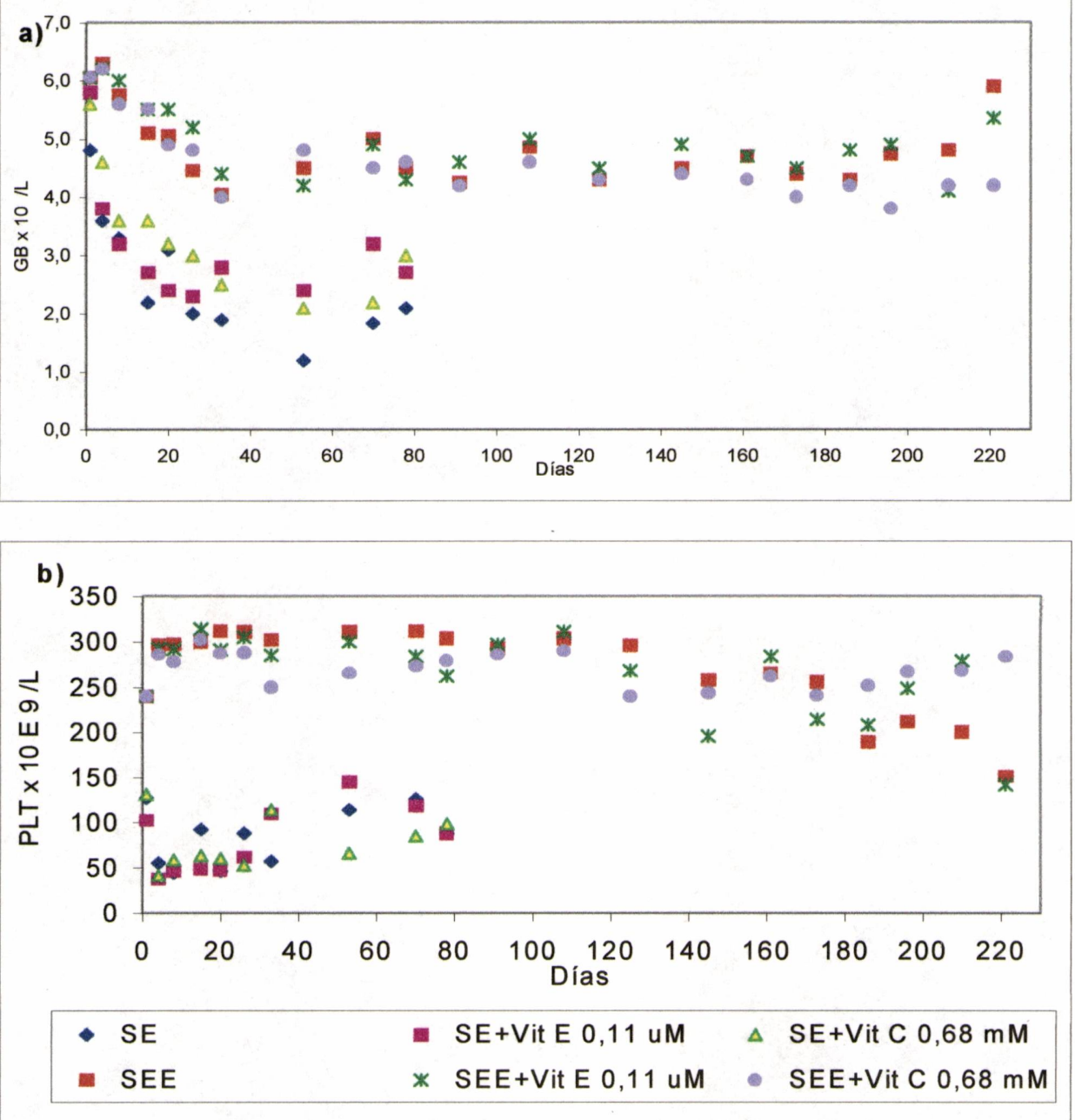

\subsubsection{Seguimiento de los parámetros hematimétricos a largo plazo}

La Tabla 6 muestra los valores de $\bar{x}, \mathrm{DE}$ y CV\% totales, desde el día 1 al 120 , para las muestras del lote SE210896, en el cual se adicionaron a la SEE diferentes concentraciones de vitamina $\mathrm{E}$. Al analizar estos valores estadísticamente (ANOVA unifactorial), se observaron diferencias significativas entre los tratamientos $(p<0,05)$ para los parámetros GB, Plt y PVM. En cuanto a GR, Hb y Hto, se observa una diferencia significativa entre la SEE y las muestras adicionadas con vitamina E $(p<0,05)$, pero no hay diferencias significativas entre los tratamientos con las diferentes 
concentraciones de la vitamina ( $\mathrm{p}>0,05)$. Para los demás parámetros, la adición de las vitaminas no mostró diferencias significativas $(\mathrm{p}>0,05)$ para las diferentes concentraciones utilizadas.

En la Tabla 7 se muestran los valores de $\bar{x}$, DE y CV\% totales, desde el día 1 al 120, para las muestras del lote SE020899, en las que se adicionaron a la SEE las diferentes concentraciones de vitamina $\mathrm{E}$, vitamina $\mathrm{C}$ y mezclas de ambas. $\mathrm{Al}$ hacer el análisis de varianza unifactorial, considerando los días como covariable, se encontró que existen diferencias significativas $(p<0,05)$ entre la muestra de SE y la de SEE y entre los diferentes tratamientos para todas las variables menos el $\mathrm{CHCM}(\mathrm{p}>0,05)$. Se observa además en esta tabla el elevado valor de CV\% obtenido para los GB y las Plt en la muestra de SE, corroborando así lo concluido en las experiencias preliminares. En la SE no se mantienen estos parámetros, pero sí en la SEE (figuras 6 y 14).

En las figuras 6 a 15 se muestran las dispersiones diarias de GB, GR, Hb, Hto, VCM, HCM, CHCM, RDW, Plt y PVM respectivamente. Las gráficas de las dispersiones se realizaron con la finalidad de estimar los tiempos de tolerancia máximos. De esta manera, se pudo observar que el tratamiento de la SEE con la adición de las vitaminas permitía alcanzar un tiempo de tolerancia máximo de 100\% (120 días) para los GB, mientras que para la muestra estabilizada este tiempo era de $83 \%$ (100 días). En los GR sucedía algo similar. En el caso de las Plt, todas las muestras menos la SE tuvieron una tolerancia de $100 \%$. En el caso del Hto, el VCM y el RDW, las muestras con mezclas de vitaminas son las que poseían mayor tolerancia máxima.

En las experiencias SE200899 y SE250200 se encontraron datos similares y las tablas 8 y 9 muestran los valores de $\bar{x} \pm 2 \mathrm{DE}$ y CV\% para todos los datos al cabo de 120 días. 
La Figura 10 muestra la variación del VCM en las diferentes muestras del lote SE020299. Así, se puede ver que el VCM de la muestra estabilizada aumentó y después de 70 días se escapó del intervalo $\bar{x}_{(\text {día } 1)} \pm 2 \mathrm{DE}(58 \%$ de tolerancia máxima). A su vez se halló que el VCM de la SEE es en general mayor al de la SE, aunque este efecto ya demostrado del glutaraldehído posee, al igual que los demás parámetros, una variabilidad interindividuo que se manifiesta en los resultados de los 12 lotes estudiados. Para las muestras adicionadas con las vitaminas se calcularon tiempos de tolerancia mayores: en el caso de la vitamina C llegó al 100\%; para los niveles de vitamina $\mathrm{E}$, dependiendo de la concentración de la misma, fue desde $17 \%(0,17 \mu \mathrm{M})$ hasta $100 \%(0,56 \mu \mathrm{M})$, mientras que en las mezclas de ambas vitaminas se determinó una tolerancia de $100 \%$ para la muestra con vitamina $\mathrm{E} 0,56 \mu \mathrm{M}$ y vitamina $\mathrm{C} 1,38 \mathrm{mM}$.

El tiempo de tolerancia máximo para el Hto aumentó también de 70 días (58\%) en la SEE a 110 días (95\%) en la SEE adicionada con estas vitaminas. El recuento de Plt permaneció en la tolerancia de $100 \%$ al igual que el número de GB. 


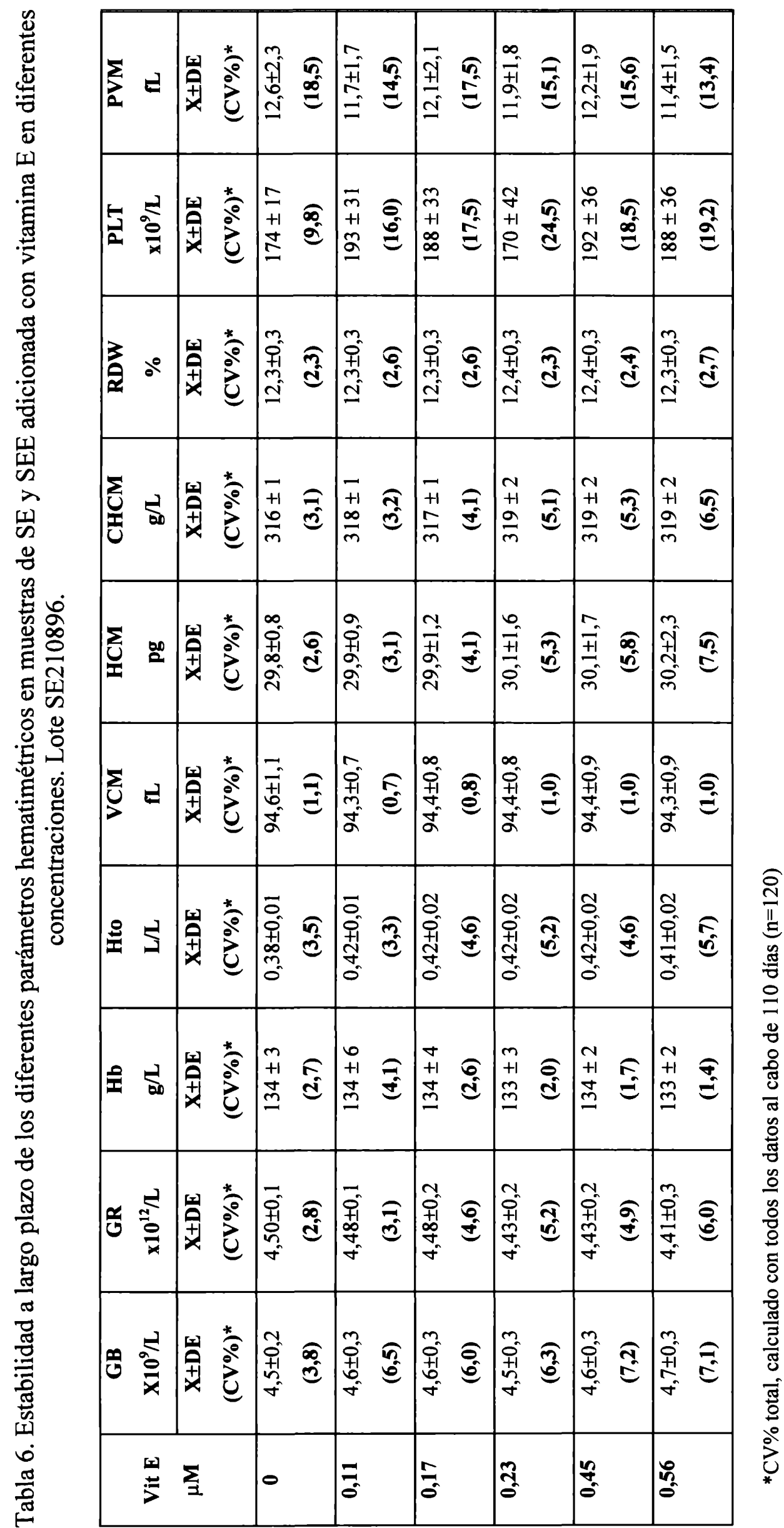




\begin{tabular}{|c|c|c|c|c|c|c|c|c|c|c|c|c|c|c|}
\hline$\sum_{D}$ & 崖递 & $\begin{array}{ll}R & \\
0 & 0 \\
+1 & 0 \\
m & 0 \\
r & \end{array}$ & $\mid \begin{array}{c}\infty \\
\infty \\
0 \\
+1 \\
+1 \\
n \\
\infty \\
\infty\end{array}$ & $\mid \begin{array}{ll}8 & \\
0 & 0 \\
+1 & 0 \\
\sigma_{2} & \vdots\end{array}$ & $\mid \begin{array}{ll}2 & \\
0 & \sigma \\
+1 & 0 \\
\alpha & = \\
\infty & =\end{array}$ & {$\left[\begin{array}{l}8 \\
-1 \\
0 \\
0 \\
0\end{array}=\right.$} & 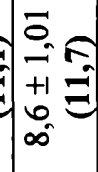 & {$\left[\begin{array}{ll}0 \\
-1 & \approx \\
+1 & 0 \\
2 & =\end{array}\right.$} & $\begin{array}{l}\infty \\
\infty \\
0 \\
+1 \\
+\infty \\
\sigma^{n}\end{array}$ & $\begin{array}{l}0 \\
0 \\
0 \\
+1 \\
\hat{0} \\
\simeq \\
0\end{array}$ & $\left\{\begin{array}{l}\Omega \\
\sigma \\
0 \\
+1 \\
\infty \\
\infty \\
\infty \\
\infty\end{array}\right.$ & 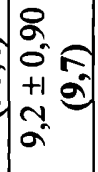 & $\mid \begin{array}{l}2 \\
2 \\
0 \\
+1 \\
2 \\
2 \\
a\end{array}$ & $\mid \begin{array}{ll}2 & 0 \\
0 & 0 \\
+1 & 0 \\
0 & 0 \\
0 & 0\end{array}$ \\
\hline 봃웛 & 崖䓹 & 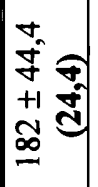 & 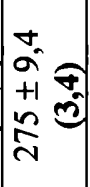 & $\begin{array}{l}n \\
m \\
+1 \\
\frac{n}{n}\end{array}$ & 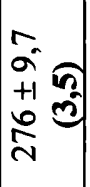 & 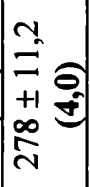 & 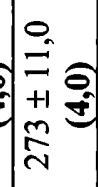 & 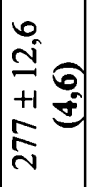 & 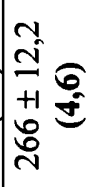 & 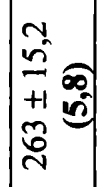 & 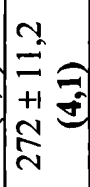 & 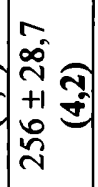 & 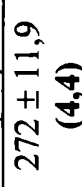 & 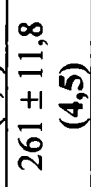 \\
\hline å & 崖呅 & 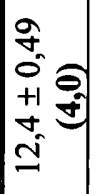 & 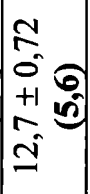 & 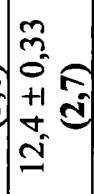 & 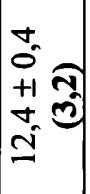 & 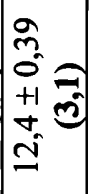 & $\mid \begin{array}{ll}\infty & 0 \\
n \\
0 \\
0 \\
+1 & 0 \\
0 & 0 \\
0 & 0 \\
\vdots & 0\end{array}$ & 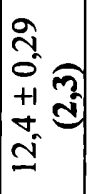 & 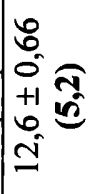 & 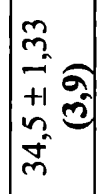 & $\left\{\begin{array}{l}0 \\
0 \\
0 \\
+1 \\
0 \\
0 \\
0 \\
0\end{array}\right.$ & $\mid \begin{array}{l}\tilde{n} \\
0 \\
+1 \\
0 \\
0 \\
0\end{array}$ & 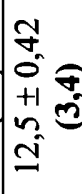 & 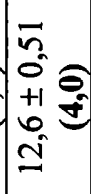 \\
\hline 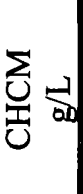 & 狅 & 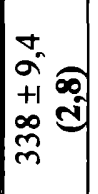 & 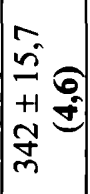 & 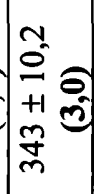 & 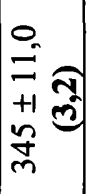 & 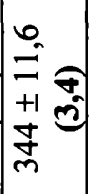 & 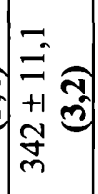 & $\mid \begin{array}{ll}0 & \\
0 & \\
+1 & 0 \\
0 & 0 \\
1 & 0\end{array}$ & 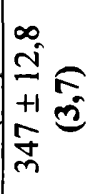 & $\begin{array}{l}m \\
m \\
+1 \\
\cdots \\
m \\
m \\
m\end{array}$ & 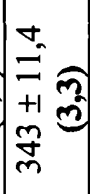 & 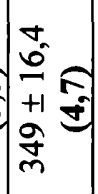 & $\mid \begin{array}{l}\infty \\
0 \\
0 \\
+1 \\
n \\
\stackrel{m}{m}\end{array}$ & 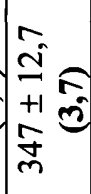 \\
\hline$\sum_{I}$ & 崖送 & $\begin{array}{l}\tilde{0} \\
0 \\
+1 \\
\pm \\
0 \\
0 \\
0\end{array}$ & 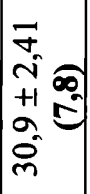 & $\mid \begin{array}{l}\infty \\
\infty \\
0 \\
+1 \\
0 \\
0 \\
0 \\
0 \\
0\end{array}$ & 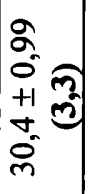 & 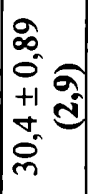 & $\mid \begin{array}{l}\infty \\
\infty \\
0 \\
+1 \\
0 \\
0 \\
0 \\
0 \\
0\end{array}$ & 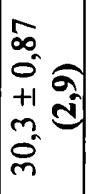 & 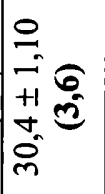 & $\begin{array}{l}n \\
\alpha \\
0 \\
+1 \\
\vdots \\
\vdots \\
0 \\
\tilde{n}\end{array}$ & 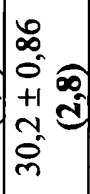 & 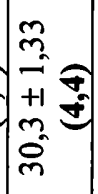 & $\mid \begin{array}{l}\infty \\
2 \\
0 \\
+1 \\
0 \\
0 \\
0 \\
0 \\
0\end{array}$ & 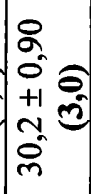 \\
\hline$\sum_{>}$ & 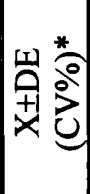 & $\begin{array}{l}\infty \\
\frac{\infty}{ \pm 1} \\
\frac{\infty}{2}\end{array}$ & $\begin{array}{l}\bar{n} \\
-1 \\
+1 \\
0 \\
\infty \\
\infty \\
\infty\end{array}$ & 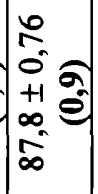 & $\begin{array}{l}0 \\
\infty \\
0 \\
+1 \\
\frac{1}{\infty} \\
0 \\
\infty\end{array}$ & $\begin{array}{l}\delta \\
\alpha \\
0 \\
+1 \\
\sim \\
\infty \\
\infty \\
\infty\end{array}$ & 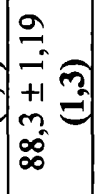 & 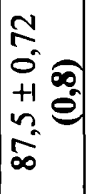 & $\begin{array}{l}0 \\
\infty \\
0 \\
+1 \\
+1 \\
n \\
0 \\
\infty \\
\infty\end{array}$ & 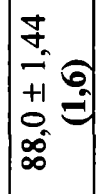 & 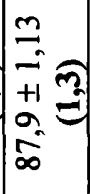 & $\mid \begin{array}{l}2 \\
\infty \\
0 \\
+1 \\
+1 \\
\infty \\
\infty \\
\infty \\
\infty\end{array}$ & $\begin{array}{l}0 \\
0 \\
0 \\
+1 \\
0 \\
0 \\
\infty \\
\infty\end{array}$ & $\mid \begin{array}{c}\frac{n}{m} \\
\frac{n}{+1} \\
\frac{n}{\infty}\end{array}$ \\
\hline 車 & 崖茧 & $\begin{array}{l}\overline{0} \\
0 \\
0 \\
+1 \\
\infty \\
\infty \\
m \\
0 \\
0\end{array}$ & {$\left[\begin{array}{l}0 \\
0 \\
0 \\
+1 \\
n \\
m \\
0\end{array}\right.$} & 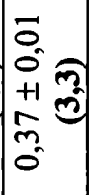 & $\begin{array}{l}\overline{0} \\
0 \\
+1 \\
+1 \\
\vdots \\
\vdots \\
0 \\
0\end{array}$ & 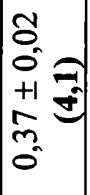 & $\mid \begin{array}{l}0 \\
0 \\
0 \\
+1 \\
0 \\
0 \\
0 \\
0 \\
0 \\
0\end{array}$ & 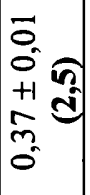 & $\begin{array}{l}\overline{0} \\
0 \\
0 \\
+1 \\
0 \\
n \\
0 \\
0 \\
0\end{array}$ & $\begin{array}{l}1 \\
0 \\
0 \\
+1 \\
0 \\
0 \\
0 \\
0 \\
0 \\
0\end{array}$ & $\mid \begin{array}{c}0 \\
0 \\
0 \\
+1 \\
0 \\
0 \\
0 \\
0 \\
0 \\
0\end{array}$ & $\begin{array}{l}\overline{0} \\
0 \\
+1 \\
+1 \\
0 \\
m \\
0 \\
0\end{array}$ & $\begin{array}{l}\tilde{1} \\
0 \\
0 \\
+1 \\
0 \\
0 \\
\tilde{n}_{2} \\
0 \\
0\end{array}$ & $\left\{\begin{array}{l}\delta \\
0 \\
0 \\
+1 \\
n \\
\cdots \\
0 \\
0\end{array}\right.$ \\
\hline 宔 & 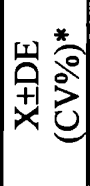 & $\begin{array}{l}= \\
+1 \\
+1 \\
\stackrel{0}{\Xi}\end{array}$ & 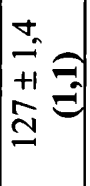 & 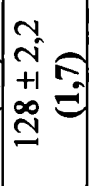 & $\begin{array}{l}\infty \\
-1 \\
+1 \\
\stackrel{d}{d}\end{array}$ & $\begin{array}{l}a \\
i+1 \\
+1 \\
\infty \\
i\end{array}$ & 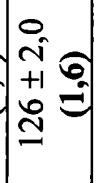 & $\begin{array}{l}\exists \\
+1 \\
+1 \\
\cong\end{array}$ & 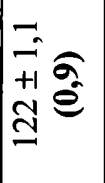 & $\mid \begin{array}{ll}0 & \\
i & 0 \\
+1 & 0 \\
& =\end{array}$ & 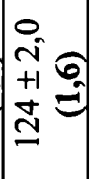 & 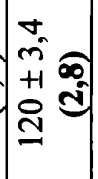 & $\begin{array}{l}\simeq \\
\dddot{+1} \\
\tilde{\Xi}\end{array}$ & 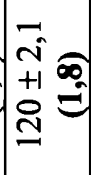 \\
\hline$\frac{+}{2}$ & 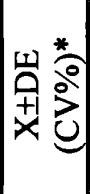 & \begin{tabular}{l}
$\infty$ \\
0 \\
0 \\
+1 \\
0 \\
\multirow{\sim}{*}{} \\
\multirow{\sigma}{*}{}
\end{tabular} & $\left|\begin{array}{ll}0 & \\
0 & 0 \\
+1 & 0 \\
9 & 0 \\
7 & 0\end{array}\right|$ & 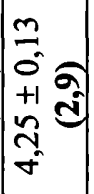 & 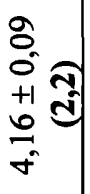 & 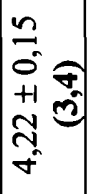 & 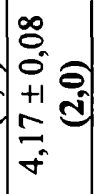 & 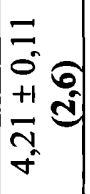 & 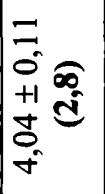 & 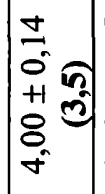 & $\begin{array}{l}n \\
0 \\
+1 \\
m \\
m \\
2 \\
\dot{\sigma}\end{array}$ & $\begin{array}{l}= \\
\overline{0} \\
+1 \\
+1 \\
0 \\
0 \\
0 \\
m\end{array}$ & 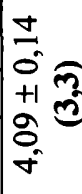 & 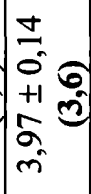 \\
\hline 잉 $\frac{2}{2}$ & 崖泀 & 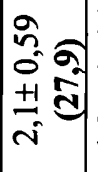 & 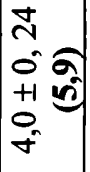 & $\mid \begin{array}{c}\infty \\
m \\
0 \\
+1 \\
n \\
m \\
m \\
m\end{array}$ & $\begin{array}{l}\vec{\sim} \\
\tilde{o}^{-} \\
+1 \\
\infty \\
\infty \\
n \\
n\end{array}$ & $\begin{array}{l}\vec{z} \\
0 \\
+1 \\
\tilde{r}_{n} \\
\dot{m}\end{array}$ & 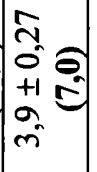 & 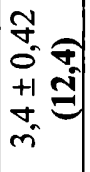 & $\begin{array}{l}\infty \\
N_{1} \\
0 \\
+1 \\
+1 \\
\infty \\
\infty \\
m \\
\infty\end{array}$ & $\mid \begin{array}{l}\hat{n} \\
0 \\
+1 \\
+1 \\
0 \\
m \\
m\end{array}$ & $\begin{array}{l}0 \\
0 \\
0 \\
+1 \\
0 \\
m \\
m\end{array}$ & $\mid \begin{array}{ll}7 & \\
0 & 0 \\
+1 & 0 \\
n & \ddots \\
m & 3\end{array}$ & 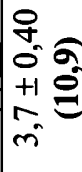 & 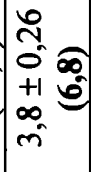 \\
\hline 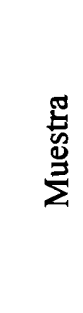 & & $\mathscr{\omega}$ & 巃 & 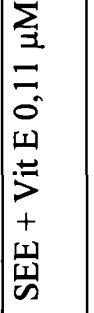 & 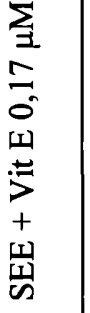 & 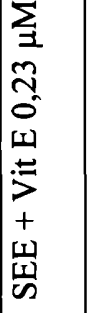 & 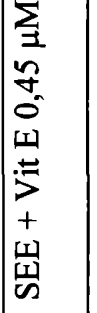 & 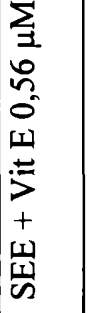 & 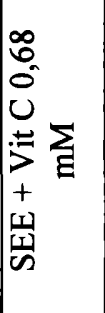 & 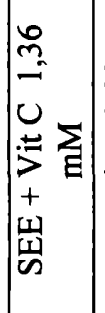 & 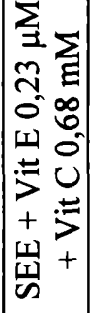 & 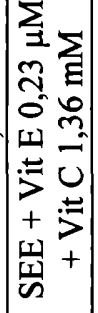 & 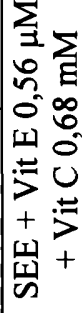 & 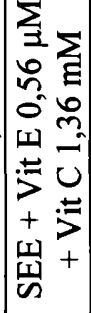 \\
\hline
\end{tabular}




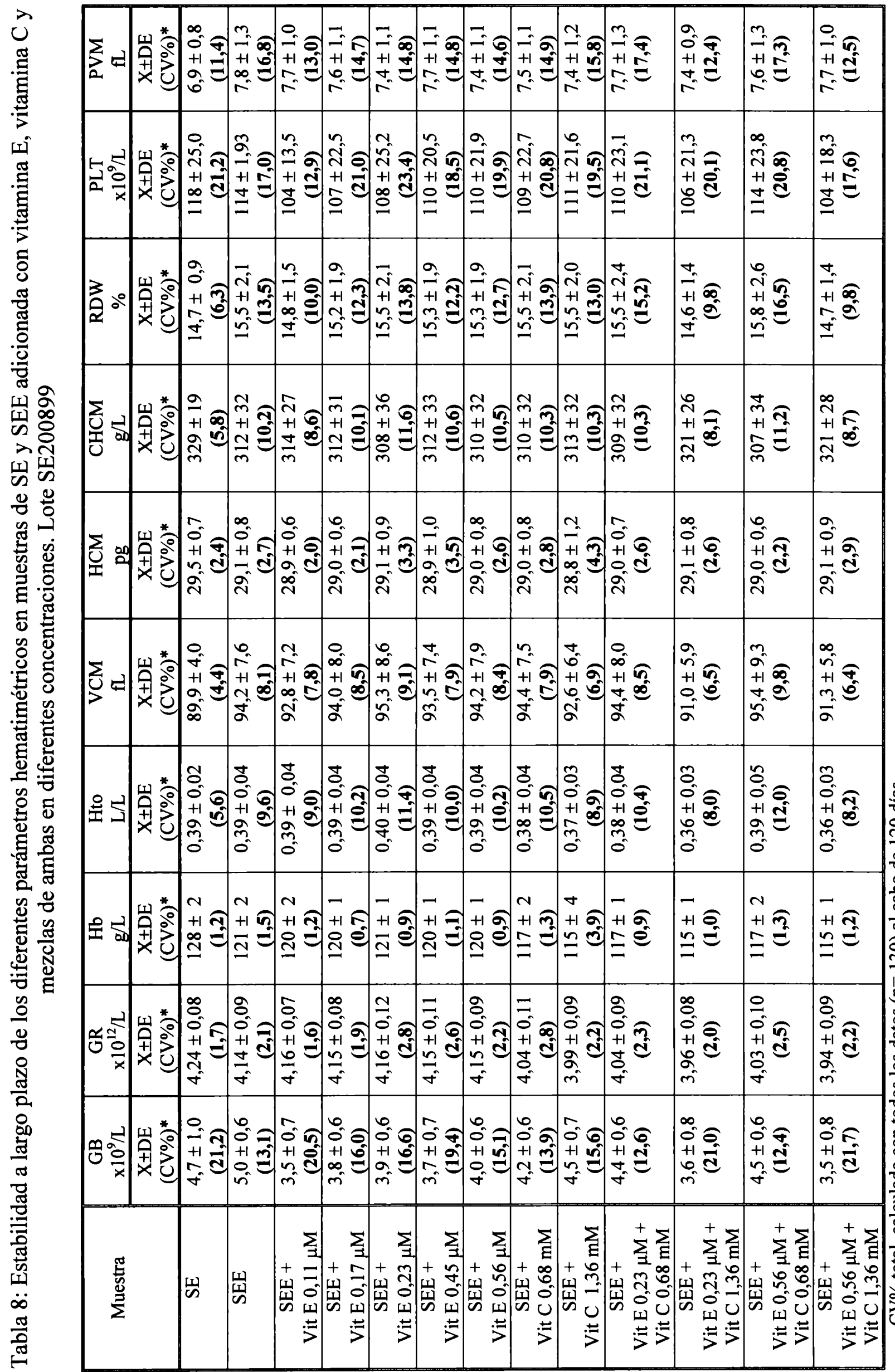




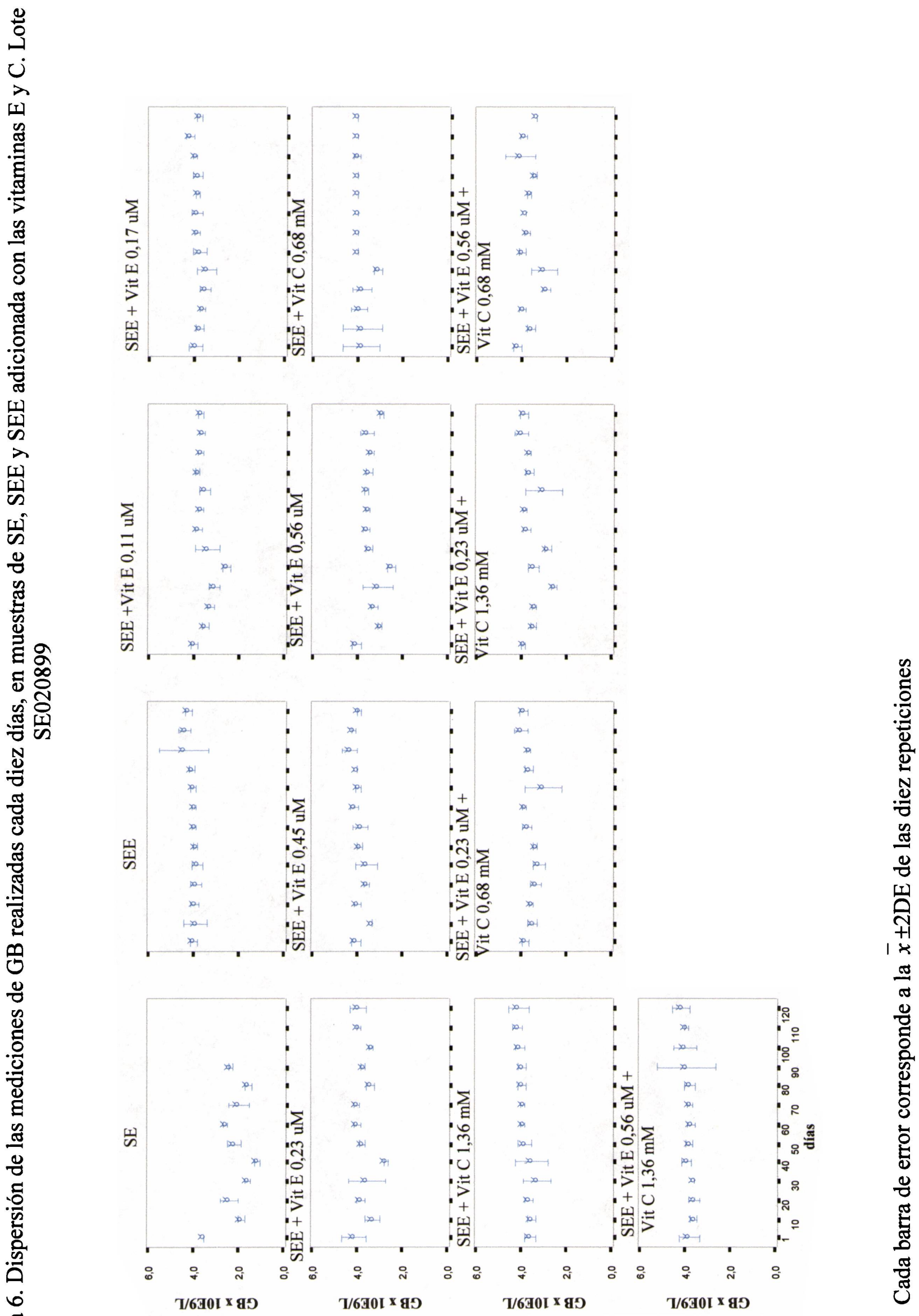




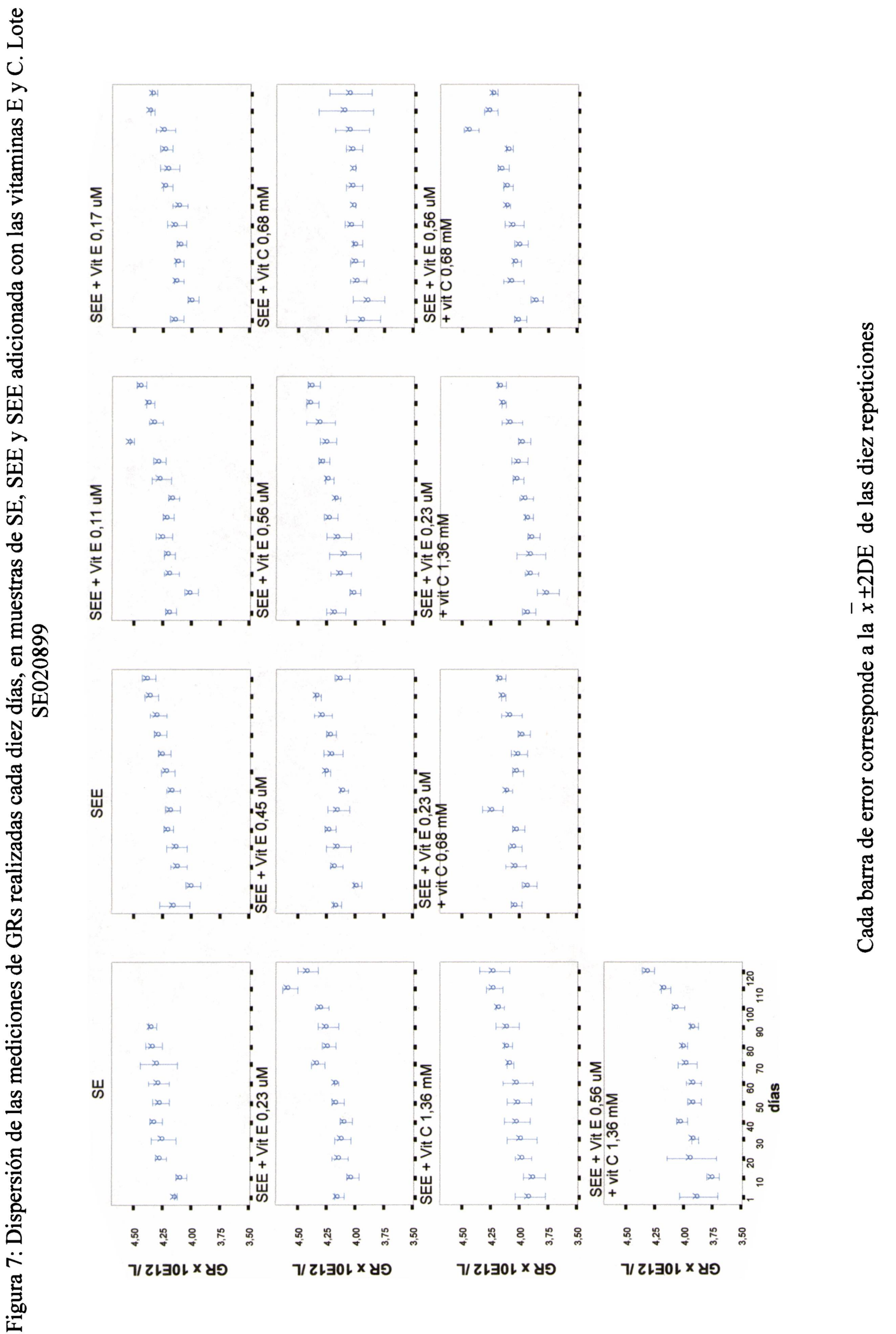


ن

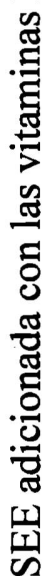

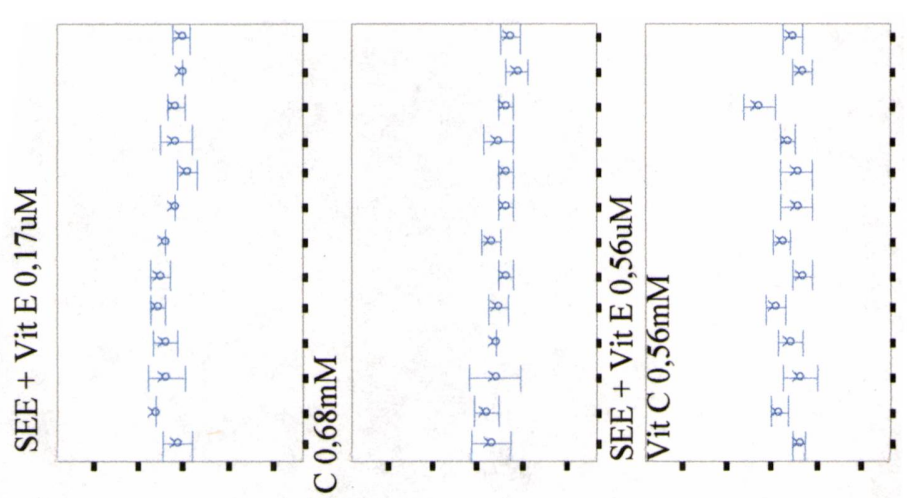

预

뇜

药

뇡

$\Xi$

몽

호

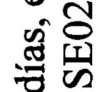

Nㅡㅁ

శ్ర

ปี

莡

圼

8

\&

:

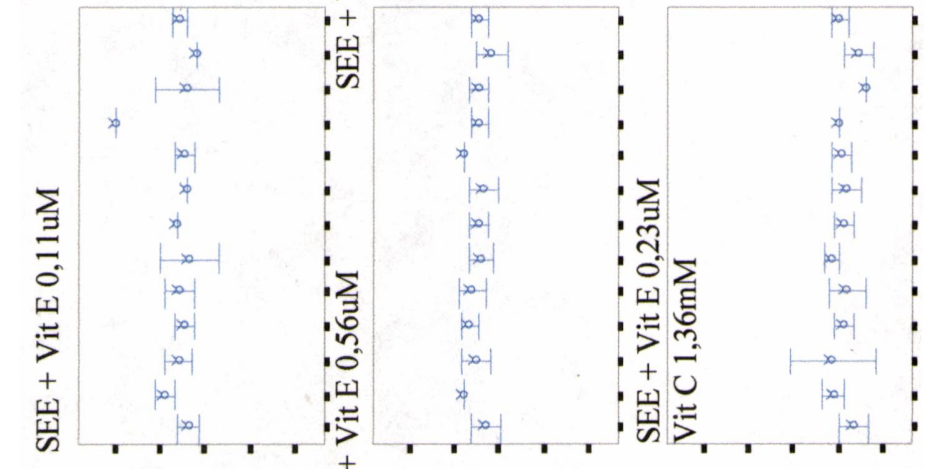

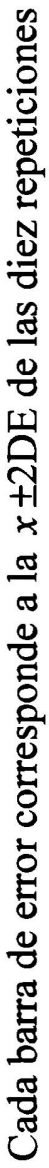

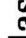

8

:옹

氙

O

$\infty$

莺
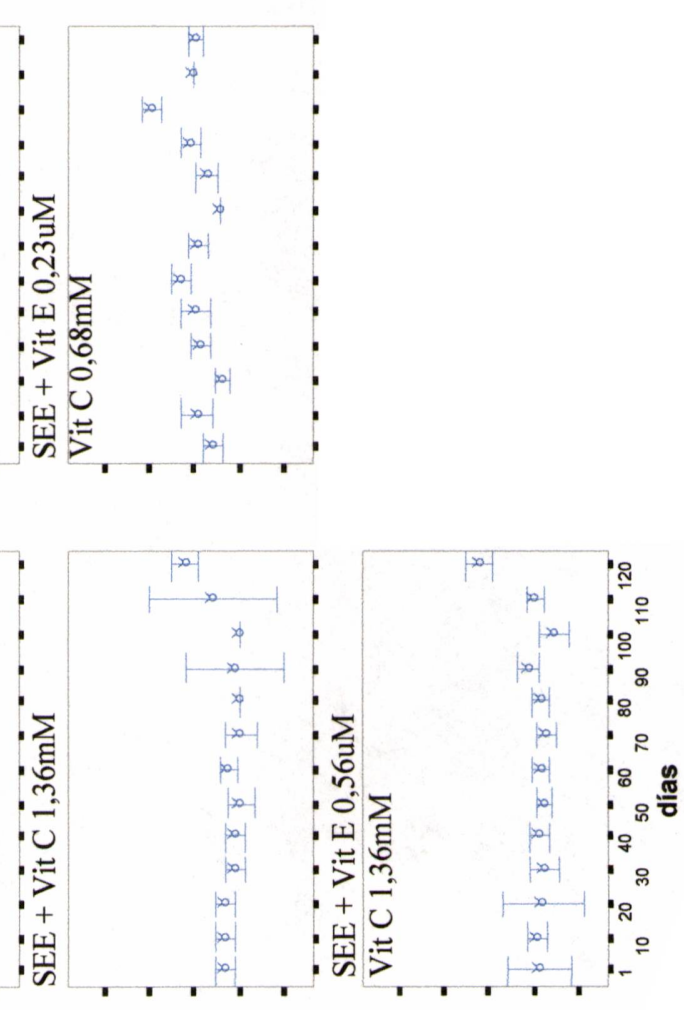

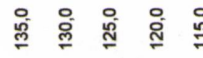

$7 / 6 \mathrm{qH}$

됭

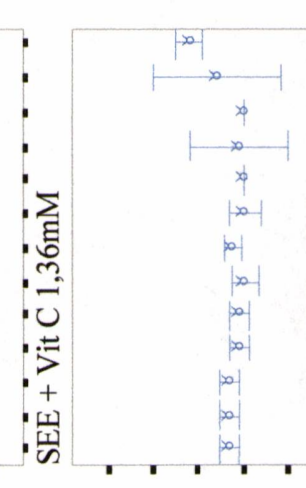

玍

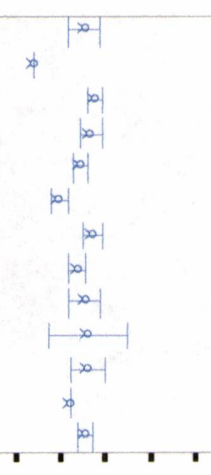

社 


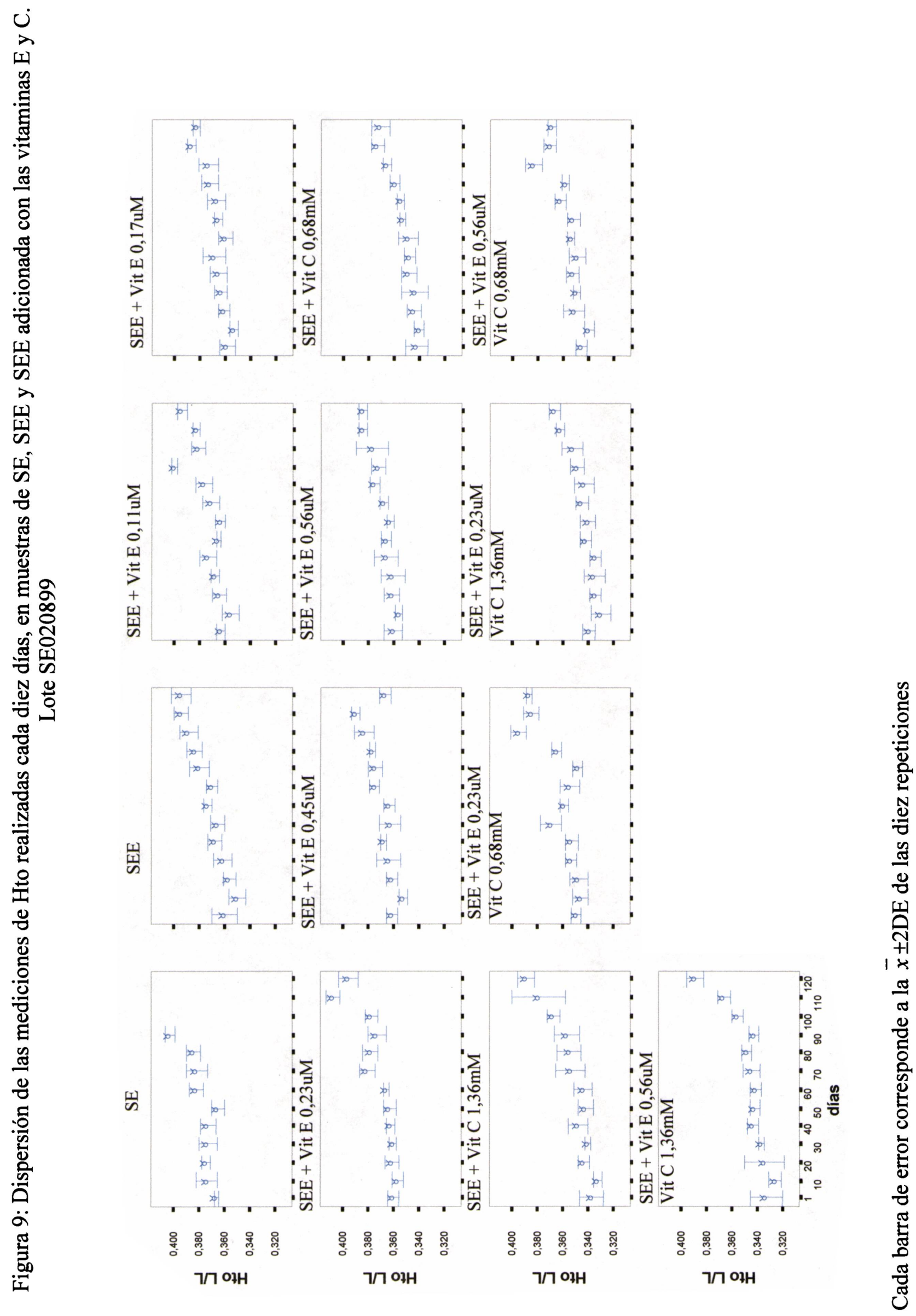




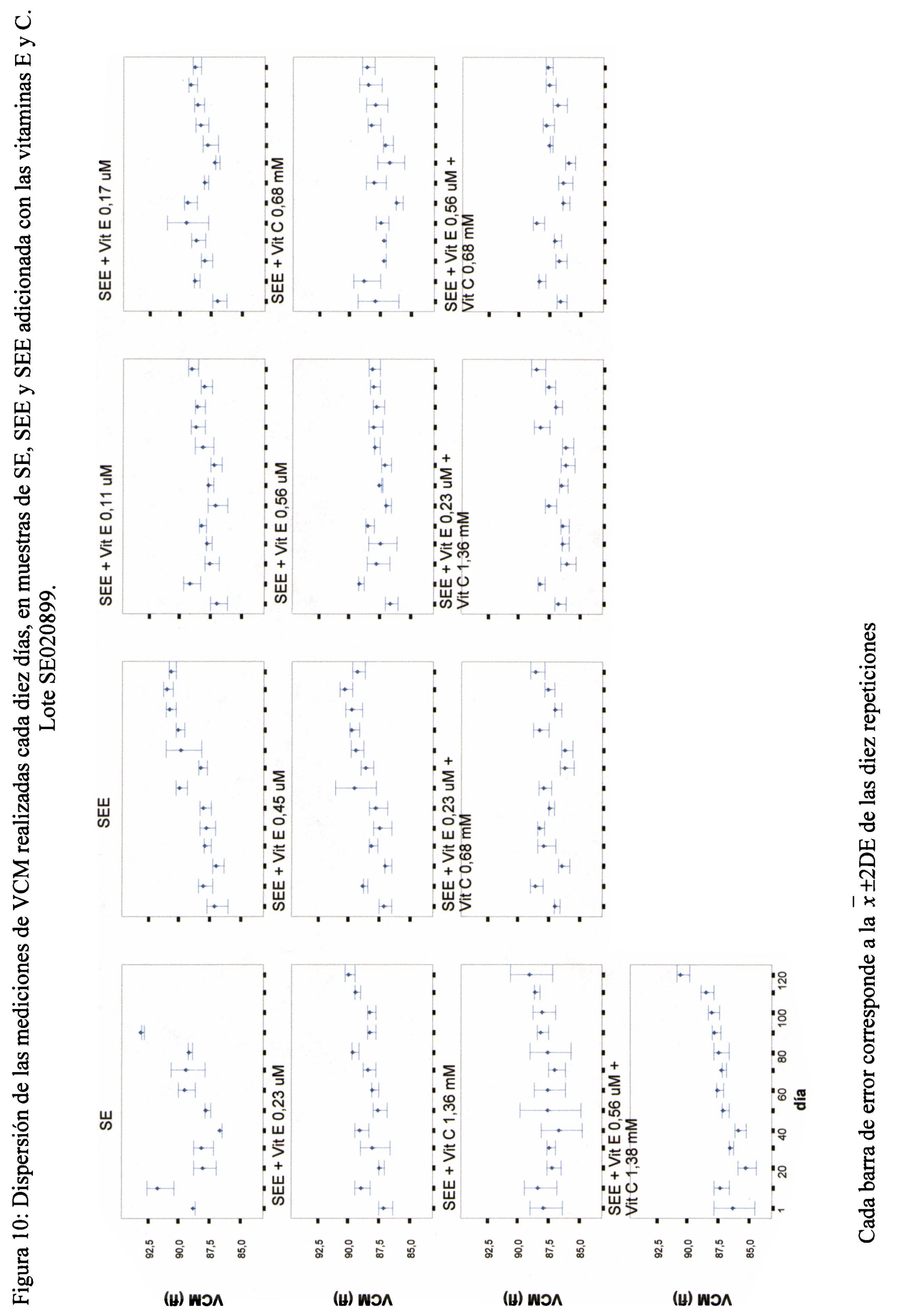




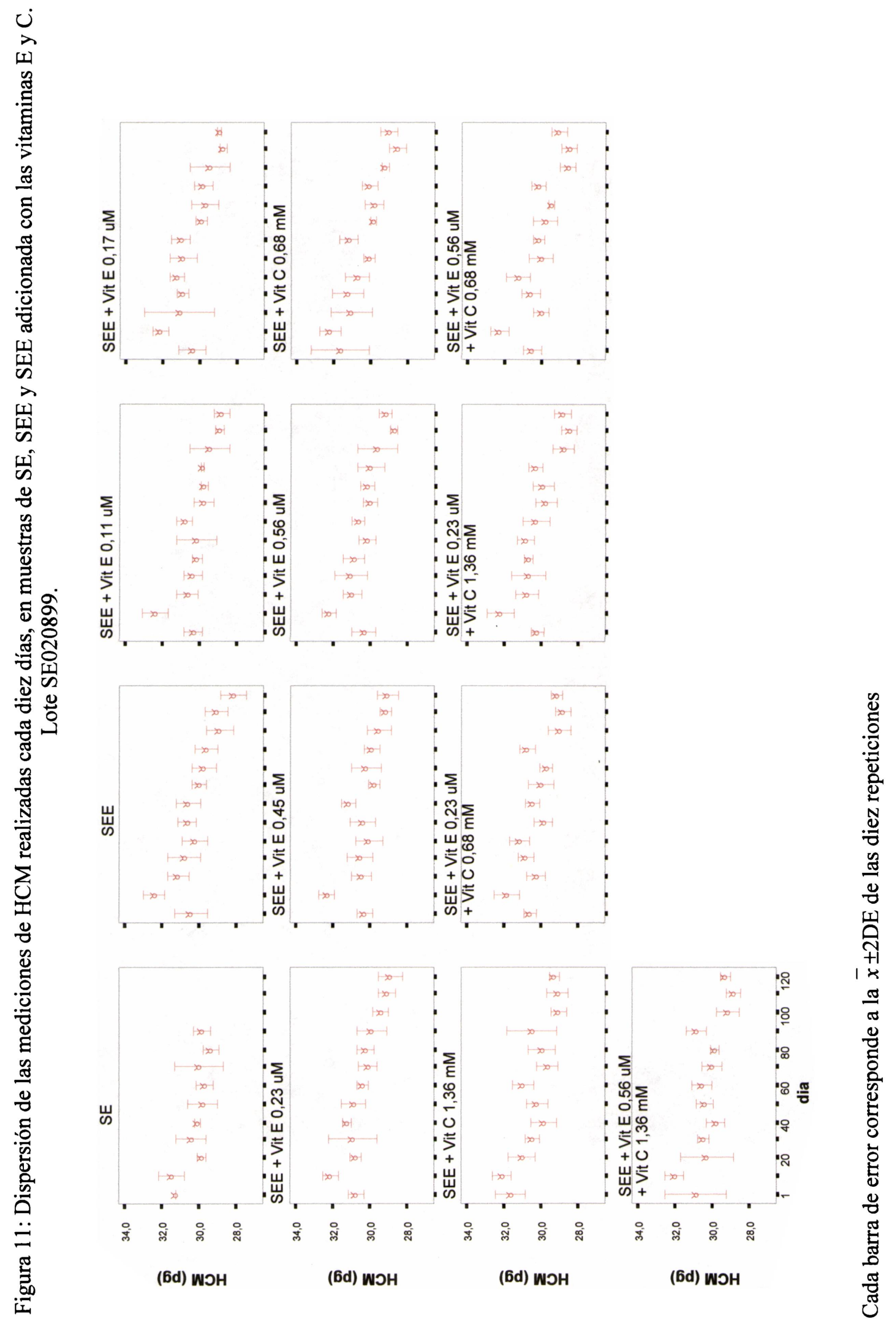



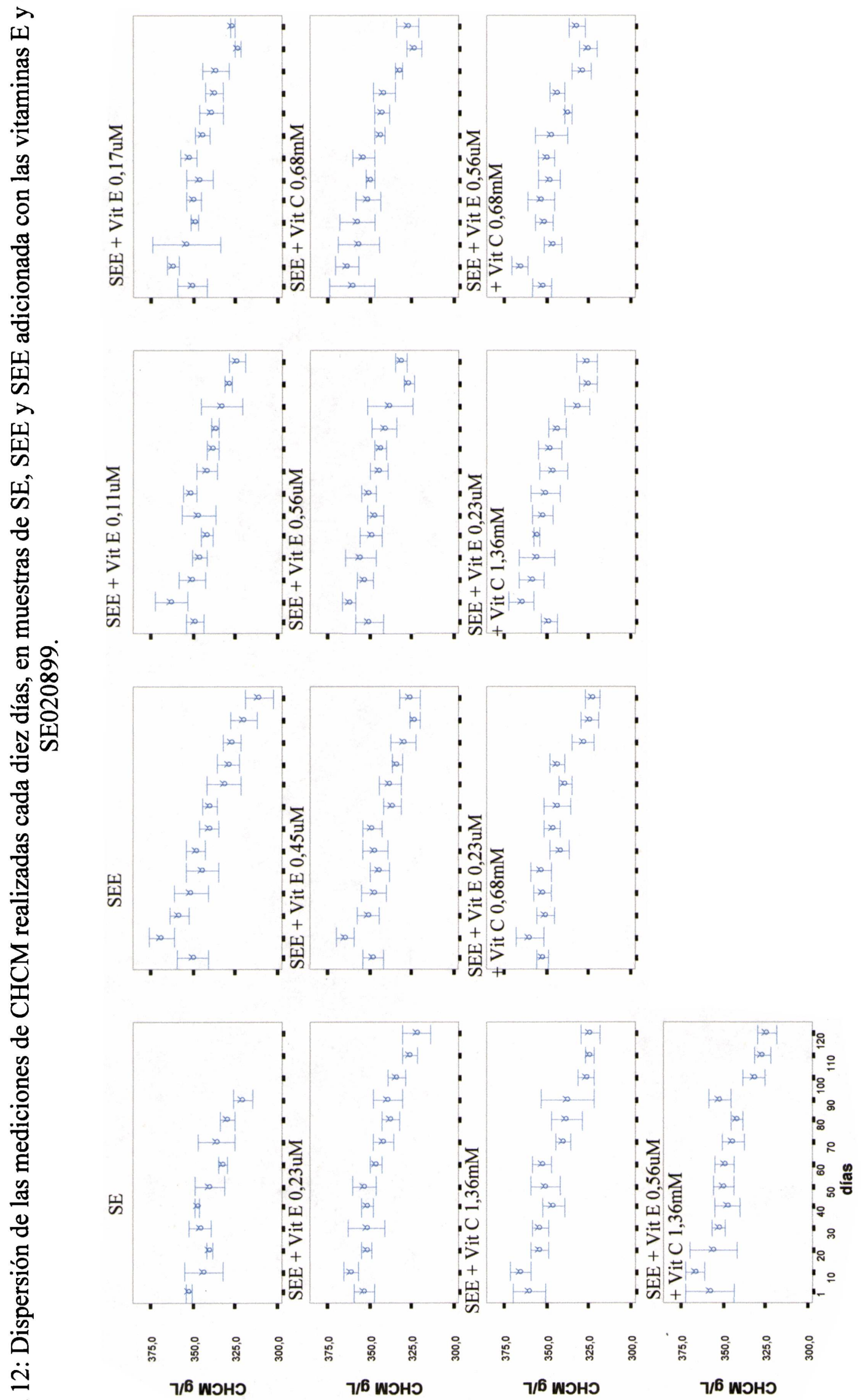


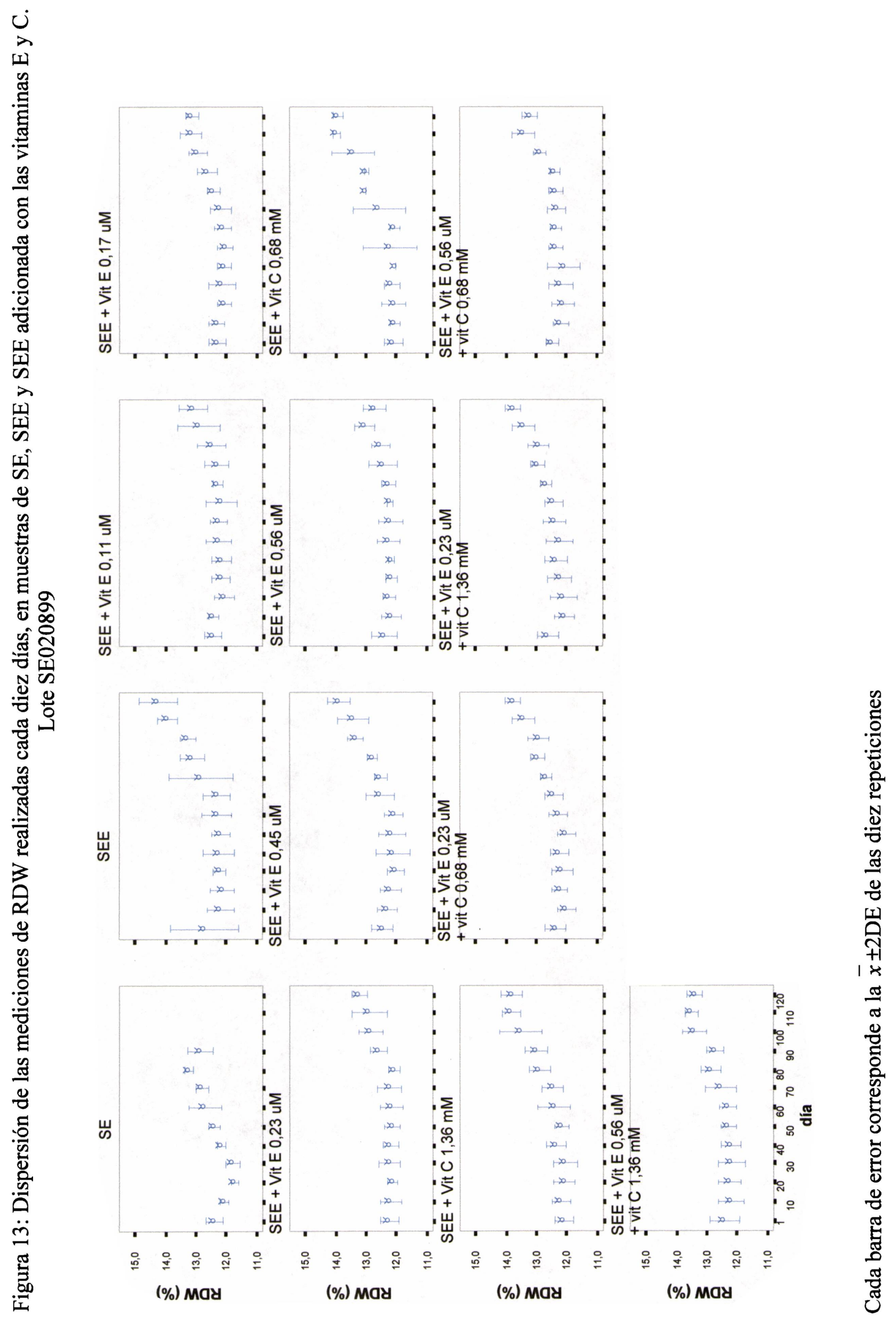




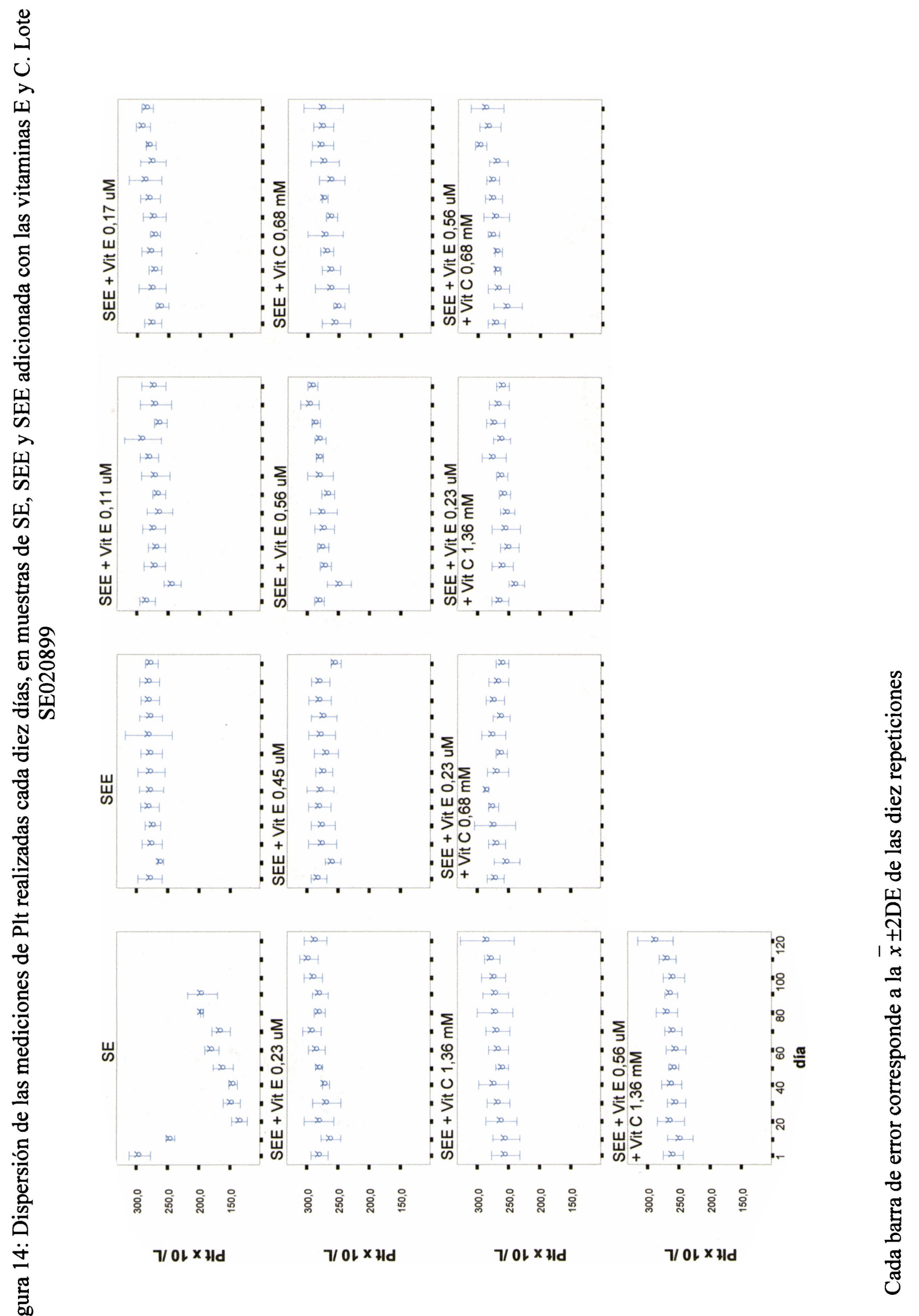



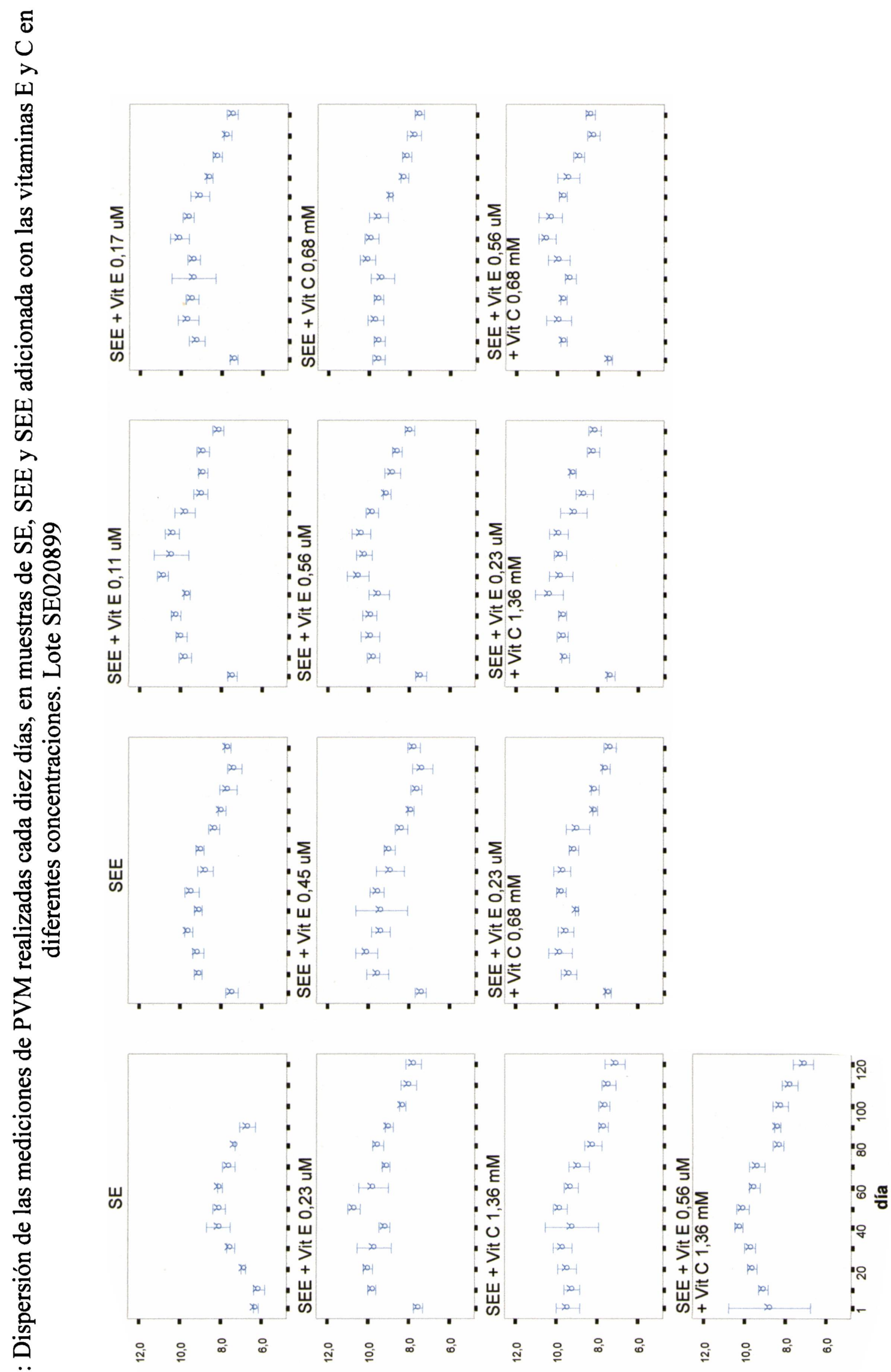

$\ddot{n}$

茀

$$
\text { (1) wnd }
$$

(If) wnd

(II) w/d

(II) wad

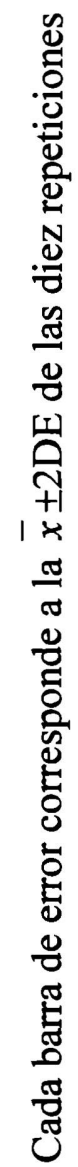




\subsubsection{Efecto del momento de adición del antioxidante}

Con la finalidad de determinar si la estabilización de las membranas plasmáticas celulares tiene alguna influencia en la acción de la vitamina $\mathrm{E}$ o la vitamina $\mathrm{C}$, en el lote SE120598, se adicionaron las vitaminas antes y después de la estabilización. La Tabla 10 muestra los valores de CV\% totales, obtenidos después de 100 días. Al hacer el análisis estadístico se encontró que existían diferencias significativas $(p<0,01)$ entre las muestras estabilizadas antes o después del agregado de la vitamina E para todos los parámetros, menos el Hto y los índices HCM y CHCM, mientras que para la vitamina $\mathrm{C}$ se encontraron diferencias significativas en todos los parámetros menos los GB ( $p>0,05)$. Se buscó comparar entonces cuál de los dos tratamientos permitía mantener los valores promedio dentro del intervalo $\bar{x}_{(\text {dia 1) }} \pm 2 \mathrm{DE}$, por un período de tiempo más prolongado. En la Figura 16 se muestra la dispersión de los datos para la vitamina E, comparando ambos tratamientos. En la Tabla 11 se muestran los datos obtenidos para la vitamina $\mathrm{C}$. Al examinar estos datos, si bien la tolerancia máxima no era diferente, se pudo observar que el agregado de las vitaminas después de la estabilización producía una menor dispersión de los datos, razón por la cual se optó por su agregado posterior a la estabilización. 


\begin{tabular}{|c|c|c|c|c|c|c|c|c|}
\hline$\sum_{a}$ & 崖苍 & 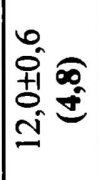 & 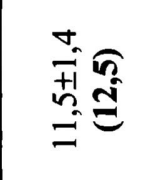 & 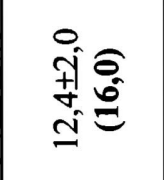 & $\begin{array}{l}\infty \\
\stackrel{\infty}{+}= \\
=\end{array}$ & 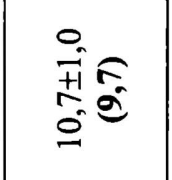 & 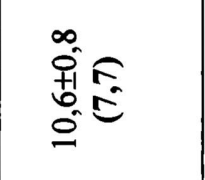 & 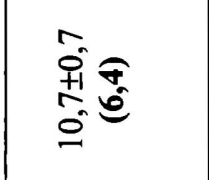 \\
\hline 봉옹 & 㠔总 & 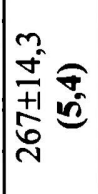 & 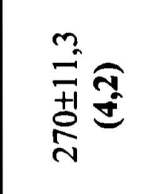 & 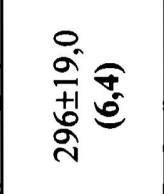 & 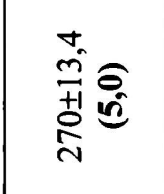 & 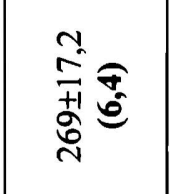 & 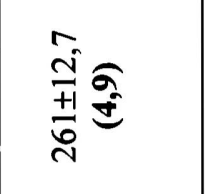 & 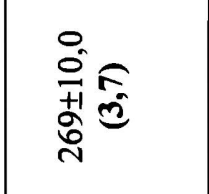 \\
\hline 客。” & 崖芳 & $\begin{array}{l}0 \\
0 \\
0 \\
0 \\
0 \\
0 \\
0\end{array}$ & 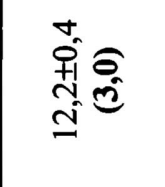 & 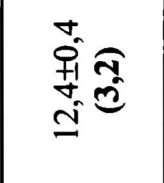 & 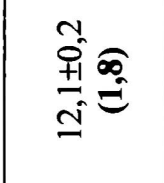 & 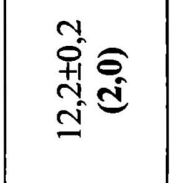 & 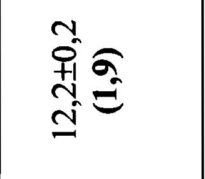 & 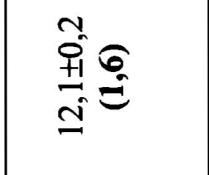 \\
\hline 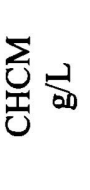 & 崖芳总 & $\begin{array}{ll} \pm \\
+1 \\
\stackrel{n}{2} \\
\stackrel{2}{m}\end{array}$ & $\begin{array}{l}\infty \\
+1 \\
\infty \\
m \\
\mathbb{N}\end{array}$ & $\begin{array}{l}m \\
\frac{m}{m} \underset{m}{m}\end{array}$ & $\begin{array}{l}n \\
+10 \\
\stackrel{0}{n}=\end{array}$ & $\begin{array}{l}n \\
+1 \\
\frac{n}{m}\end{array}$ & $\begin{array}{l}+1 \\
\stackrel{\infty}{m}=\end{array}$ & $\begin{array}{l}n \\
+10 \\
\frac{6}{m}=\end{array}$ \\
\hline$\sum_{\substack{1 \\
0}}$ & 留总 & 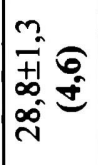 & 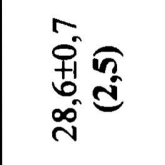 & 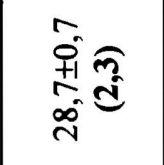 & 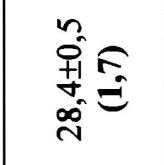 & 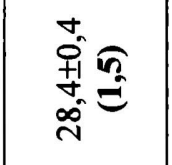 & 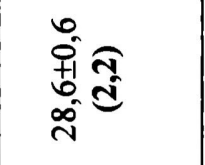 & 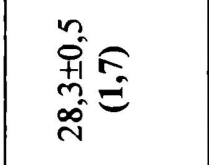 \\
\hline$\sum_{j}$ & 崖芳总 & 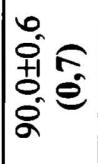 & $\begin{array}{c}\hat{\sigma} \\
\text { +1 } \\
\frac{1}{8}\end{array}$ & $\frac{0}{+1} \underset{a}{a}=$ & $\begin{array}{l}n \\
0 \\
+1 \\
a \\
2 \\
\infty\end{array}$ & 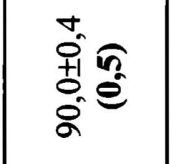 & 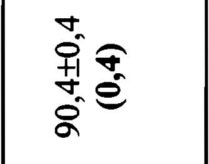 & $\begin{array}{l}n \\
0 \\
+1 \\
\infty \\
\infty \\
\infty\end{array}$ \\
\hline 总吉 & 崖芳 & $\begin{array}{l}0 \\
8 \\
0 \\
0 \\
+1 \\
\infty \\
m \\
0 \\
0\end{array}$ & $\begin{array}{l}\overline{0} \\
0 \\
+1 \\
a \\
\text { ले } \\
0 \\
0\end{array}$ & $\begin{array}{l}\infty \\
8 \\
0 \\
0 \\
+1 \\
0 \\
\text { ì } \\
0 \\
0\end{array}$ & $\begin{array}{l}\infty \\
8 \\
0 \\
+ \\
+1 \\
2 \\
\text { ì } \\
0 \\
0\end{array}$ & $\begin{array}{l}\tilde{o} \\
\delta \\
0 \\
+1 \\
o \\
\dot{q} \\
0\end{array}$ & $\begin{array}{l}\infty \\
8 \\
0 \\
+ \\
+1 \\
\tilde{m} \\
0 \\
0\end{array}$ & 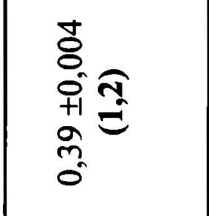 \\
\hline 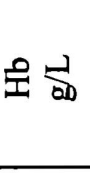 & 岑荠递 & 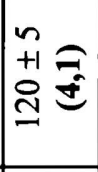 & $\stackrel{m}{+1} \underset{\underline{d}}{\stackrel{c}{c}}$ & $\begin{array}{l}m \\
+1 \\
\mathbb{I} \\
\mathbb{I}\end{array}$ & 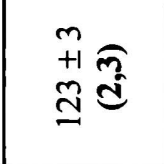 & $\begin{array}{l}N= \\
+1 \\
\cong\end{array}$ & 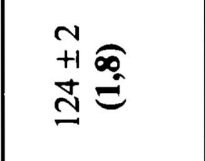 & $\stackrel{N}{+1} \underset{\Xi}{\stackrel{\sigma}{a}}$ \\
\hline$\frac{2}{0} \frac{2}{0}$ & 峷总 & 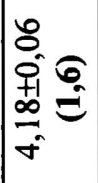 & 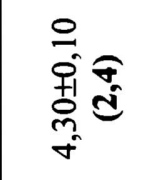 & 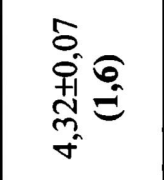 & 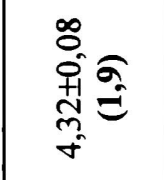 & 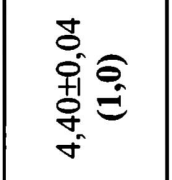 & 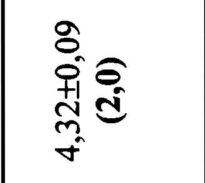 & 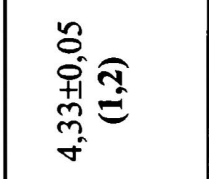 \\
\hline 윙 $\frac{2}{\circ}$ & 四莽总 & $\begin{array}{ll}m & 0 \\
0 & 0 \\
+1 & 0 \\
n & 0\end{array}$ & 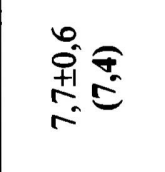 & $\begin{array}{l}0 \\
0 \\
0 \\
0 \\
+\infty\end{array}$ & 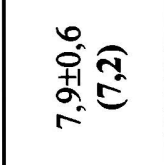 & 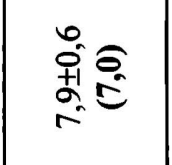 & $\begin{array}{l}0 \\
0 \\
0 \\
01\end{array}$ & $\begin{array}{l}0 \\
0 \\
+1 \\
\vdots \\
2\end{array}$ \\
\hline $\begin{array}{l}\stackrel{\mathbb{E}}{\mathrm{E}} \\
\stackrel{3}{\Sigma}\end{array}$ & & 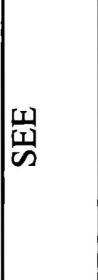 & 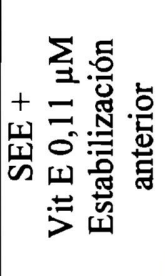 & 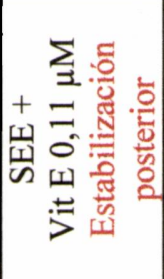 & 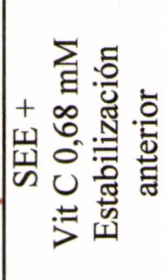 & 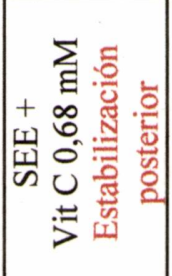 & 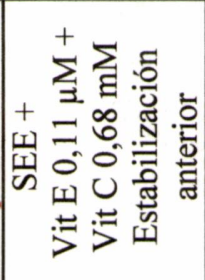 & 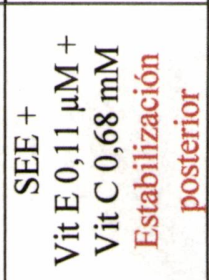 \\
\hline
\end{tabular}


Figura 16. Dispersión de las mediciones cada diez días de muestras de SEE adicionada con vitamina $\mathrm{E} 0,11 \mu \mathrm{M}$ antes y después de la estabilización. Lote SE120598

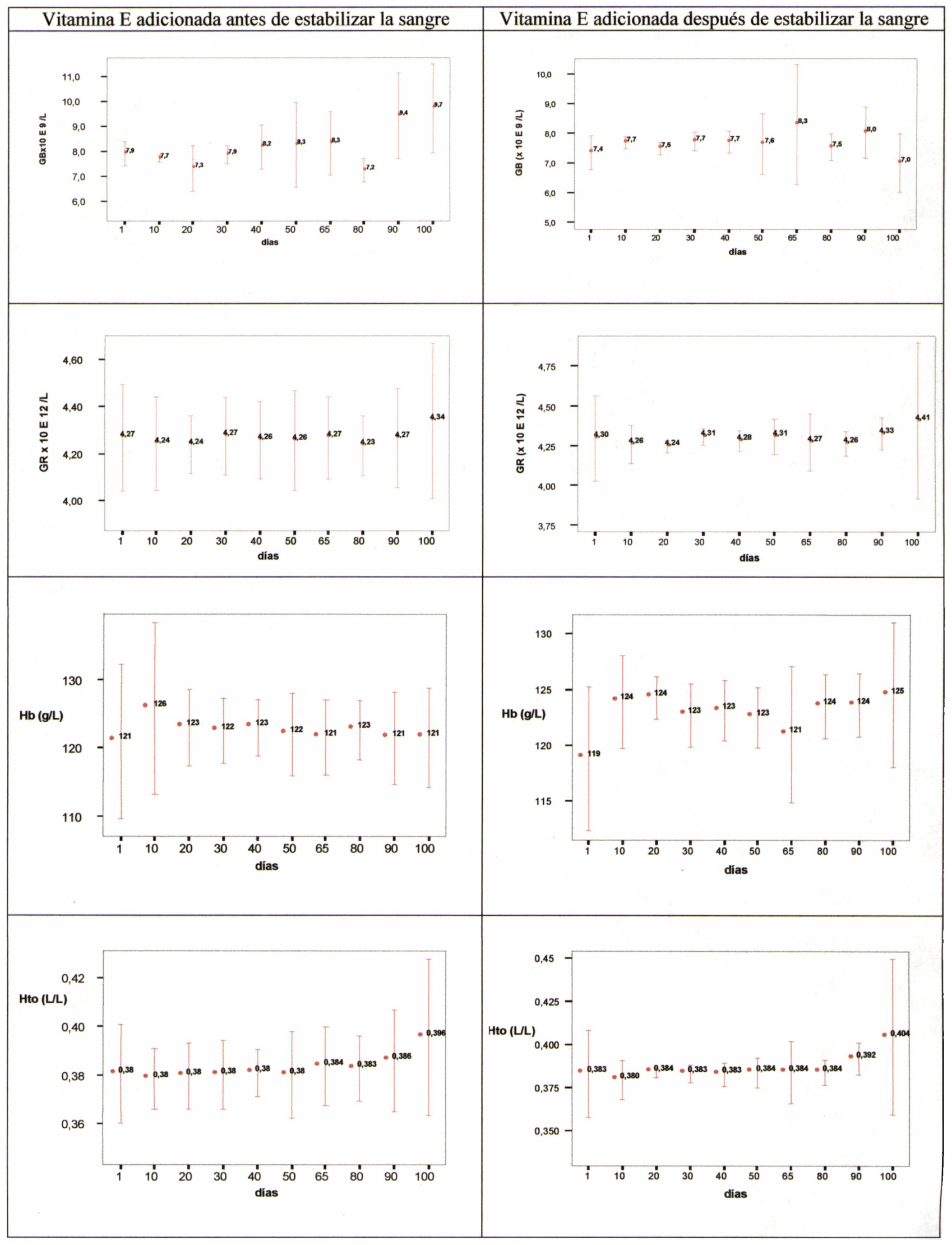




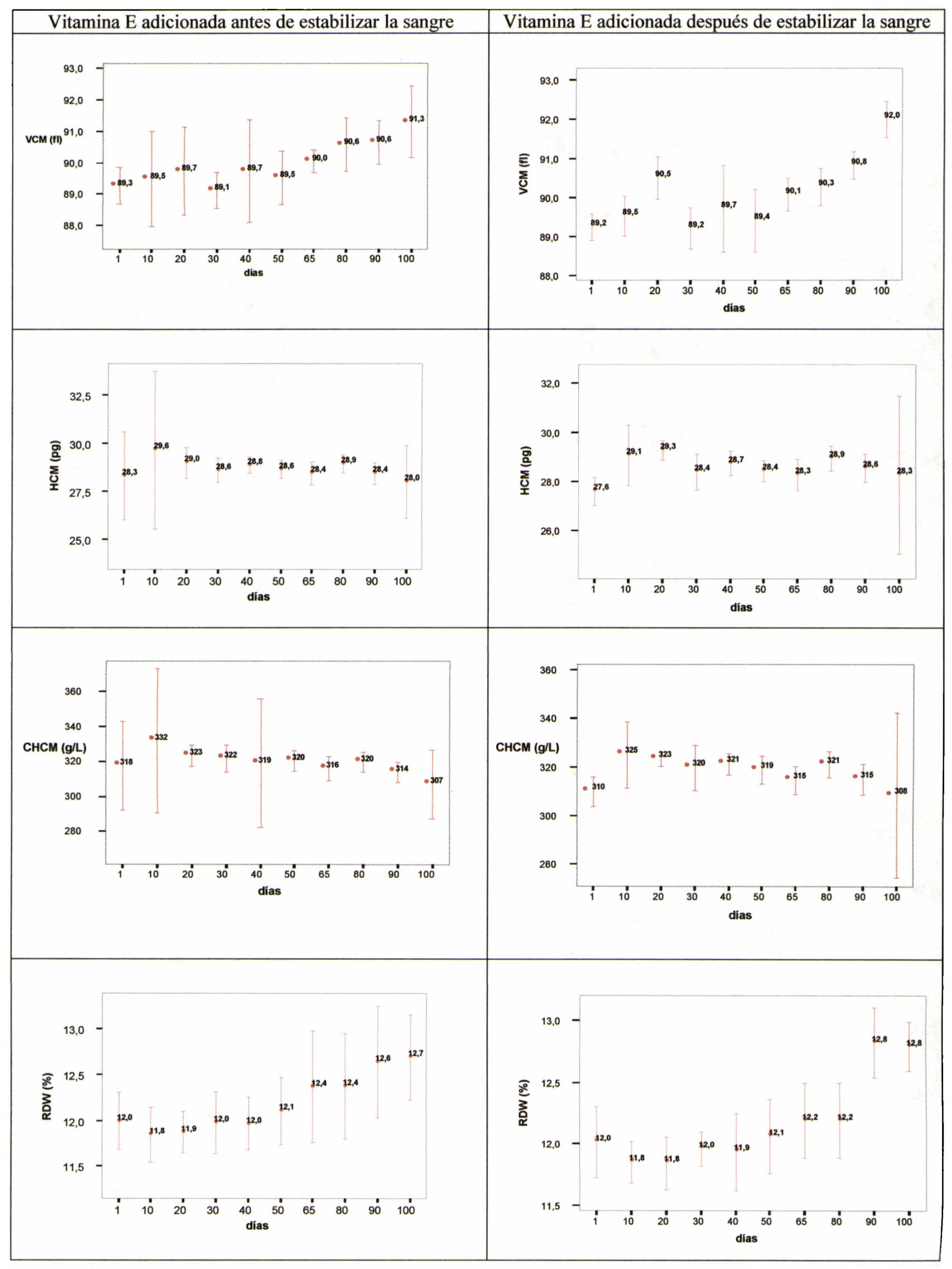

91 


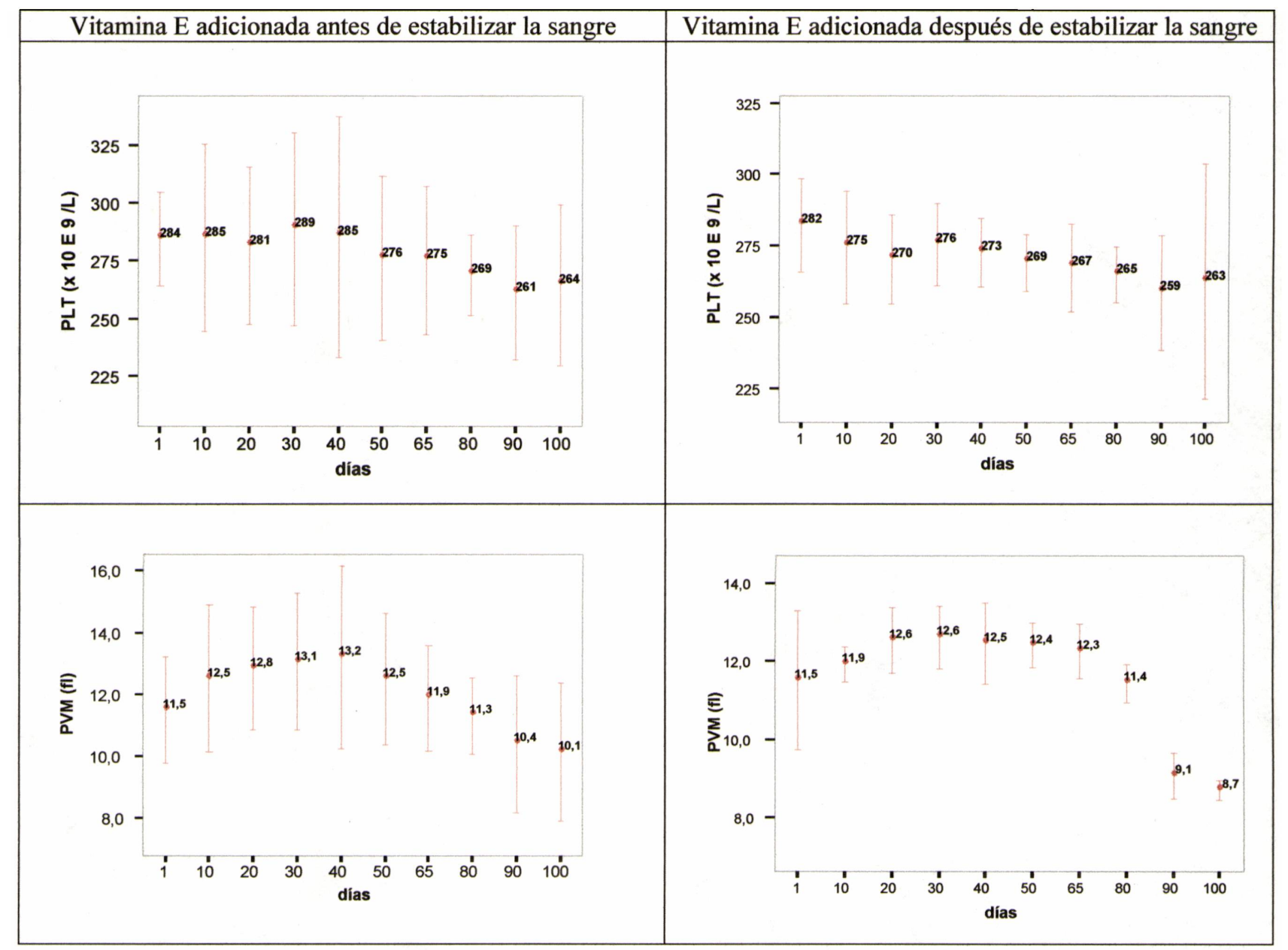




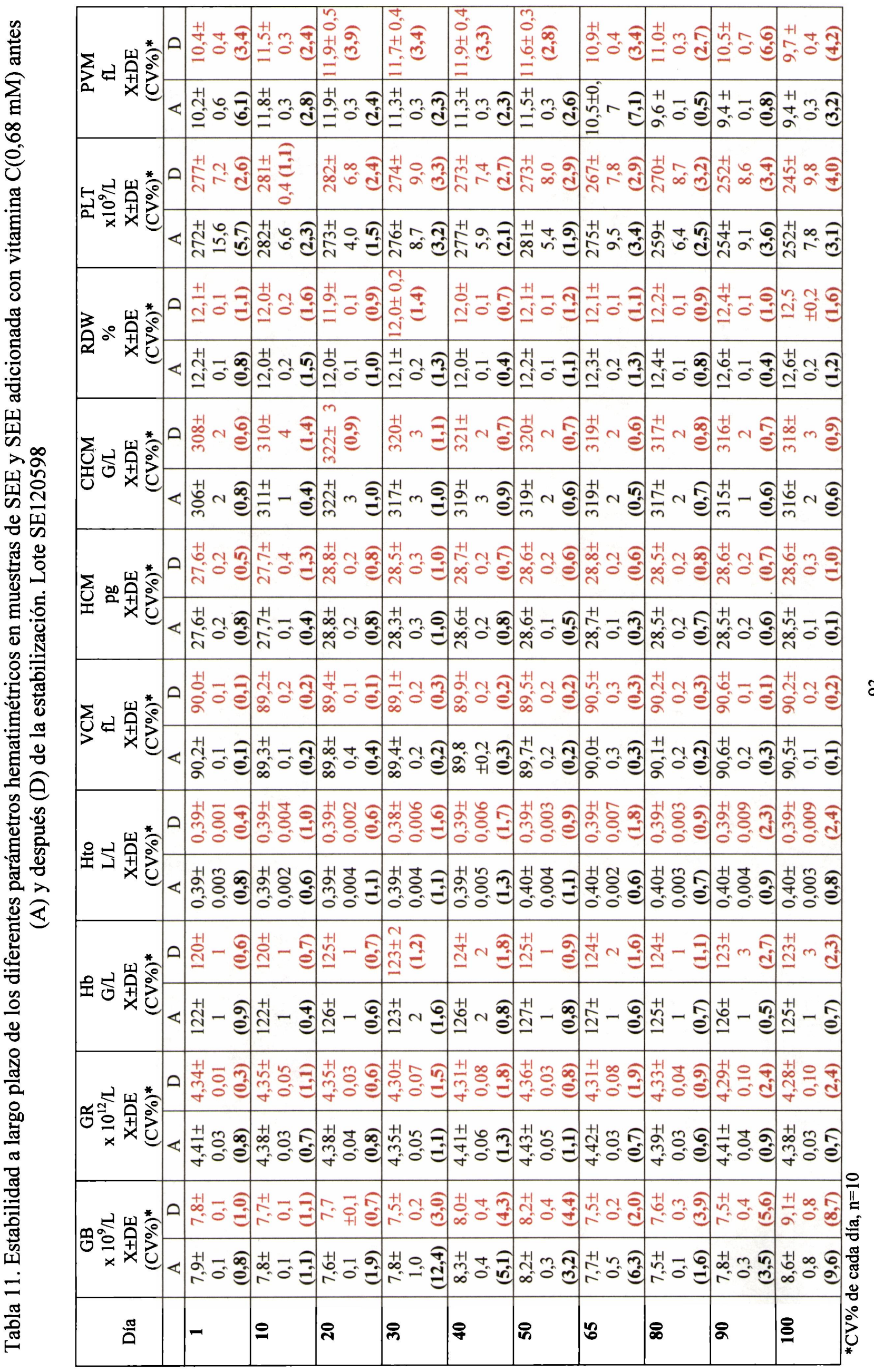




\section{Estudio de la morfología celular}

\subsection{Material y métodos}

Para observar la variación en la forma, tamaño y cromía de los GR, así como en la morfología de los GB y de las plaquetas, se realizaron coloraciones siguiendo la técnica de May Grünwald-Giemsa, de muestras de SE, SEE y SEE adicionada con los antioxidantes.

Los extendidos fueron realizados a diferentes tiempos de almacenamiento $(1,10$, $30,60,90$ y 120 días).

Técnica de May Grunwald-Giemsa:

1. Cubrir el frotis de sangre seco con solución de May Grünwald: (eosinato de azul de metileno en metanol). Dejar 5 minutos.

2. Agregar buffer fosfato isoosmótico: solución de $\mathrm{NaH}_{2} \mathrm{PO}_{4} \cdot 2 \mathrm{H}_{2} \mathrm{O}$ (150 $\mathrm{mmol} / \mathrm{L})$ y $\mathrm{Na}_{2} \mathrm{HPO}_{4}(150 \mathrm{mmol} / \mathrm{L})$ ajustada a $\mathrm{pH}$ 7,2-7,4. Dejar 5 minutos y volcar.

3. Cubrir el preparado con solución de Giemsa (azul eosina, diluida 1/10), dejar 20 minutos y lavar con buffer fosfato isoosmótico.

4. Secar al aire.

Los preparados se observaron por microscopía de inmersión (1000X) y fueron fotografiados en un miscroscopio Leitz Labor Lux S con Timer incorporado de sistema fotográfico WINDMPS 48.

\subsection{Resultados}

Las microfotografias muestran la variación de la morfología de las células, principalmente en relación a los GR, en extendidos de una muestra perteneciente al lote SE250200 (Figura 17). Se muestran extendidos realizados a los días 1, 30, 60 y 120 de 
almacenamiento, de muestras de SE, SEE y SEE adicionada con vitamina E $0,23 \mu \mathrm{M}$; vitamina $\mathrm{C} 0,68 \mathrm{mM}$ y mezcla de ambas en iguales concentraciones. Se puede observar, por ejemplo, una mayor proporción de GR crenados en la muestra de SE al compararla con las muestras de los otros tratamientos. Asímismo, se puede distinguir el mejor mantenimiento de la forma de los GR en las muestras adicionadas con las vitaminas en relación a la SEE. También se observan diferencias en los GB a medida que transcurre el tiempo de almacenamiento; éstos mantienen sus núcleos y sus membranas en mejores condiciones en las muestras de SEE adicionada con las vitaminas. Las flechas señalan los GR fantasmas que aparecen en las muestras de SE y SEE. Este dato es de interés, teniendo en cuenta que numéricamente, a pesar de la aparición de estos fantasmas, el recuento de GR no se vio afectado, ya que los mismos son reconocidos por los contadores y por lo tanto analizados como una célula más. La aparición de fantasmas está relacionada directamente con la liberación de $\mathrm{Hb}$ al medio extracelular.

En la Figura 18 se muestra también el ancho de la distribución del tamaño de GR, obtenido con el contador Coulter JT, simultáneamente con la coloración del extendido. 


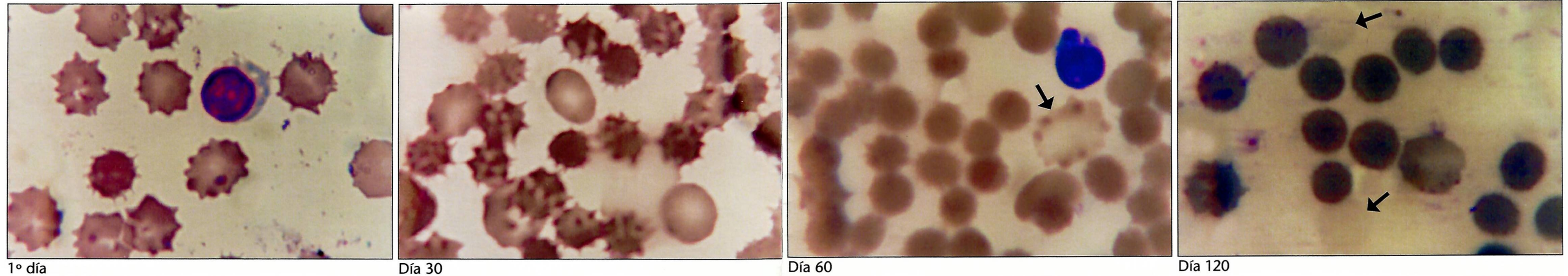

SEE

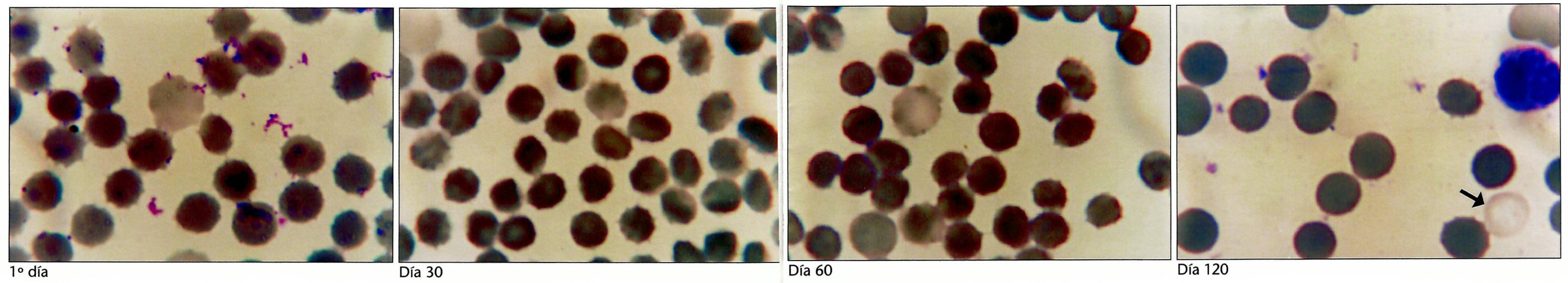

SEE + Vitamina E $0,23 \mu \mathrm{M}$

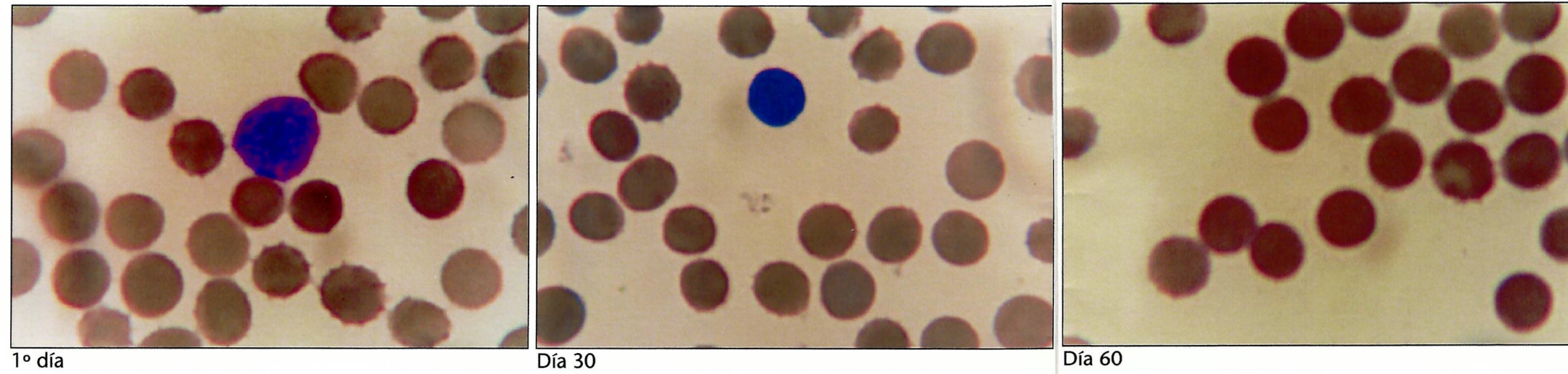

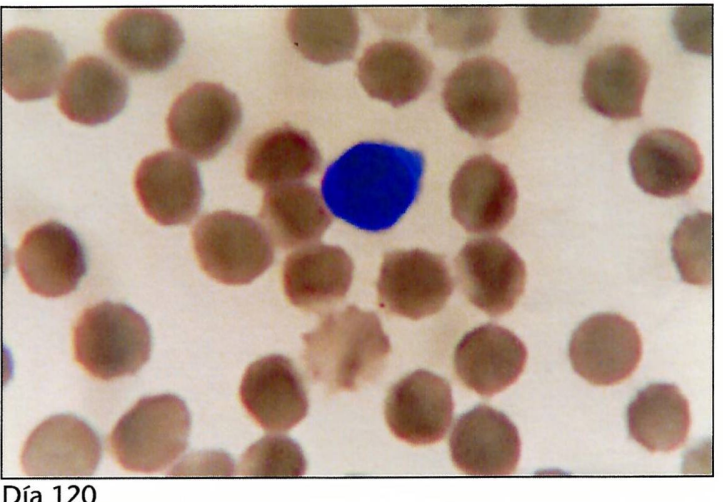
Día 120

SEE + Vitamina C $0,68 \mathrm{mM}$

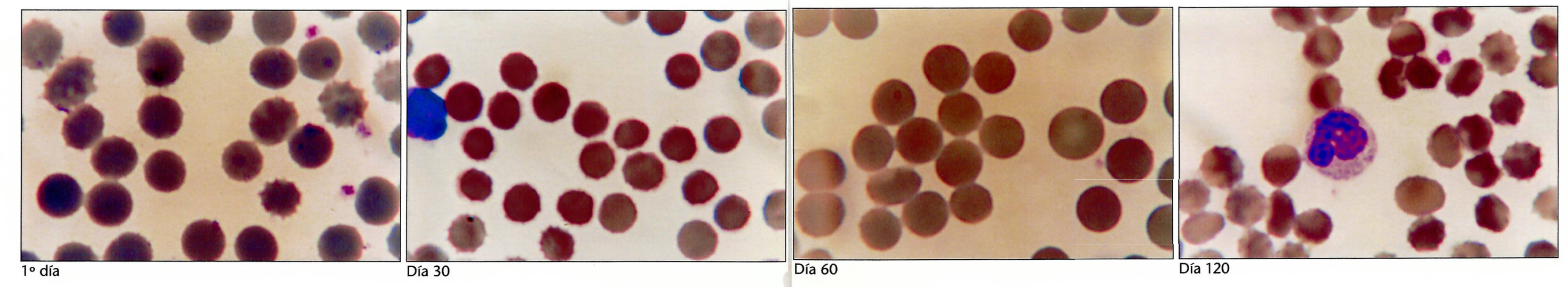

SEE + Vitamina E $0,23 \mu \mathrm{M}$

+ Vitamina C

$0,68 \mathrm{mM}$

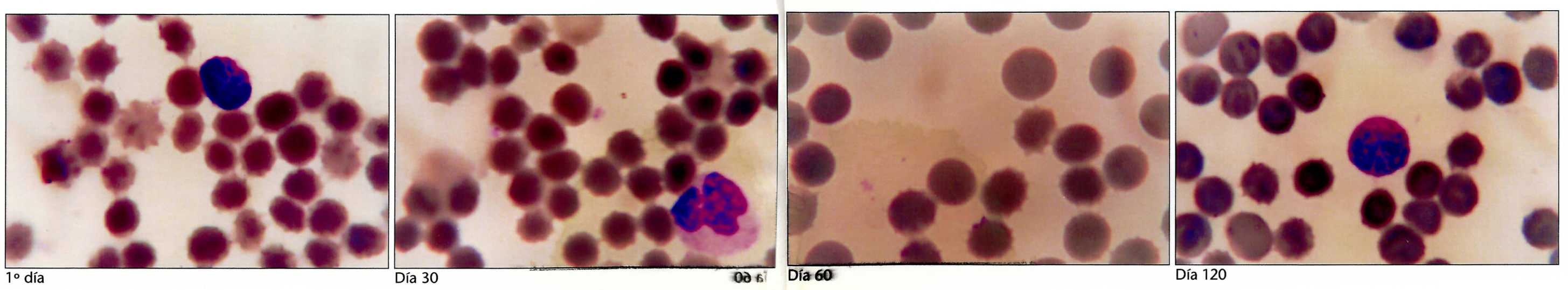


Figura 18. Estabilidad a largo plazo de RDW, en muestras de SE, SEE y SEE adicionadas con las vitaminas E y C. Lote SE250200.
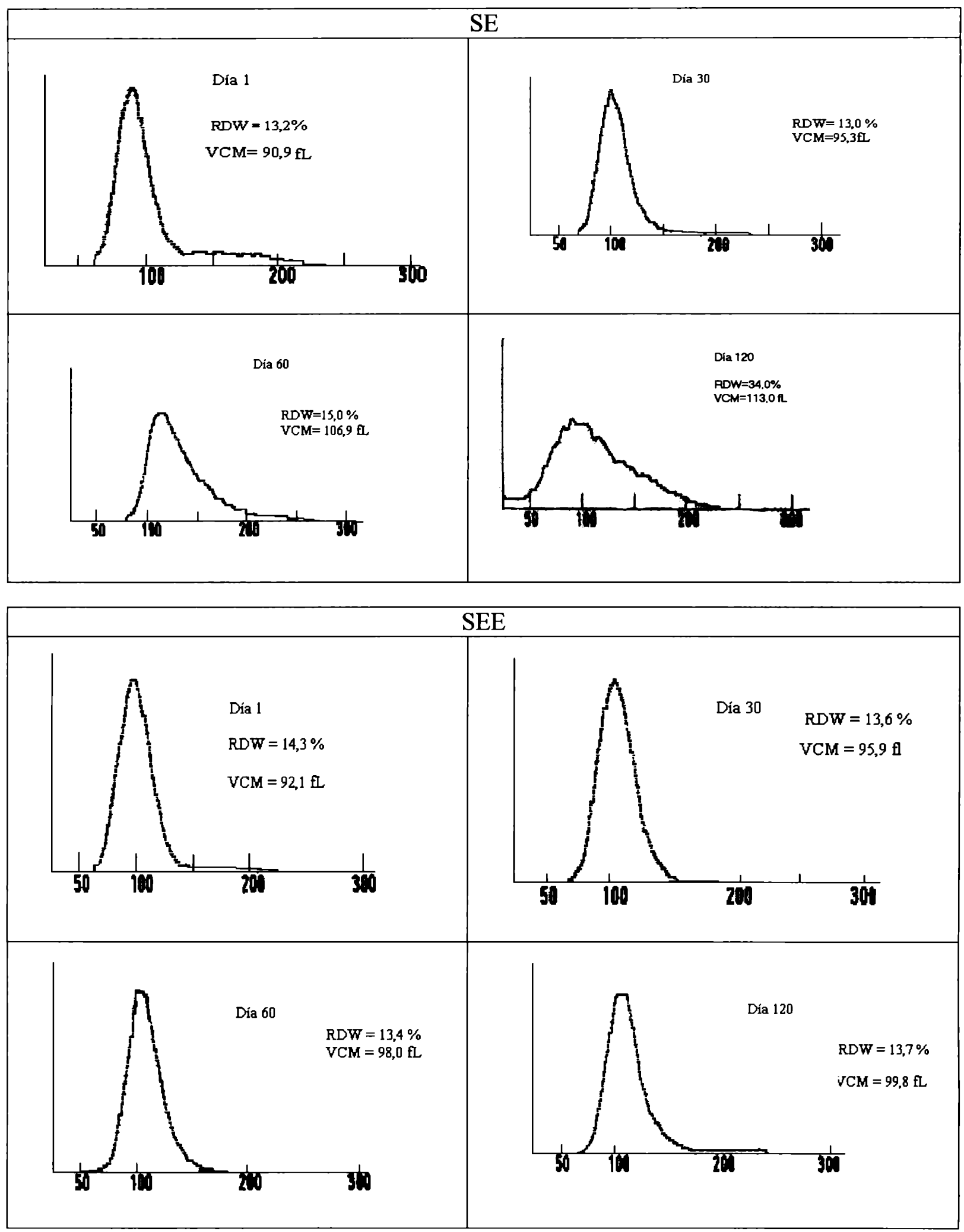

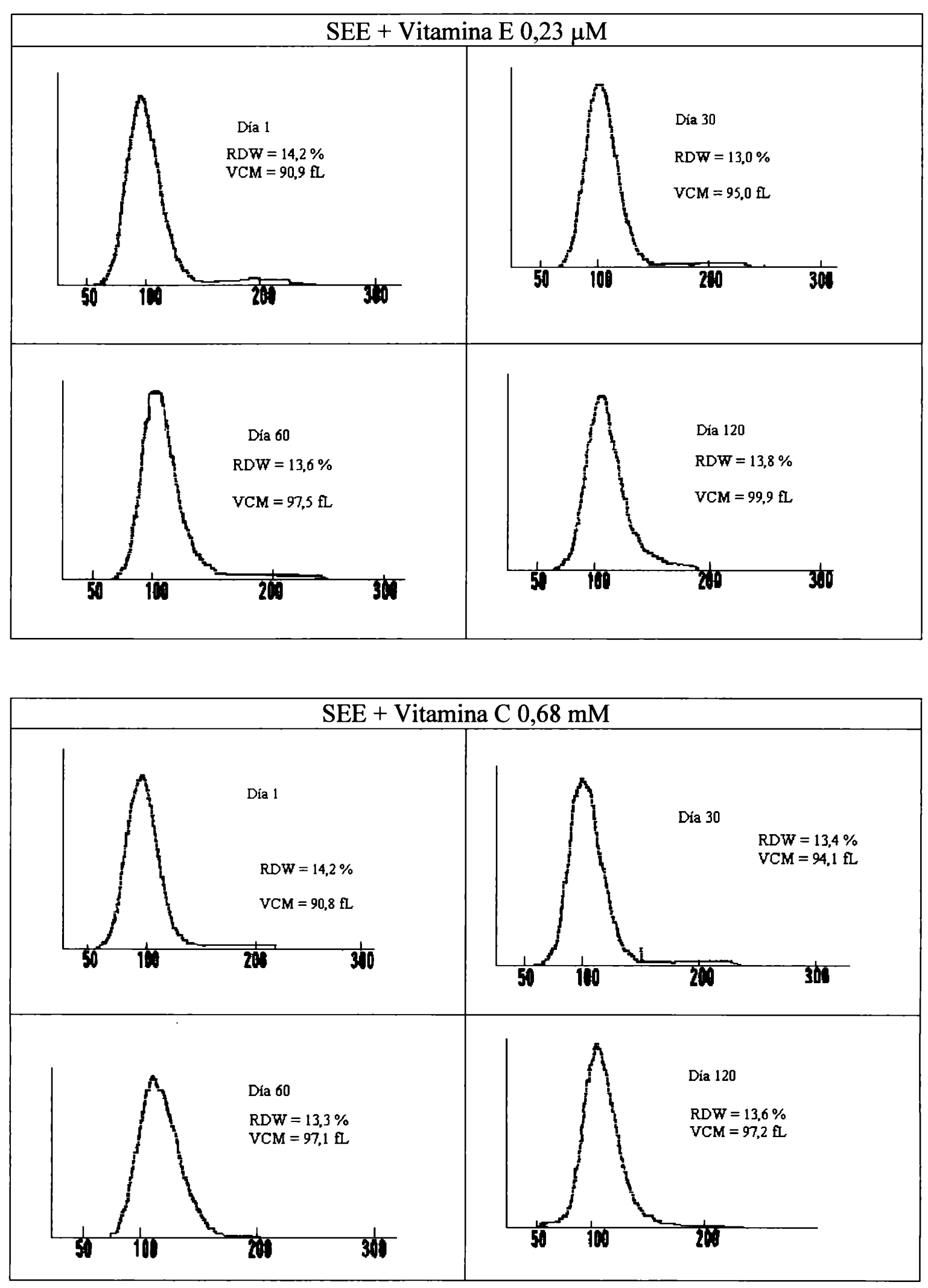


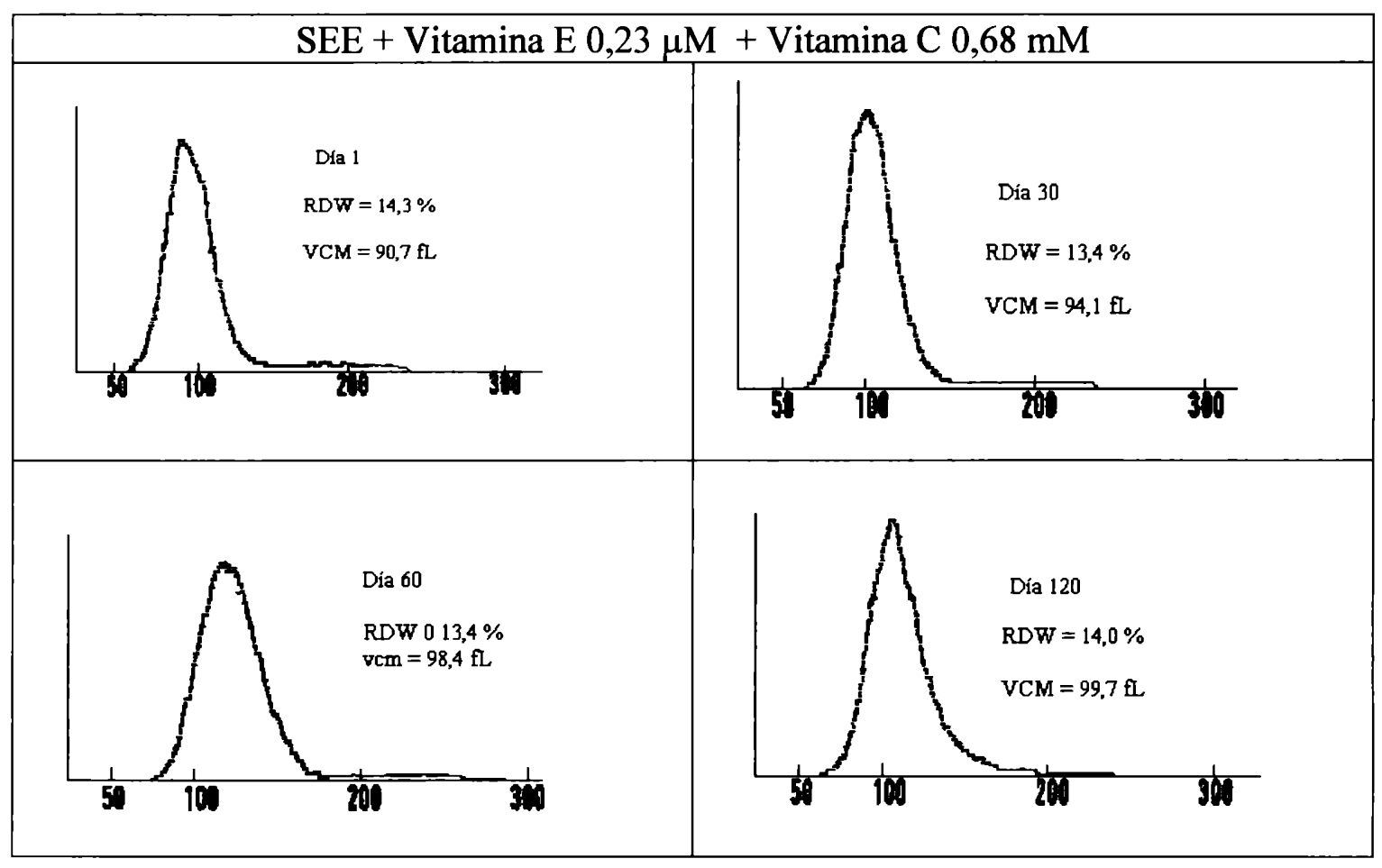

Las muestras de SEE adicionada con vitamina $\mathrm{C}$ son las que presentaron un menor aumento en el RDW y esto se correlacionó con un menor VCM al día 120 (hecho que también se observó en la fotomicrografía). 


\section{Medición de la fragilidad osmótica}

\subsection{Material y métodos}

El método utilizado fue el descrito por Dacie y Lewis,1984. Se tomaron $50 \mu \mathrm{l}$ de sangre, se adicionaron $5 \mathrm{ml}$ de soluciones de buffer fosfato, $\mathrm{pH}=7,4$ con diferentes concentraciones de $\mathrm{ClNa}(10,0,9,5,9,0,8,8,8,6,8,4,8,2,8,0,7,5,7,0,6,5,6,0$, $5,5,5,0,4,5,4,0,3,5,3,0,2,0$ y $1,0 \mathrm{~g} / \mathrm{L})$ y se centrifugaron a $2500 \mathrm{rpm}$ por 15 minutos. Se realizaron lecturas de los sobrenadantes obtenidos a $540 \mathrm{~nm}$, por duplicado, en un espectrofotómetro Zeltec UV-Vis. El sobrenadante del tubo con solución de 10,0 $\mathrm{g} / \mathrm{L}$ fue usado como blanco.

Las variaciones en la fragilidad osmótica (FO) son definidas como cambios en las curvas de hemólisis y se establecen por determinación de la [CINa] que produce $50 \%$ de hemólisis.

Para realizar los cálculos se empleó un modelo matemático propuesto por Orcutt et al., 1995.

Bases matemáticas del modelo utilizado:

La forma de la curva que muestra el grado de hemólisis en función de la [ClNa] sugiere que ésta puede ser el resultado de la distribución de las poblaciones de GR, diferenciadas de acuerdo con la resistencia de su membrana. En este modelo se asume que la función de distribución de la resistencia osmótica (fd) tiene una forma gaussiana y se puede representar por la siguiente ecuación:

$$
\mathrm{fd}=1 / 2 \exp \left[((\varepsilon-\mathrm{p} 1) / \mathrm{p} 2)^{2}\right]
$$


Donde $\varepsilon$ es una medida del estrés aplicado (las diferentes [ClNa]) y p1 y p2 son parámetros que determinan la localización del máximo de la función de distribución y su dispersión respectivamente ( $\mathrm{p} 1$ y p2 deben ser siempre $>0$ ).

Debe tenerse en cuenta que la fracción de GR que posee una resistencia mayor que un determinado valor $x$ está dada por la relación de integrales:

$$
\frac{\int f d d \varepsilon}{\int f d d \varepsilon}=\frac{1+\int \operatorname{erf}((p 1-x) / p 2)}{2}
$$

Donde erf es la función error con argumento $x$. Utilizando la función error complementaria erfc, se transforma la ecuación anterior en una equivalente, cuya expresión es:

$$
\mathrm{H}_{\mathrm{f}}=1 / 2 \operatorname{erfc}((x-\mathrm{p} 1) / \mathrm{p} 2)
$$

Donde $\mathrm{H}_{\mathrm{f}}$ es la fracción de GR hemolizados a una determinada [CINa].

Para representar las medidas de absorbancias (Abs), se adiciona a la ecuación (2), según los mismos autores, un tercer parámetro p3, que tiene en cuenta la variación en el número de GR en las muestras. Entonces, la ecuación de Orcutt, Thurmont y Ferslew, resulta:

$$
\mathrm{Abs}=\mathrm{p} 3 \text { erfc }(([\mathrm{ClNa}]-\mathrm{p} 1) / \mathrm{p} 2)
$$

Donde p3=máximo de hemólisis, p2=dispersión en $[\mathrm{ClNa}]$ que produce hemólisis en los eritrocitos y p1 = [ClNa $]$ para el 50\% de hemólisis. 
La gráfica de la Figura 19 muestra estos parámetros:

Figura 19. Representaciones gráficas de las ecuaciones 1 y 2 y su relación con los parámetros $\mathrm{p} 1$ y $\mathrm{p} 2$

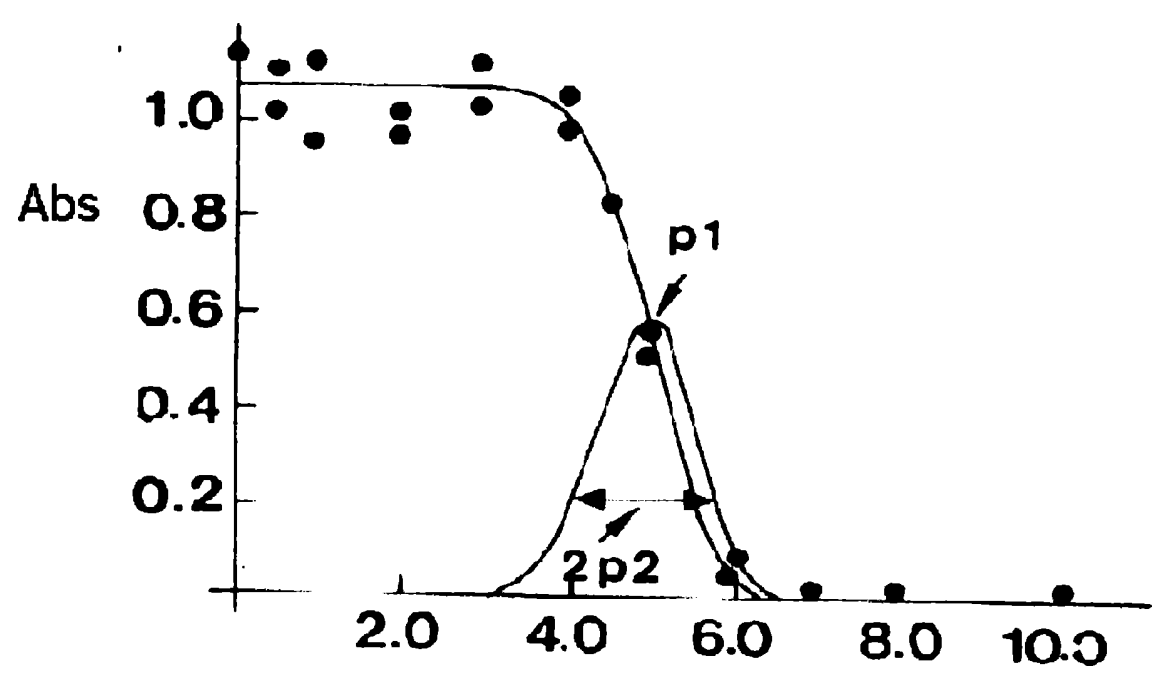

[CINa] $\mathrm{g} / \mathrm{L}$

Por otra parte, para testear los datos obtenidos utilizando este modelo matemático se midió la FO de una población de 40 individuos contrastando los resultados obtenidos por este método y los obtenidos por los métodos convencionales. Se encontró que no hay diferencias significativas entre las dos formas de cálculo, quedando establecido un intervalo para p1 (g/L) de 4,28 $\pm 0,18$; para p2 (g/L) de

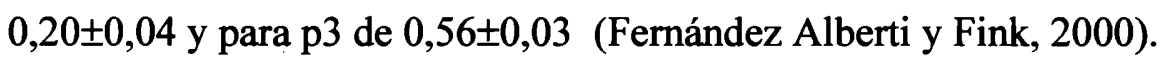

Se midió la fragilidad osmótica de muestras de SE, SEE y SEE adicionada con los antioxidantes en las concentraciones mencionadas anterioarmente. Los valores de p1, p2 y p3 se calcularon mediante un software Mathematical 2.2.1. 


\subsection{Resultados}

La Tabla 12 muestra los valores de p1 para las muestras de SE y SEE correspondientes a los lotes SE210896 y SE191297.

Tabla 12. Estabilidad a largo plazo del parámetro $\mathrm{p} 1(\mathrm{~g} / \mathrm{L})$ en una muestra control (SE) y en una muestra estabilizada (SEE).

\begin{tabular}{|c|c|c|c|c|}
\hline \multirow{2}{*}{ Días } & \multicolumn{2}{|c|}{ SE } & \multicolumn{2}{c|}{ SEE } \\
\cline { 2 - 5 } & SE210896 & SE191297 & SE210896 & SE191297 \\
\hline 1 & 4,84 & 4,44 & 4,75 & 4,04 \\
7 & 4,69 & 4,27 & 7,07 & 7,73 \\
14 & 4,87 & 4,32 & 7,51 & 7,98 \\
21 & 5,03 & 4,62 & 7,53 & 8,45 \\
28 & $*$ & $*$ & 7,80 & 8,48 \\
35 & $*$ & $*$ & 7,87 & - \\
42 & $*$ & $*$ & 7,69 & 7,29 \\
49 & $*$ & $*$ & 8,03 & 8,51 \\
56 & $*$ & $*$ & 8,35 & - \\
68 & $*$ & $*$ & 8,30 & - \\
75 & $*$ & $*$ & 8,30 & - \\
80 & $*$ & $*$ & 8,47 & - \\
\hline
\end{tabular}

* La muestra no fue estudiada en este período. Los datos corresponden a la media de dos repeticiones

Se detectaron diferencias significativas $(\mathrm{p}<0,05)$ entre estos valores de $\mathrm{p} 1$ ([CINa] para el 50\% de hemólisis) para la SE y la SEE y además hubo diferencias en la SEE entre los días 1 y $7(p<0,05)$, pero no del día 7 en adelante $(p>0,05)$.

En la Tabla 13 se muestran los valores de p1 ([CINa] para el 50\% de hemólisis), p2 (dispersión en [ClNa] que produce hemólisis en los eritrocitos) y p3 (máximo de hemólisis) para la SEE y la SE del lote SE210896 
Tabla 13: Estabilidad a largo plazo de los parámetros p1, p2 y p3 en una muestra control (SE) y en una muestra estabilizada (SEE). Lote SE210896.

\begin{tabular}{|c|c|c|c|c|c|c|}
\hline Día & \multicolumn{3}{|c|}{ SEE } & \multicolumn{3}{c|}{ SE } \\
\cline { 2 - 7 } & \multicolumn{3}{|c|}{ Parámetros } & \multicolumn{3}{c|}{ Parámetros } \\
\cline { 2 - 7 } & $\mathrm{p}^{*}$ & $\mathrm{p2}^{*}$ & $\mathrm{p} 3$ & $\mathrm{p}^{*}$ & $\mathrm{p2}^{*}$ & $\mathrm{p3}$ \\
\hline 0 & 4,84 & 0,199 & 1,056 & 4,84 & 0,199 & 1,056 \\
\hline 1 & 4,75 & 0,179 & 1,045 & 4,84 & 0,196 & 0,958 \\
\hline 7 & 7,07 & 0,767 & 0,989 & 4,69 & 0,199 & 1,056 \\
\hline 14 & 7,51 & 0,600 & 1,018 & 4,87 & 0,367 & 1,068 \\
\hline 20 & 7,53 & 0,494 & 1,020 & 5,03 & 0,488 & 1,096 \\
\hline 30 & 7,80 & 0,492 & 1,038 & ND & ND & ND \\
\hline 40 & 7,87 & 0,515 & 0,767 & ND & ND & ND \\
\hline 50 & 7,69 & 0,390 & 0,980 & ND & ND & ND \\
\hline 60 & 7,47 & 0,445 & 0,890 & ND & ND & ND \\
\hline 70 & 8,30 & 0,539 & 0,786 & ND & ND & ND \\
\hline
\end{tabular}

Los datos corresponden a la media de dos determinaciones

ND: Dato no determinado

*expresados en $\mathrm{g} / \mathrm{L}$

El análisis estadístico de estos datos muestra que hay diferencias significativas en los valores de $\mathrm{p} 1(\mathrm{p}<0,01)$, no así en los valores de $\mathrm{p} 2$ y $\mathrm{p} 3(\mathrm{p}>0,05)$.

La Figura 20 muestra el perfil de la curva de fragilidad osmótica de la muestra de SEE, y otra de SE, mostrando que la primera presenta una mayor dispersión en la población de los GR. 
Figura 20: Curvas de fragilidad osmótica a diferentes tiempos para muestras de SE y de SEE. Lote SE210896

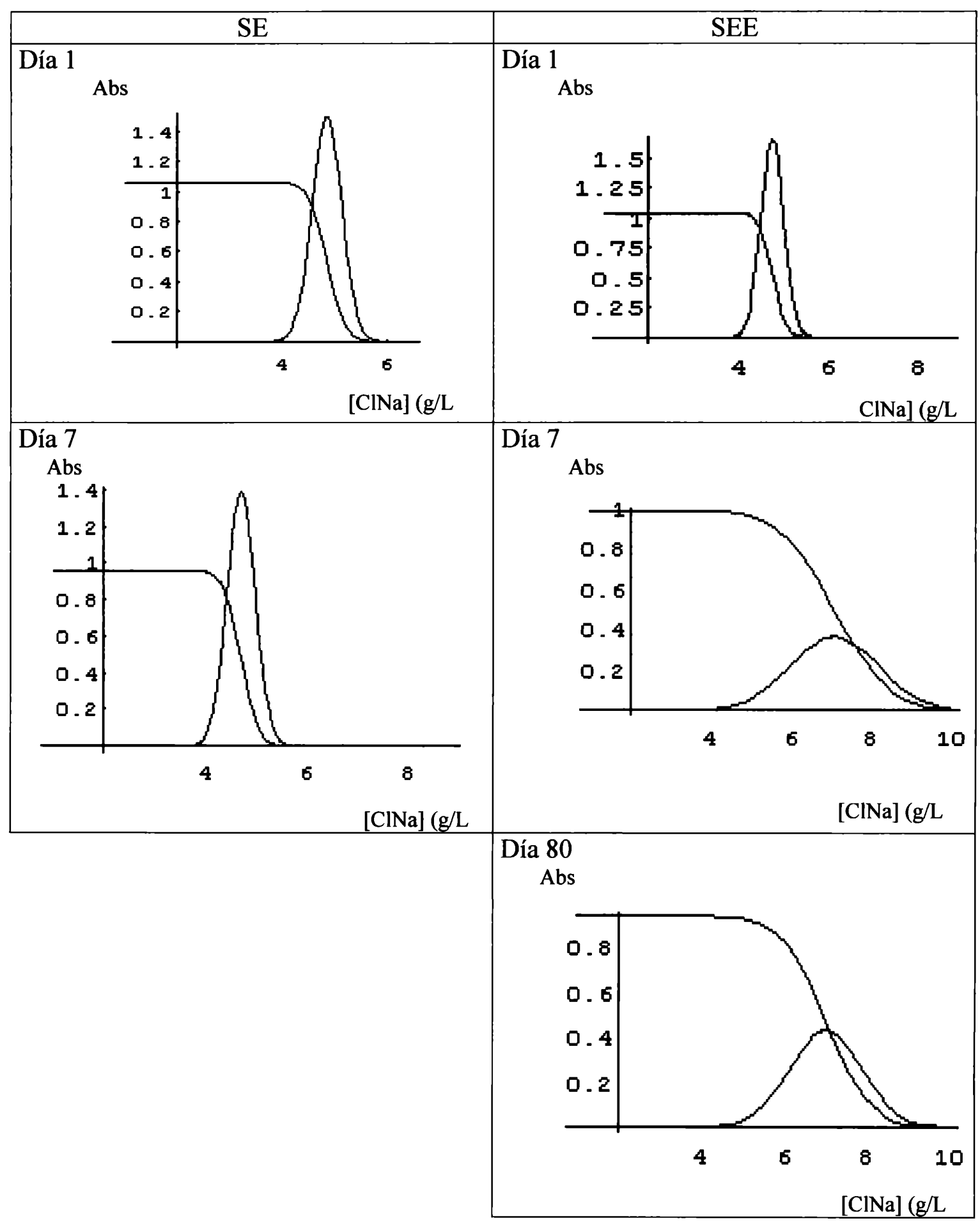


Los datos muestran una marcada diferencia en la fragilidad osmótica hallada entre las muestras de SE y SEE. Debido a esto, y a que la muestra de SE presentaba deterioros visibles, se decidió no medir por más tiempo la fragilidad de la misma.

Se realizó además la medición de la fragilidad osmótica de muestras adicionadas con vitamina $\mathrm{E}(0,11 \mu \mathrm{M})$ y con vitamina $\mathrm{C}(0,68 \mathrm{mM})$. Los datos de los parámetros $\mathrm{p} 1$, p2 y p3 calculados para estas muestras se encuentran en la Tabla 14.

Tabla 14: Estabilidad a largo plazo de parámetros p1, p2 y p3 en muestras de SEE adicionada con vitamina $\mathrm{E}$ y vitamina $\mathrm{C}$.

\begin{tabular}{|c|c|c|c|c|c|c|}
\hline \multirow{3}{*}{ Día } & \multicolumn{3}{|c|}{ SEE + vit E 0,11 $\mu \mathrm{M}$} & \multicolumn{3}{c|}{ SEE + vit C 0,68 mM } \\
\cline { 2 - 7 } & \multicolumn{3}{|c|}{ Parámetros } & \multicolumn{3}{c|}{ Parámetros } \\
\cline { 2 - 7 } & $\mathrm{p1}^{*}$ & $\mathrm{p2}^{*}$ & $\mathrm{p3}$ & $\mathrm{p}^{*}$ & $\mathrm{p2}^{*}$ & $\mathrm{p3}$ \\
\hline 1 & 5,60 & 0,479 & 0,860 & 5,60 & 0,478 & 0,860 \\
\hline 10 & 5,69 & 0,515 & 0,866 & 5,74 & 0,623 & 0,883 \\
\hline 20 & 5,70 & 0,515 & 0,880 & 6,74 & 0,744 & 1,275 \\
\hline 35 & 5,69 & 0,404 & 1,034 & 7,75 & 1,406 & 0,844 \\
\hline 70 & 7,08 & 0,638 & 0,999 & 8,20 & 0,781 & 1,187 \\
\hline 87 & 7,11 & 0,495 & 0,939 & 8,57 & 0,680 & 1,339 \\
\hline
\end{tabular}

Los datos corresponden a la media de dos determinaciones

*expresados en $\mathrm{g} / \mathrm{L}$.

En el análisis de varianza de estos datos, comparando los tratamientos y tomando al día como covariable, se encuentran diferencias significativas entre los valores de $\mathrm{p} 1 \quad(\mathrm{p}<0,01)$. Para $\mathrm{p} 2$ y $\mathrm{p} 3$, en cambio, no se encontraron diferencias estadísticamente significativas $(\mathrm{p}>0,05)$.

En el lote SE060598 se determinó la FO de muestras adicionadas con vitamina E en diferentes concentraciones. Los valores de p1, p2 y p3 se muestran en la Tabla 15. El 
análisis estadístico de estos datos mostró que no existen diferencias significativas entre los tratamientos para ninguno de los parámetros $(\mathrm{p}>0,05)$.

Durante el almacenamiento, como hemos corroborado en las mediciones de los parámetros hematimétricos, ocurre una disminución del CHCM (Figura 12). Esto llevaría a una disminución de la capacidad del GR para captar agua y por lo tanto a un aumento de la FO; por esta razón, los valores de p1 fueron correlacionados con la concentración de CHCM, obteniéndose una correlación negativa. En la Tabla 16 se muestran los valores del coeficiente de correlación (r) y del parámetro estadístico (p), para las muestras pertenecientes al lote SE060598. También se estableció la correlación entre los valores de p2 de este mismo lote y el $\mathrm{RDW}$, obteniéndose en este caso una correlación positiva. 


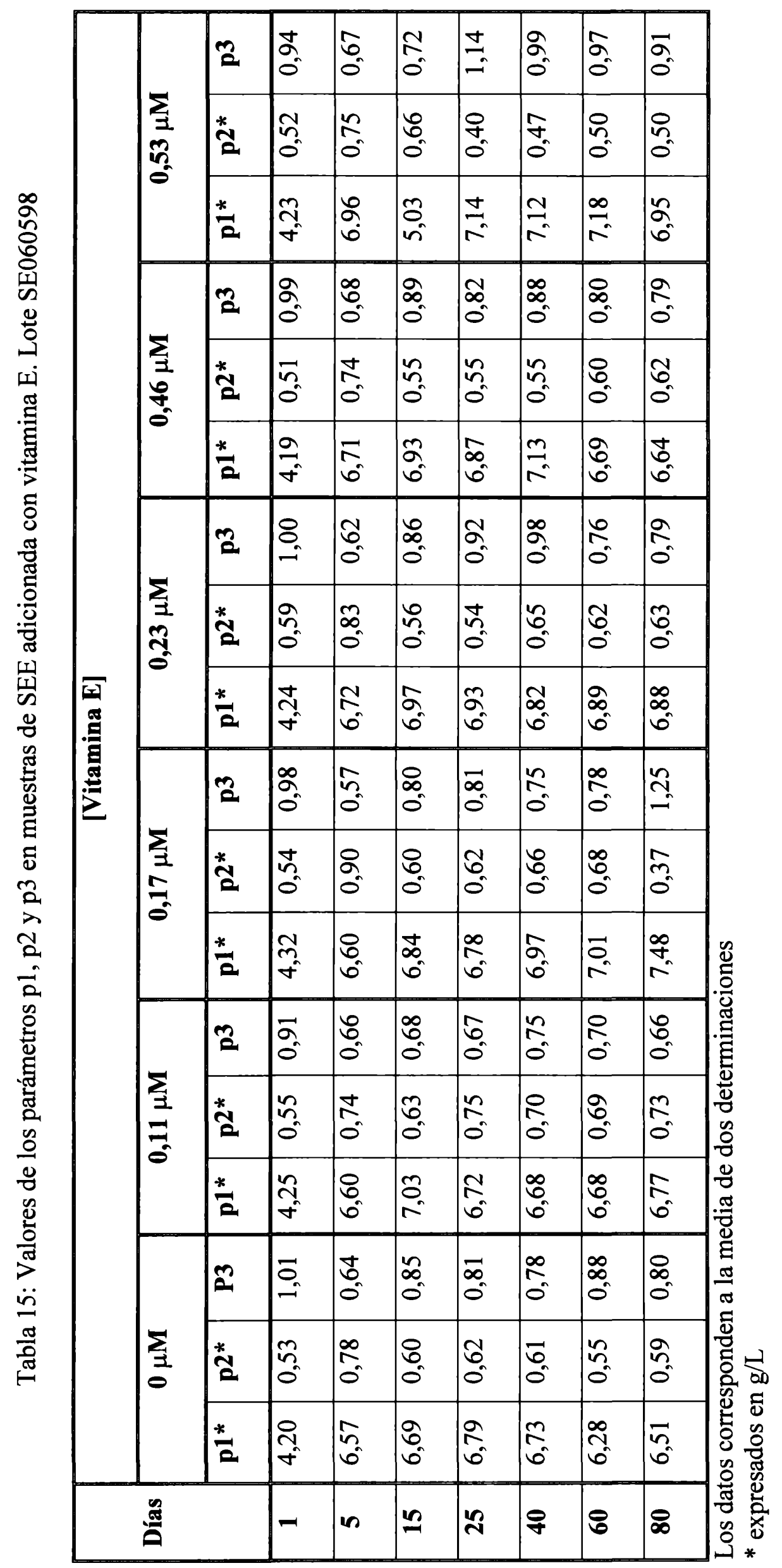




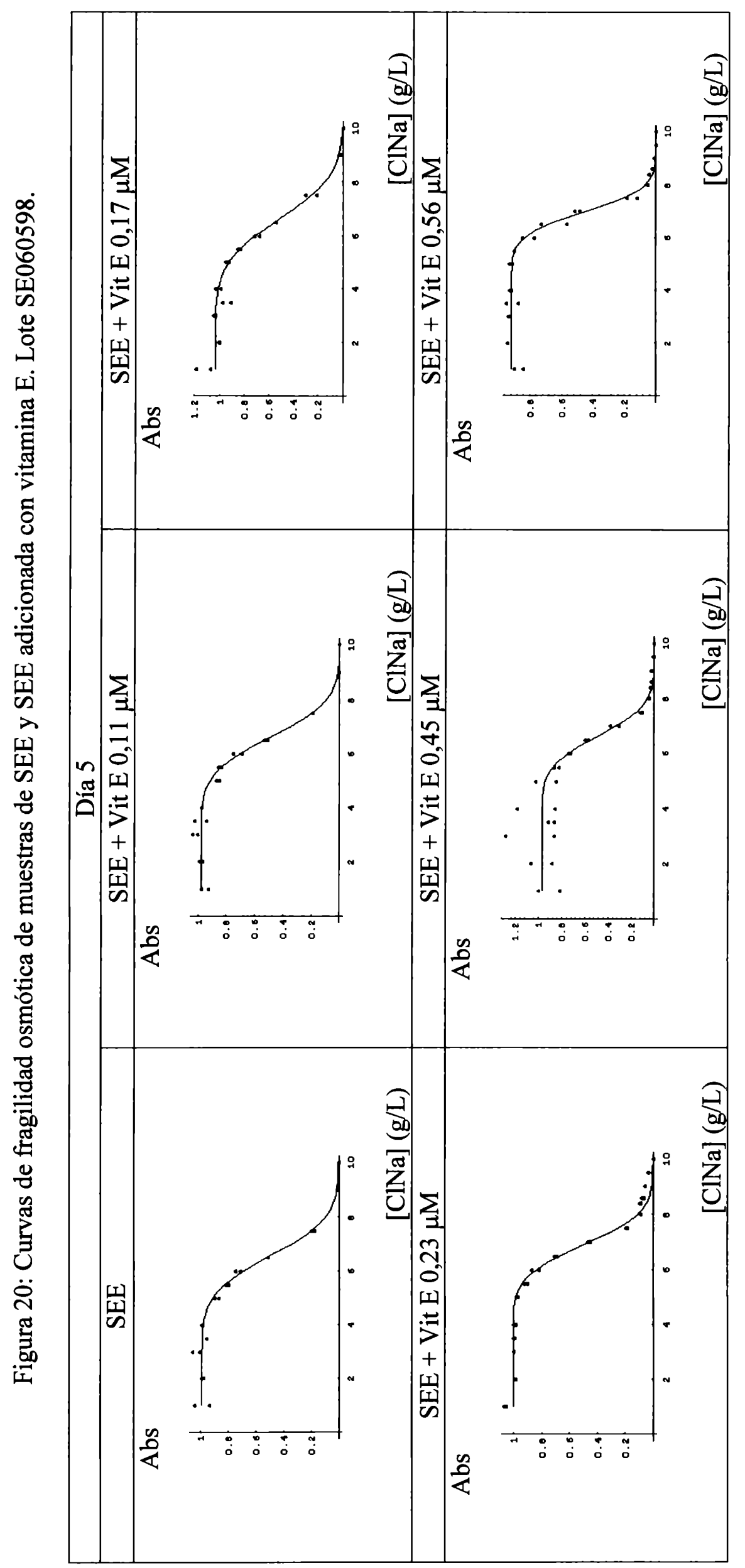




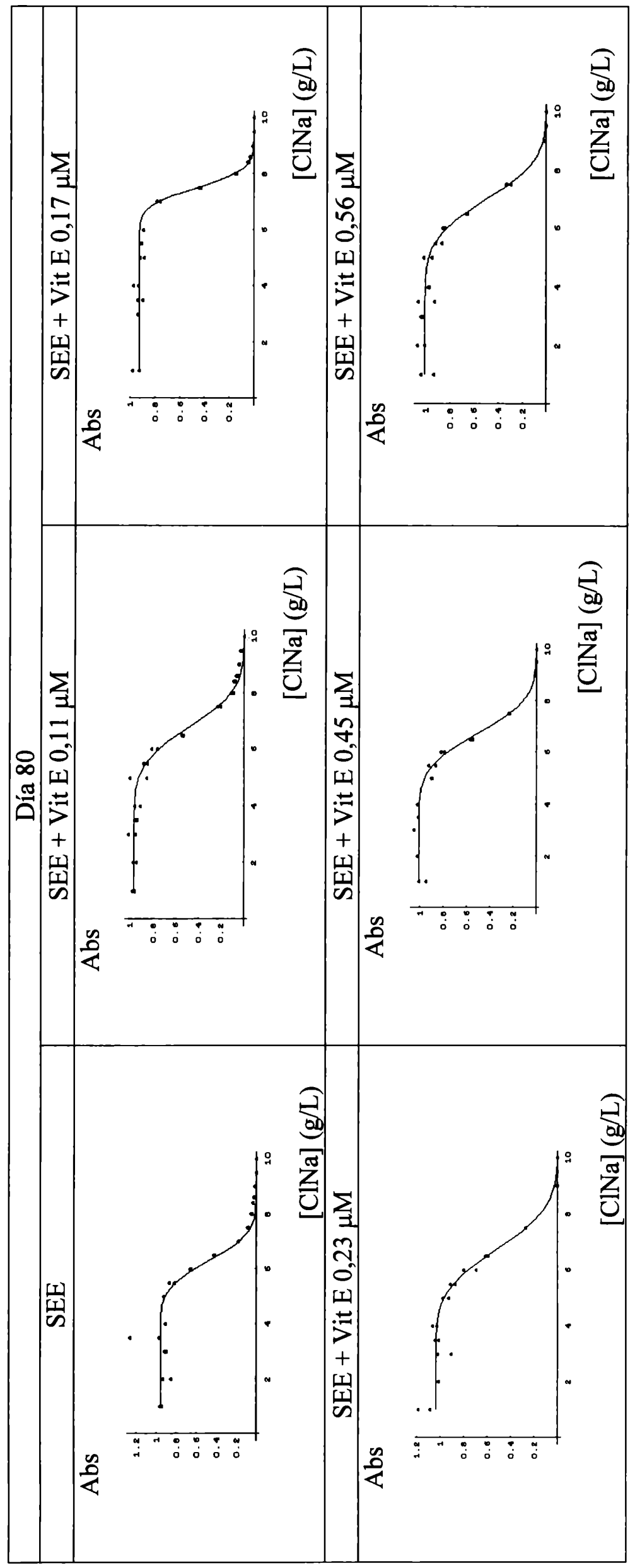


Tabla 16:Correlaciones entre los parámetros p1 y CHCM y entre p2 y RDW. Lote 060598.

\begin{tabular}{|c|c|c|c|c|}
\hline \multirow{2}{*}{ [Vitamina E] } & \multicolumn{2}{|c|}{$\mathrm{p} 1 \mathrm{vs}$ CHCM } & \multicolumn{2}{c|}{$\mathrm{p} 2 \mathrm{vs}$ RDW } \\
\cline { 2 - 5 } & $\mathrm{r}$ & $\mathrm{p}^{*}$ & $\mathrm{r}$ & $\mathrm{p}$ \\
\hline $0 \mu \mathrm{M}$ & $-0,618$ & 0,057 & 0,210 & 0,560 \\
\hline $0,11 \mu \mathrm{M}$ & $-0,672$ & $0,033^{*}$ & 0,432 & 0,212 \\
\hline $0,17 \mu \mathrm{M}$ & $-0,784$ & $0,007^{*}$ & 0,215 & 0,551 \\
\hline $0,23 \mu \mathrm{M}$ & $-0,702$ & $0,024^{*}$ & 0,622 & 0,055 \\
\hline $0,46 \mu \mathrm{M}$ & $-0,584$ & 0,076 & 0,632 & $0,050^{*}$ \\
\hline $0,53 \mu \mathrm{M}$ & $-0,686$ & $0,028^{*}$ & 0,413 & 0,235 \\
\hline
\end{tabular}

${ }^{*} \mathrm{p}<0,05$

La Figura 20 muestra las curvas de fragilidad osmótica para las muestras de la

Tabla 15, en los días 5 y 80. Como puede observarse no existen diferencias notorias entre los perfiles de los diferentes tratamientos. 


\section{Electroforesis de las proteínas de membrana}

\subsection{Material y métodos}

La electroforesis en geles de poliacrilamida de las proteínas de membrana del GR requiere de la obtención de fantasmas o ghosts, es decir GR desprovistos de Hb. Para la formación de los mismos se someten los eritrocitos a la acción de soluciones hipotónicas o de diferente fuerza iónica.

La preparación de las proteínas de membrana se realizó siguiendo la técnica descripta por Esteloto (1994). Los GR provenientes de muestras de SE, SEE y SEE adicionada con las vitaminas se centrifugaron y se lavaron con solución fisiológica para eliminarles plasma, Plt y GB y luego con una solución buffer Tris- $\mathrm{HCl}(5 \mathrm{mM})$ en $\mathrm{ClNa} 9 \mathrm{~g} / \mathrm{L}$ a pH 7,4. Luego fueron lisados con solución Tris- $\mathrm{HCl}(10 \mathrm{mM})$ en agua destilada a $\mathrm{pH}$ 7,4. En ambas soluciones se agregó fluoruro de metilfenilsulfonilo (PMSF), 2,8\% en metanol, como antiproteolítico. Luego de la lisis, las membranas fueron aisladas por centrifugación a $4^{\circ} \mathrm{C}$, en una centrífuga Presvac a 6500 rpm, durante 30 minutos. Se lavaron, al menos 3 veces, con la solución lisante hasta obtener un pellet blanco. Los estromas fueron congelados a $-20^{\circ} \mathrm{C}$ hasta la realización de la corrida electroforética.

Las electroforesis se realizaron en geles de poliacrilamida $7,5 \%$ de $7 \mathrm{~cm}$ de largo, siguiendo la técnica de Steck y Yu (1973), modificada según Esteloto (1994). Se corrió durante 3,5 horas a $17 \mathrm{~mA}$ por placa. El buffer de corrida contenía SDS $10 \%$, glicina $1,44 \%$ y Trisma Base $0,5 \mathrm{M}$. Las proteínas se tiñeron con una solución de ácido acético $10 \%$, isopropanol $25 \%$ y azul brillante de Coomasie en agua destilada.

Los geles fueron luego densitometrados con un Computer Scanner Densitometer GlobAl Scan II- MALTA SRL (Milán, Italia). 


\subsection{Resultados}

En la Figura 21 se muestra una fotografia correspondiente a una electroforesis obtenida a partir de muestras de SE fresca y SEE con once días de almacenamiento a $4^{\circ} \mathrm{C}$, donde se observan claramente los polímeros que se forman y que son de mayor PM que la Sp.

Figura 21: Fotografia correspondiente a proteínas de membrana en PAGE-SDS de muestras de SEE y SE.

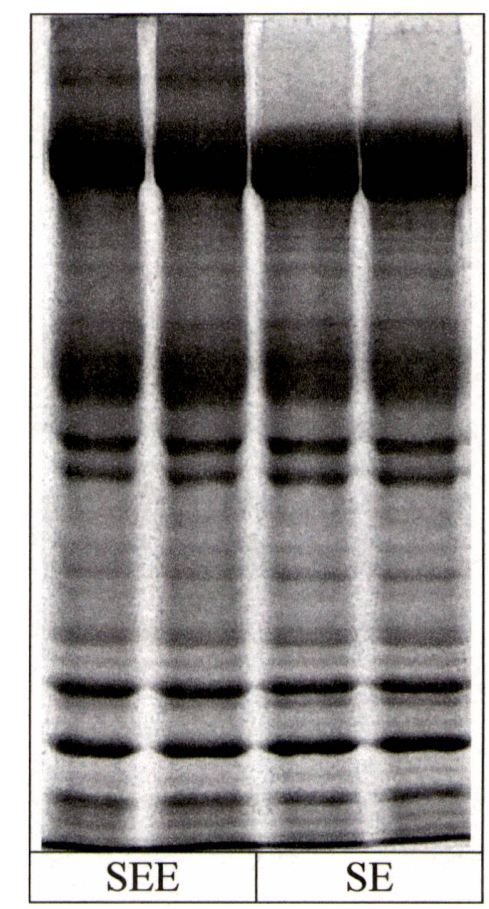

La SEE posee once días de almacenamiento a $4^{\circ} \mathrm{C}$

En la Figura 22 se muestran las fotografias y las densitometrías correspondientes a proteínas de membrana plasmática de eritrocitos en PAGE-SDS, obtenidas a partir de muestras de SE, SEE y SEE adicionada con vitamina $\mathrm{E}$ en concentraciones de $0,11,0,17$, $0,23,0,45$ y $0,56 \mu \mathrm{M}$. Las mismas fueron realizadas en los días $1,20,40$ y 60 de almacenamiento a $4^{\circ} \mathrm{C}$. En la electroforesis correspondiente al día 1 se observan claramente los polímeros de alto PM. Estos polímeros también están presentes en las electroforesis 
correspondientes a las muestras con más días de almacenamiento, aunque sus bandas son más difusas, posiblemente debido a una degradación de los mismos durante el almacenamiento.

Como puede observarse, las electroforesis correspondientes a las proteínas de membrana de eritrocitos almacenados durante 1, 20, 40 y 60 días, estabilizados y adicionados con vitamina $\mathrm{E}$, no mostraron grandes diferencias con las muestras estabilizadas.

En la Tabla 17 se muestran los porcentajes correspondientes a las diferentes fracciones proteicas obtenidas en cada uno de los geles de la Figura 22. De estos datos se puede remarcar la disminución de las fracciones de alto PM como la $\mathrm{Sp}$, que desciende en relación a su nivel original entre un $8 \%$ y un $35 \%$, las bandas 2.1 y 2.9 , así como la proteína banda 3 que disminuye entre un $24 \%$ y $50 \%$, siendo el tratamiento sin vitaminas el que presentó un descenso mayor. Asímismo, se observó un aumento de las fracciones de proteínas de bajo PM. 
Figura 22 : Fotografías y densitometrías de electroforesis en PAGE-SDS de proteínas de membrana de eritrocitos de muestras de SE, SEE y SEE adicionadas con vitamina E, a diferentes tiempos de almacenamiento.
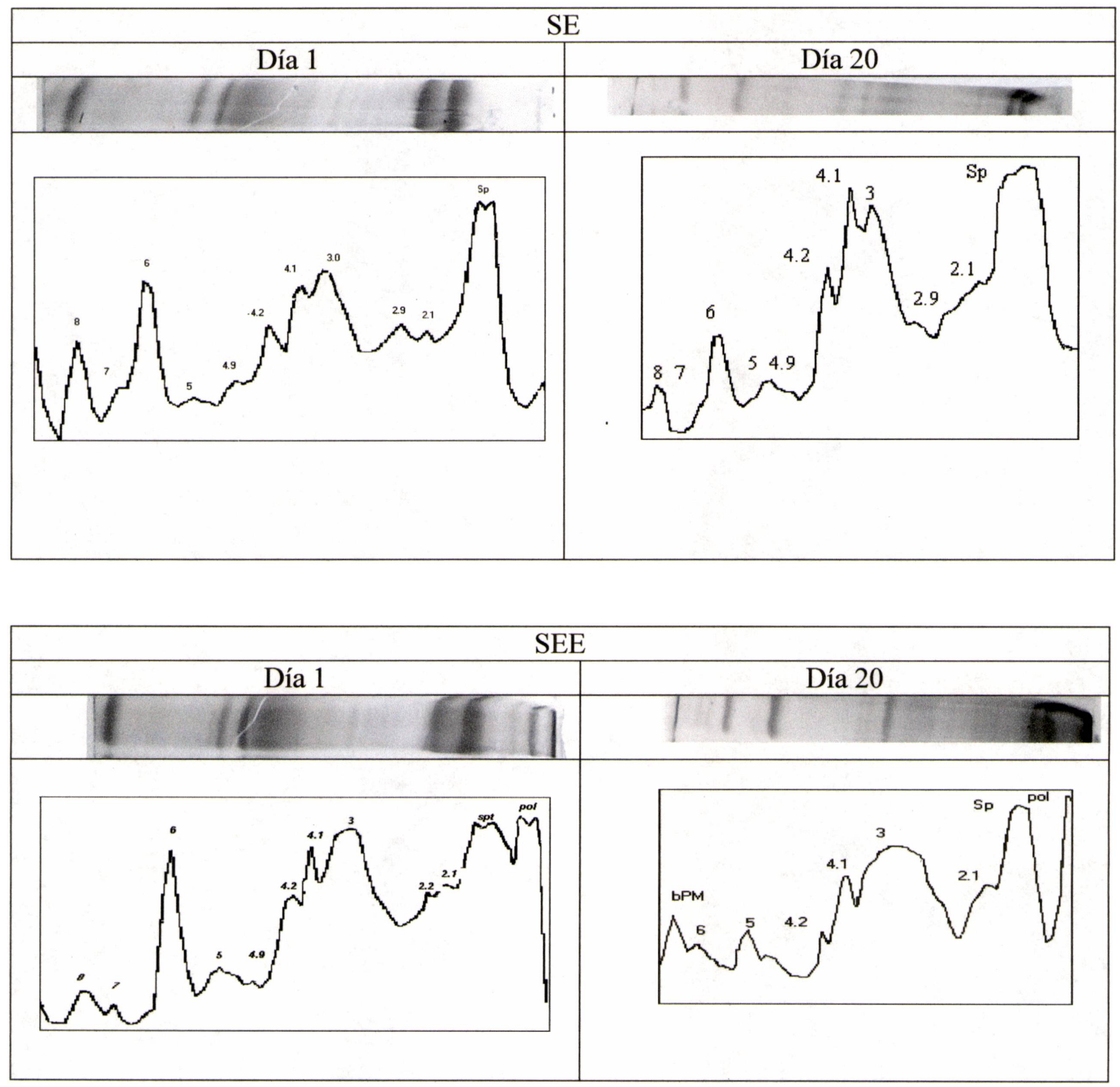

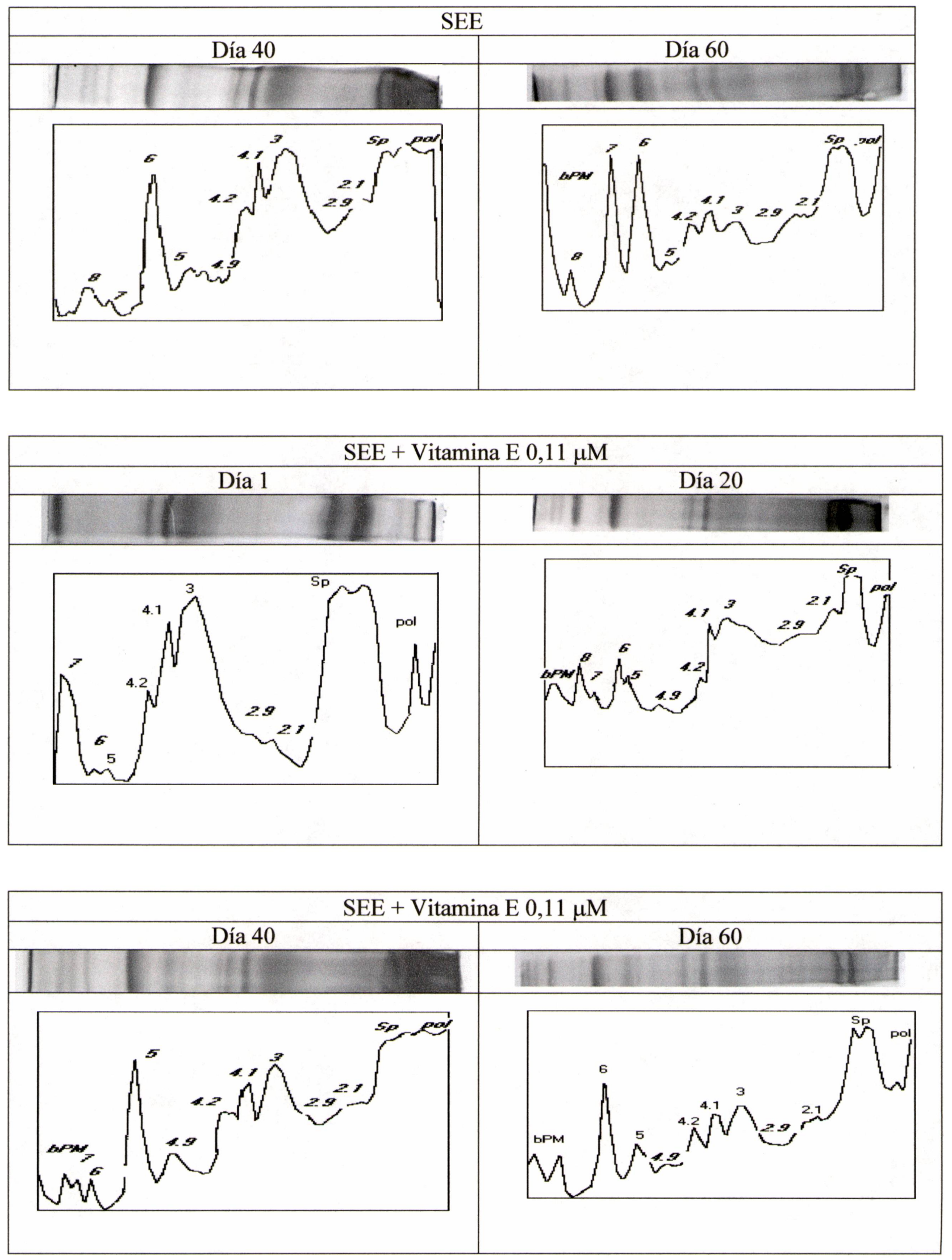

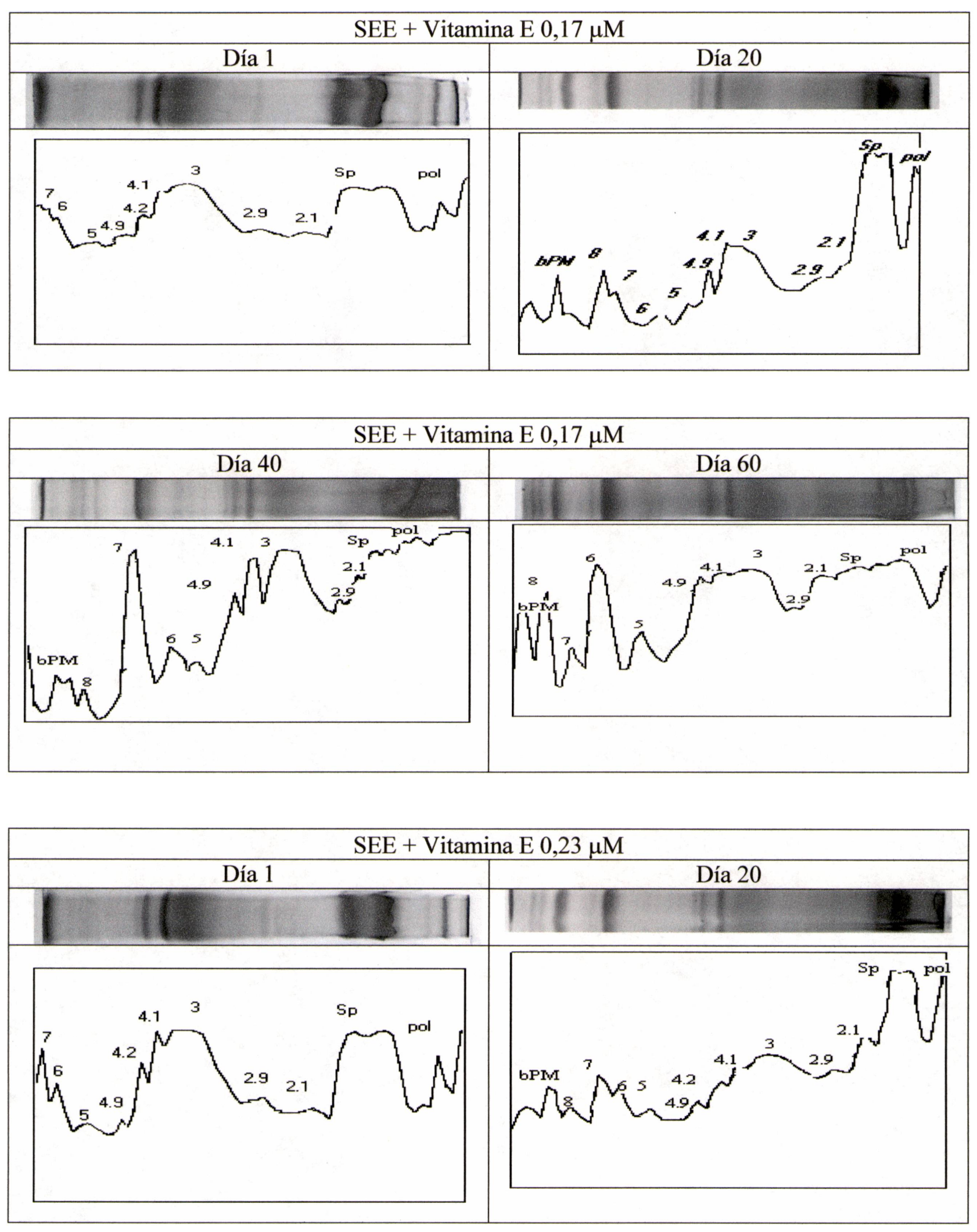

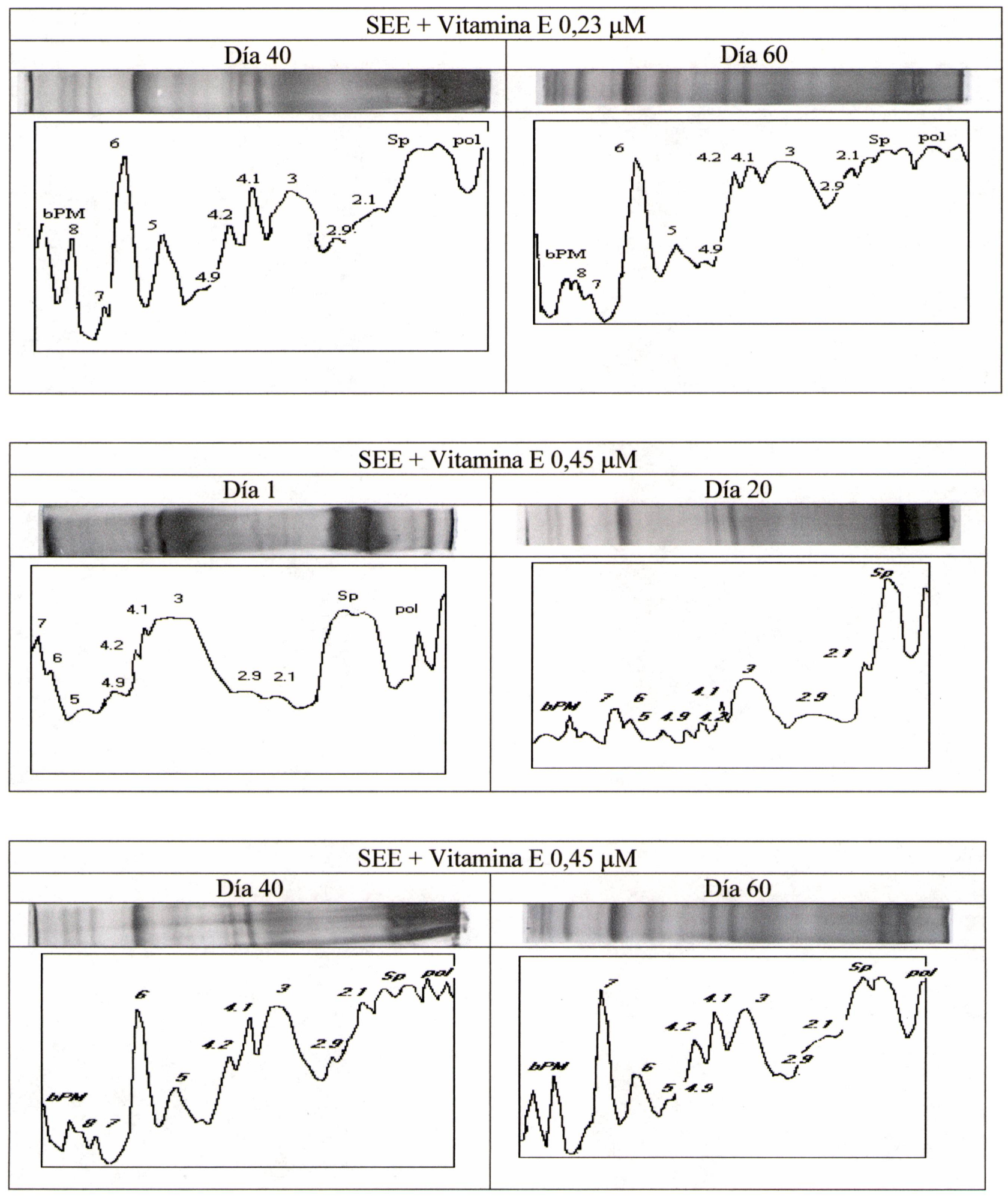

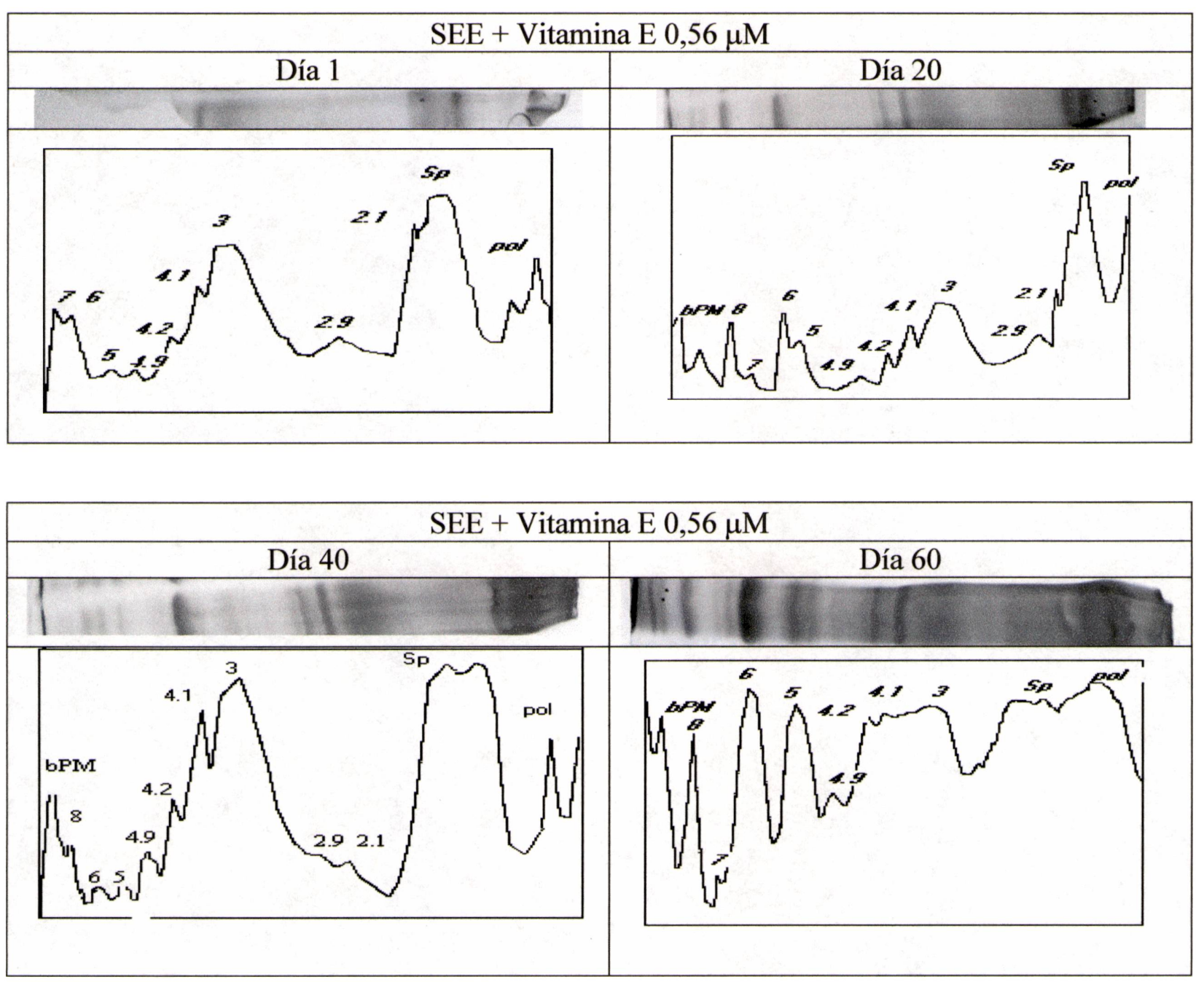


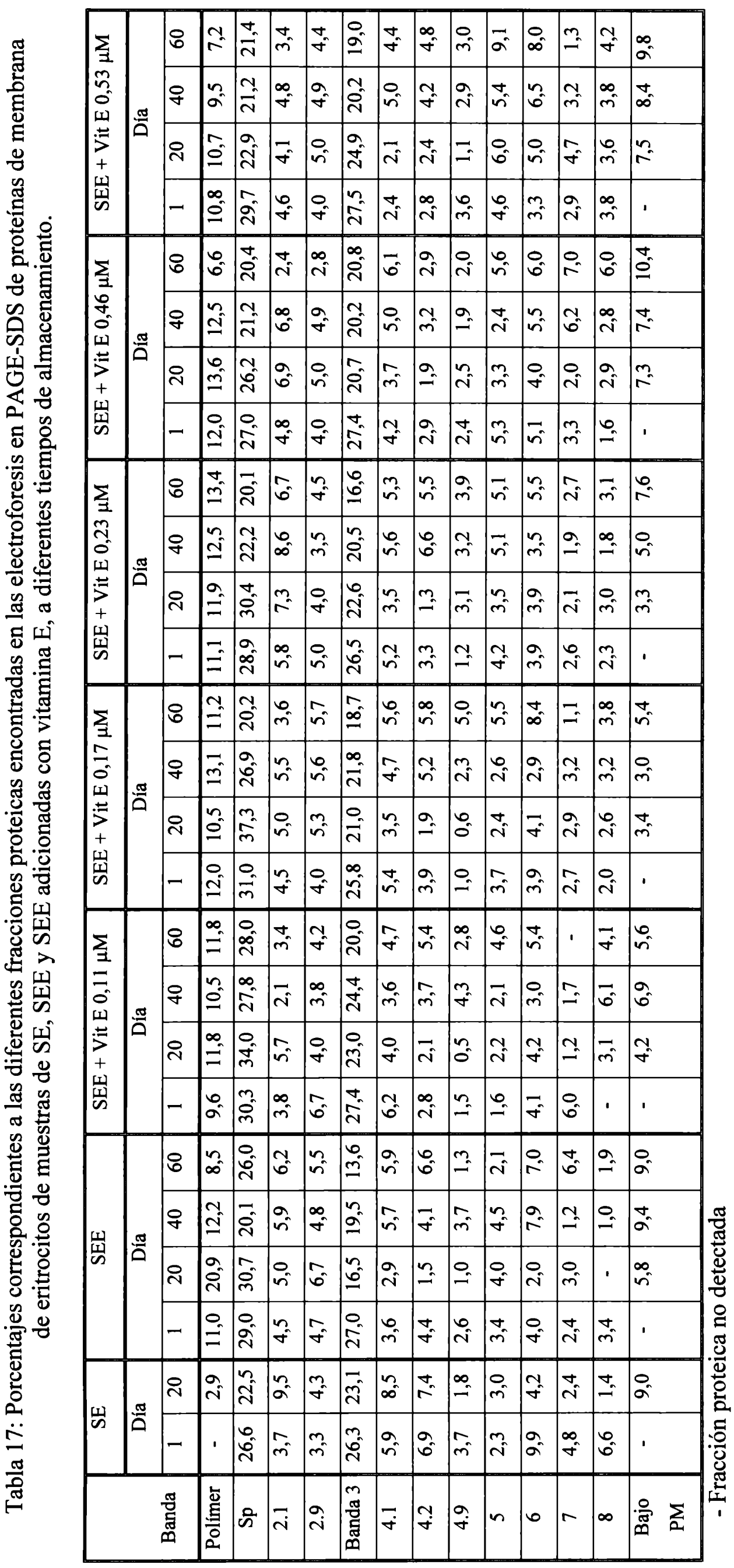




\section{Medición de 2,3-difosfoglicerato}

\subsection{Material y métodos}

El método empleado se fundamenta en que el 2,3-DPG es hidrolizado a 3fosfoglicerato (3-PG) por medio de la fosfoglicerato mutasa (PGM), activada por el 2fosfoglicerato (2-PG). Esta reacción es acoplada a la conversión del NADH en NAD ${ }^{+}$ por medio de la gliceraldehido-3-fosfato deshidrogenasa (GAP-DH) y de la fosfoglicerato kinasa (PGK).

La secuencia de reacciones es:

1) $2,3-\mathrm{DPG} \underset{\text { 2-PG }}{\stackrel{\mathrm{PGM}}{\longrightarrow}} \mathrm{PG}+\mathrm{P}_{\mathrm{i}}$

En esta reacción se puede formar tanto el 3-PG como el 2-PG; éste último es luego isomerisado por la PGM,

2) $2-\mathrm{PG} \stackrel{\mathrm{PGM}}{\longrightarrow} 3-\mathrm{PG}$

3) $3-\mathrm{PG}+\mathrm{ATP} \stackrel{\mathrm{PGK}}{\longrightarrow} 1,3-\mathrm{DPG}+\mathrm{ADP}$

4) $1,3-\mathrm{DPG}+\mathrm{NADH}+\mathrm{H}^{+} \stackrel{\text { GAP-DH }}{\longrightarrow}$ Gliceraldehido-3- fosfato $+\mathrm{NAD}^{+}+\mathrm{P}_{\mathrm{i}}$

5) Gliceraldehido-3- fosfato $\stackrel{\text { TIM }}{\longrightarrow}$ Dihidroxiacetona-P (TIM=Triosafosfato isomerasa)

6) Dihidroxiacetona-P + NADH $+\mathrm{H}^{+} \stackrel{\mathrm{GDH}}{\longrightarrow}$ Glicerol-3-P $+\mathrm{NAD}^{+}$ $(\mathrm{GDH}=$ glicero-3-fosfato deshidrogenasa)

De esta manera se oxidan 2 moles de NADH por cada mol de 2,3-DPG. Luego se mide a $340 \mathrm{~nm}$ la absorbancia del $\mathrm{NAD}^{+}$producido. Las reacciones 2 a 6 son llevadas a cabo antes del agregado de la PGM, para eliminar los sustratos que puedan estar presentes en la mezcla de reacción. 
Se partió de $1,0 \mathrm{ml}$ de sangre entera y se desproteinizó en frío con 5,0 $\mathrm{ml}$ de ácido perclórico. El sobrenadante fue luego neutralizado con $0,5 \mathrm{ml}$ de carbonato de potasio 2,5 M. Se dejó al menos 30 minutos en hielo, se filtró el precipitado de perclorato y se tomó $1,0 \mathrm{ml}$ del filtrado. En el extracto neutralizado, el 2,3-DPG es estable durante 1 día, a $4^{\circ} \mathrm{C}$ y por varios meses a $-70^{\circ} \mathrm{C}$. Al filtrado se le agregaron los buffers (trietanolamina, $48 \mathrm{mmol} / \mathrm{L}, \mathrm{pH} \mathrm{7,6} ; \mathrm{Cl}_{2} \mathrm{Mg}, 5,3 \mathrm{mmol} / \mathrm{L}$; EDTA, 5,2 mmol/L), los cofactores necesarios (ATP $40 \mathrm{mmol} / \mathrm{L}, \mathrm{NADH} \mathrm{9,6} \mathrm{mmol} / \mathrm{L}$ ) las enzimas: PGM $\left(14 \times 10^{3} \mathrm{U} / \mathrm{L}\right)$, PGK $\left(94 \times 10^{4} \mathrm{U} / \mathrm{L}\right)$, GAP-DH $\left(14 \times 10^{3} \mathrm{U} / \mathrm{L}\right), \mathrm{TIM}\left(50 \times 10^{4} \mathrm{U} / \mathrm{L}\right)$ y GDH $\left(1 \times 10^{4} \mathrm{U} / \mathrm{L}\right) \mathrm{y}$, como activador 2-PG $(48 \mathrm{mmol} / \mathrm{L})$. Luego se determinaron las absorbancias a $340 \mathrm{~nm}$, a $20-25^{\circ} \mathrm{C}$, en un espectrofotómetro Shimadzu 1601 .

La concentración de 2,3-DPG se calculó según:

$$
[2,3-\mathrm{DPG}](\mathrm{g} / \mathrm{L} \text { de sangre })=(\mathrm{V} \times \mathrm{PM} \times \mathrm{F} /(\varepsilon \times \mathrm{d} \times \mathrm{v} \times 1000 \times 2)) \times \mathrm{DA}=3,112 \times \mathrm{DA}(340 \mathrm{~nm})
$$

Donde $\mathrm{V}=$ volumen del filtrado, $\mathrm{PM}=$ peso molecular del 2,3-DPG, $\mathrm{F}=$ factor de dilución, $\mathrm{v}=$ volumen de sangre y $\varepsilon=$ coeficiente de absorción del 2,3-DPG.

Se dispuso de un equipo de reactivos comercial (Boehringer Mannheim, Alemania) para la determinación del analito, razón por la cual se midieron sus niveles en un solo lote (SE141098), cada 10 días. Se extrajo el 2,3-DPG de cada muestra y el extracto fue conservado a $-70^{\circ} \mathrm{C}$ hasta procesar todas las muestras al día 100 . Simultáneamente, para determinar la variabilibilidad del método se realizaron 5 mediciones en muestras de sangre fresca.

Se realizó un ajuste estadístico de los datos, buscando para cada tratamiento el mejor ajuste, o sea el mayor valor del coeficiente de correlación $\left(\mathrm{R}^{2}\right)$. Este ajuste se realizó con el programa SPSS 10.0 para Windows. 


\subsection{Resultados}

Los datos obtenidos en las 5 muestras de SE se detallan en la Tabla 18, siendo el intervalo de $\bar{x} \pm 2 \mathrm{DE}$ determinado de 4,12 $\pm 1,00 \mathrm{mmol} / \mathrm{L}$ de $\mathrm{GR},(\mathrm{CV} \%=12)$. El intervalo de referencia según el método es $4,83 \pm 0,15 \mathrm{mmol} / \mathrm{L}$ de $\mathrm{GR}(\mathrm{n}=10)$.

Tabla 18: Reproducibilidad de la cuantificación de 2,3-DPG en SE $(n=5)$.

\begin{tabular}{|c|c|c|}
\hline Muestra & $\begin{array}{c}{[2,3-\mathrm{DPG}]} \\
\text { mmol/L sangre }\end{array}$ & $\begin{array}{c}{[2,3-\mathrm{DPG}]} \\
\mathrm{mmol} / \mathrm{L} \text { GR }\end{array}$ \\
\hline 1 & 1,4157 & 4,16 \\
\hline 2 & 1,6614 & 4,89 \\
\hline 3 & 1,1934 & 3,51 \\
\hline 4 & 1,4157 & 4,16 \\
\hline 5 & 1,3221 & 3,89 \\
\hline
\end{tabular}

En la Figura 23 se muestra la variación de la concentración del metabolito en los tratamientos con diferentes concentraciones de vitamina $\mathrm{E}(0,11,0,17,0,23,0,45$ y $0,56 \mu \mathrm{M})$, con vitamina $(\mathrm{C} 0,68 \mathrm{mM})$ y con una mezcla de ambas vitaminas (Vit E 0,23 $\mu \mathrm{M}+$ Vit $\mathrm{C}$ 0,68 mM). De estas gráficas se desprende que en la muestra de SEE estabilizada los niveles de 2,3-DPG no descienden nunca a niveles indetectables por el método, a diferencia de la SE en la que sus niveles fueron indetectables después de 40 días. Se observa que si bien no hay grandes diferencias entre los tratamientos, los descensos son menos pronunciados en las muestras adicionadas con antioxidantes que en la SEE. 
Figura 23: Estabilidad a largo plazo de los niveles de 2,3-DPG en muestras de SE, SEE y SEE adicionada con vitaminas. Lote SE141096.
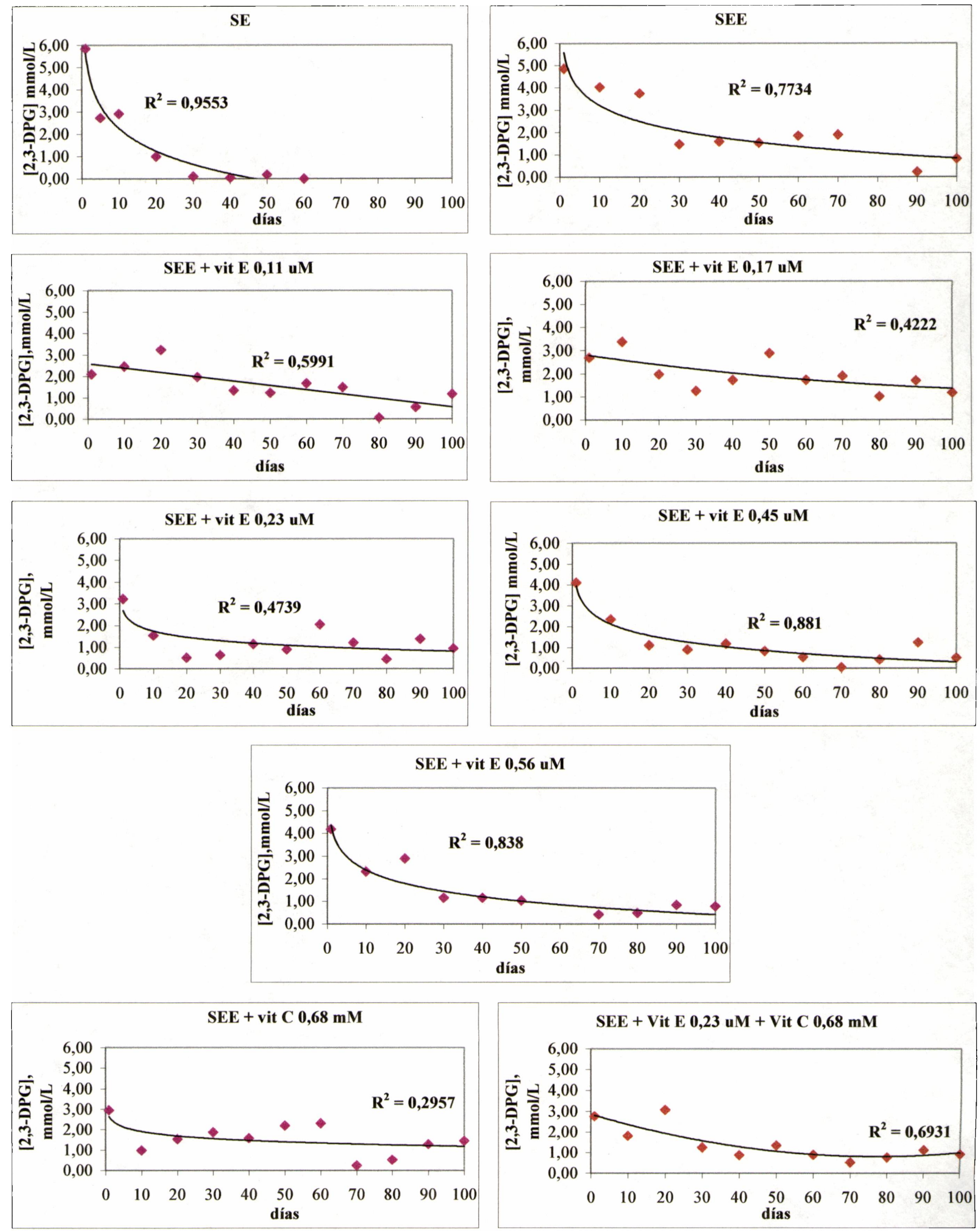


\section{Medición de la actividad de colinesterasas}

\subsection{Material y métodos}

Las colinesterasas catalizan la hidrólisis de ésteres como, por ejemplo de la acetilcolina:<smiles>CC(=O)OCCN=C(C)[C@H](O)[C@H](O)C(=O)O</smiles>

Se midió la actividad de la colinesterasa eritrocitaria y de la colinesterasa plasmática cada diez días en las experiencias SE020899, SE200899 y SE250200.

\subsubsection{Medición de colinesterasa eritrocitaria (AChE)}

La enzima colinesterasa de la membrana de GR hidroliza el sustrato acetiltiocolina formando acetilato y tiocolina. Esta última reacciona a $\mathrm{pH}$ regulado con el ácido $5,5^{\prime}=$ ditiobis-2 nitrobenzoico (DTNB) para formar un compuesto amarillo cuya absorción se mide a $412 \mathrm{~nm}$. La actividad de la enzima en la muestra se expresa en $\mathrm{U} / \mathrm{ml}$ de paquete celular.

Su actividad se midió cinéticamente a $412 \mathrm{~nm}$, usando ioduro de acetiltiocolina como sustrato y siguiendo la técnica de Weber (1966). Se partió de $50 \mu \mathrm{l}$ de sangre entera -cuyo hematocrito se determinó previamente- y se lavaron las células con solución fisiológica. El paquete globular se resuspendió en $5 \mathrm{ml}$ de buffer fosfatos $\left(0,050 \mathrm{~mol} / \mathrm{L}, \mathrm{NaH}_{2} \mathrm{PO}_{4} \cdot 2 \mathrm{H}_{2} \mathrm{O}(23,4 \mathrm{~g} / \mathrm{L})\right.$ y $\mathrm{Na}_{2} \mathrm{HPO}_{4}(21,3 \mathrm{~g} / \mathrm{L})$, ajustada a $\left.\mathrm{pH} 7,2\right) . \mathrm{Se}$ realizó una dilución 1/5 en el mismo buffer y se tomó $1 \mathrm{ml}$ al que se le agregaron $2 \mathrm{ml}$ de DTNB $(0,25 \mathrm{mmol} / \mathrm{L})$. Se incubó durante 3 minutos a $30^{\circ} \mathrm{C}$, se le agregaron $100 \mu \mathrm{l}$ 
de sustrato $(0,031 \mathrm{~mol} / \mathrm{L})$ y se leyeron las absorbancias en un espectrofotómetro Shimadzu 1601 , termostatizado a $30^{\circ} \mathrm{C}$, cada 60 segundos durante 6 minutos. Para cada muestra se preparó un blanco conteniendo $2,1 \mathrm{ml}$ de DTNB y $1 \mathrm{ml}$ de la suspensión de GR.

El cálculo se realizó según:

Actividad (U/L de células $)=\Delta \mathrm{A} / \min \times 500 \times 10^{3} \times 3,1 /($ Hto $\times 13,6 \times \mathrm{d})$

Donde: $\Delta \mathrm{A} / \min =$ promedio de los $\Delta \mathrm{A}$ cada 60 segundos, $500=$ factor de dilución, $10^{3}=$ para expresar el resultado en litros, 3,1 = volumen de reacción, Hto=Hematocrito de la muestra, 13,6 $=\varepsilon$ del producto amarillo y d = camino óptico.

\subsubsection{Medición de colinesterasa plasmática}

Se realizó según el método de Szasz (1968), comercializado por GTLab (Rosario, Argentina). La enzima colinesterasa del plasma hidroliza el sustrato butirilcolina formando butirato y tiocolina. Esta última reacciona a $\mathrm{pH}$ regulado, con DTNB para formar 2-nitro-5-mercaptobenzoato, el cual presenta un pico de absorción a $405 \mathrm{~nm}$. La velocidad de formación de este compuesto es proporcional a la actividad de la enzima en la muestra.

Se partió de $10 \mu \mathrm{l}$ de plasma al que se le agregaron $1,5 \mathrm{ml}$ de reactivo conteniendo el sustrato $(0,007 \mathrm{~mol} / \mathrm{L})$, buffer fosfatos $(0,050 \mathrm{~mol} / \mathrm{L},(0,050 \mathrm{~mol} / \mathrm{L}$, $\mathrm{NaH}_{2} \mathrm{PO}_{4} .2 \mathrm{H}_{2} \mathrm{O}(23,4 \mathrm{~g} / \mathrm{L})$ y $\mathrm{Na}_{2} \mathrm{HPO}_{4}(21,3 \mathrm{~g} / \mathrm{L})$, ajustada a pH 7,7$)$ y DTNB $(0,25$

mmol/L). La lectura se llevó a cabo en un espectrofotómetro Shimadzu 1601, termostatizado a $30^{\circ} \mathrm{C}$ y a $405 \mathrm{~nm}$. Se leyeron las absorbancias a 0, 30, 60 y 90 segundos. La actividad se calculó: $\Delta \mathrm{A} / 30 \mathrm{seg} \times 22710$. El factor 22710 contiene el coeficiente de extinción molar del producto a esa temperatura y el factor de dilución de la muestra. 
En ambos casos se realizó ANOVA univariado y test de Student, para comparar estadísticamente los resultados entre experiencias y entre tratamientos con el programa SPSS para Windows.

\subsection{Resultados}

\subsubsection{Medición de colinesterasa eritrocitaria}

La reproducibilidad del método fue testeada midiendo 10 repeticiones de una muestra de SEE, obteniendo un valor de $\bar{x} \pm \mathrm{DE}=4740,5 \pm 418,8 \mathrm{U} / \mathrm{L}$ de células y un $\mathrm{CV} \%=8,9$.

Para verificar si nuestros resultados coincidían con el intervalo de referencia dado por el método (8000 - $13000 \mathrm{U} / \mathrm{L}$ de células), se realizaron las mediciones por duplicado en muestras de sangre entera anticoagulada en ACD y provenientes de diez individuos, obteniéndose un intervalo 3700 - $20500 \mathrm{U} / \mathrm{L}$ de células, siendo el rango de estos datos más amplio que el informado por el fabricante.

La Figura 24 muestra la variación de los valores de $\mathrm{AChE}$ durante 120 días en muestras de SE (gráfica A) y SEE (gráfica B) pertenecientes a tres lotes diferentes. El lote SE040900 fue incluido en esta prueba para verificar los resultados previos y fue estudiado durante 70 días.

Con los datos de los lotes SE020899 y SE250200 se realizó un análisis de varianza tomando en cuenta dos factores, tratamiento y experiencia, considerando el día como covariable. De este análisis surgió que existen diferencias significativas entre las experiencias $(p<0,05)$ y entre los diferentes tratamientos $(p<0,05)$. Se realizó el mismo análisis sin tener en cuenta como tratamiento a la muestra de SE sin estabilizar, o sea comparando sólo las muestras estabilizadas adicionadas con diferentes cantidades de vitaminas. Se obtuvo como resultado que no existen diferencias significativas entre los 
tratamientos $(p>0,05)$, pero sí entre experiencias $(p<0,05)$. Así, en la Figura 25 se muestra la variación de los valores de $\mathrm{AChE}$ para estos dos lotes, considerando a los tratamientos como repeticiones de una misma muestra $(n=13)$.

Figura 24: Estabilidad a largo plazo de los niveles de AChE en muestras de SE (Gráfica A) y de SEE (gráfica B).

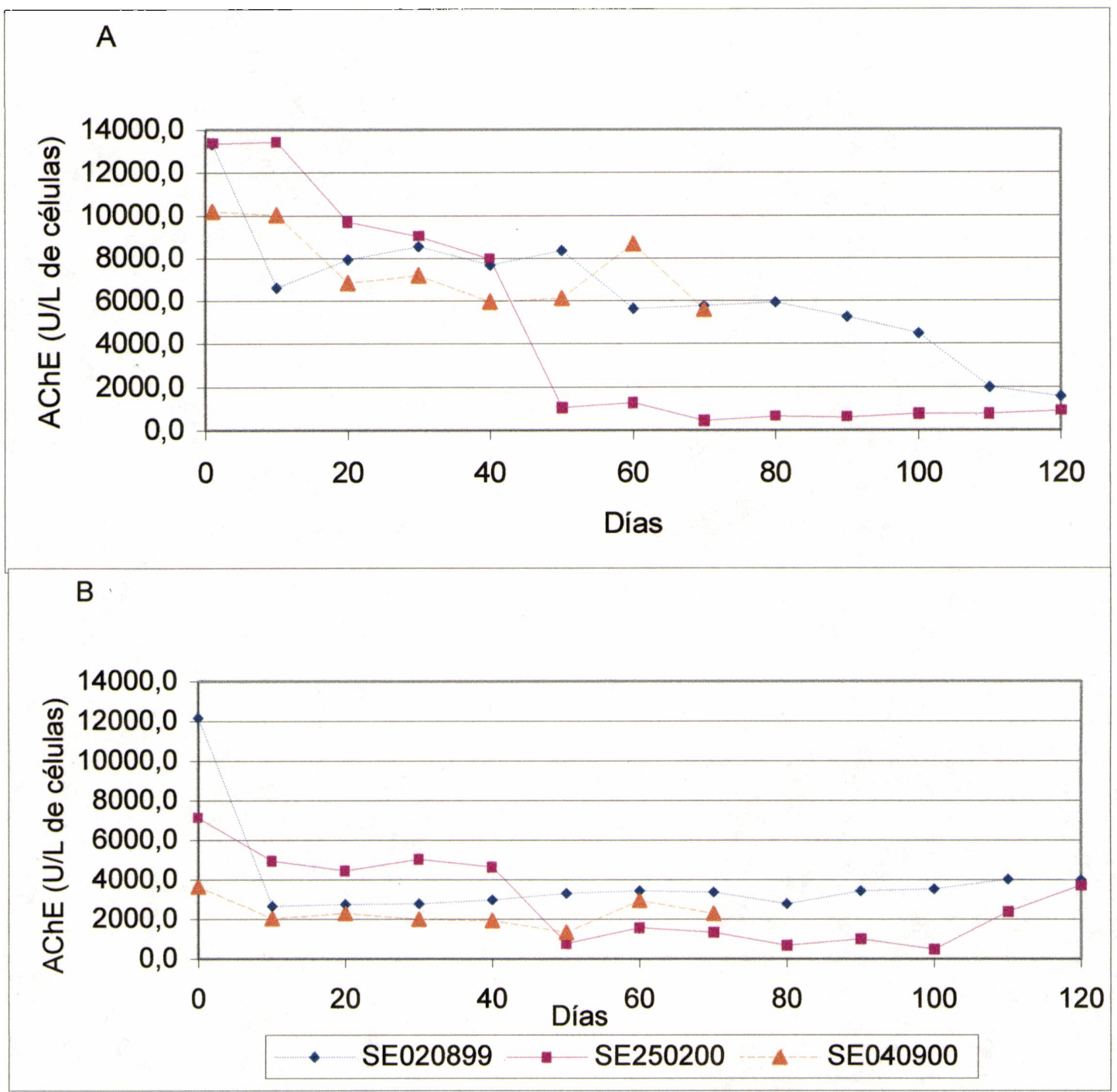


Figura 25: Estabilidad a largo plazo de los niveles de $\operatorname{AChE}(n=13)(\mathrm{U} / \mathrm{L}$ de GR)

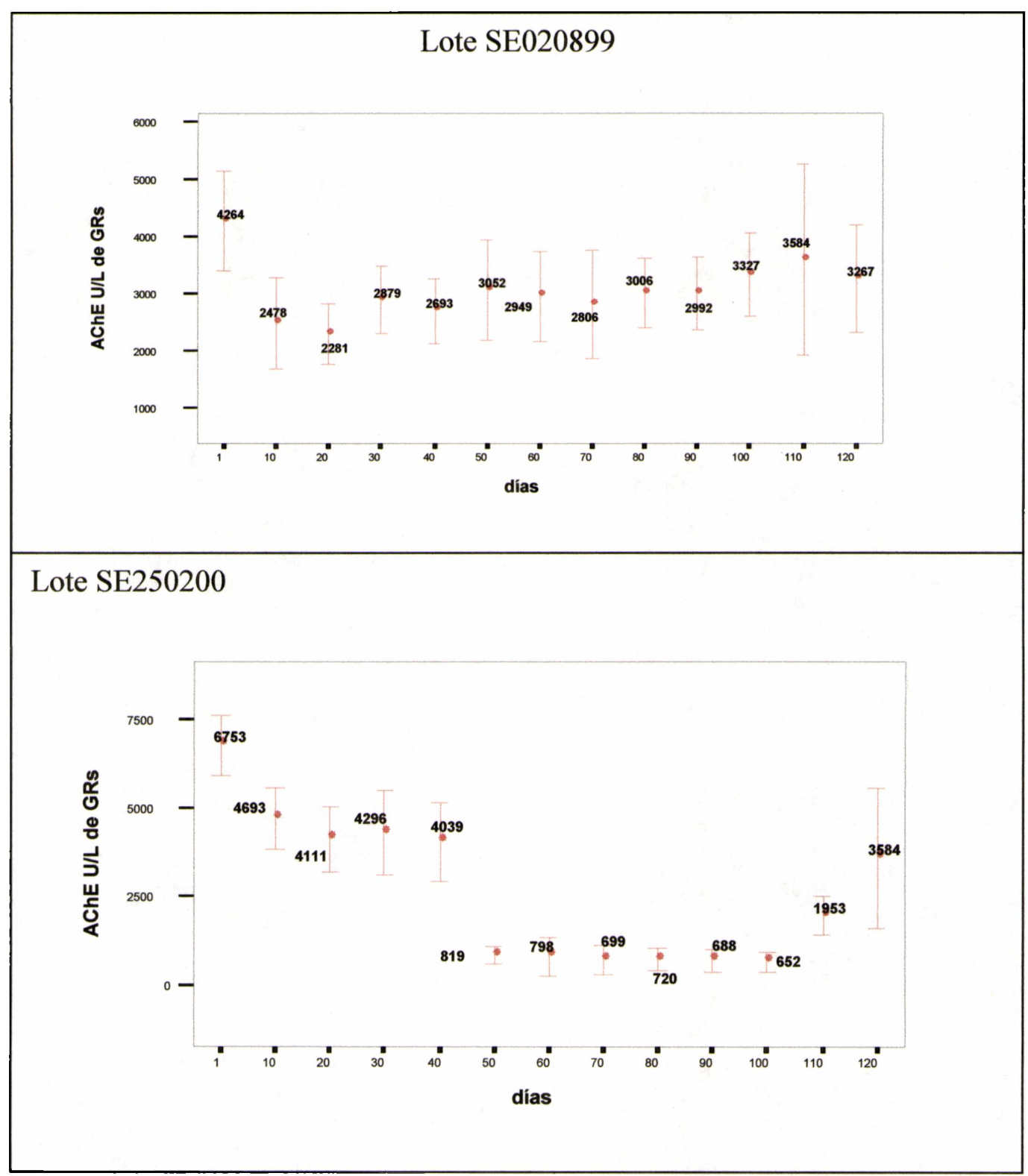


En la Tabla 19 se muestran los valores de $\mathrm{AChE}$, cada 10 días de almacenamiento a $4^{\circ} \mathrm{C}$, en las muestras de SE y SEE de los lotes SE020899, SE200899 y SE250200.

Tabla 19: Estabilidad a largo plazo de los niveles de AChE (U/L de GR) en muestras de $\operatorname{SE}$ y $\operatorname{SEE}(n=2)$.

\begin{tabular}{|c|c|c|c|c|c|c|}
\hline \multirow{3}{*}{ Dia } & \multicolumn{6}{|c|}{ AChE U/L de GR } \\
\hline & \multicolumn{2}{|c|}{ Lote SE020899 } & \multicolumn{2}{|c|}{ Lote SE200899 } & \multicolumn{2}{|c|}{ Lote SE250200 } \\
\hline & SE & SEE & SE & SEE & SE & SEE \\
\hline 1 & 13335,4 & 12167,4 & 20585,3 & 11927,8 & 13334,7 & 7123,2 \\
\hline 10 & 6627,9 & 2648,5 & 10590,1 & 20447,7 & 13410,5 & 4962,5 \\
\hline 20 & 7923,5 & 2756,1 & 11026,2 & 11479,4 & 9710,4 & 4446,5 \\
\hline 30 & 8545,2 & 2802,0 & 10537,3 & 11871,9 & 9022,7 & 5035,3 \\
\hline 40 & 7689,7 & 3498,9 & 8818,4 & 7263,1 & 7967,9 & 4663,4 \\
\hline 50 & 8349,7 & 3305,9 & 6684,0 & 4758,6 & 1051,0 & 785,3 \\
\hline 60 & 5658,0 & 3456,8 & 5225,6 & 4620,7 & 1284,9 & 1559,4 \\
\hline 70 & 5788,0 & 3367,8 & 4012,1 & 4787,7 & 463,8 & 1336,5 \\
\hline 80 & 5925,5 & 2799,3 & 4295,7 & 4791,8 & 643,4 & 699,8 \\
\hline 90 & 5279,0 & 3457,7 & 3647,9 & 4929,9 & 610,2 & 1018,5 \\
\hline 100 & 4510,7 & 3535,3 & 3127,6 & 4705,6 & 759,8 & 501,8 \\
\hline 110 & 1987,6 & 4025,0 & 3134,8 & 3982,6 & 772,1 & 2400,5 \\
\hline 120 & 1564,8 & 4005,8 & 2895,8 & 4383,5 & 762,5 & 3732,1 \\
\hline
\end{tabular}


En las tablas 20, 21 y 22 se muestran las variaciones de los datos de la $\mathrm{AChE}$ en las muestras de SEE adicionada con las diferentes concentraciones de vitamina $\mathrm{E}$, vitamina C y mezcla de ambas vitaminas, para el lote SE020899.

Tabla 20: Estabilidad a largo plazo de los niveles de AChE (U/L de GR) en muestras de SEE adicionada con vitamina E. Lote $020899(n=2)$.

\begin{tabular}{|c|c|c|c|c|c|c|}
\hline \multirow{2}{*}{ Día } & \multicolumn{5}{|c|}{ [Vitamina E] $\mu \mathrm{M}$} \\
\cline { 2 - 7 } & 0 & 0,11 & 0,17 & 0,23 & 0,45 & 0,56 \\
\hline 1 & 12167,4 & 4008,3 & 3888,9 & 4553,5 & 3930,2 & 3883,2 \\
\hline 10 & 2648,5 & 3126,7 & 2631,3 & 3984,3 & 1996,6 & 2006,2 \\
\hline 20 & 2756,1 & 2581,2 & 2241,5 & 2362,5 & 2434,7 & 2409,9 \\
\hline 30 & 2802,0 & 3463,5 & 2510,1 & 2728,6 & 2969,3 & 3153,6 \\
\hline 40 & 3498,9 & 2422,6 & 2501,5 & 2888,5 & 2596,3 & 2781,8 \\
\hline 50 & 3305,9 & 2898,7 & 3878,2 & 2626,9 & 2747,2 & 3233,3 \\
\hline 60 & 3456,8 & 2757,8 & 2655,6 & 2767,5 & 2632,5 & 3013,1 \\
\hline 70 & 3367,8 & 2887,7 & 2475,6 & 2667,3 & 2522,5 & 2813,1 \\
\hline 80 & 2799,3 & 3642,8 & 3338,4 & 2694,2 & 3044,3 & 3125,3 \\
\hline 90 & 3457,7 & 3311,1 & 2757,3 & 2877,3 & 2791,3 & 3096,2 \\
\hline 100 & 3535,3 & 3046,2 & 2793,4 & 2814,1 & 3665,5 & 3521,9 \\
\hline 110 & 4025,0 & 3203,9 & 3210,0 & 3314,8 & 5961,5 & 3414,2 \\
\hline 120 & 4005,8 & 3157,8 & 3208,8 & 2940,4 & 3058,9 & 3551,7 \\
\hline
\end{tabular}


Tabla 21: Estabilidad a largo plazo de los niveles de AChE (U/L de GR) en muestras de SEE adicionada con vitamina C. Lote $020899(n=2)$.

\begin{tabular}{|c|c|c|}
\hline \multirow{2}{*}{ Día } & \multicolumn{2}{|c|}{ [Vitamina C] mM } \\
\hline & 0,68 & 1,36 \\
\hline 1 & 4846,5 & 4106,3 \\
\hline 10 & 1977,5 & 2231,3 \\
\hline 20 & 2335,7 & 2054,6 \\
\hline 30 & 2901,6 & 2888,4 \\
\hline 40 & 3363,6 & 2723,7 \\
\hline 50 & 2450,8 & 3582,4 \\
\hline 60 & 2354,1 & 3155,3 \\
\hline 70 & 1894,1 & 3053,2 \\
\hline 80 & 2782,4 & 3076,7 \\
\hline 90 & 2791,2 & 3634,1 \\
\hline 100 & 3404,6 & 3122,8 \\
\hline 110 & 2862,0 & 4117,3 \\
\hline 120 & 3092,5 & 3470,6 \\
\hline
\end{tabular}


Tabla 22: Estabilidad a largo plazo de los niveles de AChE (U/L de GR) en muestras de $\mathrm{SEE}$ adicionada con vitaminas E y C. Lote $020899(\mathrm{n}=2)$.

\begin{tabular}{|c|c|c|c|c|}
\hline \multirow{2}{*}{ Día } & \multicolumn{4}{|c|}{ [Vitamina E] $\mu \mathrm{M}+[$ Vitamina C] mM } \\
\cline { 2 - 5 } & $0,23 \mu \mathrm{M}+0,68 \mathrm{mM}$ & $0,23 \mu \mathrm{M}+1,36 \mathrm{mM}$ & $0,56 \mu \mathrm{M}+0,68 \mathrm{mM}$ & $0,56 \mu \mathrm{M}+1,36 \mathrm{mM}$ \\
\hline $\mathbf{1}$ & 4027,6 & 4258,5 & 5220,9 & 4174,4 \\
\hline $\mathbf{1 0}$ & 2723,0 & 2653,6 & 2346,4 & 2301,6 \\
\hline $\mathbf{2 0}$ & 1850,2 & 1944,9 & 2051,0 & 2343,1 \\
\hline $\mathbf{3 0}$ & 2731,2 & 2585,6 & 3266,3 & 2542,1 \\
\hline $\mathbf{4 0}$ & 2706,7 & 2496,7 & 2819,7 & 2319,2 \\
\hline $\mathbf{5 0}$ & 2707,7 & 2960,3 & 2743,1 & 3493,5 \\
\hline $\mathbf{6 0}$ & 3216,5 & 3412,9 & 3467,8 & 2489,5 \\
\hline $\mathbf{7 0}$ & 3306,7 & 2741,9 & 3577,8 & 2367,5 \\
\hline $\mathbf{8 0}$ & 2586,5 & 2711,2 & 3095,9 & 3171,3 \\
\hline $\mathbf{9 0}$ & 2935,1 & 2547,2 & 2923,6 & 3207,4 \\
\hline $\mathbf{1 0 0}$ & 3831,3 & 2968,3 & 3497,3 & 2780,0 \\
\hline $\mathbf{1 1 0}$ & 3503,0 & 3269,0 & 2923,5 & 3922,6 \\
\hline $\mathbf{1 2 0}$ & 2547,4 & 2577,5 & & \\
\hline
\end{tabular}

\subsubsection{Medición de colinesterasa plasmática}

La reproducibilidad del método fue testeada midiendo 10 repeticiones de una muestra de sangre entera anticoagulada en ACD obteniendo un valor de $\bar{x}=2712,2 \pm 195,2 \mathrm{U} / \mathrm{L}$ y un $\mathrm{CV} \%=7,2$.

Con la finalidad de determinar los valores en muestras normales, según nuestras condiciones experimentales, se realizaron las mediciones por duplicado en muestras de 
sangre entera anticoagulada en ACD provenientes de diez individuos, obteniendo un intervalo de 1500 - $5900 \mathrm{U} / \mathrm{L}$. El CV\% interensayo resultó ser igual a 28,8\%. El intervalo de referencia dado por el método para esta temperatura es $4000-11200 \mathrm{U} / \mathrm{L}$, siendo nuestros valores más bajos que los indicados por el fabricante.

La variación de los valores de $\mathrm{PChE}$ en $\mathrm{SE}$ y $\mathrm{SEE}$, cada 10 días de almacenamiento a $4^{\circ} \mathrm{C}$, en los lotes SE020899, SE200899 y SE250200, se muestra en la Tabla 23. En las tablas 24,25 y 26 se muestran los valores promedio $(\bar{x} \pm \mathrm{DE})$ y los CV\% totales de las mediciones de PChE realizadas cada 10 días durante 120 días de almacenamiento a $4^{\circ} \mathrm{C}$ en los tres lotes, para los diferentes tratamientos. 
Tabla 23: Estabilidad a largo plazo de los niveles de PChE (U/L de plasma) en muestras de SE y SEE

\begin{tabular}{|c|c|c|c|c|c|c|}
\hline \multirow{2}{*}{ Dia } & \multicolumn{5}{|c|}{ PChE U/L } \\
\cline { 2 - 7 } & Lote SE020899 & \multicolumn{2}{|c|}{ Lote SE200899 } & \multicolumn{2}{|c|}{ Lote SE250200 } \\
\cline { 2 - 7 } & SE & SEE & SE & SEE & SE & SEE \\
\hline 1 & 2610,9 & 3671,5 & 1757,8 & 1468,6 & 3190,8 & 2795,6 \\
\hline 10 & 2915,2 & 2221,0 & 2336,9 & 1076,4 & 3152,9 & 2765,3 \\
\hline 20 & 2720,7 & 3643,4 & 2092,4 & 2145,3 & 3558,7 & 3227,1 \\
\hline 30 & 4446,6 & 3494,3 & 2756,2 & 2504,2 & 3291,4 & 2561,7 \\
\hline 40 & 4372,4 & 3599,5 & 2512,5 & 2768,3 & 2449,6 & 2652,8 \\
\hline 50 & 3623,0 & 3459,5 & 3470,8 & 3342,9 & 2545,0 & 1467,1 \\
\hline 60 & 2881,1 & 3483,7 & 3559,4 & 3255,1 & 2388,3 & 2317,9 \\
\hline 70 & 4665,4 & 4588,9 & 3174,1 & 3124,1 & 2619,2 & 1798,6 \\
\hline 80 & 4326,3 & 3454,9 & 3124,9 & 3101,4 & 2962,1 & 2340,6 \\
\hline 90 & 4574,6 & 3877,4 & 2426,2 & 3078,7 & 2595,8 & 2968,9 \\
\hline 100 & 2750,9 & 3327,0 & 3291,4 & 3361,1 & 2794,8 & 2454,2 \\
\hline 110 & 2765,9 & 2557,9 & 2759,3 & 3136,2 & 1997,7 & 2522,3 \\
\hline 120 & 2850,8 & 3493,6 & 2825,9 & 2813,8 & 2374,7 & 2257,4 \\
\hline$x \pm D E$ & 3500,3 & 3451,7 & 2776,0 & 2705,9 & 2763,2 & 2471,5 \\
& $\pm 842,2$ & $\pm 571,2$ & $\pm 542,7$ & $\pm 727,4$ & $\pm 443,4$ & $\pm 465,6$ \\
\hline & $24,1 \%$ & $16,5 \%$ & $19,5 \%$ & $26,9 \%$ & $16,0 \%$ & $18,8 \%$ \\
\hline
\end{tabular}

Al realizar un test de student para comparar los dos tratamientos (muestra SE y SEE) no se encontraron diferencias significativas en ninguna de las experiencias $(p>0,05)$. 
Tabla 24: Valores de y CV\% de la PChE (U/L de plasma) en muestras de SEE adicionada con diferentes concentraciones de vitamina $E(n=13)$

\begin{tabular}{|c|c|c|c|c|c|}
\hline \multirow{4}{*}{ Lote } & \multicolumn{5}{|c|}{ [Vitamina E] } \\
\cline { 2 - 6 } & $0,11 \mu \mathrm{M}$ & $0,17 \mu \mathrm{M}$ & $0,23 \mu \mathrm{M}$ & $0,45 \mu \mathrm{M}$ & $0,56 \mu \mathrm{M}$ \\
& $\bar{x} \pm \mathrm{DE}(\mathrm{CV} \%)$ & $\bar{x} \pm \mathrm{DE}(\mathrm{CV} \%)$ & $\bar{x} \pm \mathrm{DE}(\mathrm{CV} \%)$ & $\bar{x} \pm \mathrm{DE}(\mathrm{CV} \%)$ & $\bar{x} \pm \mathrm{DE}(\mathrm{CV} \%)$ \\
\hline SE020899 & $3179,0 \pm 754,8$ & $3135,0 \pm 603,7$ & $3351,5 \pm 689,8$ & $3255,4 \pm 895,2$ & $3239,7 \pm 1027,6$ \\
& $(\mathbf{2 3 , 7 \% )}$ & $(\mathbf{1 9 , 3} \%)$ & $\mathbf{( 2 0 , 6 \% )}$ & $\mathbf{( 2 7 , 5 \% )}$ & $\mathbf{( 3 1 , 7 \% )}$ \\
\hline SE200899 & $3025,0 \pm 462,4$ & $3105,4 \pm 608,7$ & $2928,7 \pm 646,4$ & $2906,4 \pm 656,7$ & $3192,7 \pm 617,0$ \\
& $(15,3 \%)$ & $(19,6 \%)$ & $\mathbf{( 2 2 , 1 \% )}$ & $\mathbf{( 2 2 , 6 \% )}$ & $(\mathbf{1 9 , 3 \% )}$ \\
\hline SE250200 & $2582,4 \pm 581,0$ & $\mathbf{2 5 1 3 , 5 \pm 4 6 8 , 4}$ & $\mathbf{2 7 4 4 , 8 \pm 3 6 4 , 4}$ & $\mathbf{2 5 6 4 , 9 \pm 7 2 9 , 8}$ & $2547,3 \pm 393,0$ \\
& $(\mathbf{2 2 , 5 \% )}$ & $(\mathbf{1 8 , 6 \% )}$ & $\mathbf{( 1 3 , 3 \% )}$ & $\mathbf{( 2 8 , 5 \% )}$ & $(\mathbf{1 5 , 4 \% )}$ \\
\hline
\end{tabular}

Tabla 25: Valores de $\bar{x} \pm$ DE y CV\% de la PChE (U/L de plasma) en muestras de SEE adicionada con diferentes concentraciones de vitamina $C(n=13)$

\begin{tabular}{|c|c|c|}
\hline \multirow{2}{*}{ Lote } & \multicolumn{2}{|c|}{ Vitamina C] } \\
\cline { 2 - 3 } & $0,68 \mathrm{mM}$ & $1,36 \mathrm{mM}$ \\
& $\bar{x} \pm \mathrm{DE}(\mathrm{CV} \%)$ & $\bar{x} \pm \mathrm{DE}(\mathrm{CV} \%)$ \\
\hline SE020899 & $3143,4 \pm 813,1(\mathbf{2 5 , 9} \%)$ & $3559,0 \pm 964,9(\mathbf{2 7}, 1 \%)$ \\
\hline SE200899 & $2985,4 \pm 670,6(22,5 \%)$ & $3007,0 \pm 535,7(\mathbf{1 7}, 8 \%)$ \\
\hline SE250200 & $2667,2 \pm 660,6(25,3 \%)$ & $2630,5 \pm 610,4(\mathbf{2 3}, 2 \%)$ \\
\hline
\end{tabular}


Figura 27: Curva de calibración

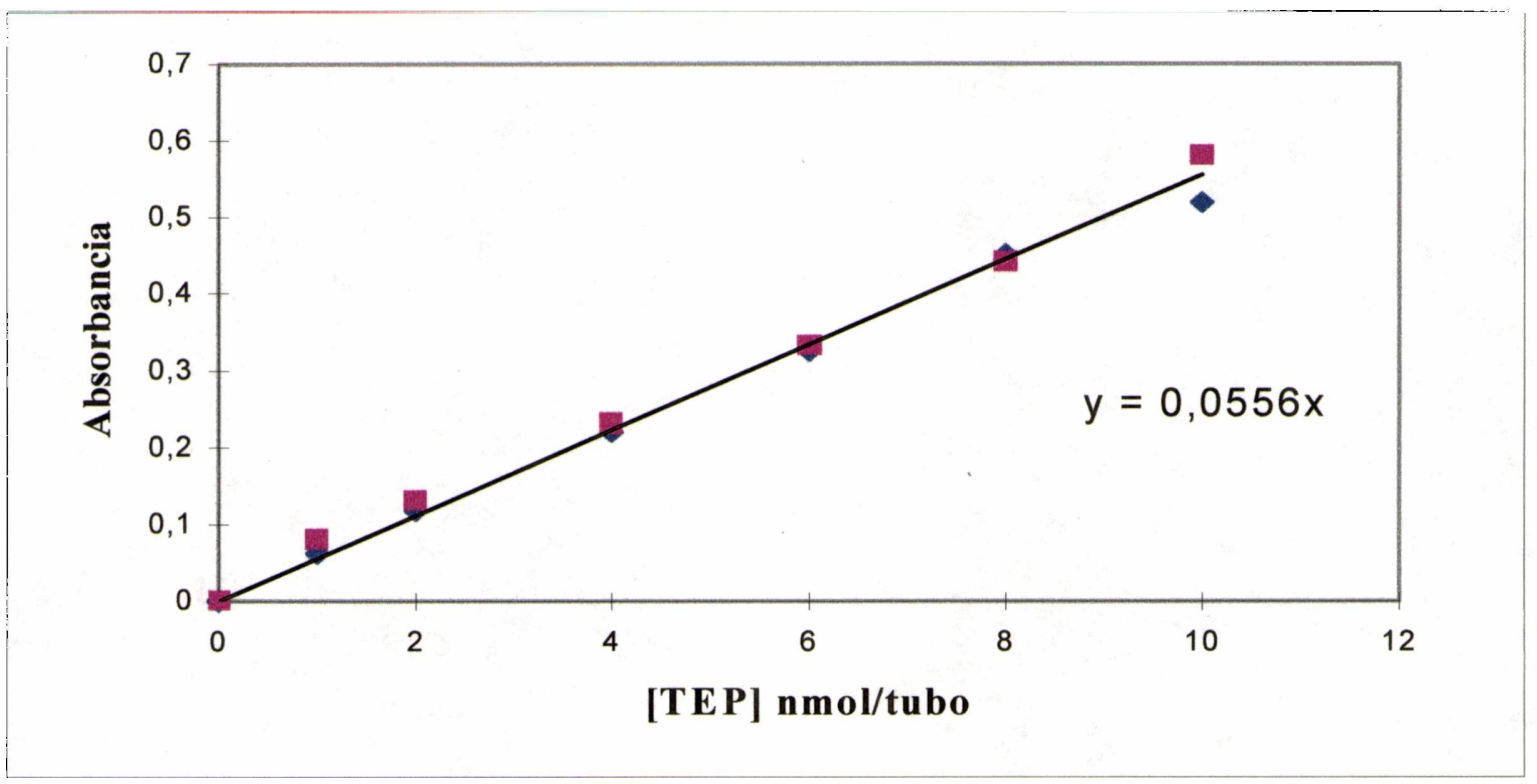

La precisión del método se determinó realizando 10 repeticiones de una misma muestra obteniendo un valor de $\bar{x} \pm \mathrm{DE}$ de $7,00 \pm 0,21 \mathrm{nmol} / \mathrm{ml}$ de plasma, con un $\mathrm{CV} \%=3,0$. Este valor es cercano al hallado en la literatura de 3,3\% (Coudray et al, 1995). El rango de valores normales hallado al realizar las mediciones en diez individuos fue de $15,22 \pm 3,98 \mathrm{nmol} / \mathrm{ml}$ de plasma.

Los datos de MDA en $\mathrm{nmol} / \mathrm{ml}$ de plasma, pertenecientes a los diferentes lotes estudiados, se resumen en las tablas 27 y 28 . Los datos corresponden a medias de determinaciones hechas por duplicado.

El lote 200899 dio valores extremadamente altos en las muestras estabilizadas. Cuando se realizó el análisis de varianza tomando en cuenta los factores, tratamiento y experiencia y teniendo en cuenta al día como covariable, surgió que existían diferencias significativas entre las experiencias $(p<0,05)$ aún eliminando dicha experiencia del análisis. También existen diferencias entre los tratamientos $(\mathrm{p}<0,05)$ si no se tiene en cuenta la muestra de SE sin estabilizar, es decir comparando sólo las muestras estabilizadas adicionadas con diferentes cantidades de vitaminas. Como resultado se 
Tabla 26: Valores de $\bar{x} \pm \mathrm{DE}$ y CV\% de la PChE en muestras de SEE adicionada con diferentes concentraciones de ambas vitaminas $(n=13)$

\begin{tabular}{|c|c|c|c|c|}
\hline \multirow{2}{*}{ Lote } & \multicolumn{4}{|c|}{ [Vitamina E] + [Vitamina C] } \\
\cline { 2 - 5 } & $0,23 \mu \mathrm{M}+0,68 \mathrm{mM}$ & $0,23 \mu \mathrm{M}+1,36 \mathrm{mM}$ & $0,56 \mu \mathrm{M}+0,68 \mathrm{mM}$ & $0,56 \mu \mathrm{M}+1,36 \mathrm{mM}$ \\
& $\bar{x} \pm \mathrm{DE}(\mathrm{CV} \%)$ & $\bar{x} \pm \mathrm{DE}(\mathrm{CV} \%)$ & $\bar{x} \pm \mathrm{DE}(\mathrm{CV} \%)$ & $\bar{x} \pm \mathrm{DE}(\mathrm{CV} \%)$ \\
\hline SE020899 & $3465,1 \pm 661,5$ & $3098,4 \pm 855,9$ & $3208,2 \pm 1141,6$ & $3120,8 \pm 676,2$ \\
& $(\mathbf{1 9 , 1 )}$ & $(\mathbf{2 7 , 6 \% )}$ & $\mathbf{( 3 5 , 6 \% )}$ & $\mathbf{( 2 1 , 7 )}$ \\
\hline SE200899 & $2980,8 \pm 492,8$ & $2701,5 \pm 706,2$ & $3129,9 \pm 624,8$ & $3064,4 \pm 411,3$ \\
& $(\mathbf{1 6 , 5 \% )}$ & $(\mathbf{2 6 , 1 \% )}$ & $\mathbf{( 2 0 , 0 \% )}$ & $\mathbf{( 1 3 , 4 \% )}$ \\
\hline SE250200 & $2497,5 \pm 482,7$ & $2712,5 \pm 580,1$ & $2493,3 \pm 779,1$ & $2791,8 \pm 437,7$ \\
& $(\mathbf{1 9 , 3 \% )}$ & $(\mathbf{2 1 , 4 \% )}$ & $\mathbf{( 3 1 , 2 \% )}$ & $\mathbf{( 1 5 , 7 \% )}$ \\
\hline
\end{tabular}

Se realizó un análisis de varianza tomando en cuenta a los tratamientos como factor y al día como covariable y se encontró, que no existen diferencias significativas entre ninguno de los tratamientos, en ninguna de las experiencias ( $>>0,05)$. Teniendo en cuenta esto último, en la Figura 26 se muestra la variación de los valores de PChE en distintas experiencias, en diferentes días, considerando los distintos tratamientos como repeticiones del mismo día. 
Figura 26: Estabilidad a largo plazo de los niveles de PChE (U/L de plasma)

\section{Lote SE020899}

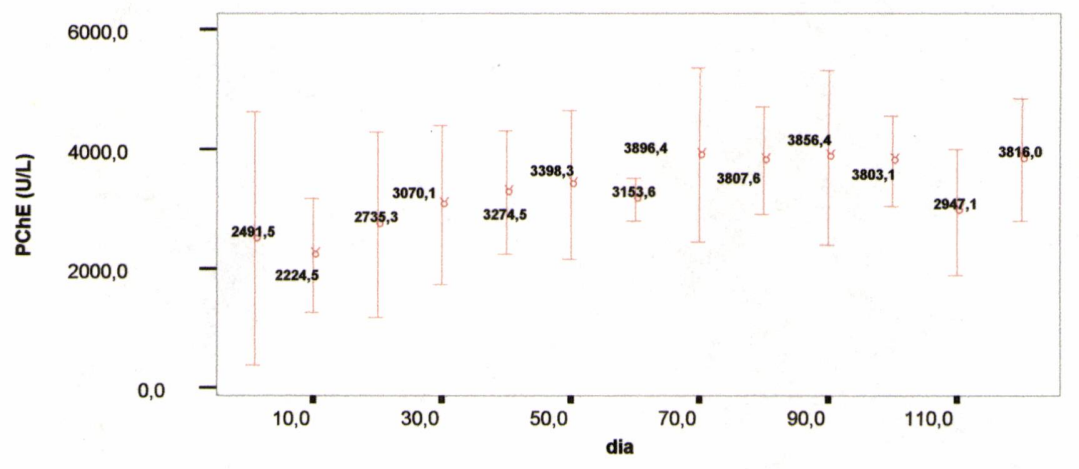

Error Bars show Mean $+1-2,0$ SD

Lote SE250200

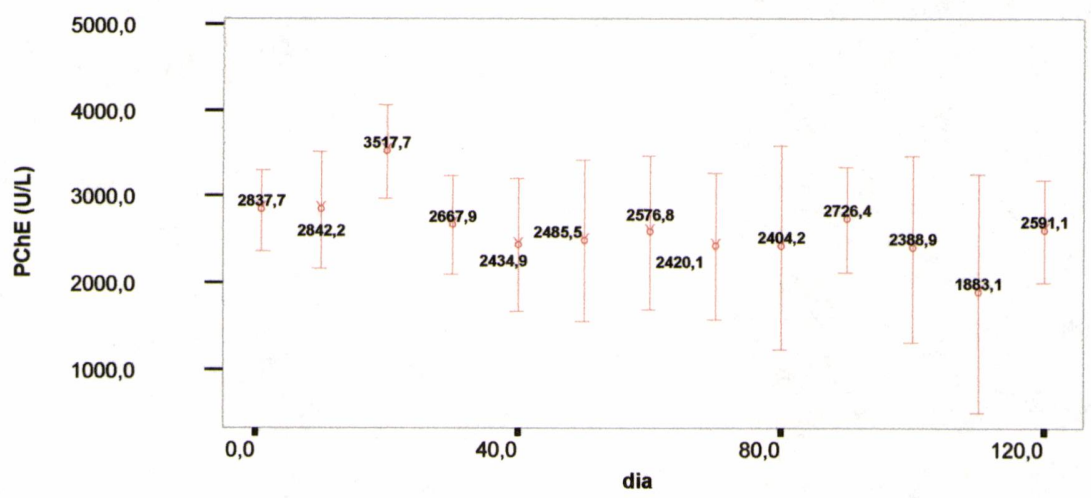




\section{Lipoperoxidación}

\subsection{Material y métodos}

Como es extremadamente difícil medir directamente las especies reactivas del oxígeno, debido a su alta reactividad, su corta vida media y sus bajas concentraciones, hay métodos basados en la determinación de productos de degradación de las sustancias peroxidadas para evaluar el nivel oxidativo de la célula. Los radicales $\mathrm{OH}^{\circ}$ pueden extraer un átomo de $\mathrm{H}$ que está unido a un $\mathrm{C}$ de la cadena de un ácido graso poliinsaturado, formando así un hidroperóxido lipídico. Luego, por división o por ruptura homolítica, éste puede dar compuestos de menor PM. La estimación de la peroxidación lipídica en sangre ha estado basada en la determinación del contenido en plasma de dienos conjugados, de hidroperóxidos lipídicos o de malondialdehido (MDA).
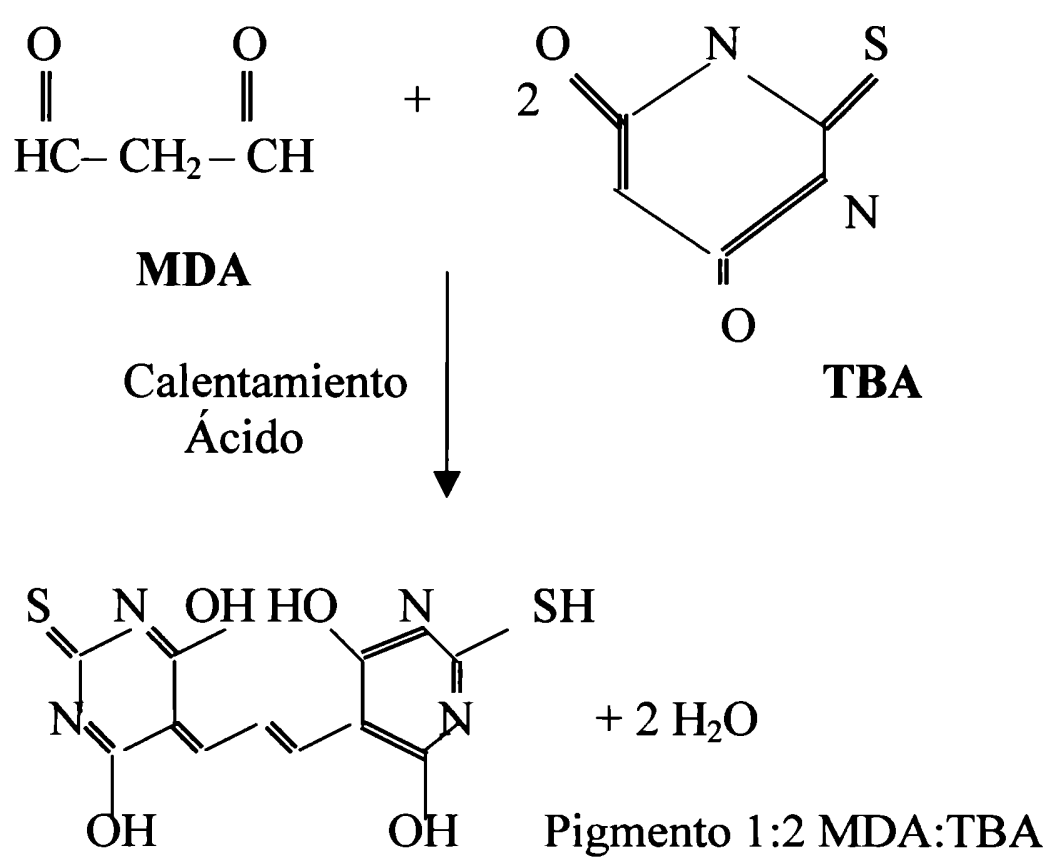

Este último, es un producto cuya formación está en proporción constante a la lipoperoxidación, forma parte de un grupo de sustancias agrupadas con el nombre de TBARS, es por lo tanto un buen indicador de peroxidación tanto in vivo como in vitro 
(Ruiz et al., 1999). Por acción del calor y a bajo $\mathrm{pH}$, el MDA reacciona con el ácido tiobarbitúrico (TBA) dando un compuesto de adición $\mathrm{MDA}(\mathrm{TBA})_{2}$ color rosa con una alta absortibidad molar a $532 \mathrm{~nm}$ :

La reacción tiene un pH óptimo de 4,5 (Ohkawa, 1979), siendo este factor una de las variables más importante a controlar en esta reacción. La técnica utilizada en este trabajo fue la descripta por Wong et al.,1987, con modificaciones menores. Se colocaron $750 \mu \mathrm{l}$ de $\mathrm{H}_{3} \mathrm{PO}_{4}(0,44 \mathrm{~mol} / \mathrm{L}, \mathrm{pH}=4,5)$, se agregaron $50 \mu \mathrm{l}$ de plasma y 750 $\mu \mathrm{l}$ de TBA $0,67 \%$, se mezcló en vortex y se calentó a ebullición durante 1 hora. Se frenó la reacción en hielo y se leyó la absorbancia a $532 \mathrm{~nm}$ en un espectrofotómetro Shimadzu 1601. Se realizaron controles para comprobar que los aldehídos adicionados a la SE no interferían en la reacción; los mismos se llevaron a cabo siguiendo la técnica antes mencionada, agregando en lugar de plasma, $50 \mu \mathrm{l}$ del aldehído en la concentración utilizada en la estabilización.

Para calcular la concentración de MDA, en nmoles/tubo o en en $\mu \mathrm{mol} / \mathrm{L}$ de plasma, se utilizó una curva de calibración trazada con 1,1,3,3-tetrahidroxipropano (TEP) como patrón, ya que éste se comporta exactamente igual que el MDA y es más estable. Se midieron, por duplicado y cada diez días, los valores de MDA en muestras de las experiencias SE020899, SE200899 y SE250200.

\subsection{Resultados}

La concentración de MDA en las muestras, se calculó utilizando la curva de calibración mostrada en la Figura 27, obtenida usando TEP como patrón: 
obtuvo que no existen diferencias significativas entre los tratamientos $(p>0,05)$, pero sí entre experiencias $(p<0,05)$.

La muestra de SEE presentó desde el primer día un valor más alto en los niveles de MDA que la muestra de SE. Pero, teniendo en cuenta el aumento porcentual relativo al primer día, la muestra de SE presenta mayor aumento relativo que los demás tratamientos. 


\begin{tabular}{|c|c|c|c|c|c|c|c|c|c|c|c|c|c|}
\hline 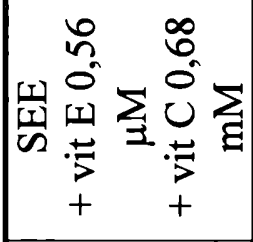 & $\hat{\tilde{N}}$ & $\vec{\sim}$ & $\vec{m}$ & $\begin{array}{l}a \\
\dot{m}\end{array}$ & $n$ & $\begin{array}{l}m \\
\infty \\
\infty\end{array}$ & $\begin{array}{l}n \\
0 \\
0 \\
i\end{array}$ & $\begin{array}{c}n \\
\infty \\
\infty \\
m\end{array}$ & $\frac{n}{n}$ & $\begin{array}{l}0 \\
\tilde{n} \\
i n\end{array}$ & i & $\sigma^{\circ}$ & $\infty$ \\
\hline 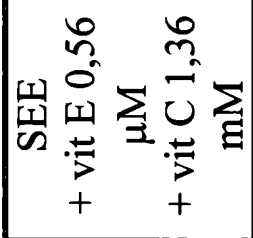 & $\hat{\tilde{N}}$ & $\begin{array}{l}\infty \\
\sim \\
\sim\end{array}$ & $\begin{array}{l}0 \\
\text { â }\end{array}$ & $\tilde{m}$ & $\begin{array}{l}0 \\
\stackrel{\rho}{\sigma}\end{array}$ & $\begin{array}{l}0 \\
\text { Ni } \\
\text { ñ }\end{array}$ & $\begin{array}{l}0 \\
0 \\
\rho_{n}\end{array}$ & $\begin{array}{l}0 \\
g \\
q\end{array}$ & $\frac{m}{n}$ & $\begin{array}{l}\dot{*} \\
\dot{n}\end{array}$ & $\begin{array}{l}\infty \\
\tilde{\sigma}\end{array}$ & $\stackrel{m}{2}^{2}$ & $\varkappa_{\infty}$ \\
\hline 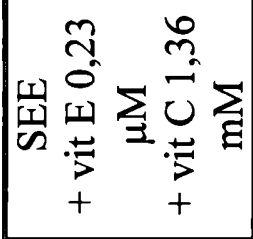 & $\vec{m}$ & 完 & $\hat{n}$ & $\tilde{m}$ & గ̌ & $\hat{\tilde{N}}$ & $\begin{array}{l}0 \\
\tilde{n}\end{array}$ & $\hat{n}$ & $\tilde{n}$ & สิ & $\tilde{n}$ & $n$ & ר్ \\
\hline 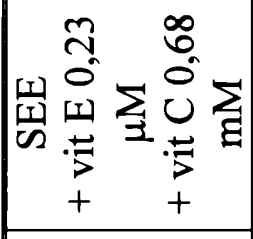 & $\frac{\hat{m}}{m}$ & बे & in & 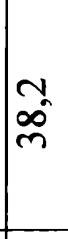 & $\hat{\sigma}$ & 㐫 & $\dot{\sim}_{\tilde{m}}^{+}$ & $\frac{\hat{n}}{n}$ & $\sqrt{6}$ & $\begin{array}{l}0 \\
\dot{J}\end{array}$ & $\mid \infty$ & $\vec{\circ}$ & ๙ু \\
\hline 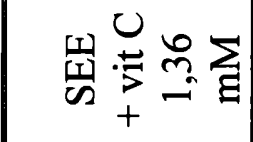 & $\stackrel{\infty}{\infty}$ & $\begin{array}{l}\sigma_{2} \\
\vec{m}\end{array}$ & î & $\tilde{m}^{2}$ & $\hat{q}$ & $\stackrel{\dot{m}}{m}$ & $\begin{array}{l}0 \\
\tilde{n} \\
m\end{array}$ & $\frac{\sigma}{n}$ & $\begin{array}{l}2 \\
\infty\end{array}$ & రె. & $\begin{array}{l}\infty \\
n \\
n\end{array}$ & in & $\begin{array}{l}\infty \\
\sigma^{-}\end{array}$ \\
\hline 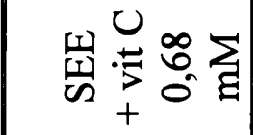 & on & $\begin{array}{l}m \\
\dot{m}\end{array}$ & $\stackrel{\sim}{\mathcal{Y}}$ & $\frac{\pi}{\sigma}$ & $\dot{f}^{\circ}$ & $\tilde{n}$ & $\begin{array}{l}0 \\
\infty \\
\infty \\
\sim\end{array}$ & $\begin{array}{l}\dot{\sigma} \\
g \\
g\end{array}$ & $\begin{array}{l}m \\
\infty \\
\infty\end{array}$ & 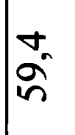 & \begin{tabular}{l}
$\forall$ \\
\multirow{\sigma}{*}{}
\end{tabular} & $\begin{array}{l}0 \\
\text { ชิ }\end{array}$ & $\frac{\infty}{\infty}$ \\
\hline 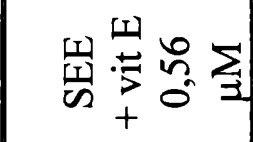 & $\hat{n}$ & ๙2. & $\begin{array}{l}0 \\
\stackrel{f}{\mathcal{F}}\end{array}$ & $\frac{0}{\vec{f}}$ & $\tilde{y}^{\circ}$ & Ñ & $\begin{array}{l}\infty \\
\sim \\
\sim\end{array}$ & $\frac{n}{n}$ & $\begin{array}{l}0 \\
0 \\
i n \\
i n\end{array}$ & $\begin{array}{l}0 \\
\text { î }\end{array}$ & ลิ & $\stackrel{0}{8}$ & $\begin{array}{l}g \\
\dot{J}\end{array}$ \\
\hline 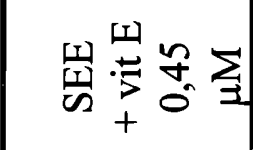 & $\frac{N}{N}$ & $\begin{array}{l}0 \\
\dot{m}\end{array}$ & 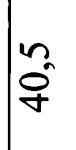 & $\begin{array}{c}m \\
\infty \\
\infty\end{array}$ & 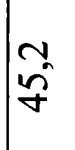 & 我 & $\begin{array}{l}\sigma \\
\text { ते }\end{array}$ & $\underset{\substack{+\dot{\infty}}}{\infty}$ & $\begin{array}{l}a \\
\infty \\
\infty \\
\infty\end{array}$ & ๙ู & $\approx$ & 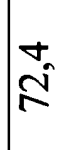 & $\mid \begin{array}{l}\infty \\
\varnothing \\
\varnothing\end{array}$ \\
\hline 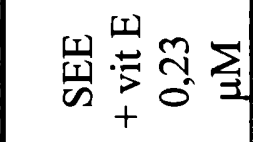 & $\underset{⿱}{\dot{\infty}}$ & $\begin{array}{l}\sigma^{\prime} \\
\dot{m}\end{array}$ & ชู & $\begin{array}{l}0 \\
\stackrel{n}{f}\end{array}$ & 次 & $\begin{array}{l}\infty \\
n \\
n\end{array}$ & $\begin{array}{l}n \\
n \\
m\end{array}$ & $\hat{n}$ & $a^{2}$ & ले & $\hat{n}$ & $\overrightarrow{e^{n}}$ & $m^{m}$ \\
\hline 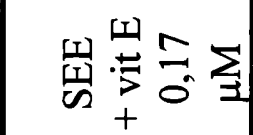 & $\stackrel{+}{\infty}$ & $\begin{array}{l}m \\
\mathfrak{b}^{\circ}\end{array}$ & $\begin{array}{l}a \\
b^{\circ}\end{array}$ & $\begin{array}{l}\sigma \\
b^{\circ}\end{array}$ & $\stackrel{n}{\mathscr{m}}$ & $\frac{\pi}{m}$ & $\tilde{\sim}$ & $\stackrel{\sigma_{n}}{\stackrel{f}{f}}$ & $\begin{array}{l}0 \\
a^{n} \\
n\end{array}$ & $\frac{\pi}{6}$ & $\frac{\infty}{\sigma}$ & $\begin{array}{l}a \\
\dot{d} \\
0\end{array}$ & $a^{\circ}$ \\
\hline 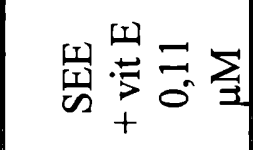 & $\hat{\imath}$ & $\begin{array}{l}0 \\
\infty \\
i\end{array}$ & $\begin{array}{l}\infty \\
0 \\
\infty \\
\infty\end{array}$ & $\tilde{\gamma}^{2}$ & $\stackrel{n}{\mathscr{m}}$ & $\frac{n}{m}$ & $\vec{\sim}$ & $\begin{array}{l}0 \\
\infty \\
\infty \\
m\end{array}$ & 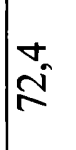 & $\frac{n}{n}$ & $\vec{n}$ & $\frac{\pi}{2}$ & $\frac{m}{a}$ \\
\hline 岀 & $\hat{\vec{N}}$ & 茫 & $\hat{\tilde{m}}$ & $\begin{array}{l}n \\
0 \\
\infty \\
m\end{array}$ & $\begin{array}{l}n \\
n \\
m\end{array}$ & $\frac{a}{N}$ & $\frac{\sigma_{m}}{m}$ & $\begin{array}{l}n \\
\tilde{f}\end{array}$ & $\begin{array}{l}0 \\
b_{0}^{\circ}\end{array}$ & $\frac{n}{N}$ & 吕 & $\frac{\vec{n}}{\infty}$ & $\frac{\sigma^{\circ}}{\not{\infty}}$ \\
\hline 됭 & నू & $\tilde{\sim}$ & 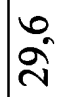 & $\underset{\infty}{\sigma^{\prime}}$ & గn & $a^{2}$ & $\frac{n}{n}$ & $\begin{array}{l}0 \\
n^{n} \\
f\end{array}$ & $\hat{q}$ & $\stackrel{\sigma}{\mathscr{\sigma}}$ & $\stackrel{n}{n}$ & $i$ & $\stackrel{m}{R}^{2}$ \\
\hline$\stackrel{\mathscr{*}}{a}$ & - & 으 & 유 & i & 앙 & in & 8 & 유 & $\infty$ & প & 8 & 을 & 오 \\
\hline
\end{tabular}




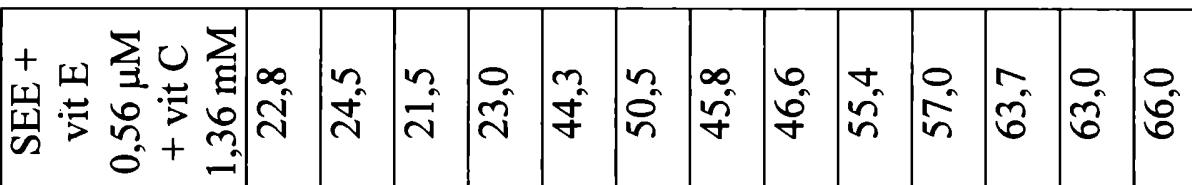

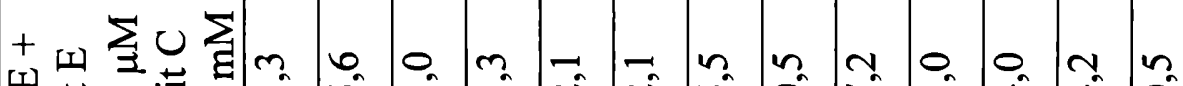

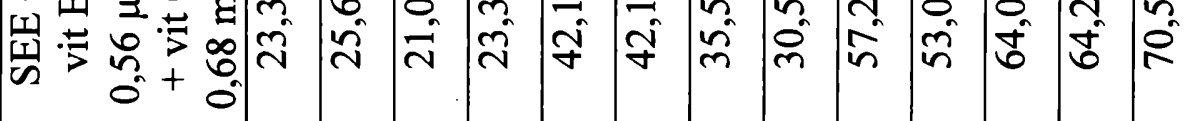

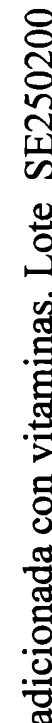

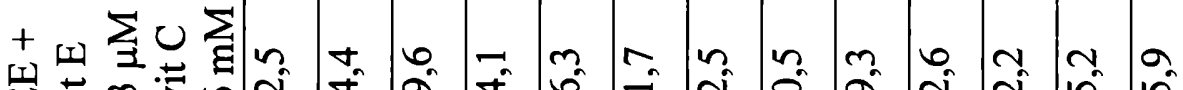

芔

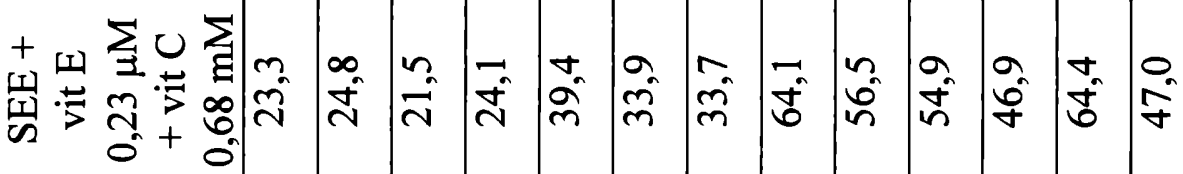

$\sum \sum_{g}$

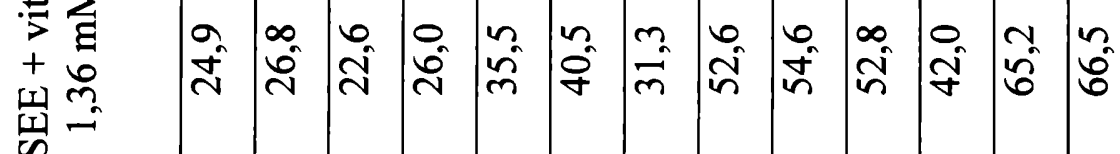

焉

䍃

药

8

莺

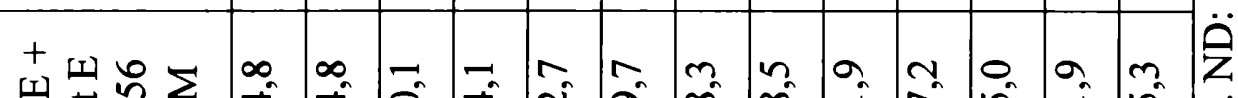

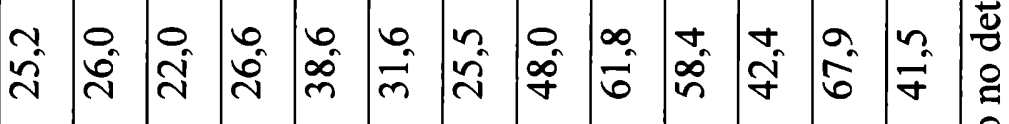

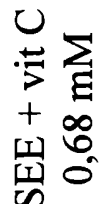

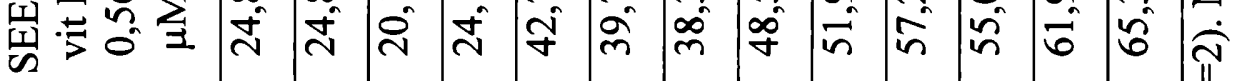

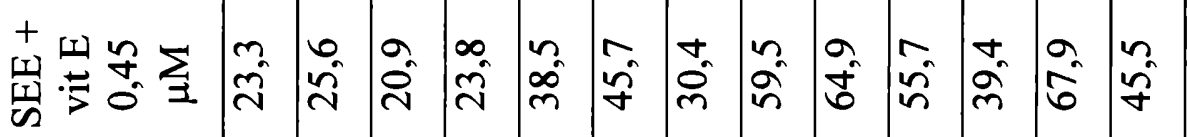

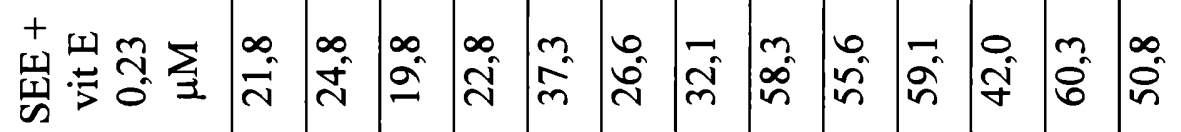

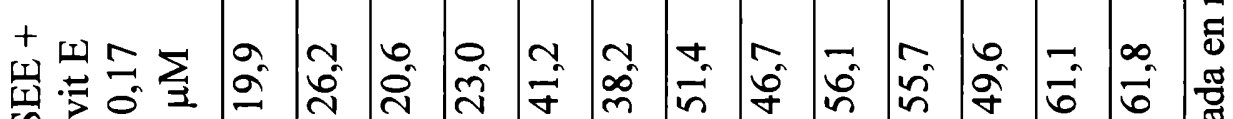

으

용

$\frac{\text { 곤 }}{2}$

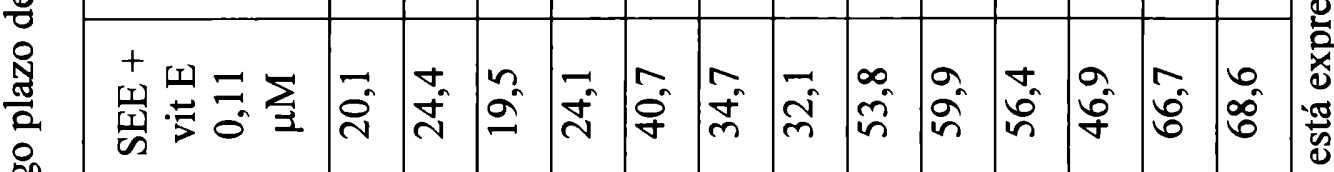

矛

跑

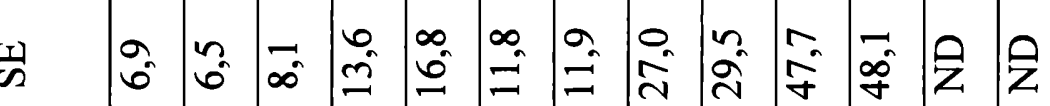

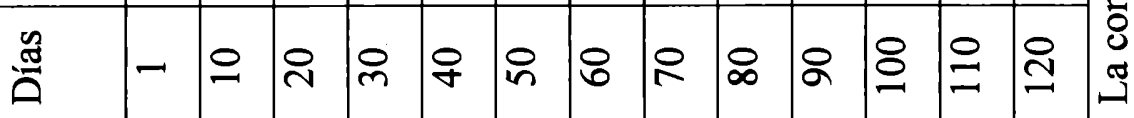




\section{Medición de la vitamina $\mathbf{E}$ plasmática}

\subsection{Material y métodos}

Para determinar los niveles iniciales de vitamina $\mathrm{E}$ y la disminución de los mismos en el tiempo de almacenamiento a $4^{\circ} \mathrm{C}$, se cuantificó utilizando el método de HPLC en muestras de SE, SEE y SEE adicionada con vitamina E (succinato ácido de $\alpha$ tocoferol) en las concentraciones de $0,0,11,0,17,0,23,0,45$ y $0,56 \mu \mathrm{M}$. Las mediciones fueron realizadas en los días $1,10,30,60$ y 90 de almacenamiento a $4^{\circ} \mathrm{C}$.

Se siguió la técnica de De-Leenher et al, 1978 con algunas modificaciones. Se partió de $2 \mathrm{ml}$ de sangre entera que fueron centrifugados a $3000 \mathrm{~g}$, en una centrífuga Presvac, para separar el plasma del paquete celular. Se procedió luego a la desproteinización del plasma, se tomaron $300 \mu \mathrm{l}$ del sobrenadante que se mezclaron con $900 \mu \mathrm{l}$ de ácido tricloroacético 6\%, se agitó vigorosamente y se incubó en frío, durante 10 minutos. Se procedió luego a una centrifugación a $4^{\circ} \mathrm{C}$ a $3000 \mathrm{~g}$. Se separó el sobrenadante y se mezcló con 1,5 ml de isooctano, se dejó decantar y se separó la fase sobrenadante (isooctano que contiene la vitamina E), que se filtró con filtros de $13 \mathrm{~mm}$ de diámetro y de $0,45 \mu \mathrm{m}$ de tamaño de poro. Se tomaron $100 \mu \mathrm{l}$ del filtrado que fueron inyectados en una columna de HPLC Nova-Pak, Sílica $4 \mu-60 \AA, 3,9 \mathrm{~mm}$ x $150 \mathrm{~mm}$, fabricada por Waters. La fase móvil fue una solución de isooctano/clorometano (80:20) con $400 \mu \mathrm{l} / \mathrm{L}$ de alcohol isopropílico, la velocidad de flujo fue de $1 \mathrm{ml} / \mathrm{min}$. La vitamina E fue detectada usando un detector de absorbancia UV, Waters 996 (Protodiode Array Detector), a $280 \mathrm{~nm}$.

Para cuantificar la vitamina se realizó una curva de calibración $r^{2}=0,8472$, usando la misma técnica de extracción, a diferentes concentraciones de la droga pura (succinato ácido de $\alpha$-tocoferol), por duplicado. 
La recuperación de la vitamina E en la extracción fue total.

\subsection{Resultados}

En la Figura 28 se muestra la curva de calibración obtenida con la droga pura, la misma fue utilizada para relacionar las áreas de las curvas obtenidas en el cromatógrafo para las distintas muestras, con los mg de vitamina E presentes en las mismas.

Figura 28: Curva de calibración

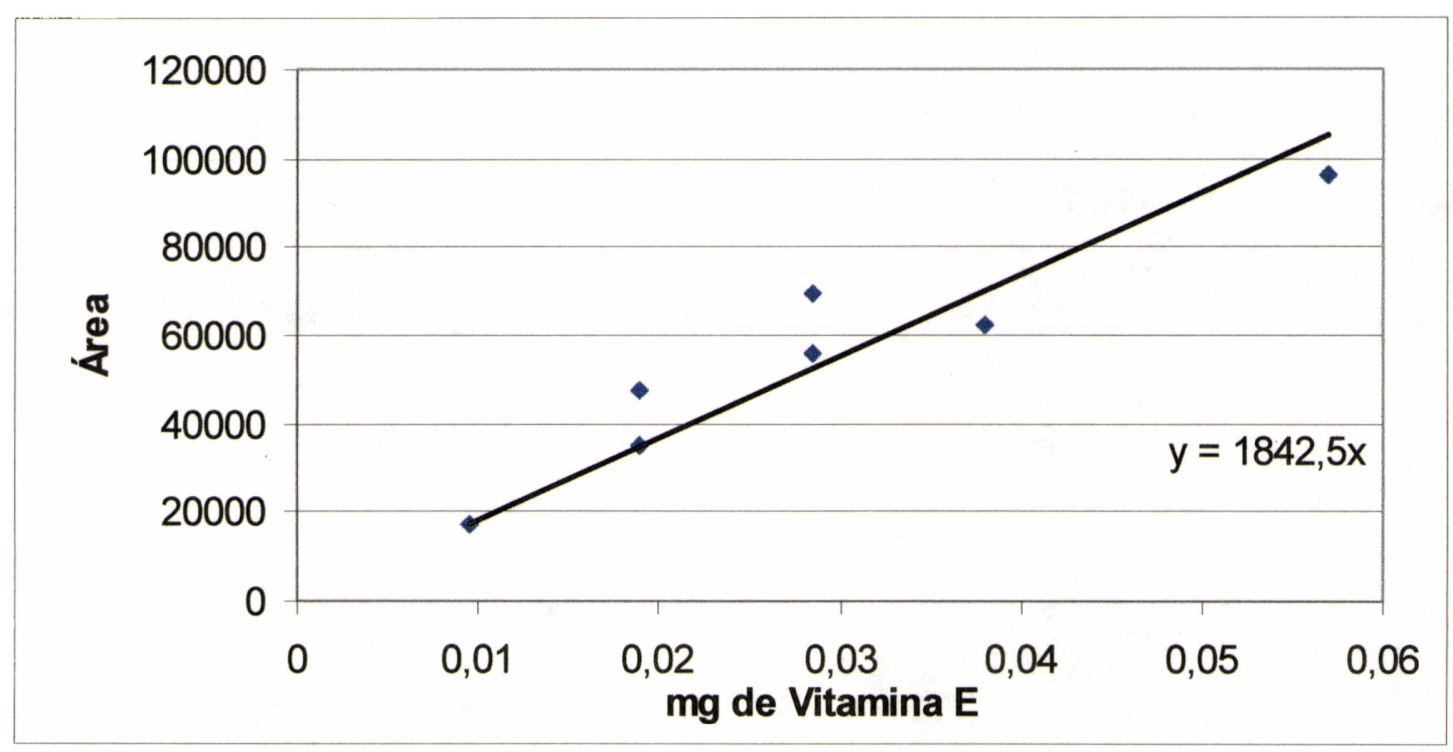

Al dosar los niveles de vitamina $\mathrm{E}$ en una muestra de SE y de una muestra de SEE en función del tiempo de almacenamiento a $4^{\circ} \mathrm{C}$, se obtuvieron las curvas que se muestran en la Figura 29. 
Figura 29: Niveles plasmáticos de vitamina $\mathrm{E}$ en SE y SEE, almacenadas a $4^{\circ} \mathrm{C}$, durante 90 días. Medidos como $\mu \mathrm{g}$ de succinato de $\alpha$-tocoferol en un $\mathrm{ml}$ de plasma.

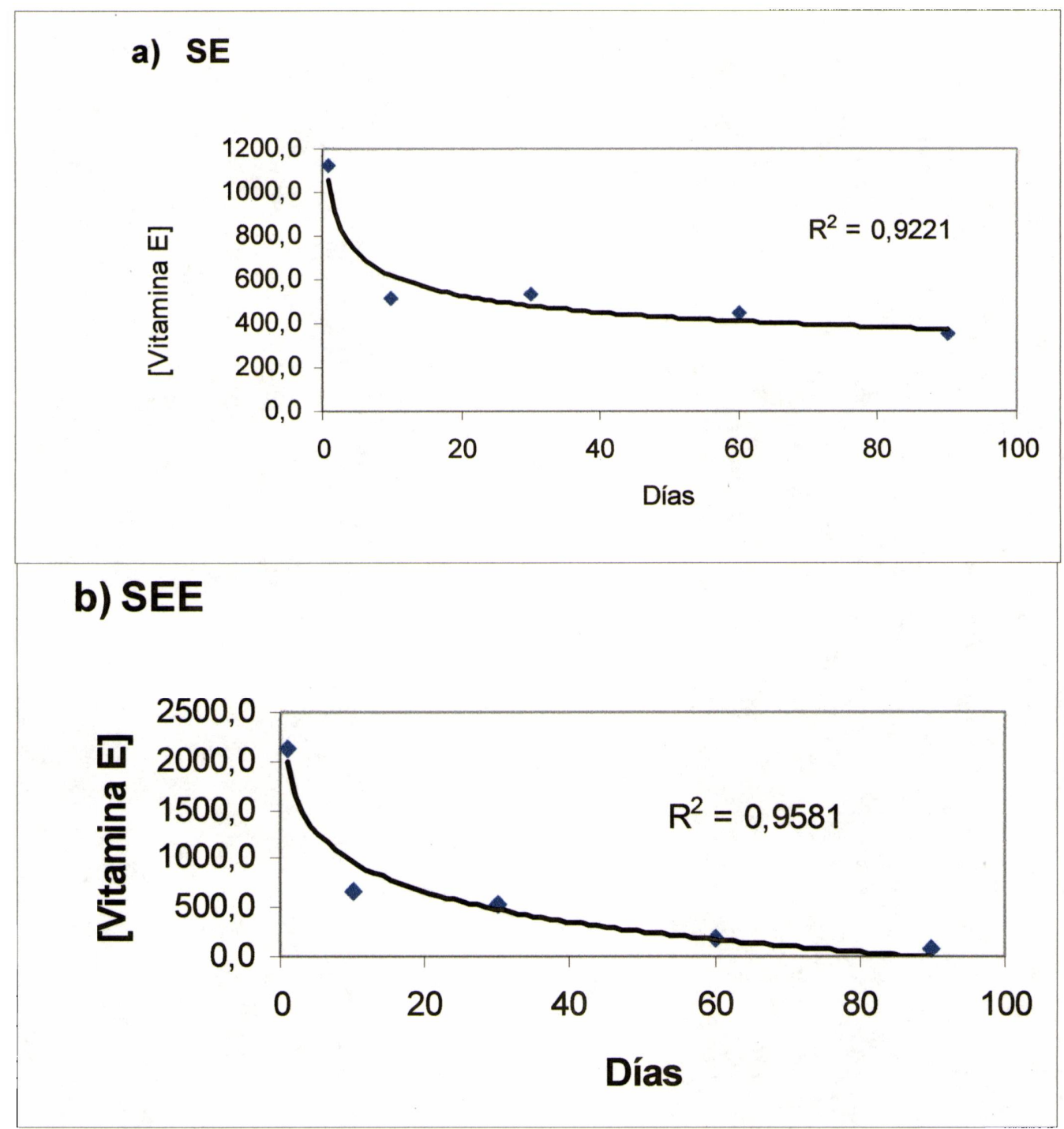


Estas curvas muestran que el descenso de los niveles de la vitamina en la SEE es mayor al de la SE. La Figura 30 muestra los porcentajes de vitamina medidos luego de 90 días de almacenamiento, relativos al primer día, para cada uno de los tratamientos. Se observa que en las muestras conteniendo vitamina $\mathrm{C}$ además de la vitamina $\mathrm{E}$, los niveles de esta última son aún mayores a los del primer día.

Figura 30. Niveles plasmáticos de Vitamina $\mathrm{E}$ luego de 90 días de almacenamiento a $4^{\circ} \mathrm{C}$, medidos como porcentaje del nivel inicial

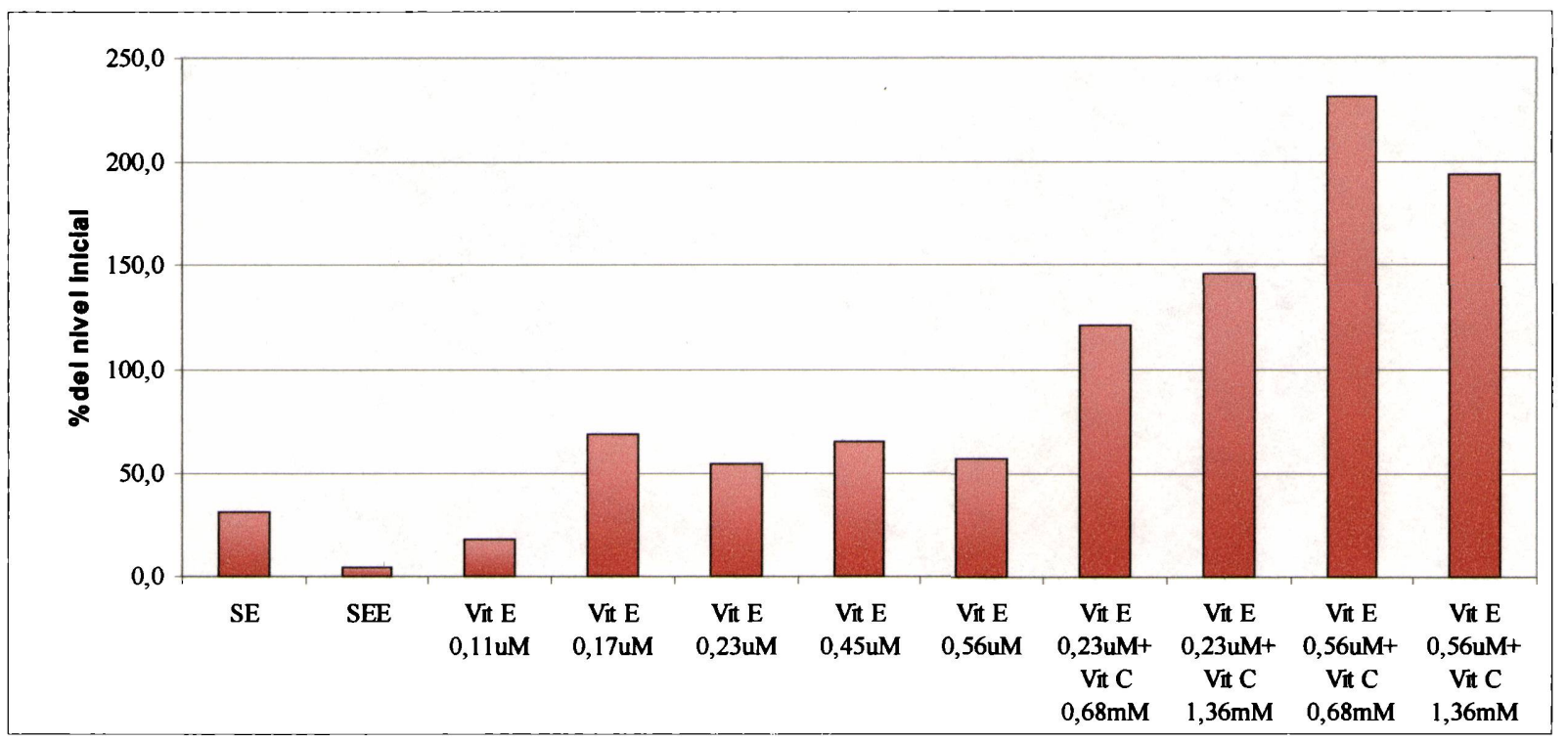




$$
\mathrm{DISCUSIÓN}^{\mathrm{N}}
$$


Durante años se ha intentado cambiar los medios de almacenamiento de la SE con la finalidad de prolongar la vida media de sus componentes, ya sea para utilizar la SE o sus derivados y emplearlos con diversos fines como las transfusiones, o como material para control de calidad, entre otros. Todos estos estudios han permitido, en forma indirecta, avanzar en el conocimiento de la fisiología y la bioquímica de las células sanguíneas, en particular de los GR.

Así, por décadas el interés ha estado localizado en preservar los GR y mejorar su viabilidad en la hemoterapia. En un principio se adicionó a la SE una solución de citrato y dextrosa que disminuía la probabilidad de desarrollar anemias luego de las transfusiones. Esta solución fue luego acidificada, obteniéndose así el ACD. Más adelante, para disminuir la hemólisis, la solución fue suplementada con fosfatos, obteniéndose el CPD (Mollison, 1972). Luego, debido a que se consideraba que los principales cambios sufridos por los GR durante el almacenamiento eran consecuencia directa de la disminución de los niveles de ATP, las soluciones utilizadas para preservar la SE fueron modificándose mediante la adición de inosina o adenina, con la finalidad de evitar este suceso y aumentar la viabilidad postransfusional (Wood y Beutler, 1967; Mollison, 1972). Sin embargo, se ha demostrado que en los eritrocitos ocurren cambios que dependen de otros factores, por ejemplo los cambios de forma que se deben a variaciones en el equilibrio iónico, pérdida de cationes y modificaciones en la integridad de la membrana (Feo y Mohandas, 1977). Mas adelante, ante la hemólisis incipiente que ocurría en estos medios adicionados con electrolitos, glucosa, adenina y fosfatos, la introducción de una variante como por ejemplo el manitol, estuvo orientada a disminuir esta hemólisis por efecto osmótico (Beutler y Kuhl, 1988). Para aumentar entonces, la vida media de los GR luego de las transfusiones y/o mejorar su conservación in vitro, a las soluciones preservadoras se le fueron agregando, por ejemplo $\mathrm{ClNH}_{4}$ y fósforo 
inorgánico (Pi) con el propósito de aumentar los niveles de ATP. Tanto el amonio como el Pi ejercen un efecto sobre el metabolismo del ATP y el 2,3-DPG. El amonio es estimulador de la vía de las pentosas con lo cual se incrementa la formación de fosforibosilpirofosfato (PRPP), necesario para la fosforilación de la adenina. La adición de Pi también ayuda a mantener los niveles de ATP durante las primeras semanas de almacenamiento por un mecanismo que involucra al PRPP. Se ha considerado además, el hecho de que los efectos de ambos sean aditivos (Meryman et al., 1986). También se han probado medios con diferentes osmolaridades para conservar el volumen de los GR (Beutler y Kuhl, 1988), con o sin glicerol, para mantener los niveles de 2,3-DPG y manitol con el fin disminuir el porcentaje de hemólisis (Lombarts y Leijnse, 1983a; Dumaswala et al., 1994).

Si el interés es preservar la SE para ser usada como material de control de calidad, tenemos que tomar en cuenta las características que debe reunir una muestra para poder ser usada con este fin. Según Leonart et al. (1986), una muestra ideal para ser usada en control de calidad de eritrocitos debe estar constituida por una suspensión de los mismos, mantenidos durante largos períodos con sus características propias de forma, metabolismo, fluidez de membrana, maleabilidad, resistencia a la hemólisis, entre otras. Existen muestras comerciales con estas características, pero desde hace años se trabajó para conseguir un material que pueda ser preparado fácilmente por los mismos laboratorios, con el objetivo de disminuir los costos (Leonart et al., 1986).

A continuación se discutirán los datos obtenidos sobre estudios a largo plazo de parámetros bioquímicos, hematimétricos y morfológicos de GR estabilizados con aldehídos y el efecto de la adición de antioxidantes sobre estos parámetros con el objeto de prolongar su estabilidad. 


\section{Estabilidad a largo plazo de la muestra de SEE}

\subsection{Estudios hematológicos}

\subsubsection{Variación de los parámetros hematimétricos}

La estabilidad de la SEE preparada según Reardon et al. (1991) fue estudiada por Rodríguez et al. (1994), quienes encontraron que este material es estable por un período de 75 días. Los CV\% interensayo obtenidos para los GB y la $\mathrm{Hb}$ estuvieron por debajo de 3\%, para los GR y el Hto por debajo de $4 \%$ y para las Plt por debajo de $7 \%$ que son más bajos que los obtenidos en nuestro trabajo.

En la Tabla 29 se resumen datos de una muestra de SE adicionada con una solución de glutaraldehído (concentración final 0,56\%) utilizada en el Programa de Evaluación Externa de Calidad de Dinamarca, donde encontraron que este material es estable por un mes cuando es conservado a $4^{\circ} \mathrm{C}$ y sólo tres días cuando permanece a temperatura ambiente (Christensen, 1998). Estos datos también resultaron más bajos que los obtenidos en este trabajo. Nosotros evaluamos los diferentes parámetros hematimétricos de la SEE durante períodos más prolongados de tiempo. La Tabla 30 muestra los valores obtenidos por Reardon et al. (1991) y los obtenidos en este trabajo en dos de los lotes estudiados, para varios parámetros hematimétricos. 
Tabla 29: Estabilidad de parámetros de $\mathrm{SE}$ almacenada a $4^{\circ} \mathrm{C}$ durante un mes (Christensen, 1998)

\begin{tabular}{|c|c|c|}
\hline Componentes & CV\% total $^{\text {1 }}$ & Deterioro $^{2}$ (\%) \\
\hline $\mathrm{Hb}$ & 0,87 & 0 \\
\hline $\mathrm{N}^{\circ}$ de GR & 1,01 & 5 \\
\hline VCM & 1,53 & 6 \\
\hline $\mathrm{CHCM}$ & 2,91 & 39 \\
\hline $\mathrm{N}^{\circ}$ de GB & 16,7 & 12 \\
\hline $\mathrm{N}^{\circ}$ de Plt & 4,30 & \\
\hline
\end{tabular}

CV\% calculado con todos los datos desde el día 1 al 33

${ }^{2}$ Medido como variación de la media entre el primero y el último día

Tabla 30: Comparación de la estabilidad a largo plazo de varios parámetros hematimétricos en SEE en diferentes laboratorios

\begin{tabular}{|c|c|c|c|c|c|c|c|c|}
\hline Días & $\mathrm{N}$ & $\begin{array}{c}\mathrm{GB}^{*} \\
\times 10^{9} / \mathrm{L}\end{array}$ & $\begin{array}{c}\mathrm{GR}^{*} \\
\times 10^{12} / \mathrm{L}\end{array}$ & $\begin{array}{c}\mathrm{Hb}^{*} \\
\mathrm{~g} / \mathrm{L}\end{array}$ & $\begin{array}{c}\mathrm{VCM}^{*} \\
\mathrm{fL}\end{array}$ & $\begin{array}{c}\text { Plt} \\
\times 10^{*} / \mathrm{L}\end{array}$ & $\begin{array}{c}\text { PVM* } \\
\mathrm{fL}\end{array}$ & Fuente \\
\hline 50 & 227 & 5,7 & 4,53 & 137 & 93,2 & 296 & 9,1 & Reardon et al., \\
69 & 7 & 5,8 & 4,61 & 136 & 93,0 & 297 & 8,4 & 1991 \\
175 & 24 & 5,7 & 4,59 & 137 & 94,6 & 296 & 7,1 & \\
\hline 1 & 10 & 3,8 & 4,37 & 124 & 89,7 & 163 & 7,6 & Este trabajo \\
50 & 52 & 3,8 & 4,58 & 130 & 92,7 & 149 & 8,6 & SE191297 \\
105 & 36 & 4,2 & 4,87 & 139 & 96,3 & 128 & 8,9 & \\
\hline 1 & 10 & 5,8 & 4,06 & 120 & 85,2 & 134 & 7,7 & Este trabajo \\
50 & 60 & 5,3 & 4,08 & 121 & 87,5 & 100 & 8,8 & SE200899 \\
120 & 60 & 4,7 & 4,20 & 120 & 101,2 & 119 & 6,7 & \\
\hline
\end{tabular}

${ }^{*}$ Valores de las medias acumuladas entre diferentes tiempos de almacenamiento a $4^{\circ} \mathrm{C}$

Nuestros resultados muestran que parámetros como el VCM y las Plt presentan diferencias significativas $(\mathrm{p}<0,05)$ entre el primero y el último día, con deterioros que en algunos lotes alcanzaron un valor máximo de 67\% (lote SE141098). También según 
los datos de la Tabla 30, en los primeros 50 días el VCM aumenta un 3\% mientras que entre el día 50 y el 100 este aumento llega a un $16 \%$ en nuestra muestra. Estos datos son algo diferentes comparados con el leve aumento del $2 \%$ entre los días 50 y 175 , obtenidos por los autores. Por otro lado, en nuestro trabajo observamos una disminución de hasta un $15 \%$ para el número de Plt lo que tampoco coincide con lo hallado por Reardon et al. (1991).

Debido a estas diferencias nos propusimos analizar otros criterios de estabilidad. Para evaluar la estabilidad de un material en el tiempo es necesario determinar que un constituyente del mismo, bajo condiciones específicas, mantiene su valor de medida dentro de ciertos límites previamente establecidos (Thiers et al., 1976). Estos límites deben ser determinados teniendo en cuenta la precisión del instrumento de medida, el cual debe poseer un DE mínimo y un CV\% dentro de los límites aceptables. Estos CV\% deben ser determinados para cada analito antes de comenzar las mediciones (Tabla 3).

Varios criterios pueden considerarse para establecer el límite de estabilidad de un material para un parámetro determinado: a) considerar el $\mathrm{CV} \%$ total a largo plazo, b) tener en cuenta que un parámetro se puede considerar estable mientras su valor se mantenga dentro del intervalo determinado por la media $\bar{x} \pm 1 \mathrm{DE}$ o, en condiciones aun más permisivas, el intervalo podría quedar determinado por $\bar{x} \pm 2 \mathrm{DE}$.

Teniendo en cuenta estos criterios, en las dos primeras experiencias (SE080296 y SE010396) se observó una clara diferencia entre la SE y la SEE. Las tablas 4 y 5 muestran los valores promedio para estas dos muestras, la primera presenta una disminución significativa en el número de GB y Plt $(\mathrm{p}<0,01)$ y con valores de CV\% totales más elevados que para la SEE, lo que muestra un claro beneficio del tratamiento de estabilización. 
Como era de esperar, se observa que los valores de los CV\% totales -teniendo en cuenta todas las mediciones desde el primero al último día de todos los parámetros- son mayores que los CV\% obtenidos en nuestro laboratorio (tablas 3, 6, 7, 8 y 9). Si se considera un criterio de aceptabilidad más amplio, considerando la variabilidad analítica interensayo e intraensayo y la variabilidad biológica, podemos considerar los valores de CV\% propuestos por Fraser (1990). Así, los valores permitidos de acuerdo con este autor serían: $\mathrm{Hb}=2,4 ; \mathrm{Hto}=2,6 ; \mathrm{GR}=4,2 ; \mathrm{GB}=13,4 ; \mathrm{Plt}=7,8 ; \mathrm{VCM}=2,2 ; \mathrm{HCM}=1,6$; $\mathrm{CHCM}=1,6$. De esta manera, se puede observar que las muestras de SEE presentan valores de CV\% dentro de estos límites en la mayoría de los parámetros (Tablas 6 y 7).

En otros trabajos previos consideramos la posibilidad de dejar madurar el material por un período de diez días y luego determinar la media del día 10 y observar durante cuánto tiempo los valores se mantienen dentro del intervalo $\bar{x}_{\text {(dia 10) }} \pm 2 \mathrm{DE}$. En la Figura 31 se muestran los resultados publicados considerando este criterio. En estas condiciones, los tiempos máximos de almacenamiento (\% de tolerancia) permitidos mejoraban para todos los parámetros (Fernández Alberti y Fink, 1998).

El VCM es un factor que varía durante el almacenamiento, pudiendo aumentar o disminuir, dependiendo de la tonicidad del medio de preservación (Tabla 31). Esa variación está directamente relacionada con el porcentaje de hemólisis de los GR (Greenwalt, 1997). En ACD, el VCM aumenta progresivamente, llegando a aumentar en un 12\% luego de 42 días de almacenamiento (Beutler y Kuhl, 1988). Este efecto está también relacionado con la temperatura de almacenamiento; cuando la SE es almacenada a $4^{\circ} \mathrm{C}$, la actividad de las bombas dependientes de ATP disminuye, con lo cual los iones $\mathrm{K}^{+}$salen del interior del GR al exterior y los cationes $\mathrm{Na}^{+}$junto con las moléculas de agua son impulsados al interior, produciendo un aumento del VCM (Lombarts y Leijnse, 1983a). 
Figura 31: Tiempos máximos de almacenamiento para los distintos parámetros hematimétricos

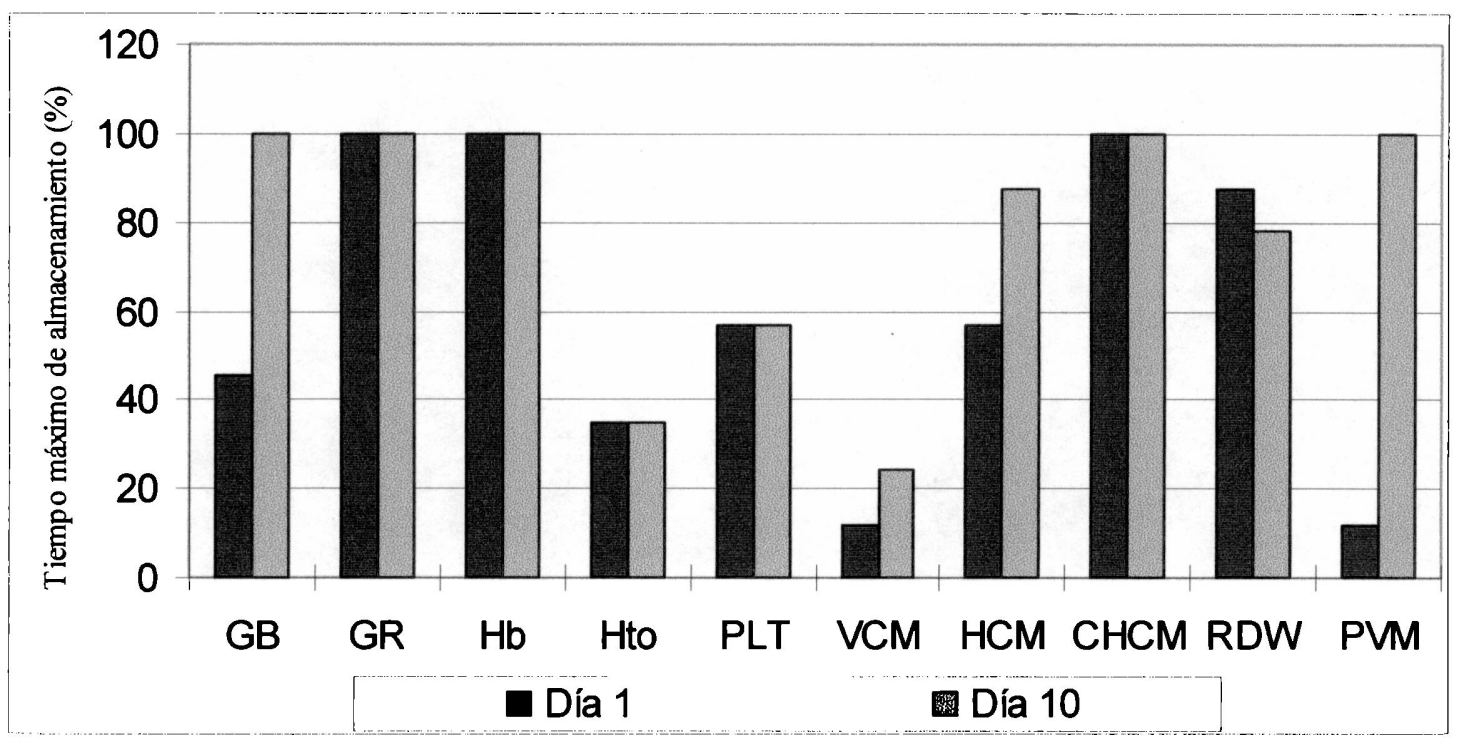

Tabla 31: Estabilidad a largo plazo de valores de VCM de muestras almacenadas a $4^{\circ} \mathrm{C}$ y en distintos medios de conservación

\begin{tabular}{|c|c|c|c|c|c|}
\hline \multirow{2}{*}{ MEDIO } & \multicolumn{3}{|c|}{ VCM (fl) } & VARIACIÓN & FUENTE \\
\cline { 2 - 4 } & DIA 1 & DIA 42 & DIA 84 & $(\mathrm{fl})$ & \\
\hline ADSOL & $90,4 \pm 3,8$ & $90,6 \pm 4,0$ & $87,6 \pm 3,0$ & $-2,8$ & $\begin{array}{c}\text { Dumaswala et al., } \\
\end{array}$ \\
& & & & & 1994 \\
\hline EAS 25 & $113,3 \pm 5,6$ & $106,6 \pm 5,0$ & $100,3 \pm 5,0$ & $-13,0$ & $\begin{array}{c}\text { Dumaswala et al., } \\
\end{array}$ \\
\hline EAS 38 & $88,3 \pm 3,9$ & $102,2 \pm 2,7$ & $96,5 \pm 2,9$ & $+8,2$ & 1994 \\
\hline ACD & 88,0 & 98,6 & ND & $+10,6$ & Beutler et al., 1988 \\
\hline CPD-SE & $90,9 \pm 1,4$ & $102,3 \pm 0,2$ & $113,0 \pm 0,3$ & $+22,1$ & Este trabajo \\
CPD-SEE & $90,9 \pm 0,2$ & $98,4 \pm 0,4$ & $98,3 \pm 0,2$ & $+7,4$ & SE250299 \\
\hline
\end{tabular}

El efecto del glutaraldehído sobre la disminución en la deformabilidad de la membrana, que depende del tiempo de exposición al mismo y de la concentración empleada (Corry y Meiselman, 1978; Nishi et al., 1983) puede ser el causante del mayor VCM medido, en casi todos los lotes, para la SEE en relación a la SE. Este efecto fue 
explicado por Corry y Meiselman (1978) quienes demostraron que el glutaraldehído no ejerce un efecto directo sobre el volumen celular, sino que el VCM determinado electrónicamente no sólo depende del verdadero volumen de la célula, sino también de su orientación al pasar a través del orificio de medida del equipo. Los discocitos que pasan a través del mismo con su mayor dimensión paralela al eje del orificio tienen un aumento aparente del volumen 1,2 veces mayor a su verdadero tamaño y cuando su longitud mayor es perpendicular al eje del orificio, tienen un VCM aparente 2,9 veces mayor. En la determinación del VCM por cálculo a partir del Hto, el aumento del mismo se debe a la disminución en la eficiencia del empaquetamiento celular ocasionada por la disminución en la deformabilidad (Corry y Meiselman, 1978). Por otra parte, el VCM de los GR estabilizados aumenta con el tiempo de almacenamiento, pero este aumento es menor al observado para los mismos GR sin estabilizar (Figura 10).

Al observar el recuento plaquetario, las experiencias piloto permitían concluir que en la muestra de $\mathrm{SE}$, la disminución de las Plt ocurre rápidamente, y a los 10 días el descenso del número de Plt es significativo. En sangre anticoagulada con EDTA y almacenada a $4^{\circ} \mathrm{C}$, después de 5 días se produce un descenso del $2 \%$ en el número de Plt, con un aumento estadísticamente significativo $(\mathrm{p}<0,01)$ del PVM (Cohle et al., 1981). Este descenso es explicado como una consecuencia de la destrucción de las Plt, ya que durante el almacenamiento a $4^{\circ} \mathrm{C}$ si bien la actividad metabólica de las Plt es baja, se sabe que las mismas sufren un aumento del PVM debido a la forma esférica que adquieren como consecuencia de la pérdida de los microtúbulos (Gosttschall et al., 1985). Esto mismo se puede verificar en la Figura 5 donde se observa claramente que en la muestra de SE, luego de 10 días, el recuento medio de Plt queda fuera del intervalo determinado por $\bar{x}_{\text {(dia 1) }} \pm 2 \mathrm{DE}$ ( $8 \%$ de tolerancia). Además, los CV\% totales para la SE 
son mayores a los establecidos considerando la variabilidad biológica (Fraser, 1990), que es la situación aceptada más permisiva. En la SEE, en cambio, el recuento de Plt presenta una tolerancia de $100 \%$ durante el período de 120 días de almacenamiento. Coincidentemente, los CV\% totales no sobrepasan los criterios mencionados.

En el recuento de GB ocurre algo similar, la SEE no presenta una variabilidad significativa en las medias a lo largo del tiempo de almacenamiento, con un $\mathrm{CV} \%$ total que dependiendo del lote oscila entre $2,0 \%$ y $13,1 \%$ y una tolerancia máxima de $100 \%$ durante los 120 días (Figura 5 y tablas 6, 7, 8 y 9). La SE en cambio, presenta un CV\% total de $28 \%$ y una tolerancia máxima de sólo 10 días. Es bien conocido que los leucocitos poseen proteasas que son liberadas al medio durante la lisis y que pueden actuar sobre las membranas de los GR sobre todo en ausencia de inhibidores plasmáticos (Beutler et al., 1976; Hogman et al., 1978; Leonart et al., 1988). Por lo general, en la preparación de los materiales para control de calidad en Hematología, los GB son removidos y reemplazados por eritrocitos de ave, o de otros animales, fijados, debido justamente a la inestabilidad de estas células (Morgan et al., 1978). Por ejemplo, un material para control de calidad de GB por un período de 10 meses, puede prepararse a partir de GR humanos fijados con formaldehído. Estos no lisan con los reactivos hipotónicos usados para los recuentos de GB y por lo tanto son reconocidos en los contadores como tales, es decir como pseudoleucocitos (Lombarts y Leijnse, 1983b) La estabilización con aldehídos por un lado protegería a los GR de la acción de estas proteasas y por otra parte, como se desprende de nuestros resultados, disminuye la lisis de los GB, reflejado en que no hay una disminución significativa en el número de GB hasta 120 días de almacenamiento a $4^{\circ} \mathrm{C}$.

La escasa estabilidad de los elementos formes de la sangre anticoagulada dificulta su empleo como muestra control para evaluar la calidad de los constituyentes 
hematimétricos. Por esta razón se debe recurrir a estabilizar, mediante métodos químicos, los diferentes componentes de la misma, de esta manera se logra prolongar la estabilidad de las células, pero también se acentúan las diferencias entre las muestras control y las muestras de sangre humana, pudiendo entonces llegar a ser inadecuadas para el control de algunos elementos y/o métodos (Hernández et al., 1988). En 1978, fue preparado por Morgan et al. un material de sangre entera preservada, que consiste en GR previamente separados del plasma y tratados con glutaraldehído en una solución buffer isotónica, de manera de estabilizarlos, pero sin fijarlos. Luego se mezclan estos eritrocitos con células de pollo fijadas (pseudoblancos), antibióticos y plasma humano. Este material mantiene los valores de los parámetros hematimétricos estables durante al menos 60 días (Morgan et al., 1978). Otra opción ha sido recurrir a sangre de animales que no presenten grandes diferencias con la sangre humana en la cantidad y morfología de sus células, por ejemplo la sangre de equino. Esta última ha sido probada y puede ser empleada como material control por un período de tres meses para $\mathrm{GR}, \mathrm{Hb}$, Hto y VCM, no así para GB y Plt (Hernández et al., 1988).

La muestra de SEE según Reardon et al. (1991), tiene la ventaja de no necesitar de la adición de GB y/o Plt de otros orígenes y por lo tanto puede ser empleada como material control para las técnicas manuales y para los equipos automatizados. Además según estos autores, la estabilización con aldehídos permite mantener los parámetros hematimétricos estables por un período de seis meses. Posteriormente esta muestra fue recomendada por el Comité Internacional de Estandarización en Hematología (ICSH), quienes han informado que el período de estabilidad es de tres meses (Lewis, 1995).

Además está demostrado que la exposición de los GR a concentraciones graduales de glutaraldehído posibilita el cambio de ciertas propiedades del GR (deformabilidad, FO, entre otras) $\sin$ afectar seriamente otras propiedades 
físicoquímicas como la densidad celular (Corry y Meiselman, 1978). Por otro lado, también fue propuesto por estos autores y corroborado por nosotros, que existe una variabilidad individual en la captación de glutaraldehído a la misma concentración. Así, en los niveles de aldehídos adicionados en nuestro trabajo (aproximadamente 5 $\mu \mathrm{mol} / 10^{10}$ células) la captación podría influir en la intensidad de los cambios producidos en las propiedades de los GR estudiadas en este trabajo (Fernández Alberti y Fink, 1998).

\subsubsection{Cambios en la morfología celular}

El almacenamiento de GR en ACD a $4^{\circ} \mathrm{C}$, lleva a cambios morfológicos en los mismos apareciendo, después de 3 a 5 semanas, los discos crenados y los equinocitos, luego de 9 semanas los GR esféricos con menor cantidad de área de membrana y, luego de 15 semanas, la mayoría se vuelven esferocitos (Nishi et al., 1983).

En las fotomicrografías de nuestros extendidos de SE (Figura 17), se observa desde el primer día una alta proporción de GR crenados y ya a los 10 días aparecen los esquistocitos. A los 30 días prácticamente todos los GR son crenados, con halos centrales, se visualizan fantasmas y hay una gran anisocitosis. Los GB aparecen al mes de almacenamiento a $4^{\circ} \mathrm{C}$, parcialmente lisados; se observa una disminución de los mismos en los preparados, coincidiendo con lo hallado en los recuentos. A los 60 días se observa el aumento en la proporción de fantasmas de GR que se alternan entre los crenados y los GB prácticamente no se observan o se encuentran alterados, casi destruidos. La gran anisocitosis observada en los extendidos entre los días 60 a 120

confirman los valores elevados del RDW (Figura 18) Los GR se hinchan, lo cual provoca un estiramiento de la membrana perdiendo las espículas, por lo que pierden su condición de crenados, se transforman en esferocitos al igual que lo descripto 
previamente (Nishi et al., 1983). Así, el gran aumento de VCM de 90,3 fl hasta 113,0 fl explicaría que el aumento de volumen de la célula provoque un estiramiento de la membrana. Además esto está de acuerdo con la ya mencionada pérdida de membrana en forma de microvesículas (Wagner, 1986).

Por el contrario, Meryman et al (1986) propusieron que las soluciones hipotónicas, que inducen a un aumento en la tensión de la membrana de los GR mediante un aumento de volumen, retardan la aparición de equinocitos y la liberación de microvesículas. La estabilización de la membrana, como fue demostrado por Nishi et al (1983), provoca un estiramiento de la misma, lo que explicaría el retardo en la aparición de equinocitos, tal como se observa en las fotomicrografías.(Figura 17).

\subsection{Estudios bioquímicos}

\subsubsection{Cambios en la FO}

La FO, como ya se mencionó, mide el grado de resistencia de los GR a la lisis en función de la disminución de la concentración de ClNa en el medio. Este test está directamente relacionado con la capacidad de deformación o elasticidad de la membrana del GR. Refleja la habilidad de los eritrocitos para captar agua sin lisar. Ha sido muy usado experimentalmente como medida de la viabilidad del GR y clínicamente con fines diagnósticos (Beutler E citado en Williams, 1995).

En condiciones patológicas la FO se ve aumentada en anemias hemóliticas como la esferocitosis hereditaria, luego del tratamiento con drogas (por ejemplo la indometacina), mientras que se ve disminuida en la anemia con células S (sickle cells), anemias por deficiencia de hierro y talasemias (Luzzato y Roper citados en Dacie y Lewis, 1984; Fernández Alberti y Fink, 2000). 
En GR almacenados en ACD, se ha demostrado que a medida que aumenta el tiempo de almacenamiento aumenta la FO, por lo tanto se incrementa la concentración de $\mathrm{ClNa}$ requerida para comenzar la hemólisis, pero recién después de 5 semanas cambia la [ClNa] que causa la hemólisis completa (Nishi et al., 1983). Esto está de acuerdo con los datos encontrados por nosotros. La SE luego de 3 semanas de almacenamiento no muestra cambios significativos en el valor de $\mathrm{p} 1([\mathrm{ClNa}]=50 \%$ de hemólisis) (Tabla 12).

Los valores más altos hallados para el parámetro pl en las muestras de SEE que en las de SE (Tabla 11) están de acuerdo con el hecho de que la membrana del GR estabilizado es menos deformable que la membrana de un GR sin estabilizar. Esto se debe, a que como consecuencia de la estabilización con glutaraldehído y formaldehído se producen oxidaciones de los grupos - $\mathrm{SH}$ de las proteínas de la membrana; las mismas conducen a rearreglos en las proteínas que alteran las interacciones proteínalípidos, induciendo a una reorientación en los PLP como es la migración de PS y PE desde la porción interna de la membrana a la externa, disminuyendo así, la ya mencionada, capacidad de deformación y elasticidad de la membrana del GR (Haest et al., 1978; Nishi et al., 1983; Kuypers et al., 1993).

Sin embargo, se ha demostrado que la [CINa] que produce el $50 \%$ de hemólisis disminuye a medida que aumenta la cantidad de glutaraldehído adicionada. Este fenómeno se ha explicado sugiriendo que el glutaraldehído se une covalentemente a la $\mathrm{Hb}$ y por lo tanto la mantiene unida a la membrana, disminuyendo su liberación al medio (Corry y Meiselman, 1978; Nishi et al., 1983). En nuestros resultados hallamos que las muestras estabilizadas son menos resistentes al estrés osmótico, comparadas con una muestra no estabilizada, hecho directamente relacionado con la menor deformabilidad de los GR de las primeras. A su vez, también encontramos que los 
valores de absorbancia máxima alcanzados por las muestras estabilizadas son menores a los de la $\mathrm{SE}$, corroborando la menor liberación de $\mathrm{Hb}$ al medio. Estos hechos pueden confirmarse en los datos mostrados en la Figura 20 y en la Tabla 13. A los 7 días, se observa una variación significativa en el valor del parámetro p1. Si se observan los valores hallados para la $\mathrm{SE}$, en este mismo lapso de tiempo, se verifica que los glóbulos de la muestra sin estabilizar mantienen su resistencia osmótica.

Como se desprende de los datos de la Tabla 13, la muestra sin estabilizar, mantiene el valor de p1 cercano a los valores normales $(4,0-4,45)$, con apenas un leve aumento del mismo a los 21 días. Por otra parte, al séptimo día, la muestra sin estabilizar tiene un valor de $\mathrm{p} 2(\mathrm{p} 2=0,199)$ menor al de la muestra estabilizada (p2=0,767), indicando que en esta última hay una mayor dispersión en la susceptibilidad a la hemólisis de los diferentes GR. Esto indicaría que, en la SEE, existe una población de GR con resistencia de sus membranas muy variable frente al estrés osmótico. Relacionado con esto, nos pareció de interés determinar si existe una correlación entre el RDW, indicador de la distribución en el tamaño de la población de GR y el parámetro p2; se encontró que existe una correlación positiva no resultó ser estadísticamente significativa $(p>0,05)$ (Tabla 16). Esto indicaría que un aumento en la heterogeneidad del tamaño eritrocitario está relacionado con una mayor heterogeneidad en la velocidad de lisis.

Bowdler et al., (1981) han encontrado que la FO puede correlacionarse negativamente con el parámetro $\mathrm{CHCM}$. Si disminuye la concentración de $\mathrm{Hb}$ dentro del GR, éste incorpora una mayor cantidad de agua, por lo tanto a menor CHCM habrá un mayor valor de pl porque en esas condiciones se alcanza el $50 \%$ de lisis a concentraciones mayores de $\mathrm{ClNa}$. $\mathrm{Al}$ analizar nuestros datos se corroboró que existe efectivamente una correlación negativa entre estos parámetros con un valor de 
significancia $\mathrm{p}<0,05$, con excepción de dos tratamientos (Tabla 16), en los cuales si bien existe una correlación negativa, no es estadísticamente significativa.

\subsubsection{Cambios en las proteínas de la membrana plasmática eritrocitaria}

Como se mencionara en la Introducción de este trabajo, está demostrado que durante el almacenamiento de GR en medios como ACD, CPD, ADSOL, EAS, hay liberación de microvesículas y que las mismas contienen diferentes cantidades de proteínas de membrana y Hb, dependiendo del medio (Snyder et al., 1985; Meryman et al., 1986; de Jong et al., 1996; Dumaswala et al., 1996a.; Greenwalt, 1997). Se ha demostrado, por otra parte, que en un medio hipotónico, el aumento de la tensión en la membrana reduce la formación de estas microvesículas (Meryman et al 1986). Las formación de estas microvesículas puede ser responsable de la disminución en el porcentaje de algunas fracciones proteicas (banda 3 principalmente) en el almacenamiento (Tabla 17).

Entre las alteraciones que sufren las proteínas del citoesqueleto en el almacenamiento en CPD, se ha descripto una disminución en la interacción Sp-proteína 4.1-actina, es decir en la habilidad de la Sp para unirse a la actina en presencia de la proteína 4.1. Este hecho puede ser responsable de alteraciones como la fragmentación celular, hemólisis, aumento de la FO (Podgorski y Elbaum, 1985; Wolfe, 1986). Además, la oxidación de tan solo dos de los grupos - $\mathrm{SH}$ de la Sp son suficientes para que falle la unión Sp-banda 4.1. Este daño oxidativo de la Sp aumenta en forma lineal durante las primeras 6 semanas de almacenamiento en CPD (Wolfe, 1986).

Se ha demostrado en SE almacenada en CPD, que la Sp no participa en la formación de agregados de proteínas de alto PM, aunque sí fue posible observar un aumento de $\mathrm{Hb}$ asociada a la membrana que puede afectar las uniones $\mathrm{Sp}-\mathrm{Sp}$ (Bartlett, 
1974; Wolfe, 1986). Nuestros resultados mostraron efectivamente que en la SE no se forman, ni aún después de 20 días, agregados de alto PM y, por otra parte, se observó un aumento de proteínas de bajo PM que podría estar condicionando una degradación (figuras 21 y 22).

Hemos comprobado también que la extracción de los fantasmas libres de $\mathrm{Hb}$, de muestras de SEE, se hace más difícil a medida que aumenta el tiempo de almacenamiento. Esto podría estar relacionado con los hemicromos formados por oxidación de la $\mathrm{Hb}$ unidos a la banda 3 (Gallagher et al., 1998) o con la ya mencionada unión entre el gultaraldehído y la Hb (Corry y Meiselman, 1978).

Según Burt et al (1990), las proteínas de membrana tratadas con glutaraldehído presentan una disminución en las bandas de $\mathrm{Sp}$ y de la banda 4.1, explicado esto por la formación de polímeros de alto PM. En nuestros resultados se observó la formación de estos polímeros, pero no la disminución inmediata en los niveles de $\mathrm{Sp}$. El descenso de estos niveles se observó recién después de 20 días de almacenamiento. La fracción proteica que sí presentó un descenso es la denominada banda 3.

En nuestros resultados se manifestó además un aumento, a medida que transcurría el tiempo de almacenamiento, del porcentaje relativo de estos polímeros. Esto está de acuerdo con el hecho de que en ghosts obtenidos de muestras con bajo contenido de ATP, incubados con glutaraldehído, aparecen bandas de alto PM que no aparecen en muestras de sangre fresca (Liu y Palek, 1979). 


\subsubsection{Cambios en los niveles de 2,3-DPG}

El mantenimiento de los niveles de 2,3-DPG, durante períodos prolongados de tiempo en el almacenamiento de la $\mathrm{SE}$ y/o los $\mathrm{GR}$ a $4^{\circ} \mathrm{C}$, es algo que con ninguno de los medios utilizados actualmente se pudo lograr (Beutler, 2000).

En el medio ADSOL por ejemplo, luego de 28 días de almacenamiento, los niveles de este metabolito descienden hasta un $15 \%$ del nivel inicial y sólo persiste un 3,25\%, luego de 84 días (Greenwalt et al., 1990). La adición de Pi y adenina a estos medios fue realizada, como se mencionara anteriormente, para mantener los niveles de 2,3-DPG y ATP. Por ejemplo, en el medio CPD adicionado con adenina, inosina y Pi, los niveles de 2,3-DPG se mantienen por 21 días cerca de los valores iniciales y desciende a un 50\% de ese valor luego de 42 días (Dawson, 1981). Greenwalt et al., 1990, hallaron que una solución EAS conteniendo una concentración de Pi 40 mM, presentaba niveles del metabolito iguales al $15 \%$ del inicial después de 28 días y el descenso alcanzaba un 97\% a los 84 días. El medio designado BAGPM, que contiene bicarbonato, adenina, glucosa, fosfato y manitol, permite mantener los niveles de 2,3DPG en un valor igual a 50\% del normal luego de 42 días de almacenamiento (Beutler, 2000).

En este trabajo, como se mostró en la Figura 23, encontramos que la sangre sin estabilizar presentaba ya a los 20 días niveles de 2,3-DPG que correspondían a un $20 \%$ de la concentración inicial, similar a lo encontrado por Heaton et al (1981) y un valor más alto que el $1 \%$ hallado por Greenwalt et al (1990) en el medio ADSOL. Este descenso a niveles indetectables con nuestro método fue a los 60 días. En cambio, la SEE presenta, luego de 40 días, un descenso de sólo el $50 \%$ en los valores de este metabolito. En la SEE la disminución más lenta en los niveles de este metabolito puede estar relacionada con el menor requerimiento de ATP por estos GR, ya que el consumo 
de 2,3-DPG durante el almacenamiento puede deberse, en parte, a la necesidad de fosfatos para generar uniones de alta energía.

Se ha demostrado que propiedades de la membrana del GR como son la deformabilidad y la estabilidad están en gran parte reguladas por las proteínas de citoesqueleto, pero también se ha encontrado, como se mencionara en la Introducción, que tratamientos con 2,3-DPG llevan a una disminución en la deformabilidad y a un aumento de la estabilidad de la membrana, y que ambos efectos se pueden revertir, indicando que las alteraciones del 2,3-DPG sobre las proteínas no son irreversibles (Chasis y Mohandas, 1986). Se ha observado que concentraciones milimolares de 2,3DPG podían provocar la disociación de las proteínas del citoesqueleto y además restringir el movimiento lateral de las proteínas integrales dentro de la bicapa; sin embargo este efecto no es muy específico y puede asignarse también a otros polifosfatos (Sheetz et al., 1978).

La disminución de los niveles de un anión polivalente como es el 2,3-DPG, durante el almacenamiento provoca un aumento del VCM, ya que la célula intenta reemplazarlo con aniones monovalentes que ejercen un mayor efecto osmótico. Los iones $\mathrm{Cl}^{-}$, por ejemplo, ejercen un efecto osmótico 3-7 veces mayor (Lombarts y Leijnse, 1983a; Beutler y Kuhl, 1988). Esto se confirmó en la SEE donde a los 60 días, cuando los niveles de 2,3-DPG disminuyeron a un 40\% del valor inicial, el VCM aumentó un 5\% (Figuras 18 y 23).

\subsubsection{Cambios en la actividad de las colinesterasas}

La AChE es una enzima ligada a la membrana, por lo tanto, su actividad varía junto con los cambios de la misma durante el envejecimiento del eritrocito, tanto in vivo 
como in vitro. En muestras de hemolizado almacenadas a $-20^{\circ} \mathrm{C}$ se ha encontrado que la actividad de esta enzima disminuye entre un 10-18\% en 21 días (Meuling et al., 1992) .

Mediante ensayos histoquímicos Halbhuber et al. (1984) han mostrado que la desintegración de la membrana del GR está acompañada de una activación de moléculas de AChE, que estaban prácticamente inactivas en la membrana intacta. Esto podría explicar los elevados valores de actividad de la $\mathrm{AChE}$ aún después de 50 días de almacenamiento a $4^{\circ} \mathrm{C}$ en las muestras de SE (Figura 24, gráfica $\mathrm{A}$ ). Se podría decir entonces que un incremento en la actividad de la $\mathrm{AChE}$ indicaría serios disturbios en la membrana del GR.

El glutaraldehído es una sustancia que forma enlaces covalentes estables con los grupos $\varepsilon$-lisina de las proteínas. Se ha estudiado el efecto que produce el cross-linking, ocasionado por el glutaraldehído sobre la actividad de la enzima. La enzima es un dímero en presencia de Triton X-100 y luego de la remoción del detergente forma agregados de diferentes PM. Si estos agregados son incubados con glutaraldheído y luego analizados en presencia de detergente, se observa que el mismo no puede disociar las especies oligoméricas debido a que están estabilizadas por uniones covalentes. Por otro lado, cuando se estudió el efecto del cross-linking en presencia del detergente, se observó que no hay variación en la actividad antes y después del mismo. La incubación con glutaraldheído podría llevar a la formación de oligómeros de la enzima (RömerLüthi et al., 1980), lo que podría explicar el menor valor en la actividad de esta enzima en la SEE al primer día, con respecto a la SE (Tabla 20). Se ha demostrado, además, que concentraciones de glutaraldheído de $0,5 \%$ producen una inhibición en la enzima que depende del tiempo de exposición al aldehído, alcanzando un $27 \%$ de inhibición luego de 4,5 horas de fijación (Skaer, 1973). En la estabilización llevada a cabo por nosotros, la concentración de aldehídos total utilizada es de $0,04 \%$, mucho menor a la descripta 
como inhibidora de la enzima, pero igualmente se ha encontrado que esta estabilización provoca una disminución en su actividad. Este hecho se observa claramente en la Figura 24 y en los análisis de varianza, en los cuales se encuentra una diferencia estadísticamente significativa entre los valores encontrados para la muestra de SE y la de SEE.

También se encontró que existen diferencias significativas en los resultados de las diferentes experiencias (variaciones interindividuos), pero se puede observar que en todas ellas, los valores de $\mathrm{AChE}$ entre los días 10 y 40 no presentan variaciones significativas. El hecho de que los valores de AChE en SEE no sean tan elevados como en la SE, estaría de acuerdo con los cambios de la membrana producidos por la estabilización, que si bien en un principio lleva a una disminución en la actividad de la enzima, posteriormente ayuda a mantenerla dentro de un intervalo dado por la $\bar{x} \pm 2 \mathrm{DE}$. El leve aumento de la actividad de $\mathrm{AChE}$, observado en algunos días, podría deberse a la ruptura de los dímeros unidos por puentes disulfuro, ya que la forma monomérica de la cruz es activa (Ott et al., 1984).

La PChE es una enzima estable durante 80 días a $4^{\circ} \mathrm{C}$ y durante 126 días a $-20^{\circ} \mathrm{C}$ en muestras de hemolizado (Meuling et al., 1992). Del análisis de los valores de esta enzima en las diferentes muestras, se desprende que la misma no presenta variaciones significativas y que el proceso de estabilización no modifica su actividad, esto se observa claramente en los valores de la Tabla 23.

En cuanto al método empleado en la medición de las enzimas (PChE y $\mathrm{AChE}$ ), se ha demostrado que en hemolizados, la especificidad de ambas enzimas por sus respectivos sustratos es del $95 \%$ (Meuling et al. 1992), lo cual nos asegura que los aumentos en la actividad de las mismas son específicos de cada una de las enzimas. 
Se conoce además, que la actividad de estas dos enzimas depende de la exposición individual a compuestos que inhiben la actividad de colinesterasas, como por ejemplo, los carbamatos y los compuestos organofosforados, los cuales ejercen efectos crónicos y agudos en el sistema nervioso que son también manifestados en la inhibición de la AChE eritrocitaria. A pesar de que generalmente la actividad de la PChE decrece más rápidamente en respuesta a la exposición a estos compuestos que la $\mathrm{AChE}$, la OMS recomienda medir ambas enzimas cuando se monitorea la exposición de los trabajadores a estos inhibidores (Meuling, 1992). Así, la SEE entre los días 10 y 40 desde su estabilización, podría ser útil como material de control interno de este monitoreo.

\subsubsection{Lipoperoxidación}

La lipoperoxidación ha sido ampliamente implicada en las reacciones y en las alteraciones de las membranas asociadas con el envejecimiento de células y tejidos (Hochstein y Jain, 1981). Se ha demostrado que, la peroxidación de fosfolípidos es un determinante en el envejecimiento de los GR normales y en el envejecimiento acelerado y la anemia siguientes a la administración de ciertos agentes hemolíticos como por ejemplo la fenilhidrazina (Hochstein y Jain, 1981).

La formación de peróxidos lipídicos en la membrana del GR lleva por un lado a la alteración de las propiedades mecánicas de la célula causadas por la formación de polímeros entre las proteínas de la membrana y, por otra parte, causa una disminución en los niveles de fosfolípidos en la membrana (PS y PE) y una inhibición de enzimas asociadas a la membrana como por ejemplo la AChE (Hochstein y Jain, 1981). Estas alteraciones contribuyen a deformar el GR. Así, productos de la oxidación de los lípidos como el colesterol oxidado y los PLP oxidados, afectan la estructura y función de la membrana del GR (Chiu et al., 1989). Una consecuencia en la oxidación de las 
proteínas se refleja en la alteración de las enzimas involucradas en la captura y turnover de los PLP, lo cual afecta, como se mencionara en otra sección, a la forma de los GR (Kuypers et al., 1993). Otra consecuencia es la oxidación de grupos tioles que conduce a la polimerización de las proteínas (Chiu et al., 1989).

En este trabajo se midieron los TBARS, que son usados como medición de los niveles del estrés oxidativo, o sea como marcadores plasmáticos de la lipoperoxidación (Ruiz et al., 1999). La determinación del MDA según su reacción con el TBA, no mide solamente el MDA liberado antes de la reacción. Por el contrario, se ha demostrado que el $98 \%$ del MDA que reacciona en este test no estaba presente antes de la reacción, sino que se genera en la misma a partir de los lipoperóxidos presentes en la muestra durante el calentamiento a ebullición en medio ácido (Halliwell, 1984; Gutteridge y Quinlan, 1983). Por lo tanto, los valores determinados en nuestras experiencias están indicando un aumento en los niveles de lipoperóxidos a medida que transcurre el tiempo de almacenamiento a $4^{\circ} \mathrm{C}($ tablas 28 y 29$)$.

Los GR que envejecen en la circulación, así como los GR almacenados durante largos períodos, poseen una menor capacidad antioxidante, por lo tanto la iniciación y propagación de las reacciones relacionadas con los radicales libres proceden rápidamente (Hochstein y Jain, 1981); esto explicaría el aumento en los niveles de MDA con el almacenamiento (tablas 28 y 29).

De nuestros resultados se desprende, además, que los niveles de lipoperoxidación en las muestras de SEE son mayores al día 1 que los de la SE, un hecho que podría relacionarse con la oxidación ocurrida durante la estabilización, ya que los niveles de MDA sólo aumentan significativamente hasta después de 60 días $(\mathrm{p}>0,05)$. 


\section{Efecto de la adición de antioxidantes sobre la estabilidad a largo plazo de la SEE}

Teniendo en cuenta todas las alteraciones ya mencionadas, sufridas por los GR tanto in vivo como in vitro durante su envejecimiento, es de esperar que el contenido de un antioxidante como la vitamina $\mathrm{E}$, el único liposoluble que se encuentra tanto en plasma (unido a lipoproteínas) como en la membrana del GR, disminuya con el envejecimiento del GR (Burton, 1986). Esto está de acuerdo con lo obtenido en nuestros resultados al cuantificar la vitamina E en el plasma, en el tiempo de almacenamiento (Figura 29). Además los resultados in vivo indican que la proporción de vitamina E en la membrana de los GR aumenta con la edad de los mismos (Burton, 1986), con su consecuente disminución en plasma. La mayor disminución de la vitamina $\mathrm{E}$ plasmática en la SEE podría relacionarse con el aumento lipoperoxidación observado en esta muestra, en relación a la SE. La vitamina E sería capturada por la membrana del GR como mecanismo de protección.

Es bien conocido que, cuando los GR son conservados in vitro en soluciones preservadas para ser usadas en transfusiones, un gran número de los mismos son rápidamente capturados por el bazo y que la velocidad con que son removidos de circulación aumenta con el período de preservación. Los mecanismos que llevan a esta rápida captura están relacionados con la oxidación, por lo tanto una forma posible de prolongar el período de almacenamiento de los GR in vitro sería la protección de los mismos frente al estrés oxidativo por medio de la adición de antioxidantes (Ando $\mathrm{K}$ et al., 1993).

La vitamina E, como ya se explicó en la Introducción, reacciona con el radical peroxilo donando un $\mathrm{H}$ de su anillo fenólico que conduce a la formación de un radical 
$\alpha$-cromanóxido que puede reaccionar con otro igual dando un dímero o, como ocurre en presencia de radicales peróxido, puede reaccionar directamente con éstos. De esta forma cada molécula de vitamina E consume dos radicales peroxilo (Niki et al., 1984). Este efecto se ha demostrado sobre la peroxidación del linolato, usando concentraciones de vitamina de $22,45,67$ y $112 \mu \mathrm{M}$. Por otra parte se ha demostrado que la vitamina $\mathrm{C}$ en concentraciones de 110 y $166 \mu \mathrm{M}$ actúa como un antioxidante frenando la peroxidación de las cadenas lipídicas (Niki et al., 1984).

En este trabajo, como ya se detalló, se estudió la estabilidad a largo plazo de una muestra de SEE adicionada, con dos antioxidantes la vitamina E (sal sódica de succinato de $\alpha$-tocoferol) y la vitamina $C$, tratando de prolongar la estabilidad de la SEE.

\subsection{Estudios hematológicos}

Entre las soluciones que permitan conservar las características de los GR que se han preparado se encuentra el medio CE, una solución isoosmolar que contiene glucosa, citrato de sodio, cloruro de sodio, cloruro de potasio, fosfato ácido de sodio, $\mathrm{Na}_{2}$-EDTA, antibióticos, cortisona, albúmina sérica bovina, con un $\mathrm{pH}=7,3$. En esta solución los valores de número de GR, Hb y HCM se mantienen durante 34 días, mientras que los valores de VCM y Hto, muestran un claro aumento a los 25 días (Leonart et al., 1986). Más tarde, a este medio CE se le adicionó vitamina E liposoluble y glutaraldehído con la finalidad de mejorar la preservación en la integridad de la membrana del GR. De esta manera se encontró que los parámetros como recuento de GR, concentración de $\mathrm{Hb}$, Hto, VCM, HCM y CHCM se mantenían estables (sus valores estaban dentro del intervalo $\bar{x} \pm 2 \mathrm{DE}$ ) aproximadamente durante 100 días (Leonart et al., 1989). 
Observando los CV\% encontrados por la autora, como muestra la Tabla 32, éstos fueron mayores a los encontrados por nosotros en todos los lotes estudiados.

Tabla 32: CV\% totales para los diferentes parámetros hematimétricos en diferentes muestras adicionadas con vitamina $\mathrm{E}$

\begin{tabular}{|c|c|c|c|c|c|c|c|}
\hline [Vit E] & GR & $\mathrm{Hb}$ & Hto & VCM & HCM & CHCM & FUENTE \\
\hline $21 \mathrm{mg} / 1$ & $\begin{array}{c}5,71 \\
(n=232)\end{array}$ & $\begin{array}{c}5,38 \\
(n=237)\end{array}$ & $\begin{array}{c}3,46 \\
(n=110)\end{array}$ & $\begin{array}{c}5,94 \\
(n=106)\end{array}$ & $\begin{array}{c}6,09 \\
(n=227)\end{array}$ & $\begin{array}{c}5,42 \\
(n=106)\end{array}$ & $\begin{array}{c}\text { Leonart } \\
\text { et al., } 1989\end{array}$ \\
\hline $\begin{array}{r}300 \\
\mu \mathrm{g} / \mathrm{L}\end{array}$ & $\begin{array}{c}1,74 \\
(n=120)\end{array}$ & $\begin{array}{c}1,21 \\
(n=120)\end{array}$ & $\begin{array}{c}5,69 \\
(n=120)\end{array}$ & $\begin{array}{c}4,40 \\
(n=120)\end{array}$ & $\begin{array}{c}2,37 \\
(n=120)\end{array}$ & $\begin{array}{c}5,84 \\
(n=120)\end{array}$ & $\begin{array}{c}\text { Este } \\
\text { trabajo } \\
\text { SE200899 }\end{array}$ \\
\hline
\end{tabular}

En este punto debemos mencionar que hemos encontrado una discrepancia con lo expuesto por Leonart et al. (1989) en su trabajo en cuanto a la adición del $\alpha$ tocoferol, ya que al intentar adicionar la vitamina E (Ephynal Roche) a la SE, nos encontramos con el hecho de que la misma no se solubiliza en el plasma, permaneciendo como una fase oleosa separada del mismo, ya que por su solubilidad se trata de una vitamina liposoluble. Por esta razón, decidimos adicionar a nuestras muestras de SE una sal de la vitamina E que fuera hidrosoluble. Además, su àcción antioxidante fue comprobada en tejidos animales sometidos al estrés oxidativo provocado por el naftaleno, un metabolito que induce la lipoperoxidación (Vuchetich et al., 1996). Por otra parte, se sabe que es un éster del $\alpha$-tocoferol que se ha demostrado inhibe la hemólisis inducida in vitro por la vitamina A en eritrocitos de conejo, cuando es adicionada en concentraciones entre 6 y $65 \mu \mathrm{g} / \mathrm{ml}$ (Lucy, 1964) y que además presenta efectos antitumorales (Timerstein, 1998).

Por otra parte, como se mencionó en la introducción, la vitamina $\mathrm{C}$ es un antioxidante plasmático no sólo capaz de defender la célula de la acción de radicales 
libres como el $\mathrm{OH}^{\bullet}$ sino que además actúa regenerando la vitamina $\mathrm{E}$ (Chiu et al., 1989; Sies et al.,1992; May et al., 1998).

En nuestras experiencias se comprobó que el agregado de las vitaminas a la SE no permitía mejorar su conservación a largo plazo, los CV\% son similares a la SE sin vitaminas (Tabla 4). La única diferencia aquí encontrada es en el recuento de Plt, donde la muestra de $\mathrm{SE}$ adicionada con vitamina $\mathrm{E} 0,11 \mu \mathrm{M}$ presentó un $\mathrm{CV} \%$ menor. Se sabe que una de las alteraciones más importantes de las Plt es la oxidación de sus membranas y que aún in vivo la incorporación de vitamina $\mathrm{E}$ a la membrana de las mismas aumenta con la edad (Burton, 1986). El efecto encontrado en este trabajo se relacionaría entonces con una protección de la vitamina E sobre la membrana de las Plt. Además, se sabe que la oxidación de los ácidos grasos poliinsaturados está relacionada con varios procesos patológicos, uno de ellos es la agregación plaquetaria (Niki et al., 1984). De los resultados del análisis estadístico en los primeros experimentos se desprendía que la adición de vitamina E mejoraba la conservación de las Plt.

Racek et al. (1997) demostraron que la sangre almacenada en CPD-A $A_{1}$ sufría cambios debidos la acción de radicales libres generados durante el almacenamiento, como por ejemplo la pérdida excesiva de $\mathrm{K}^{+}$con la consecuente entrada de agua y hemólisis. Cuando se administraba a los donantes durante diez días antes de la extracción de sangre, una dosis diaria de una mezcla de antioxidantes conteniendo 36 $\mathrm{mg}$ de $\beta$-caroteno, $300 \mathrm{mg}$ de vitamina $\mathrm{E}, 200 \mathrm{mg}$ de vitamina $\mathrm{C}$ y $40 \mathrm{mg}$ de Selenio, se mejoraba la calidad de la sangre desde el punto de vista de las acciones deletéreas provocadas por los radicales (Racek et al., 1997). Este hecho está de acuerdo con el menor aumento del VCM observado en las muestras de SEE adicionada con las mezclas de vitamina E y vitamina C (Figura 10). 
En cuanto al resto de los parámetros hematimétricos no se observaron diferencias significativas entre las muestras de SEE sin las vitaminas y las muestras adicionadas con las mismas, salvo pequeñas excepciones (figuras 6 a 15).

Los cambios morfológicos, ocasionados por la estabilización de la membrana de los GR, no son diferentes a los de la SEE sin la adición de vitaminas. De acuerdo con lo encontrado en la hematimetría, el aumento de tamaño de los GR (VCM) es menor y esto se observa en las fotografías (Figura 17) y en la Figura 18.

\subsection{Estudios bioquímicos}

\subsubsection{Cambios en la FO}

Como ya se mencionó, Nishi et al., 1983, demostraron que el glutaraldehído disminuye la capacidad de deformación del GR con lo cual, resistiría la entrada de menos cantidad de agua, produciendo un aumento de la FO. Este efecto no puede ser evitado por el agregado de los antioxidantes y así lo confirman los resultados obtenidos (Tabla 15). En la muestra adicionada con vitamina E, se observa un aumento de la FO consecuencia de la estabilización, y el valor de pl se mantiene dentro de los mismos valores que en la SEE sin la vitamina (Tabla 15).

Si bien se mencionó que el test de FO se usa como marcador de la integridad de la membrana, esto se debe aplicar a GR cuyas membranas no han sido tratadas con aldehídos. El $\alpha$-tocoferol es un antioxidante que protege a la membrana, pero como se demuestra en estos resultados no puede evitar los cambios en la deformabilidad de la misma ocasionados por los aldehídos in vitro. Por otra parte se ha descripto que los GR adultos, donde el contenido de vitamina $\mathrm{E}$ en la membrana es más elevado que en los jóvenes, son más frágiles osmóticamente, indicando que no existe una correlación entre los niveles de vitamina E y la FO (Burton, 1986). In vivo se ha demostrado que la FO 
disminuye luego del suministro de estabilizadores de la membrana como el $\alpha$-tocoferol. (Orcutt et al., 1995). Sin embargo se encontró, que cuando los GR de ratas eran suplementados in vitro con dosis de acetato de $\alpha$-tocoferol cercanas a las fisiológicas, las mismas no disminuían la FO de estas células (Marques et al., 1986). Sin embargo, una pequeña diferencia puede observarse en los valores de p3 entre las muestras de SEE y las adicionadas con vitamina E (Tabla 15). Como se mencionó, este parámetro está relacionado con el máximo de absorbancia, lo cual indicaría que en las muestras con vitamina $\mathrm{E}$ la $\mathrm{Hb}$ estaría menos unida a la membrana, probablemente debido a una menor formación de hemicromos.

$\mathrm{Al}$ realizar las correlaciones entre los parámetros p1 y CHCM para las muestras de SEE adicionadas con las diferentes concentraciones de vitamina E (Tabla 16), se encontró que en todos los casos con excepción de la concentración $0,45 \mu \mathrm{M}$ la correlación es estadísticamente significativa. Esto significa que, como lo mencionaran Bowdler et al., (1981), el aumento de la FO se correlaciona perfectamente con una disminución del $\mathrm{CHCM}$, pero cuando la [vitamina $\mathrm{E}]=0,45 \mu \mathrm{M}$, la disminución del CHCM es menos pronunciada (Figura 12). Una manera de medir la integridad de la membrana es por la liberación de $\mathrm{Hb}$, el $\mathrm{CHCM}$ es una medida de la concentración intracorpuscular de $\mathrm{Hb}$, con lo cual si ésta disminuye poco, indica una membrana más íntegra.

\subsubsection{Cambios en las proteínas de la membrana plasmática eritrocitaria}

La oxidación de las proteínas de membrana lleva asociada un cross-linking de las moléculas de $\mathrm{Sp}$ (Bergman et al., 1984). Se ha demostrado que la adición de antioxidantes como el benzoato de sodio, disminuye la injuria producida en la membrana de los GR por la oxidación de la Sp (Wolfe, 1989). Como se observa, el 
agregado de la vitamina E no impidió la formación de los polímeros ni el aumento de fracciones proteicas de menor peso molecular (Tabla 18). Se observa, sin embargo, una diferencia en los porcentajes de disminución de algunas bandas. Por ejemplo la banda 3 , que se sabe que esta proteína sufre alteraciones en el almacenamiento debido a la oxidación, como por ejemplo el incremento en la sensibilidad a la unión a anticuerpos (Ando, 1993), la unión a la $\mathrm{Hb}$ (Gallagher, 1998). El hecho de que su porcentaje de disminución en el tiempo, en los ghosts obtenidos de muestras de SEE adicionadas con vitamina $\mathrm{E}$, fue menor (Tabla 18), indicaría que la misma puede estar protegiéndola de estas alteraciones ocasionadas por la oxidación.

\subsubsection{Cambios en los niveles de 2,3-DPG}

El GR maduro consume el $90 \%$ de la glucosa a través de la ruta de EmbdenMeyerhof, formando lactato como producto final y produciendo 2 moles de ATP y 2 moles de $\mathrm{NADH}$ por cada mol de glucosa. Normalmente el $10 \%$ restante es en gran parte utilizado para generar el poder reductor (NADPH) a través de la vía de las pentosas y otra pequeña porción es utilizada para generar 2,3-DPG, necesario para modular la unión de la $\mathrm{Hb}$ al oxígeno (Moore, 1987). Puede pensarse que, en presencia de antioxidantes, la célula no necesite generar tanto poder reductor y de esta manera aumente la producción de moléculas de 2,3-DPG y a su vez su consumo se vea disminuido. Esto podría relacionarse con los datos mostrados en la Figura 23; si bien los niveles de 2,3-DPG, como era de esperarse, disminuyen en todas las muestras, en aquéllas adicionadas con las vitaminas este descenso es menos pronunciado que en la muestra de SEE. La adición de vitamina E permitió mantener los niveles de este metabolito entre un $20 \%$ y un $56 \%$ después de 100 días, dependiendo de la concentración utilizada. La vitamina $\mathrm{C}$ por su parte permitió mantener los niveles en un 
$50 \%$ en este mismo tiempo y la mezcla de ambas vitaminas presentó una disminución del 2,3-DPG más leve. Por otra parte, está demostrado que el ascorbato, adicionado a los GR almacenados en CPD, permite mantener los niveles de 2,3-DPG por 28 días, en un nivel aproximadamente igual al 50\% del inicial (Wood y Beutler, 1974). En nuestros resultados, esto se verifica (Figura 22). La muestra adicionada con vitamina $\mathrm{C}$ fue la que presentó una menor disminución en los niveles de este metabolito. Si bien la vitamina $\mathrm{C}$ adicionada fue el ácido ascórbico, a pH fisiológico éste rápidamente se ioniza formando el ascorbato (Creutz, 1981).

Por otra parte, como se mencionó más arriba, la disminución del 2,3-DPG está relacionada con un aumento del VCM. En las muestras de SEE adicionada con vitaminas estos dos hechos estarían perfectamente correlacionados según nuestros resultados. Así, una disminución más leve del 2,3-DPG (Figura 23) está relacionada con un aumento menor en el VCM de las mismas muestras (Figura 10)

\subsubsection{Cambios en la actividad de las colinesterasas}

La adición de los antioxidantes no modificó en forma significativa la actividad de las enzimas (tablas 20, 21 y 22), como se demostró en el hecho de que no existan diferencias significativas entre los tratamientos en cada experiencia. Esto está de acuerdo con lo encontrado por Shinar et al., 1983, acerca de que los scavengers de radicales oxidrilos, entre los que se encuentra el $\alpha$-tocoferol, no proveen protección a esta enzima; sólo el manitol a concentraciones superiores a $1 \mathrm{M}$ ha mostrado prevenir su inactivación. Por otra parte, se encontraron diferencias entre las experiencias, poniendo una vez más de manifiesto la distinta respuesta entre individuos a la estabilización (Corry y Meiselman, 1978; Fernández Alberti y Fink, 1998). 
La PChE es una enzima muy estable que no sufre alteraciones en el tiempo (Meuling, 1992). Nuestros resultados coinciden con este hecho, como se desprende de la Figura 24 y de los CV\% obtenidos cuando se tomaron en cuenta todos los datos desde el inicio al final de cada experiencia, siendo menores a los propuestos para la variación interensayo. Por otra parte, las diferencias entre experiencias están relacionadas con que la actividad de esta enzima depende de varios factores como son el peso corporal, el sexo y el fenotipo (Brock y Brock, 1990).

\subsubsection{Lipoperoxidación}

En el almacenamiento se debe tener en cuenta, como se mencionara en la Introducción de este trabajo, que la sangre es rica en ácidos grasos poliinsaturados y en colesterol. Esto, asociado a que en la SE almacenada hay exposición a la luz, liberación de radicales por acción de los leucocitos, etc., lleva a pensar que estos compuestos pueden ser fácilmente convertidos en hidroperóxidos inestables que llevarían a la producción de MDA. Esta alteración durante el almacenamiento puede reducirse mediante la administración, antes de la extracción de sangre, de una mezcla de antioxidantes (Racek et al., 1997).

La adición de antioxidantes lipídicos como la vitamina $\mathrm{E}$ reduce los niveles de lipoperoxidación; por ejemplo, la adición de $\alpha$-tocoferol $0,33 \mathrm{mM}$ a una muestra de hidroperóxido linoleico disminuía la absorbancia en la medición de los TBARS en al menos un 12\% (Gutteridge y Quinlan, 1983). En nuestro trabajo las concentraciones usadas de vitamina $\mathrm{E}$ son 1000 veces menores y se observa que también hay un porcentaje de inhibición que alcanza el $27 \%$. Se ha encontrado además que en sangre de cordón de pacientes que poseían bajos niveles de vitamina $\mathrm{E}$, los valores de MDA por este test son mayores a los valores esperados (Stocks et al., 1971). 
En estudios in vivo realizados en ratas, se ha encontrado que al administrar vitamina $\mathrm{E}$ en la dieta, en concentraciones de 100 y 1500 ppm, ésta rápidamente aumenta sus niveles en plasma y disminuye los niveles de TBARS comparados con ratas sin vitamina en su dieta (Lii et al., 1998). La adición de una mezcla de vitamina $\mathrm{E}$ (15 mg/día), vitamina C (30 mg/día) y $\beta$-caroteno (15 o $30 \mathrm{mg} /$ día ) a voluntarios sanos, protegía a sus eritrocitos de la acción oxidante del oxígeno singlete inducida in vitro mediante irradiación (Postaire et al., 1995). Así mismo, se ha estudiado el efecto de la administración de antioxidantes en forma oral a los donantes diez días antes de la donación para mejorar la conservación, encontrándose que existía una disminución en los niveles de $\mathrm{Hb}$ plasmática, MDA y $\mathrm{K}^{+}$plasmático (Greenwalt, 1997; Racek et al., 1997).

Se ha demostrado que la adición de ambas vitaminas tiene un efecto sinérgico en la inhibición de la oxidación. Si bien la vitamina C no se solubiliza en lípidos, su mecanismo de protección sobre la vitamna E se explica, ya que se ha demostrado que el grupo fenólico de esta última se encuentra cerca de los grupos polares de los PLP, en la interfase entre la membrana y el plasma. El mecanismo antioxidante en el que participan ambas vitaminas, puede simplificarse de la siguiente manera: a) la reacción de iniciación que se produce entre el radical $\operatorname{LOO}^{\circ}$ y la vitamina $\mathrm{E}, \mathrm{b}$ ) el radical de la vitamina $\mathrm{E}$ formado reacciona con la vitamina $\mathrm{C}$, regenerándose entonces en $\alpha-$ tocoferol (Buettner, 1993). El siguiente diagrama representa este efecto:
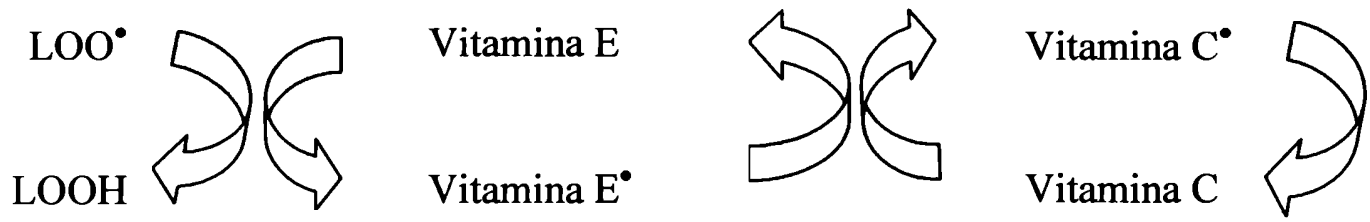
Este sinergismo se reflejaría muy levemente en nuestros resultados en cuanto a los niveles plasmáticos de MDA (Tabla 28). Pero si se observa en la cuantificación de la vitamina $\mathrm{E}$ plasmática, después de 90 días los niveles de vitamina $\mathrm{E}$ en las muestras que contenían también vitamina $\mathrm{C}$ eran mayores a los del primer día. El aumento de los niveles plasmáticos puede deberse en parte a que la vitamina $\mathrm{C}$ actuó regenerando tanto la vitamina $E$ endógena y exógena y en parte a una liberación de la vitamina $E$ que se encontraba inicialmente en la membrana al plasma.

Además, se ha demostrado que la desaparición de las vitaminas del medio ocurre en forma lineal en el tiempo cuando son usadas solas. Cuando se agregan juntas, la vitamina $\mathrm{C}$ se consume primero, mientras que la vitamina $\mathrm{E}$ se consume luego que la $\mathrm{C}$ desaparece (Niki et al., 1984).

Las vitaminas E y C sirven como moléculas antioxidantes porque: a) sus radicales reaccionan muy pobremente con el oxígeno; b) sus propiedades cinéticas requieren que con sólo pequeñas cantidades de los mismos se observen efectos antioxidantes; c) pueden ser reciclados, directa o indirectamente, por sistemas enzimáticos.

Estas tres características se han reflejado en nuestros resultados. Así, la adición de ambas vitaminas a la SEE permitió mejorar la estabilidad a largo plazo de algunos parámetros hematimétricos (Hto, VCM, Plt, PVM) y bioquímicos (2,3-DPG). 
CONCLUSIONES 
1. La estabilización de la SE con aldehídos según el método de Reardon et al. (1991), permite obtener una muestra que puede ser utilizada en el laboratorio clínico para control de los parámetros hematimétricos, pero con diferentes límites de tiempos. La adición de antioxidantes a la SEE, en las concentraciones utilizadas, no permitió mejorar en forma significativa los tiempos máximos de almacenamiento a $4^{\circ} \mathrm{C}$, aunque si mejoró los CV\% de algunos parámetros.

2. Los GR de la SEE, por poseer una membrana estabilizada y, por lo tanto, menos deformable, presentan un elevado valor en la FO, el cual se mantiene durante el almacenamiento sin variaciones significativas $(\mathrm{p}<0,05)$.

3. La estabilización de la membrana de los GR produce cambios en las proteínas del citoesqueleto que se mantienen estables durante un período de por lo menos 80 días. La adición de vitamina $\mathrm{E}$ protege a las mismas de los daños oxidativos.

4. La estabilización de la membrana del GR disminuye el requerimiento energético del mismo, ya que la disminución en un metabolito como el 2,3-DPG, íntimamente relacionado con el metabolismo energético es menor que en la SE. La adición de antioxidantes permitió mejorar la conservación de este metabolito.

5. La muestra de $\mathrm{SEE}$ es un material que permite la medición de $\mathrm{AChE}$ por este método; luego de pasados diez días de su preparación, por un período de al menos 40 días, se mantiene en niveles constantes, por lo cual podría ser usado como material de control. La colinesterasa plasmática no sufre variaciones significativas 
durante los 120 días de almacenamiento. La adición de los antioxidantes no modificó en forma significativa la actividad de las enzimas.

6. La estabilización protege los GR del ataque de los oxidantes durante el almacenamiento, mientras que los niveles de antioxidantes adicionados en este trabajo no permitieron disminuir en forma significativa los niveles plasmáticos de MDA a los 120 días de almacenamiento a $4^{\circ} \mathrm{C}$.

7. La adición de las vitaminas $\mathrm{E}$ y $\mathrm{C}$ a la $\mathrm{SEE}$ permitió mejorar la estabilidad a largo plazo de algunos parámetros hematimétricos (Plt, PVM, VCM y Hto) y bioquímicos (2,3-DPG). 


\section{BIBLIOGRAFÍA}


- Ando K, Beppu M, Kikugawa K, Hamasaki N. Increased susceptibility of stored erythrocytes to anti-band $3 \mathrm{IgG}$ autoantibody binding. Acta Biochim Biophys 1993; 1778:127-34.

- Ando K, Beppu M, Kikugawa K. Evidence for accumulation lo lipid hydroperoxides during the aging of human red blood cells in the circulation. Biol Pharm Bull 1995; 15:659-63.

- Arduini A, Holme S, Sweeney JD, Dottori S, Sciarroni AF, Calvani M. Addition of L-carnitine to additive solution-suspended red cells stored al $4^{\circ} \mathrm{C}$ reduces in vitro hemolysis and improves in vivo viability. Transfusion 1997; 37:166-74.

- Babcock JG, Lippert LE, Derse-Anthony CP, Mechling M, Hess JR: A hypotonic storage solution did not prolong the viability of RBCs. Transfusion 2000; 40:994-99.

- Barretto OCO, Nonoyama K, Sawatani E, Tanaka K, Okumura Y, Jamra M. Viabilidade de sangue conservado em recipientes de varias procedencias. Rev Assoc Med Bras 1983; 29:102-5.

- Bartlet GR. Red Cell metabolism: review highlighting changes during storage. In: Greenwalt TJ, Jamieson GA, editors. The humane red cell in vitro. New York: Grune and Stratton, 1974:5-28.

- Bartosz G. Eythrocyte aging. In: Advances in cell aging and gerontology. 1996. Vol 1, Chap 3: 63-88.

- Bellamy GJ, Hinchliffe RF: Effect of storage of blood count variables in small samples. Med Lab Sci 1990; 47:230-3.

- Bergmann WL, Dressler V, Haest CWM, Deuticke B. Crosslinking of SH-groups in the erythrocyte membrane enhances transbilayer orientation of phospholipids: Evidence for a limited acces of phospholipids to the reorientation sites. Biochim Biophys Acta 1984; 769:390-8.

- Beutler E, West C, Blume KG: The removal of leukocytes and platelets from whole blood. J Lab Clin Med 1976; 88:328-33.

- Beutler E. Red cell metabolism: a manual of biochemical methods. 3 ed. Orlando: Grune \& Stratton, 1984.

- Beutler E. How do red cell enzimes age? A new perspective. Br J Haematol 1985; 61:377-84.

- Beutler E, Kuhl W. Volume control of erythrocytes during storage: the rol of mannitol. Transfusion 1988; 28:353-7. 
- Beutler E. Back to the future in RBC preservation. Transfusion 2000; 40:893-5.

- Bland J: Lipid antioxidant nutrition. En: Kaplan LA, Pesce AJ, editores. Química Clínica. Buenos Aires: Panamericana, 1986.

- Bon S, Vigny M, Massoulie J: Asymmetric and globular forms of acetylcholinesterase in mammals and birds. Proc Natl Acad Sci USA 1979; 76:254650 .

- Bonnet D, Begard E: Interaction of anilinonapthyl labeled spectrin with fatty acids and phospholipids: fluorescence study. Biochem Biophys Res Comm 1984; 120:344.

- Bowdler AJ, Dougherty RM, Bowdler NC: Age as a factor affecting erythrocyte osmotic fragility in males. Gerontology $1981 ; 27: 224-31$.

- Brock A, Brock V: Plasma cholinesterase activity in a healthy population group with no occupational exposure to known cholinesterase inhibitors: relative influence of some factors related to normal inter- and intra- individual variations. Scand J Clin Lab Invest 1990; 50:401-8.

- Buettner GR. The pecking order of free radicals and antioxidants: lipid peroxidation, alpha-tocopherol, and ascorbate. Arch Biochem Biophys 1993; 300:535-43.

- Burton GW, Cheng SC, Webb A, Ingold KU. Vitamin E in young and old red blood cells. Biochim Biophys Acta 1986; 860:84-90.

- Cohen RM, McLellan C. The effects of glutaraldehyde cross-linking on the function of the adenylate cyclase complex of turkey erythrocytes. Life Sci 1986; 38:2151-61.

- Cohle SD, Saleem A, Makkaqui DE: Effects of storage of blood on stability of hematologic parameters. Am J Clin Pathol 1981; 76:67-9.

- Combs GF, Noguchi T, Scott ML. Mechanisms of action of selenium and vitamin E in protection of biological membranes. Fed Proc 1974; 34(11): 2090-5.

- Combs GF, Scott ML. Dietary requirements for vitamin e and selenium measured at the cellular level in the chick. J Nutr 1974; 104:1292-6.

- Corry WD, Meiselman HJ. Modification of erythrocyte physicochemical properties by millimolar concentrations of glutaraldehyde. Blood Cells 1978; 4:465-80.

- Coudray C, Richard MJ, Favier AE. Determination of primary and secondary lipid peroxidation products: plasma lipid hydroperoxides and thiobarbituric acid reactive substance. In: Favier AE, Cadet J, Kalyanaraman B, Fontecave M, Pierre JL, editors. Analysis of free radicals in biological systems. Basel: Birkhäuser Verlag, 1995:184200. 
- Creutz C. The complexities of ascorbate as a reducing agent. Inorg Chem 1981; 20:4449-52.

- Chasis JA, Mohandas N. Erythrocyte membrane deformability and stability: two distinct membrane properties that are independently regulated by skeletal protein associations. J Cell Biol 1986; 103:343-50.

- Chiu D, Kuypers F, Lubin B. Lipid peroxidation in human red cells. Semin Hematol $1989 ; 26: 257-76$.

- Christensen NJ. EQA and IQC in routine haematology-testing using minimally processed fresh donors' blood. EQAnews 1998; 9:36.

- Dacie JV, Lewis SM. Practical haematology. 6 ed. Edinburgh: Churchill Livingstone, 1984.

- Dawson RB, Sisk LD, Meyer DR, Hershey RT, Myers-Helbert CS. Blood preservation: 33. Phosphate enhancement of ribose maintenance of 2,3-DPG and ATP. Transfusion 1981; 21:215-8.

- de Jong K, Beleznay Z, Ott P: Phospholipid asymmetry in red blood cells and spectrin-free vesicles during prolonged storage. Biochim Biophys Acta 1996; 1281:101-10.

- De Leenher AP, De Bevere VO, Cruyl AA, Claeys AE. Determination of serum $\alpha$ tocopherol (vitamin E) by high-performance liquid cromatography. Clin Chem 1978; 24:585-90.

- De Sandre G, Ghiotto G, Perona G: Erythrocytic acetylcholinesterase activity in paroxysmal nocturnal haemoglobinuria. In: Proceedings of the 9th Congress of European Society of Haematology, Lisbon II/I, 775. Basel, New York: Karger, 1963.

- Devaux PF: Protein involvement in transmembrane lipid asymmetry. Ann Rev Biophys Biomol Struct 1992; 21:417.

- Dzandu JM, Deh ME, Barrat DL, Wise GE. Detection of erythrocyte membrane proteins, sialoglycoproeins, and lipids in the same polyacrilamide gel using a doublestaining technique. Proc Natl Acad Sci. USA 1984; 81:1733-7

- Dumaswala UJ, Bentley NL, Greenwalt TJ: Studies in red blood cell preservation: 8. Liquid storage of red cells in a glycerol-containing additive solution. Vox Sang 1994; 67:139-43. 
- Dumaswala UJ, Dumaswala RU, Levin DS, Greenwalt TJ. Improved red blood cell preservation correlates with decreased loss of bands 3: 4.1 Acetylcholinesterase, and lipids in microvesicles. Blood 1996a; 87:1612-6.

- Dumaswala UJ, Wilson MJ, José T, Daleke DL. Glutamine-and phosphatecontaining hipotonic storage media better mantain erythrocyte membrane physical properties. Blood 1996b; 88:697-704.

- Esteloto AC. Banda 3 eritrocitaria: anticorpos espontâneos e induzidos [Tesis doctoral]. Río de Janeiro: Universidade Federal do Rio de Janeiro, 1994.

- Fagiolo E, Mores N, Pelliccetti A, Gozzo ML, Zuppi C, Littarru GP. Biochemical parameters to assess viability of blood stored for transfusional use. Folia Haematol $1986 ; 113: 783-9$.

- Favier AE. How to demonstrate the occurrrence of an oxidative stress in human?. Analysis of Free Radicals in Biological Systems, 1995; 99-119.

- Feo C, Mohandas N. Clarification of role of ATP in red-cell morphology and functional. nature 1977; 265:167-8.

- Fernández Alberti MA, Fink NE. Long-term stability of a whole blood control material. Lab Hematol 1998; 4:239-43.

- Fernández Alberti MA, Fink NE. Red blood cell osmotic fragility confidence intervals: a definition by application of a mathematical model. Clin Chem Lab Med $2000 ; 38(5): 433-6$.

- Fraser CG. Analytical goals for haematology tests. Eur J Haematol 1990; 45(suppl 53):2-5.

- Frei B, England L Ames B. Ascorbate is an outstanding antioxidant in human blood plasma. Proc Nat Acad Sci 1989; 86:6377-81.

- Frenkel ET, Roelofsen B, Brodbeck U, Van Deenen LLM, Ott P: Lipid-protein interactions of human erythrocyte-membrane acetylcholinesterase. Eur J Biochem $1980 ; 109: 377-82$.

- Gallagher PG, Forget BG, Lux SE. Disorders of the erythrocyte membrane en hematology of infancy and childhood. En: Nathan DG, Orkin SH, editors. Hematology of infancy and chilhood. $5^{\text {th }}$ ed. Vol 1. Chapter 16, 1998.

- Galbraiths DA, Watts DC: Human erythrocyte acetylcholinesterase in relation to cell age. Biochem J 1981; 195:221-8. 
- Goldin AR, Rubenstein AH, Bradlow BA, Elliot GA: Malathion poisoning with special reference to the effect of cholinesterase inhibition on erythrocyte survival. $\mathrm{N}$ Engl J Med 1964; 271:1289-93.

- Gottschall JL, Rzad L, Aster RH. Studies of the minimum temperature at which human platelets can be stored with full maintenance of viability. Transfusion 1986; 26:460-2.

- Greenwalt TJ, Dumaswala UJ. Effect of red cell age on vesiculation in vitro. Br J Haematol 1988; 68:465-7.

- Greenwalt TJ, McGuinness CG, Dumaswala UJ, Carter HW. Studies in Red Blood Cell Preservation 3. A Phosphate-Ammonium-Adenine-Additive Solution. Vox Sang 1990; 58: 94-9.

- Greenwalt TJ, Dumaswala UJ, Dhingra N, Allen CM, Silberstein EB. Studies in red blood cell preservation: 7 . In vivo and in vitro studies with a modified phosphateammonium additive solution. Vox Sang 1993;65:87-94.

- Greenwalt TJ, Dumaswala UJ, Rugg N. Studies in red blood cell preservation $10 .{ }^{51} \mathrm{Cr}$ recovery of red cells after liquid storage in a glycerol-containing additive solution. Vox Sang 1996;70:6-10.

- Greenwalt TJ: Recent developments in the long-term preservation of red blood cells. Transfusion Med 1997; 4: 431-5.

- Grzelinska E, Bartosz G. Aging of the erythrocyte. Enzyme 1983; 30:95-8.

- Gutteridge JMC, Quinlan GJ. Malondialdehyde formation from lipid peroxides in thiobarbituric acid test: the rol of lipid radicals, iron salts, and metal chelators. J Appl Biochem 1983; 5:193-9.

- Haest CWM, Plasa G, Kamp D, Deuticke B. Spectrin as a stabilizer of the phospholipid asymmetry in the human erythrocyte membrane. Biochem Biophys Acta, 1978; 509:21-32.

- Halbhuber KJ, Lemke C, Stibenz D, Linss W: Activation of acetylcholinesterase $(\mathrm{AChE})$ as a sign of erythrocyte membrane alteration. Exp Pathol 1984; 25:35-44

- Halliwell B. Oxygen radicals: a commonsense look at their nature and medical importance. Med Biol 1984; 62:71-7.

- Halliwell B, Gutteridge JMC. Oxygen toxicity, oxygen radicals, transition metals and disease. Biochem J 1984; 219:1-14. 
- Hartwig JH. Actin-binding proteins: 1. Spectrin superfamily. Protein Prof 1995; 2:703-39.

- Heaton A, Miripol J, Grapka B et al. Improved storage of high hematocrit cell concentrates using a manitol, adenine, saline, glucose solution. Transfusion 1981; 21:600-1.

- Heaton A, Miripol J, Aster R et al. Use of adsol preservation solution for prolonged storage of low viscosity AS-1 red blood cells. Br J Haematol 1984; 57:467-78.

- Heller M, Hanahan DJ: Human erythrocyte membrane bound enzyme acetylcholinesterase. Biochim Biophys Acta 1972; 255:251-72.

- Hernández JL, Bolufer P, Aznar J. Estabilidad de la sangre de equino para su empleo como control de calidad en hematología. Rev Diag Biol 1988; 37:91-5.

- Hess JR, Lippert LE, Derse-Anthony CP et al. The effects of phosphate, $\mathrm{pH}$, and AS volume on RBCs stored in saline- adenine- glucose-mannitol solutions. Transfusion 2000a; 40:1000-6.

- Hess JR, Rugg N, Knapp AD, Gormas JF, Greenwalt TJ. Succesful storage of RBCs for 10 weeks in a new additive solution. Transfusion 2000b; 40:1012-6.

- Hochstein P, Jain SK. Association of lipid peroxidation and polimerization of membrane proteins with erythrocyte aging. Fed Proc 1981; 40:183-8.

- Högman CF, Hedlund K, Zetterstrom H. Clinical usefulness of red cells preserved in protein-poor mediums. N Engl J Med 1978; 299:1377-82.

- Högman CF, Eriksson L, Ericson A, Reppucci AJ. Storage of saline-adenineglucose-mannitol-suspended red cells in a new plastic container: polyvinylchloride plasticized with butyryl-n-trihexyl-citrate. Transfusion 1991; 31:26-9.

- Horwitt MK, Harvey CC, Harmon EM. Lipids, $\alpha$-tocopherol, and erythrocyte hemolysis. Vitam Horm NY 1968; 26:487-99.

- Ideguchi H, Nishimura J, Nawata H, Hamasaki N. A genetic defect of erythrocite band 4.1 protein associated with hereditary spherocytosis. Br J Haematol 1990; 74:347-53.

- Inaba M, Gupta KC, Kuwara M, Takagashi T, Benz EJ, Maede Y. Deamidation of human erythrocyte protein 4.1: a possible role in aging. Blood 1992; 79:3355-61.

- Janero DR. Malondialdehyde and thiobarbiturc acid-reactivity as diagnostic indices of lipid peroxidation and peroxidative tissue injury. Free Radical Biol Med 1990; 9:515-40. 
- Jarolim P, Palek J, Rubin HL, Prchal JT, Korsgren C, Cohen CM. Band 3 Tuscaloosa: Pro $^{327} \rightarrow \mathrm{Arg}^{327}$ substitution in the cytoplasmic domain of erythrocyte band 3 protein associated with spherocytic hemolytc anemia and partial deficiency of protein 4.2. Blood 1992. 82:523-9.

- Kakimoto H, Imai Y, Kawata S, Inada M, Ito T, Matsuzawa Y: Altered lipid composition and differential changes in activities of membrane-bound enzymes of erythrocytes in hepatic cirrhosis. Metabolism 1995; 44: 825-32.

- Kamber E, Poyiagi A, Deliconstantinos G: modifications in the activities of membrane-bound enzymes during in-vivo ageing of human and rabbit erythrocytes. Comp Biochem Physiol 1984; 77B:95-9.

- Knight JA, Voorhees RP, Martin L, Anstall H. Lipid peroxidation in store red cells. Transfusion 1991; 32:354-6.

- Knight JA, Pieper RK, Smith SE. Increased urinary lipoperoxides in drug abusers. Ann Clin Lab Sci 1988; 18:374-7.

- Krinsky NI, Bymun EN, Packer L. Retention of $\mathrm{K}^{+}$gradientes in imidoester crosslinked erythrocyte membranes. Arch Bioch Bioph 1974; 160:350-2.

- Krinsky NI. Mechanism of action of biological antioxidants. Proc Soc Exp Biol Med 1992; 200:248-54.

- Kuypers FA, Lubin BH, Yee M, Agreo P, Devaux PF, Geldwerth D. The distribution of erythrocyte phospholipids in hereditary spherocytosis demonstrates a minimal role for the erythrocyte spectrin on phospholipid diffusion and asymmetry. Blood 1993; $81: 1051-7$

- Lachant NA, Noble NA, Myrhe BA, Tanaka KR. Antioxidant metabolism during blood storage and its relationship to post-transfusion red cell survival. Am J Hematol $1984 ; 17: 237-49$.

- Lampasso JA. Changes in hematologic values induced by storage of ethylenendiaminetetraacetate human blood for varying periods of time. Am J Clin Pathol 1968; 38:443-7.

- Langsdorf LJ, Zydney AL. Effect of uremia on the membrane transport characteristics of red blood cells. Blood, 1993; 81: 820-7.

- Lawson AA, Barr RD: Acetylcholinesterase in red blood cells. Am J Hematol 1987; 26: $101-12$. 
- Leonart MSS, Granato ES, do Nascimento AJ, Hashimoto Y, Leonart R: Soluçao preservadora de eritrócitos para controle de qualidade do eritrograma. Rev Bras Anál Clín 1986; 18:7-12.

- Leonart MSS, da Silva EL, Weffort Santos AM, Scatezini M, do Nascimento AJ : Estudos sobre a preservaçao dos leucocitos. Rev Bras Anál Clín 1988; 20:53-6.

- Leonart MSS, da Silva EL, Stinghen ST, do Nascimento AJ: Amostra para controle de qualidade do eritrograma estável durante 100 dias. Rev Bras Anál Clín 1989; 21:111-3.

- Lepage L, Schiele F, Guegen R, Siest G. Total cholinesterase in plasma: biological variations and reference limits. Clin Chem 1985; 31:546-50.

- Lewis SM. Quality assurance in hematology. Geneva: Wodld Health Organization. 1992 (WHO/LBS/92.4).

- Lii CK, Ko YJ, Chiang MT, Sung WC, Chen HW. Effect of dietary vitamin E on antioxidant status and antioxidant enzyme activities in Sprague-Dawley rats. Nutr Cancer 1998; 32:95-100.

- Liu SC, Palek J. Metabolic dependence of protein arrangement in human erythrocyte membranes: II. Crosslinking of major proteins in ghosts from fresh and ATPdepleted red cells. Blood 1979; 54:1117-31.

- Lombarts AJPF, Leijnse B. Preparation and evaluation of a 7-parameter intralaboratory control blood of 4-month stability. Ann Clin Biochem 1983a; 20:3027.

- Lombarts AJPF, Leijnse B. A white blood cell control of long-term stability. Clin Chim Acta 1983b; 129:79-83.

- Lucy JA, Dingle JT: Fat-soluble vitamins and biological membranes. Nature 1964; 204:156-60.

- Lucy JA: Funcional and structural aspects of biological membranes: a suggested structural role for vitamin $\mathrm{E}$ in the control of membrane permeability and stability. Ann NY Acad Sci 1972; 203

- Lund-Karlsen R, Sterri S, Lyngaas S, Fonnum F: Reference values for erythrocyte acetylcholinesterase and plasma cholinesterase activities in children, implications for organophosphate intoxication. Scand J Clin Lab Invest 1981; 41:301-2.

- Marques Díez ML, Cazaña Lucio FJ, Rodríguez Puyol M. In vitro response of erythrocytes to alpha-tocopherol exposure. Int J Vit Nutr 1986; 56:311-5. 
- May JM, Qu Z, Mendiratta S: Protection and Recycling of $\alpha$-Tocopherol in Human Erythrocytes by Intracellular Ascorbic Acid. Archives of Biochemistry and Biophysics, 1998; 349: 281-289.

- Meuling WJA, Jongen MJM, van Hemmen JJ: An automated method for the determination of acetyl and pseudo cholinesterase in hemolyzed whole blood. Am $\mathbf{J}$ of Ind Med 1992; 22:231-41.

- Meryman HT, Hornblower MLS, Syring RL. Prolonged storage of red cells at $4^{\circ} \mathrm{C}$. Transfusion 1986; 26:500-5.

- Metz J, Stevens K, Van Rensburg NJ, Hart D: Failure of in vivo inhibition of acetylcholinesterase to affect erythrocyte life span: the significance of the enzyme defect in paroxysmal nocturnal haemoglobinuria. Br J Haematol 1961; 7:458-63.

- Mohandas N, Chasis JA: Red blood cell deformability, membrane material properties and shape: regulation by transmembrane, skeletal and cytosolic proteins and lipids. Semin Hematol. 1993; 30:171. In: Palek J. The red cell membrane. In: Beutler E, Lichtman MA, Coller BS, Kipps TJ, editors. Williams: Hematology. $5^{\text {th }}$ ed. New York: McGraw-Hill, 1995:406-17.

- Mollison PL. Blood transfusion in clinical medicine. $5^{\text {th }}$ ed. London: Blackwell Scientific Publications, 1972.

- Moore GL. Additive solutions for better blood preservation. Crit Rev Clin Lab Sci, $1987 ; 25: 211-29$.

- Morgan LO, Jones WG, Fisher JO, Cauvil T. A whole blood control for the Coulter model S. J Clin Pathol 1978; 31:50-3.

- Nishi K, Yamada M, Wakasugi C: Effects of treatment with glutaraldehyde and storage in acid-citrate-dextrose solution on agglutinability of erythrocytes. Jpn J Legal Med 1983; 37:757-63.

- Ohkawa H, Ohishi N, Yagi K. Assay for lipid peroxides in animal tissues by thiobarbituric acid reaction. Ann Biochem 1979; 95:359-63.

- Orcutt RH, Thurmond TS, Ferslew KE. Mathematical modeling of the osmotic fragility of rabbit red blood cells. J Pharm Toxicol Meth 1995; 34:169-74.

- Ott P, Brodbeck U: Amphiphile dependency of the monomeric and dimeric forms of acetylcholinesterase from human erythrocyte membrane. Biochim Biophys Acta $1984 ; 775: 71-6$. 
- Palek J. The red cell membrane. In: Beutler E, Lichtman MA, Coller BS, Kipps TJ, editors. Williams: Hematology. $5^{\text {th }}$ ed. New York: McGraw-Hill, 1995:406-17.

- Parker JC. Glutaraldehyde fixation of sodium transport in dog red blood cells. J Gen Physiol 1984; 84:789-803.

- Pierre JL. Chemistry of oxygen and its activated species. In: Favier AE, Cadet J, Kalyanaraman B, Fontecave M, Pierre JL, editors. Análisis of free radicals in biological systems. Basel: Birkhäuser Verlag, 1995:1-11.

- Pincemail J: Free radicals and antioxidants in human diseases. In: Favier AE, Cadet J, Kalyanaraman B, Fontecave M, Pierre JL, editors. Análisis of free radicals in biological systems. Basel: Birkhäuser Verlag, 1995:83-98.

- Podgorski A, Elbaum D. Properties of red cell membrane proteins: mechanism of spectrin and band 4.1 interaction. Biochemistry 1985; 24:7871-6.

- Postaire E, Regnault C, Simonet L, Rousset G, Bejot M: Increase of singlet oxygen protection of erythrocytes by vitamin $\mathrm{E}$, vitamin $\mathrm{C}$, and $\beta$ carotene intakes. Biochem Mol Biol Int 1995; 35:371-4.

- Racek J, Herynkova R, Holecek V, Jerabek Z, Slama V. Influence of antioxidants on the quality of stored blood. Vox Sang 1997; 72:16-9.

- Reardon DM, Mack D, Warner B, Hutchinson D. A whole blood control for blood count analyzers, and source material for an external quality assessment scheme. Med Lab Sci 1991; 48:19-26.

- Rocchigiani M, Pescaglini M, Sestini S, Micheli V, Ricci C: Density increase and ageing of erythrocytes in stored blood. J Int Med Res 1989; 17:461-6.

- Rodriguez CC, de Jesús Colina Rodriguez A, del Portillo de Juan I: Recomendaciones para la preparación fácil y rápida de un material de control estable para hematología. Bioquimia 1994; 19:126-9.

- Römer-Lüthi CR, Ott P, Brodbeck U: Reconstitution of human erythrocyte membrane acetylcholinesterase in phospholipid vesicles. Biochim Biophys Acta 1980; 601:123-33.

- Rosenberry TL, Scoggin DM: Structure of human erythrocyte acetylcholinesterase, J Biol Chem 1984; 259:5643-52.

- Ruiz C, Alegría A, Barberá R, Farré R, Lagarda MJ: Lipid peroxidation and antioxidant enzyme activities in patients with type I diabetes mellitus. Scand Clin Lab Invest 1999; 59:99-106. 
- Saint-Blancard J, Allary M, Pringent N el Roussilhe A: Effects of the glyoxylate on the red blood cells preservation parameters. Ann Pharm Franc 1988; 46:331-7.

- Scott ML, Hill FW, Norris LC, Dobson DC, Nelson TS: Studies on vitamin E in poultry nutrition. J Nutr 1956; 56:387-402.

- Sheetz MP, Casaly J. 2,3-diphosphoglycerate and ATP dissociate erythrocyte membrane skeletons. J Biol Chem 1980; 225:9955-60.

- Shinar E, Navok T, Chevion M: The analogous mechanisms of enzymatic inactivation induced by ascorbate and superoxide in the presence of copper. $\mathrm{J}$ Biol Chem 1983; 258: 14778-83.

- Shohet SB, Beutler E. The red cell membrane. Beutler E, editor. Williams: hematology. $4^{\text {th }}$ ed. New York: McGraw Hill, 1990; Chap 36.

- Sies H, Stahl W, Sundquist AR. Antioxidant functions of vitamins: vitamins E and C, beta-carotene, and other carotenoids. Ann NY Acad Sci 1992; 669:7-20.

- Skaer RJ: Acetylcholinesterase in human erythroid cells. J Cell Sci 1973; 21:911-23.

- Snyder LM, Fairbanks G, Trainor J, Fortier NL, Jacobs JB, Leb L. Properties and characterization of vesicles released by young and old human red cells. $\mathrm{Br} \mathrm{J}$ Haematol 1985; 59:513-22.

- Sohmer PR, Beutler E, Moore GL: Clinical trials with CPDA-2. Transfusion 1981; 600 .

- Steck TL, Yu J. Selective solubilization of proteins from red blood cell membranes by proteins perturbants. J Supramol Struct 1973; 220-31.

- Stefanidou M, Pappas F, Methenitou G, Dona A, Alevisopoulos G, Koutselinis A: Bee pseudocholinesterase as an indicator of exposure to anticholinesterase insecticides. Vet Hum Toxicol 1998; 40-6:326-7.

- Stocks J, Kemp M, Dormandy TL. Increased susceptibility of red-blood-cell lipids to autoxidation in haemilytic states. Lancet $1971 ; 266-9$.

- Stocks J, Ofeerman EL, Modell CB, Dormandy TL: The susceptibility to autoxidation of human red cell lipids in health and disease. Br J Haematol 1972; 23:713-24.

- Suzuky T, Dale GL. Membrane proteins in senescent erythrocites. Biochem.J 1989; 257:37-41.

- Szasz G. Cholinesterase determination in serum with acetyl- butyrylthiocholine as substrate. Clin Chim Acta 1968; 19:191-204. 
- Takeda K, Shimada Y, Amano M, Sakai T, Okada T, Yoshiya I: Plasma lipid peroxides and alpha-tocopherol in critically ill patients. Critical Care Medicine, 1984; 12:957-959.

- The Merck index. $11^{\text {th }}$ ed. Rahway: Merck \& C., Inc, 1989.

- Thiers RE, Wu GT, Reed AH, Oliver LK. Sample Stability: A Suggested Definition and Method of Determination. Clin. Chem 1976; 22: 176-83.

- Tirmenstein MA, Watson BW, Haar NC, Fariss MW. Sensitive method for measuring tissue alpha-tocopherol and alpha-tocopheryloxybutyric acid by highperformance liquid chromatography with fluorometric detection. J Chromat B: Biomed Sci 1998; 707:308-11.

- Vuchetich PJ, Bagchi D, Bagchi M, Hassoun EA, Tang L, Stohs SJ. Naphthaleneinduced oxidative stress in rats and the protective effects of vitamin $\mathrm{E}$ succinate. Free Radical Biol Med 1996; 21:577-90.

- Wagner GM, Chiu DT, Yee MC, Lubin BH. Red cell vesiculation: a common membrane physiologic event. J Lab Clin Med 1986; 315-24.

- Williams WJ, Beutler E, Erslev AJ, Lichtman MA, editors. Williams: Hematology. $4^{\text {th }}$ ed. Chapter 37: 383.

- Whittaker M, Wicks RJ, Britten JJ: Studies on the inhibition by propanolol of some human erythrocyte membrane enzymes and plasma cholinesterase. Clin Chim Acta 1982; 119:107-14.

- Wolfe L, Byrne A, Becker P, John K, Lux S. Reversable injury to the red blood cell membrane skeleton during blood storage [abstract]. Clin Res 1983; 31:486a.

- Wolfe LC. The membrane and the lesions of storage in preserved cells. Transfusion, $1985 ; 25: 185-203$.

- Wolfe LC, Byrne AM, Lux SE. Molecular defect in the membrane skeleton of blood bank-stored red cells. abnormal spectrin-protein 4.1-actin complex formation. J Clin Invest 1986; 78:1681-6.

- Wong SHY, Knight JA, Hopfer SM, Zaharia O. Lipoperoxides in plasma as measured by liquid-cromatographic separation of malondialdehyde- thiobarbituric acid adduct. Clin Chem 1987; 33: 214-20.

- Wood L, Beutler E: The viability of human blood stored in phosphate adenine media. Transfusion, 1967; 7: 401-8. 
- Wood L, Beutler E. The effect of ascorbate and dihidroxyacetone on the 2,3diphosphoglycerate and ATP levels of stored human red cells. Transfusion 1974; 14:272-7.

- Yasaka T, Ohya Y, Matsumoto J, Shiramizu T, Sasaguri Y. Acceleration of lipid peroxidation in human paraquat poisoning . Arch Intern Med 1981; 141:1169-71

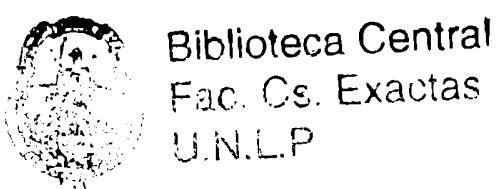

$\theta$

$$
\begin{aligned}
& 30 \text { 3t } 1700
\end{aligned}
$$

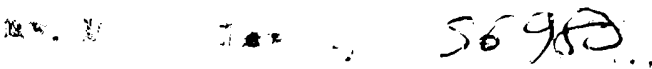

